\title{
TESTING CRITERIA AND INDICATORS FOR THE SUSTAINABLE MANAGEMENT OF FORESTS: PHASE 1 FINAL REPORT
}

Ravi Prabhu, Carol J.P.Colfer, P.Venkateswarlu, Lay Cheng Tan, Rinekso Soekmadi and Eva Wollenberg
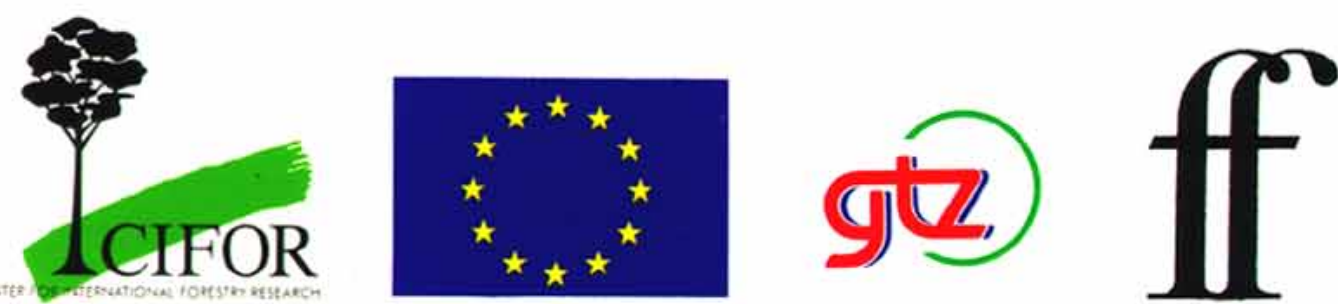

\section{USAID}

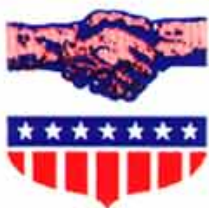

CIFOR Special Publication 


\section{TESTING CRITERIA AND INDICATORS FOR THE SUSTAINABLE MANAGEMENT OF FORESTS: PHASE 1 FINAL REPORT}

Ravi Prabhu, Carol J.P.Colfer, P.Venkateswarlu, Lay Cheng Tan, Rinekso Soekmadi and Eva Wollenberg
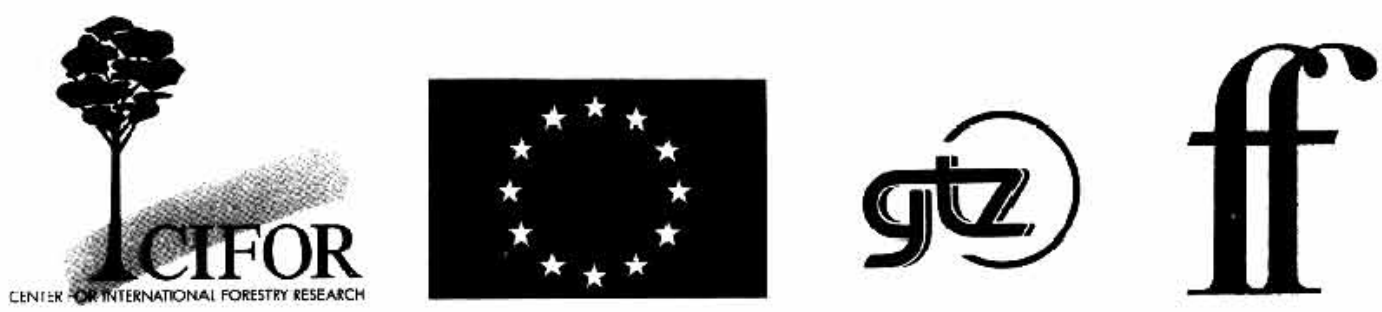

USAID

CIFOR Special Publication

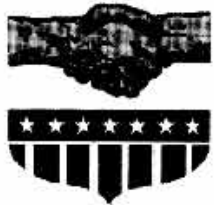


(C) 1996 Center for International Forestry Research (CIFOR)

Published by

Center for International Forestry Research (CIFOR)

P.O. Box 6596, JKPWB

Jakarta 10065

Indonesia

with support from

The European Union

Brussels, Belgium

Deutsche Gesellschaft für Technische Zusammenarbeit (GTZ) GmbH

Eschborn, Germany

The Ford Foundation

New York, United States of America

United States Agency for International Development (USAID)

Washington D.C., United States of America

ISBN 979-8764-03-X 


\section{TABLE OF CONTENTS}

Acknowledgements

Executive Summary

1. Introduction

1.1 Background

1.2 Project Purpose

2. Methods Used in Generating and Evaluating Criteria and Indicators

2.1 Overview of Methods 5

2.2 Selection of Base Sets of Criteria and Indicators, Sites, Expert Teams 7 and Partners

2.3 Conceptual Framework 10

2.3.1 Need for a Conceptual Framework 10

2.3.2 Elements of the Conceptual Framework 11

2.3.2.1 Sustainable Forest Management 11

2.3.2.2 What are Criteria \& Indicators? 14

2.3.2.3 Methods for Testing Criteria and Indicators 16

2.3.3 Using the Proposed Framework 18

2.4 Field Procedures for Generating and Evaluating Criteria and Indicators 22

2.4.1 Field Methods 22

2.4.2 Methods Used in the Austrian Test 26

2.4.3 Critical Evaluation of Field Methods 26

2.5 Analysis of Criteria and Indicators 29

2.6 General Factors Influencing the Selection of C\&I by Each Team 30

2.6.1 Selected Base Sets of C\&I 31

2.6.2 Composition of the Expert Teams 31

2.6.3 Site Specific Factors Affecting Criteria and Indicators' Selection 32

3. Sets of Criteria and Indicators Resulting out of the Tests 35

3.1 Contribution of the Five Base Sets to the C\&I Proposed by The Teams 35

3.2 Overview of C\&I Proposed by Test Teams 38

3.3 Criteria and Indicators Related to the Policy, Planning and Legal Environments within which Forest Management Takes Place
$\begin{array}{ll}\text { 3.3.1 } & \text { Major Conclusions } \\ \text { 3.3.2 Commonalities }\end{array}$
3.3.2 Commonalities 39
3.3.3 Differences 40
3.3.4 Field Experience vs Workshop Experience 42
3.3.5 Cost Effectiveness, Reliability and Utility 42
3.3.6 Results from the Test in Austria 44

38 
3.4 Criteria and Indicators Related to the Maintenance of Ecosystem Integrity 44

3.4.1 Major Conclusions 44

3.4.2 Commonalities 44

3.4.3 Differences 47

3.4.4 Field Experience vs Workshop Experience 48

3.4.5 Cost Effectiveness, Reliability and Utility 48

3.4.6 Results from the Test in Austria 49

3.5 Criteria and Indicators Related to the Social Environment within which Forest
Management Takes Place

$\begin{array}{ll}\text { Management Takes Place } & 50 \\ \end{array}$

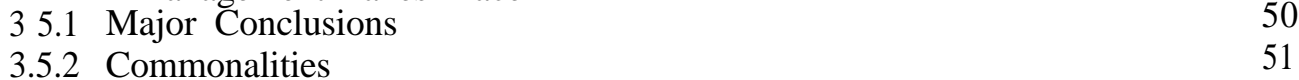

3.5.3 Differences $\quad 53$

3.5.4 Field Experience vs Workshop Experience 55

3.5.5 Cost Effectiveness, Reliability and Utility 56

3.5.6 Results from the Test in Austria 58

3.6 Criteria and Indicators Related to the Sustainable Production of Goods and Services from the Forest 58

3.6.1 Major Conclusions $\quad 58$

$\begin{array}{ll}\text { 3.6.2 Commonalities } & 59\end{array}$

3.6.3 Differences 63

3.6.4 Field Experience vs Workshop Experience 64

3.6.5 Cost Effectiveness, Reliability and Utility 64

3.6.6 Results from the Test in Austria $\quad 66$

3.7 Using the Criteria and Indicators 66

4. Future Steps $\quad 69$

$\begin{array}{ll}\text { References } & 73\end{array}$ 


\section{LIST OF ANNEXES}

Number

$1 \quad$ Excerpt from Project Proposal

2 Structure of the Project $\quad 79$

3 Publications and Papers related to the Project 81

$4 \quad$ Form 1 and Form $2 \quad 83$

5 Statistical Analysis and the Test in Germany 91

6 Analysis of Commonalities 93

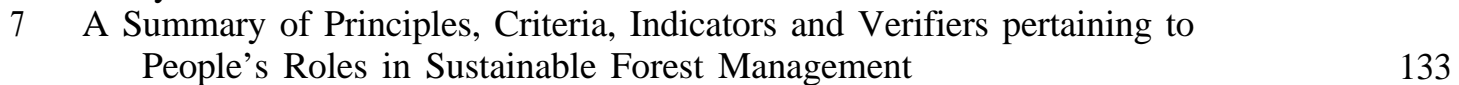

8 Sets of Principles, Criteria, Indicators and Verifiers Resulting from Tests 137

\section{LIST OF TABLES}

1 Test Sites 8

2 Test Teams 9

3 Schedule of activities during a field test 25

4 Size and Proportions of Five Original C\&I Sets 31

5 Influence of the five base sets on C\&I proposed by expert teams. 35

6 Charactersitics of use of base sets. 36

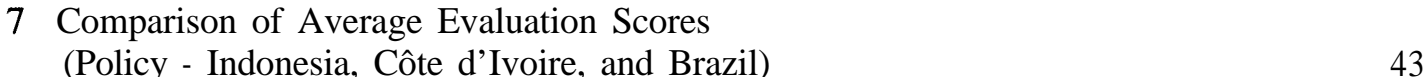

8 Comparison of Average Evaluation Scores (Ecosystem Integrity - Indonesia, Côte d'Ivoire, and Brazil) 48

9 Comparison of Average Evaluation Scores (Social - Indonesia, Côte d'Ivoire, and Brazil) 56

10 Comparison of Average Evaluation Scores (Forest Management - Indonesia, Côte d'Ivoire, and Brazil) 65

\section{LIST OF FIGURES}

1 Flow chart of the CIFOR test series showing approach adopted. 6

2 Structure of the Project. 10

3 Conceptual Framework. 15

4 The Certification Process (from Upton and Bass, 1995). 19

5 Schematic depiction of the 'top-down' and 'bottom-up' processes for 21 evaluating C\&I.

6 Flow chart of method used to evaluate C\&I during each test. 23

7 Dendrites depicting structure of the sets of C\&I proposed by the teams in $\begin{array}{ll}\text { Indonesia, Côte d'Ivoire, and Brazil. } & 37 \\ \text { Policy indicators - commonalities and differences. } & 40\end{array}$

$\begin{array}{lll}8 & \text { Policy indicators - commonalities and differences. } & 40 \\ 9 & \text { Ecosystem Integrity Indicators - commonalities and differences. } & 45\end{array}$

10 Social Indicators - commonalities and differences. 51

11 'Production' Indicators - commonalities and differences. 60

12 Underlying structure and assumptions of C\&I related to sustainable production of goods and services from the forest 


\section{LIST OF ABBREVIATIONS}

$\begin{array}{ll}\text { ATO } & \text { African Timber Organization } \\ \text { CIFOR } & \text { Center for International Forestry Research } \\ \text { CITES } & \text { Conference on Trade of Export and Species } \\ \text { CSCE } & \text { Conference on Securities and Cooperation in Europe } \\ \text { CSD } & \text { Commission on Sustainable Development } \\ \text { DBH } & \text { diameter at breast height } \\ \text { DDB } & \text { Deskundigenwerkgroep Duurzaam Bosbeheer } \\ \text { FAO } & \text { Food Agriculture Organization of the United Nations } \\ \text { FMU } & \text { Forest Management Unit } \\ \text { FSC } & \text { Forest Stewardship Council } \\ \text { IBAMA } & \text { Instituto Brasileiro do Meio Ambiente e dos Recursos Naturais Renovaveis } \\ \text { IPF } & \text { Intergovernmental Panel on Forests } \\ \text { ISO } & \text { International Standards Organization } \\ \text { ITTO } & \text { International Tropical Timber Organisation } \\ \text { ITW } & \text { Initiative Tropenwald } \\ \text { LEI } & \text { Lembaga Ekolabel Indonesia } \\ \text { NGO } & \text { non-governmental organisation } \\ \text { NTFP } & \text { non-timber forest products } \\ \text { OECD } & \text { Organization for Economical Cooperation and Development } \\ \text { OFA } & \text { Osterreichischer FachausschuB, Austrian Expert Committee } \\ \text { PFA } & \text { plant functional attribute } \\ \text { PFE } & \text { permanent forest estate } \\ \text { PRA } & \text { Participatory Rural Appraisal } \\ \text { RRA } & \text { Rapid Rural Appraisal } \\ \text { S C S } & \text { Scientific Certification System } \\ \text { SMW } & \text { Smart Wood, Rainforest Alliance } \\ \text { SODEFOR } & \text { Societe de Developpement des Forets } \\ \text { SOI } & \text { Soil Association, Woodmark } \\ \text { TCA } & \text { Tratado de Cooperation Amazonica } \\ \text { TPTI } & \text { Tebangan Pilihan dan Tanaman Indonesia (Indonesian Selective } \\ & \text { Cutting and Replanting System) } \\ \text { UNCED } & \text { UN Conference on Environment and Sustainable Development } \\ \text { UNCSD } & \text { United Nations Commission on Sustainable Development } \\ & \end{array}$




\section{ACKNOWLEDGEMENTS}

This project could not have been carried out without the tremendous support it received from a large number of institutions and individuals in several countries across the globe. It will not be possible for us to thank each one of them by name, but this in no way belittles our gratitude to them.

We would like to thank the German Federal Ministry of Economic Co-operation and Development (BMZ) and the Deutsche Gesellschaft für technische Zusammenarbeit (GTZ) $\mathrm{GmbH}$, as the first institutions to provide financial and technical support to the first phase of the project. Our special thanks to the European Union for being our major donor under the "Tropical Forests" budget heading. We thank the African Timber Organisation for their great support to us in preparing the test in Côte d'Ivoire and sponsoring participants from ten West and Central African countries to the closing workshop in Abidjan. We thank the Ford Foundation for supporting our social science work during the first phase and for supporting our work on testing criteria and indicators in forests managed by communities in the second phase. We would also like to thank the Directorate General for International Co-operation (DGIS) of the Netherlands Ministry of Foreign Affairs for providing us with financial support for a test of criteria and indicators which will take place in 1996. We thank USAID for their generous support to the project to ensure that the transition from the first to the second phase is smooth and that the results of the first phase find an appropriate entry into the international discussion on criteria and indicators. We thank the Austrian Federal Ministry of the Environment for supporting a test of criteria and indicators at home, based on the methods developed by CIFOR. This has provided us with an invaluable temperate zone reference point.

Our thanks to the Dutch Working Group of Experts (DDB), Initiative Tropenwald (ITW), Lembaga Ekolabel Indonesia (LEI), Smart Wood (Rainforest Alliance, USA) and Woodmark (Soil Association, UK) for graciously allowing us to use their sets of criteria and indicators and providing us with intellectual support during workshops and International Project Advisory Panel (IPAP) meetings.

We are very thankful for our special relationship with all the members of the IPAP, many of whom have been instrumental in the organisation of the tests in their home countries. We are grateful for the good advice received from them both during and between sessions of the IPAP. Although constituted midway through the first phase, the Scientific Support Group has provided us with invaluable guidance and review. Our sincere thanks to them. We would like to especially thank Prof. Jochen Heuveldop and his team at the $\mathrm{BFH}$, for their support of this project from the very beginning.

This report would not be complete without acknowledgement of the kind co-operation of the timber companies and agencies with whom we worked in the field: Forstamt Bovenden in Germany, P.T. Kiani Lestari in Indonesia, SODEFOR Haut Sassandra and SODEFOR \& GTZ Bossematie in Côte d'Ivoire, CEMEX in Brazil, and in Austria, the Federal Forests in Krems, Meternich forests in Grafenegg and the 'Vierzigergemeinde' smallholder forests in Langenlois.

Our most sincere gratitude to the five expert teams, who grappled day and night under stimulating but difficult conditions in search of 'minimum reliable sets of criteria and indicators'. This report is built on their expertise, intellectual creativity, hard work, willingness to cross difficult disciplinary barriers and good humour. Thank you.

Finally, we would also like to thank the numerous reviewers who have contributed to improving this report. Our special thanks to: Dennis Dykstra, Erik Lamrnerts van Bueren, Hermann Schmincke, Jean-Guy Bertault, Jochen Heuveldop, John Palmer, Kate Heaton, Kees van Tuyll, Patrice Mengin-Lecreulx, Paul Wolvekamp, Peter Burgess, Peter von Fuerstenberg, Philip Kio, Riga Adiwoso, Sepp Hackl, Tim Synnott, and Jenny Turnbull. 


\section{EXECUTIVE SUMMARY}

Although there are a variety of organisations involved in developing criteria and indicators $(C \& I)$ for sustainable forest management, this report documents the first attempt to field test these C\&I at forest management unit (FMU) level in a variety of locations. It is a report of the first phase (August 1994 - January 1996) of the CIFOR research project on "Testing Criteria and Indicators for the Sustainable Management of Forests".

Our objectives were to:

- develop a methodology to evaluate and generate $\mathrm{C} \& \mathrm{I}$,

- generate a minimum number of cost effective and reliable $C \& I$ for each test site, based on iterative and comparative field evaluations of selected sets, and

- initiate work on a system to evaluate the sustainability of forest management as a whole, based on the recommended criteria and indicators.

We anticipate that the main use of C\&I at the FMU level will probably be for on-site assessments of the quality, performance and systems of forest management. We envision probable users to include certification bodies, government officials, donors, forest managers, project managers, and scientists.

The outputs of this project should contribute towards the development of unbiased and objective systems to assess the sustainability of forest management. They are aimed ultimately to serve as tools for those wishing to develop or improve their own C\&I.

Our approach involved multi-disciplinary teams of foresters, social scientists and ecologists, selecting and evaluating C\&I from existing sets in an interdisciplinary fashion, in four locations around the world (Germany, Indonesia, Côte d'Ivoire and Brazil). Our intention was to select at least one site in each of the three tropical zones and one temperate zone during the first phase. We selected forest management units (FMUs) at each of these sites which were considered to be much better than 'average' for those conditions. We perceived the main advantage of field testing C\&I in an improved facility for evaluating their relevance and feasibility by providing real life information within the frame of reference of a particular FMU.

The selected sets of C\&I ('base sets') included those from Smart Wood (Rainforest Alliance, USA), Initiative Tropenwald (ITW - Germany), and Woodmark (Responsible Forestry Standards, Soil Association, UK) and were evaluated on all sites. The Deskundigenwerkgroep Duurzaam Bosbeheer (DDB - the Netherlands) and the Lembaga Ekolabel Indonesia (LEI - Indonesia) sets were evaluated at all sites except Germany. These five were considered to represent the most advanced generic or site specific sets of C\&I at the time of commencement of the project. In all they contained about $1100 \mathrm{C} \& \mathrm{I}$.

Our expectation in selecting four sites (later five) in four different continents, using a different team at each of them, and using the most advanced sets of $\mathrm{C} \& \mathrm{I}$ as our starting point, was that $\mathrm{C} \& \mathrm{I}$ identified as being common would be more likely to have a generic character, than if we had held one of the first two variables constant.

A parallel test was conducted in Austria in October 1995, in collaboration with CIFOR, which both provided additional results and represented an adaptation and application of the method in another context. This test was particularly welcome since the CIFOR project was still experimenting with methods when the German test was conducted, resulting in somewhat less comparable findings from that test (our only other temperate zone test). The Austrian test demonstrates the importance of applying the methods described in this report in both the tropical and temperate countries. This project has been carried out in a collaborative mode and has involved active participation of partners in all the countries named.

By an iterative process, a workable methodology was developed as briefly described above (see figure 1). This included in a preparatory phase the selection of sites, teams, sets of C\&I to assess, development of a conceptual framework and formal procedures and attributes by which $C \& I$ could be evaluated. An important part of this conceptual framework was the definition of principles, criteria and indicators under a hierarchical framework. This was revealed as necessary during the first test in Germany, where it was clear that the underlying concepts in the sets of C\&I evaluated were unclear and confusing. This was verified at other tests as well. The German test resulted in a significant improvement of methods.

One of our first analytical activities focused on the data generated during the first test in Germany. The results of this analysis suggested that the team members were using similar standards in evaluating the C\&I. After the German test, nine attributes were identified as important in assessing C\&I, and these have been used in all subsequent tests: 
1) relevance

2) unambiguously related to the assessment goal

3) precisely defined

4) diagnostically specific

5) easy to detect, record and interpret

6) reliability, especially as indicated by replicability of results

7) must be sensitive to stress on the forest management, ecological or social systems

8) provides a summary or integrative measure over space and/or time

9) appealing to users

The nine attributes and the classification described above are instruments with which the cost-effectiveness of an assessment system can be improved. The cost-effectiveness of the system will depend on whether C\&I have successfully been limited to the key areas of sustainability, how they have been defined, the amount of information they hold potentially, and only lastly, what survey and data collection methods are used.

Costs associated with an indicator were sought to be minimised by asking three questions:

1. where to place an indicator within a system in order to sum up a satisfactory amount of information on interactions,

2. how to define the indicator such that information is integrated meaningfully,

3. over what intervals of time should this information be collected, leaving the question of defining the actual field procedures for a later phase.

The test process at any one site involved three phases, conceived as three separate filters (see figure 6). It is important to note that this was not simply a mechanical sifting process. It explicitly allowed creative inputs and modifications to criteria and indicators, provided these were also subjected to the evaluation process.

In all five tests, teams, specially selected for their disciplinary and location-specific expertise, participated in month long field exercises. Each field exercise concluded with a closing workshop, to which knowledgeable representatives from government, industry, academia and NGOs were invited to discuss the selected C\&I in plenary sessions and small working groups. Their suggestions were then evaluated by the team members, and in most cases, incorporated into the final sets of $\mathrm{C} \& \mathrm{I}$.
1. Filter No. 1: Pre-fieldwork phase based on use of 'Form1' - During this first filter experts evaluated criteria and indicators on their own, using 'Form1' as their principal tool. Filter No. 1 can thus be seen as essentially being a desk exercise to carry out a preliminary evaluation of all $1100 \mathrm{C} \& \mathrm{I}$ tested. Towards the end of this stage team members met for the first time to organize and classify the results of their evaluation on Forml.

2. Filter No. 2: Fieldwork phase based on use of 'Form2' - From this point onwards interdisciplinary teamwork at and near commercial logging operations took place. Intellectually, this phase represented an ongoing oscillation between inductive and deductive approaches for the team members, as they applied their existing knowledge to the C\&I at one point, tested these conclusions against field realities, and later returned to their broader experience, in an iterative process. In addition to this kind of analysis, team members filled out assessment forms regarding each selected C\&I and exchanged information and views with representatives of other disciplines. One of the main tools for evaluation was a set of nine attributes (see 2.3.2.3) with which team members assessed C\&I. However the entire evaluation process was complex with team members calling on 'static resources' to feed dynamic processes which in turn resulted in the required decisions (see figure 6). The entire process was iterative, with the principal constraint being time. The final test of their conclusions was at the closing workshops.

3. Filter No. 3: Post-fieldwork phase Participants at the closing workshops were drawn from different institutional and disciplinary backgrounds, but were all characterised by their knowledge and interest in sustainable forest management. Discussions took place over three to five days in working groups which had the mandate to review the proposals made by the team concerned. This served two purposes: it provided peer review to the team members, but also because the frame-of-reference of workshop participants was frequently larger in scope than the selected FMU the workshop also 
provided a first window on the wider applicability of the C\&I proposed by the teams. Finally team members summarised their experience and conclusions into reports, also taking into account the recommendations of the workshops. These results were then passed on to the CIFOR team, to be examined and evaluated, both qualitatively and quantitatively, and then compared. Although a beginning has been made, the CIFORbased comparative analyses are ongoing, since a considerable quantity of interesting and valuable data were produced in this process.

The contribution of the five base sets to the proposals made by the teams varied among sites and among disciplines. For the set of C\&I proposed by the Indonesian team, about 80 percent of all C\&I owed their origin to the base sets, the remaining 20 percent were new developments by the expert team in reaction to perceived gaps in the base sets and specific site conditions. This figure dropped to 68 percent in Brazil and 62 percent in Côte d'Ivoire. The ecology C\&I across all three tropical sites showed the highest proportion of references to the base with 89 percent. Between 61 percent and 68 percent of the policy, forest management and social criteria and indicators were developed directly out of the base sets.

In absolute terms, the ITW and Woodmark sets were the sources with the largest number of references in the proposals made by the experts at each of the three tropical test sites. Relative to the number of $C \& I$ in the original set, references to the Smart Wood set were highest: $94 \%$ of Smart Wood C\&I set was used by team members as models or starting points for the sets of C\&I proposed by them. In comparison about $34 \%$ of all C\&I proposed by the three teams were based at least in part on the Smart Wood set. The ITW set with over $600 \mathrm{C} \& \mathrm{I}$ was generally considered to be the most comprehensive, in terms of conventional forest management. 233 C\&I from the ITW set were used by the teams as 'models' or starting point for $49 \%$ of all the C\&I proposed by them. The Woodmark set contributed 103 C\&I or $43 \%$ of all C\&I proposed by the teams. It was considered to be the most prescriptive of the five base sets. The LEI and DDB sets contributed 33\% and $20 \%$ respectively to the C\&I in the proposals. The DDB set was considered to be more a conceptual framework than a set of C\&I for field evaluation, therefore not surprising that references to this set were the lowest among the five.
The CIFOR team also analysed the divergence in selected C\&I among teams and tried to determine the reasons for such variation. Three important sources of variation were identified. The composition or nature of the base sets of C\&I was the most fundamental, since they formed the pool from which team members selected the best C\&I. The composition of the expert teams also proved an important influence because of individual interests and expertise among team members. Finally, a series of site-specific factors, including resource ownership and access, history of forest management, forest system ecology, demography and culture, were identified as important. As a result of the three phases listed above, a subset of principles, criteria, indicators and verifiers was identified that were common to all sites (see list below).

Preliminary analysis reveals that the percentage of C\&I held in common varied among teams from 27 percent for Brazil's social C\&I to 78 percent for Côte d'Ivoire's ecology C\&I. The social C\&I, not surprisingly, showed a markedly lower level of commonality than did the other sets of C\&I. The relevant averages for the three tests decreased from a high of 72 percent for ecology to a low of 34 percent for the social C\&I. The policy and forest management sets showed an average commonality of 57 percent and 60 percent respectively. We were therefore led to believe that a strong element of commonality existed among the sets of C\&I proposed at the three tropical sites. Comparison of these results with those obtained from the test in Austria reveal that most of the criteria and indicators identified as being common to the three tropical sites were also listed in the Austrian set. This suggests that at least in closed forest formations the development of a common 'core' set of C\&I seems possible, however site specific elements will continue to remain important particularly for social aspects and lower levels of hierarchy, such as verifiers.

The following are the common principles, criteria, and indicators identified after analysis of the underlying issues in the C\&I proposed by the test teams in Indonesia, Côte d'Ivoire, and Brazil:

\section{Policy}

PRINCIPLE: POLICY, PLANNING AND INSTITUTIONAL FRAMEWORK ARE CONDUCIVE TO SUSTAINABLE FOREST MANAGEMENT.

CRITERION: THERE IS SUSTAINED AND ADEQUATE FUNDING FOR THE MANAGEMENT OF FORESTS. 
Indicators:

- Policy and planning are based on recent and accurate information.

- Effective instruments for inter-sectoral coordination on land use and land management exist.

- There is a permanent forest estate (PFE), adequately protected by law, which is the basis for sustainable management, including both protection and production forest.

- There is a regional land use plan or PFE which reflects the different forested land uses, including attention to such matters as population, agricultural uses, conservation, environmental, economic and cultural values.

- Institutions responsible for forest management and research are adequately funded and staffed.

\section{Ecology}

PRINCIPLE: MAINTENANCE OF ECOSYSTEM INTEGRITY.

\section{CRITERION: ECOSYSTEM FUNCTION IS} MAINTAINED.

Indicators:

- No chemical contamination to food chains and ecosystem.

- Ecologically sensitive areas, especially buffer zones along water courses are protected.

- No inadvertent ponding or waterlogging as a result of forest management.

- Soil erosion is minimised

CRITERION: IMPACTS TO BIODIVERSITY OF THE FOREST ECOSYSTEM ARE MINIMISED.

Indicators:

- Endangered plant/animal species are protected.

- Interventions are highly specific, selective and are confined to the barest minimum.

- Canopy opening is minimised.

- Enrichment planting, if carried out, should be based on indigenous, locally adapted species.

CRITERION: THE CAPACITY OF THE FOREST TO REGENERATE NATURALLY IS ENSURED.

Indicators:

- Representative areas, especially sites of ecological importance, are protected or appropriately managed.

- Corridors of unlogged forest are retained.

\section{Social Environment}

PRINCIPLE [implied]: FOREST MANAGE-

MENT MAINTAINS FAIR- INTERGENERATIONAL ACCESS TO RESOURCES AND ECONOMIC BENEFITS

CRITERION: STAKEHOLDERS/FOREST ACTORS TENURE AND USE RIGHTS ARE SECURE.

Indicators:

- Tenure/use rights are well defined and upheld.

- Forest dependent people share in economic benefits of forest utilisation

- Opportunities exist for local people/forest dependent people to get employment and training from forest companies.

PRINCIPLE [implied]: STAKEHOLDERS, INCLUDING FOREST ACTORS, HAVE A VOICE IN FOREST MANAGEMENT

CRITERION: STAKEHOLDERS /LOCAL POPULATIONS PARTICIPATE IN FOREST MANAGEMENT

Indicators:

- Effective mechanisms exist for two way communication related to forest management among stakeholders.

- Forest dependent people and company officials understand each other's plans and interests.

CRITERION: FOREST DEPENDENT PEOPLE/ STAKEHOLDERS HAVE THE RIGHT TO HELP MONITOR FOREST UTILISATION.

Indicator:

- Conflicts are minimal or settled.

\section{Production of Goods and Services}

PRINCIPLE: YIELD AND QUALITY OF FOREST GOODS AND SERVICES SUSTAINABLE

CRITERION: MANAGEMENT OBJECTIVES CLEARLY AND PRECISELY DESCRIBED AND DOCUMENTED.

Indicator:

- Objectives are clearly stated in terms of the major functions of the forest, with due respect to their spatial distribution. 
Indicators:

- Maps of resources, management, ownership and inventories available.

- Silvicultural systems prescribed and appropriate to forest type and produce grown

- Yield regulation by area and/or volume prescribed.

- Harvesting systems and equipment are prescribed to match forest conditions in order to reduce impact.

\section{CRITERION: THE MANAGEMENT PLAN IS} EFFECTIVELY IMPLEMENTED.

\section{Indicators:}

- Pre-harvest inventory satisfactorily completed.

- Infrastructure is laid out prior to harvesting and in accordance with prescriptions.

- Reduced impact felling specified/implemented.

- Skidding damage to trees and soil minimised.

CRITERION: AN EFFECTIVE MONITORING AND CONTROL SYSTEM AUDITS MANAGEMENT'S CONFORMITY WITH PLANNING.

\section{Indicators:}

- Continuous forest inventory (CFI) plots established and measured regularly

- Documentation and records of all forest management activities are kept in a form that makes it possible for monitoring to occur.

- Worked coupes are protected (e.g., from fire, encroachment and pre-mature re-entry

- Tree marking of seed stock and potential crop trees

A feature that emerged in all the sets of selected C\&I was that they contained C\&I based on performance and process. This is particularly interesting in the light of discussions on whether a performance standards approach or a more procedural environmental management system approach is more suitable for assessment during certification. Results from our teams suggest that there are no grounds for a choice between them - both are necessary in combination.

Results from the tests suggest that although there are common issues that must be addressed, there will always be the need to fine tune, to selectively choose appropriate $\mathrm{C} \& \mathrm{I}$, particularly at the lower levels of generality, for any given region or locale. It seems probable that the identification of these location-specific C\&I should be a joint process involving various stakeholders.
Although there was considerable commonality in the underlying issues expressed in the C\&I selected by the teams, team members often assigned the same issue to the different hierarchical levels of principles, criteria, indicators and verifiers. This was as true for the forestry C\&I, which we had expected to be the clearest and most advanced, as for the social C\&I (those purported to be least defined). Although the teams understood and accepted the hierarchical nature of the principles, criteria and indicators, they were affected in the level they assigned to issues by the importance of a given topic for sustainability in their particular field site. Basic differences in the degree of structural complexity ascribed to sets of C\&I were observed among the experts at the three test sites (see figure 6). Particularly noticeable was the complicated structure of the 'production' C\&I in Côte d'Ivoire. At the same time, as mentioned previously, there is a high degree of commonality between the C\&I proposed by all three teams for this aspect. This suggests the need to develop tools that will promote consistency in operating with the conceptual framework of principles, criteria, indicators and verifiers. In developing the framework further we will seek to explore the utility of models of information processing towards improving consistency. However, it is also possible that a more flexible conceptualisation of the hierarchies of use in assessment of sustainable forest management will be necessary.

A subsidiary activity, to more clearly define the most relevant stakeholders, was undertaken in response to our sense that stakeholders would inevitably play an important role in sustainable forest management. Although this definition continues to evolve, considerable progress has been made in identifying important dimensions which affect this definition (e.g., proximity, pre-existing rights, dependence, indigenous knowledge, forest-culture interaction, and power deficits). Additional issues that may prove important to include, and will be further investigated in Phase II, include the existence of a sustainability ethic and poverty.

As might be expected in a topic as complex as sustainable forest management, Phase I raised as many questions as it answered. During Phase II, we expect to focus on topics identified as important during this phase. The forest management work will focus on fine tuning the selected C\&I. Ecology and social issues involve more fundamental research into the causal links among issues that were identified as important by the teams. In the social sphere, for instance, the relationships among people's participation in forest management, their intergenerational access to resources, and sustain- 
able forest management will be investigated. In ecology, efforts to address biodiversity in a better way will be a major focus, as this was revealed as a weakness both in the base sets and the proposals of the teams. We also plan to work on the process of reaching decisions based on the incomplete and conflicting information that typically results from field assessments of the sustainability of forest management. Finally there is a need to link the C\&I at the national level with those developed for use at the FMU level. The methods and framework developed by the project to test C\&I could be potentially useful for this purpose.

To conclude, although satisfactory progress towards the achievement of the first two objectives was made during Phase 1, due mainly to time constraints little work took place on the third objective. Achievement of the third objective, the develop ment of a system or, better, a 'tool-box' for sustainability assessment based on C\&I, will be the overarching goal of the second phase of the project. 


\section{INTRODUCTION}

This report provides a preliminary account of the most important and accessible results of the first phase of the Center for International Forestry Research (CIFOR) research project on testing criteria and indicators $(\mathrm{C} \& \mathrm{I})$ for sustainable forest management. It builds on existing published and unpublished reports prepared during the first phase. As far as possible, results are presented in a form that is relevant to their practical application.

The structure of the report includes three major foci, which pertain to the project's objectives. First we describe the evolution of the method we have developed for testing C\&I, and its implementation in four of the five project tests. Second, we analyse the commonalities and differences in the results of the three comparable tests (in Indonesia, Côte d'Ivoire and Brazil) and briefly compare this with the results of the Austrian test. Finally, we describe our plans for the second phase of this project.

We emphasise that this document reports "work in progress". We have completed valuable and useful work, but much remains to be done.

\subsection{BACKGROUND}

International concern about the widespread destruction and degradation of forest areas, especially in tropical countries, has led to national and international initiatives to stem this development. Notable among these are:

- ITTO Year 2000 Objective,

- the UNCED resolution on Global Forest Principles,

- the CSCE workshop on environmental C\&I for the sustainable development of Boreal and Temperate forests,

- the Ministerial Conference on the Protection of Forests in Europe, and

- the Forest Stewardship Council (FSC)'s Principles and Criteria for Natural Forest Management.

Forestry experts from Great Britain, the Netherlands and Germany met in February 1994 in Weilburg (Germany) and called for comparative field tests of the "most developed certification systems currently available for tropical forests". In a subsequent meeting of experts from France, Denmark, the Netherlands, the European
Commission and Germany in June 1994, it was agreed that this project to test $\mathrm{C} \& \mathrm{I}$ for sustainable management of forests should be co-ordinated by the CIFOR .

One of the advantages that CIFOR brings to this study is its status as an international research center. This status grants it visibility, neutrality and access that might be more difficult for a national research group to attain. This is particularly important in differentiating our efforts from those of commercial firms, for instance, who want to become involved in timber certification. We expect our results to be helpful to such certifying bodies, as organisations like the FSC require them to document and publish their procedures much more openly than they have in the past. We also expect these results to be of use to local level forest managers and to policy-makers, both of whom are trying to enhance the sustainability of forest management.

Since commencement of the project in August 1994, the importance of developing effective C\&I was underscored once more by their inclusion in the workplan of the Intergovernmental Panel on Forests (IPF), which commenced operation following the April 1995 inter-sessional meeting of the UNCSD. Whereas several international efforts have concentrated on developing C\&I at the national or global levels, CIFOR's research project is, as yet, the only international effort to evaluate and develop C\&I at the forest or management unit level (see next section).

The 1992 UNCED Conference underlined in the "Forest Principles" 2 the need to reconcile the productive functions of forests with the protective, environmental and social roles they fulfil. In Chapter 11 of Agenda 21 of UNCED, "Combating Deforestation", governments, in cooperation with special interest groups and international organisations, agreed to pursue "the formulation of scientifically sound criteria and guidelines for the management, conservation and sustainable development of all types of forests".

\section{Current Status of the Criteria and Indicators Discussion}

Based on the ideas incorporated in the UNCED document, the Helsinki, Montreal and Tarapoto processes, to name a few, have striven to define C\&I for sustainable forest management at the

\footnotetext{
1 The first test, in Germany, functioned more as a pre-test, partial results for which are available in Palmer 1995.

2 (the Non-Legally Binding Authoritative Statement of Principles for a Global Consensus on the Management, Conservation and Sustainable Development of All Types of Forests)
} 
national or global levels (Grayson 1995). The development of criteria and indicators for sustainable forest management was identified as being among the major tasks and priorities for the IPF, established in April 1995 within the framework of the CSD. The IPF is to:

"encourage national implementation of criteria and indicators for sustainable forest management and study the feasibility of further developing internationally agreed upon criteria and indicators against which progress towards sustainable forest management of all types of forests could be measured, taking into account the specific regional and subregional conditions of forests and the diversity of economic, social and cultural environments."

At the level of forests and forest management units the development of C\&I has been influenced to a lesser degree by Agenda 21, and has been driven largely by efforts to introduce independent third party certification of sustainably managed forests and labelling of the resulting timber. The actors in the discussion of criteria and indicators at the forest management unit (FMU) level have been international and regional non-governmental organisations and increasingly the timber industry. With very few exceptions, Indonesia being one, governments have until very recently taken a back seat. There are signs that this will change. The Malaysian Government, for instance, is involved in a major effort to adapt the ITTO criteria and indicators for the Malaysian FMU conditions. The development of C\&I at the forest level has received a higher degree of technical input, but it has also seen a division of the actors into those who prefer the development of certification based on performance standards and those who prefer a process oriented approach such as the ISO 14000 environmental management system. Apart from the ISO approach two other conceptually similar development umbrellas are in existence: the ITTO Criteria and Indicators and the FSC's Principles.

CIFOR's research project on testing C\&I for the sustainable management of forests was initiated in August 1994. It has been a timely and direct response to international discussions on the validity of using a C\&I based approach to evaluating sustainability of forest management at the management unit level. Our focus on the forest management unit must be re-emphasised, since this affects both our approach and the outcomes we expect from this project, vis-à-vis more national, intergovernmental and international approaches.
We see C\&I as tools which can be used to conceptualise, evaluate and implement sustainable forest management. C\&I may be identified at various levels: global, regional (and eco-regional), national, and sub-national, or, as in our case, at the FMU level. National level C\&I have been developed essentially as reporting and monitoring instruments, not as standards with which to assess sustainability. On the other hand, the development of C\&I at the FMU level has been largely for the purpose of assessing sustainability and, to a lesser degree, as tools to facilitate the implementation of better management practices. Just as it is unlikely that a single set of C\&I will apply uniformly across the globe, it is equally unlikely that a set of C\&I developed for the national level will be meaningful at the forest level.

CIFOR's mandate includes an explicit concern for poor people and solving their forest-related problems. For this reason, there has been an emphasis within the project on tropical forests (in CIFOR's three main focus areas). Nevertheless, the project recognises the importance of looking at C\&I for all types of forests (and forest dwellers). We included a German forest as the first of our test cases, and we have devoted considerable effort to finding collaborators with whom to work in testing the methods and the C\&I in temperate contexts (e.g., the Austria test).

Our emphasis on field testing of the C\&I internationally represents a unique contribution. Other international efforts to address C\&I development and improvement have been conference initiatives. We have found the field testing to be an important component in this process, and we expect our findings, as a result, to contribute more directly to national initiatives. We have attempted to undertake research which made use of CIFOR's comparative advantage, in order to complement the efforts of others involved in trying to develop and assess C\&I for evaluating sustainable forest management.

\subsection{PROJECT PURPOSE}

During its first phase, August 1994 - January 1996, the project focused on three objectives ${ }^{3}$ :

- develop a methodology to evaluate and generate $\mathrm{C} \& \mathrm{I}$,

- generate a minimum number of cost-effective and reliable C\&I for each test site, based on iterative and comparative field evaluations of selected sets, and

3 The sequence and wording of the original objectives has been modified somewhat to aid comprehension. The original wording is to be found in Annex 2. 
- initiate work on a system to evaluate the sustainability of forest management as a whole, based on the recommended C\&I.

The project did not seek to identify a single 'ideal' set of C\&I.

The first phase of the project addressed the need to evaluate C\&I related to:

- the sustainability of management,

- at the forest management unit level and

- under different site conditions.

The focus has been on identifying the smallest number of C\&I needed to reliably assess management at each of the locations, based on the evaluation of five existing sets of C\&I. About 1100 C\&I were drawn from five existing assessment systems. These were evaluated in each field test to determine the most cost-effective, reliable and relevant C\&I for the minimum set. This was an iterative process involving multiple stakeholders in several countries. In all the sites selected management focused on production of timber and as far as possible sites were located in areas designated by national authorities as belonging to permanent forest estate.

Our expectation in selecting four sites (later five) in four different continents, using a different team at each of them, and using the most advanced sets of C\&I as our starting point, was that C\&I identified as being common would be more likely to have a generic character, than if we had held one of the first two variables constant.

Although this project was initially conceptualised as intimately connected with timber certification, that emphasis has gradually moved away from "centerstage", as we have come to realise that the issues involved in fact have much broader applicability. Although the results reported here, and those planned in Phase II, can indeed be applied in certification efforts, this kind of information can also be used for various other purposes. We anticipate that the main use of C\&I at the FMU level will probably be for on-site assessments of the quality, performance and systems of forest management.

We envision probable users to include:

- certification bodies interested in the best ways to assess timber management for certification purposes,

- government officials trying to design more sustainable policies pertaining to forestry and other related sectors,

- donors wanting to evaluate the sustainability of the activities undertaken by various natural resource management projects,

- forest managers wanting to improve the sustainability of their management at the forest management unit level,

- project managers trying to plan, implement and evaluate conservation and development projects, and

- scientists, interested in the causal links among ecological, forestry and human factors of sustainability.

The outputs of this project should contribute towards the development of unbiased and objective systems to assess the sustainability of forest management. They are aimed ultimately to serve as tools for those wishing to develop or improve their own C\&I. 


\section{METHODS USED IN GENERAT- ING AND EVALUATING CRITERIA AND INDICATORS}

This chapter deals therefore with the theoretical basis for the evaluation and development of C\&I. We describe the approach we adopted and then discuss the conceptual framework we developed and used in testing the C\&I. Finally, we describe the procedures used for evaluating and generating C\&I.

\subsection{OVERVIEW OF METHODS}

Apart from the project's own objectives, two other major factors influenced the methods adopted by the project. The first was the need to comply with CIFOR's stated preferred mode of operation, in that the research was to be strategic in character and provide results that fell into the "international public goods" category; it was also to be collaborative, involving different partners. The second factor was the need to respond to the demands of major stakeholders in the project and develop methods that promised reliable, acceptable results within a short period of time.

The basic approach adopted by the project was to build on the most advanced sets of C\&I available at the time of the project's commencement, rather than beginning afresh. This, we felt, would not only reduce duplication of efforts, but would also allow us to benefit from the thinking incorporated in these advanced sets of C\&I. Comparisons among four sites in four different continents were planned in order to be able to draw global comparisons and reach conclusions about commonalities of C\&I among sites. With the addition of the Austrian test, which was funded independently of the project, the number of test sites rose to five. We have argued that in order to successfully evaluate C\&I from different sources, often developed with very different underlying philosophies, it was important that the evaluation process be both flexible and rigorous (Prabhu 1994). This we felt could be achieved by using interdisciplinary teams of experts acting within the framework of a welldefined iterative process.

Two important methodological decisions were made at the outset. The first was that the process of evaluating and generating C\&I was to be subjected to iterative process within the framework of testing existing sets of $\mathrm{C} \& \mathrm{I}$ at field locations using multi-disciplinary teams improvement, as can be seen in the flow of activities resulting in 'Objective 1 ' in figure 1 . The vehicle for these improvements was the project team in Bogor, which provided continuity. As a result each successive expert team profited from the experience of the previous team. We stress that changes to the methods remained small once the major modifications following the German test were effected. No major change to the methods was allowed to take place.

The second decision was that expert teams were not informed of the results of preceding tests, i.e. they had no knowledge of the set of C\&I proposed by their colleagues in the previous tests. The C\&I resulting from one test were therefore not influenced by the C\&I proposed by any of the other test teams (figure 1). In this respect the tests were independent of each other. Our assumption is that if commonalities existed between the C\&I proposed by the test teams they would constitute the first iteration of a 'core generic' set. We could not have made this assumption had each test built on the results of the previous test. Furthermore it would have been even more difficult to compare the results of the tests as the influence of the C\&I would have been additive from the first to the last test.

Our approach, shown in Figure 1, involved interdisciplinary teams of foresters, social scientists and ecologists, selecting and evaluating C\&I from five existing sets, in four locations around the world (Germany, Indonesia, Côte d'Ivoire and Brazil). A parallel test was conducted in Austria in October 1995, in collaboration with CIFOR, which both provided additional results and represented an adaptation and application of the method in another context. As there was little experience of carrying out field evaluations of C\&I on which to build, we decided to focus principally on testing and developing the methodology at the first site in Germany. As a result, the test team did not propose a set of $C \& I$ at the end of that test.

The selected sets of C\&I ('base sets') included those from Smart Wood (Rainforest Alliance, USA), Initiative Tropenwald (ITW - Germany), and Woodmark (Responsible Forestry Standards, Soil Association, UK) and were evaluated on all sites. The Deskundigen-werkgroep Duurzaam Bosbeheer (DDB - the Netherlands) and the Lembaga Ekolabel Indonesia (LEI - Indonesia) sets were evaluated at all sites except Germany. In the Austrian test, a pre-selection of C\&I from 14 different sets were evaluated. In this and in other respects the Austrian test was significantly different to the other four tests. We will draw attention to these differences throughout this report.

The method used can thus be divided into three major stages, as follows: 


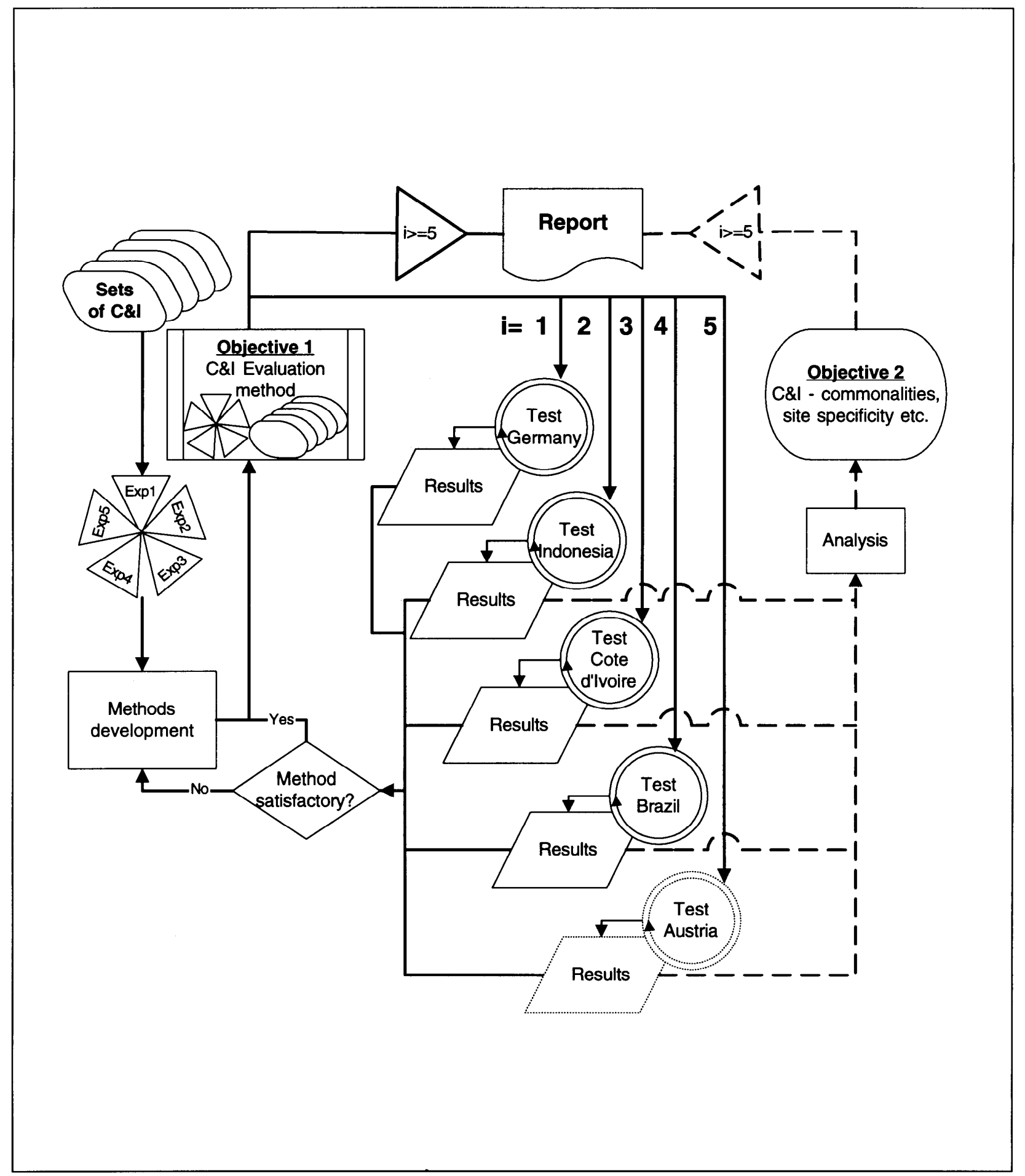

Figure 1. Flow chart of the CIFOR test series showing approach adopted. Dashed lines connect activities related specifically on Objective 2 . 
1. Activities preceding field testing: These include site selection, selection of partners, expert teams and the development of the conceptual framework. Except for the development of the conceptual framework, which is described in section 2.3, all other activities of the first stage are described in section 2.2.

2. M ethods used in the field: These include all the prescribed activities of the expert teams during their evaluation of C\&I in the field. A detailed description of field methods is presented in section 2.4.

3. Analysis of results of the field tests: This is the post-field evaluation stage, in which analysis of results takes place. A description of the analysis process is provided in section 2.4.3

\subsection{SELECTION OF BASE SETS OF C\&I, SITES, EXPERT TEAMS, AND PARTNERS}

\section{The Five Base Sets of $C \& I$}

In order to select the base sets of C\&I for the project, three main conditions were stipulated:

1. Selected sets should represent the 'state of the art' of C\&I for the assessment of sustainable forest management at the forest management unit level.

2. Wherever possible the most advanced national or regional set of C\&I was to be included.

3. They should cover ecological, economic, and social aspects of sustainability.

Inclusion was effected only with the consent of the institutions concerned.

Based on these criteria the following five sets of C\&I were selected ${ }^{4}$ :

- Smart Wood (Rainforest Alliance, U.S.A),

- Woodmark (Soil Association, U.K.),

- Criteria for an Evaluation of Sustainable Management of Tropical Forests (Initiative Tropenwald, Germany),

- Lembaga Ekolabel Indonesia (Indonesia), and

- Deskundigenwerkgroep Duurzaam Bosbeheer (Dutch Working Group - The Netherlands).

The C\&I of the Smart Wood scheme (SMW), Woodmark (SOI) and Initiative Tropenwald (ITW) were selected based on a cross sectional analysis of the criteria and guidelines of eight organisations and seven certifying bodies (Hahn-Schilling et al. 1994). The LEI C\&I were at the time of commencement of the project the most advanced set in Indonesia. They were not included in the test in Germany as they were undergoing a revision at that time? The Dutch Deskundigenwerkgroep Duurzaam Bosbeheer (DDB) C\&I represent an exception as they present more a conceptual framework for further development of C\&I than field assessment instruments. They were included following a request from some of the Indonesian partners of the project and because their slightly different approach offered interesting possibilities for comparison. Both the LEI and the DDB sets were included from the test in Indonesia onwards.

Neither the ITTO's criteria and indicators for sustainable forest management nor the FSC Principles and Criteria for good forest stewardship were considered for inclusion in the tests, despite their wide international acceptance. We considered both sets to be development umbrellas, rather than field assessment tools. Feedback received subsequently from institutions and persons involved in the development of C\&I for field assessment, under both development umbrellas, has strengthened this belief.

An analysis of how these five base sets have affected the results of the project is provided in section 3. It should be noted that all C\&I to date have been designed to test whether management is in accordance with current perceptions of best management practices or good forest stewardship. This is not really the same as assessing sustainability, as good forest stewardship is simply a statement of the "state of the art," of the means with which to reach the goal of sustainable forest management.

\section{A discussion of the overall strengths and weak- ness of any one of the base sets of $C \& I$ was not foreseen and will not be an output of the project.}

\section{Selection of Countries and Sites}

The tests were conducted in five countries and seven locations. The countries were selected to represent temperate and tropical eco-regions. The selected sites typified as far as possible regional conditions in the selected zones and were examples

\footnotetext{
4 References of the source documents for all five sets of criteria and indicators are available in Annex 4.

5 For the test in Germany it was felt that the criteria and indicators of the Ministerial Conference for the Protection of Forests in Europe might represent the equivalent of a 'regional' set. However they were subsequently dropped as they were not designed for use at the Forest Management Unit level. The African Timber Organisation's Green Label criteria and indicators were foreseen for inclusion but were not sufficiently advanced at the time of commencement.
} 


\begin{tabular}{|c|c|c|c|c|}
\hline $\begin{array}{l}\text { Country/ } \\
\text { Site }\end{array}$ & $\begin{array}{l}\text { Bio-physical } \\
\text { Environment }\end{array}$ & $\begin{array}{c}\text { Social } \\
\text { Environment }\end{array}$ & $\begin{array}{c}\text { Ownership, Tenure, } \\
\text { Management }\end{array}$ & $\begin{array}{l}\text { Dates of tests; } \\
\text { Area of FMU }\end{array}$ \\
\hline $\begin{array}{l}\text { Germany/ } \\
\text { Forstamt } \\
\text { Bovenden }\end{array}$ & $\begin{array}{l}\text { Temperate, } \\
\text { mixed Beech } \\
\text { (Fagus } \\
\text { silvatica) } \\
\text { dominated } \\
\text { broadleaf } \\
\text { forests. Heavily } \\
\text { influenced by } \\
\text { humans. }\end{array}$ & $\begin{array}{l}\text { High population } \\
\text { density, high } \\
\text { demand on } \\
\text { recreational use, } \\
\text { some local demand } \\
\text { for firewood and } \\
\text { NTFPs otherwise } \\
\text { low level of social } \\
\text { demands. }\end{array}$ & $\begin{array}{l}\text { State forests managed } \\
\text { by the State Forest } \\
\text { Service of Lower } \\
\text { Saxony. Shelter-wood } \\
\text { systems. Logging in } \\
\text { second rotation areas. }\end{array}$ & $\begin{array}{l}\text { November } 17-28 \text {, } \\
1994 ; 2000 \text { ha }\end{array}$ \\
\hline $\begin{array}{l}\text { Indonesia/ } \\
\text { PT. Kiani } \\
\text { Lestari }\end{array}$ & $\begin{array}{l}\text { Tropical } \\
\text { lowland mixed } \\
\text { dipterocarp } \\
\text { dominated } \\
\text { evergreen } \\
\text { forests. }\end{array}$ & $\begin{array}{l}\text { Relatively high } \\
\text { population density. } \\
\text { Dayak communi- } \\
\text { ties along the rivers } \\
\text { by far outnumbered } \\
\text { by recent migrants } \\
\text { from other } \\
\text { Indonesian islands. }\end{array}$ & $\begin{array}{l}\text { Privately owned forest } \\
\text { management } \\
\text { concession on state } \\
\text { forest land. TPTI } 6 \\
\text { system. Logging only } \\
\text { in primary forests. }\end{array}$ & $\begin{array}{l}\text { March 5- April 2, } \\
\text { 1995; 340,000 ha }\end{array}$ \\
\hline $\begin{array}{l}\text { Côte } \\
\text { d'Ivoire/ } \\
\text { Haut } \\
\text { Sassandra }\end{array}$ & $\begin{array}{l}\text { Tropical } \\
\text { lowland semi- } \\
\text { deciduous } \\
\text { forests. Large } \\
\text { areas degraded. }\end{array}$ & $\begin{array}{l}\text { High pressure of } \\
\text { population. } \\
\text { Traditional } \\
\text { Niedeboua } \\
\text { communities } \\
\text { reduced to } \\
\text { minorities by } \\
\text { in-migrants. }\end{array}$ & $\begin{array}{l}\text { State forests (Foret } \\
\text { Class6e - gazetted } \\
\text { forests) managed by } \\
\text { SODEFOR. Polycyclic } \\
\text { system. Logging, only } \\
\text { in the North, of } \\
\text { previously logged } \\
\text { areas. }\end{array}$ & $\begin{array}{l}\text { June 2-30,1995; } \\
102,000 \text { ha }\end{array}$ \\
\hline $\begin{array}{l}\text { Côte } \\
\text { d'Ivoire/ } \\
\text { Bossematié }\end{array}$ & $\begin{array}{l}\text { Tropical } \\
\text { lowland semi- } \\
\text { deciduous } \\
\text { forests. Mostly } \\
\text { degraded and in } \\
\text { the process of } \\
\text { rehabilitation. }\end{array}$ & $\begin{array}{l}\text { Very high pressure } \\
\text { of population. } \\
\text { Traditional } \\
\text { communities } \\
\text { dominate, but with } \\
\text { increasing } \\
\text { in-migration. }\end{array}$ & $\begin{array}{l}\text { As above. } \\
\text { No logging. } \\
\text { Management } \\
\text { concentrates on } \\
\text { rehabilitation and } \\
\text { protection. }\end{array}$ & $\begin{array}{l}\text { June } 2-30,1995 ; \\
22,000 \text { ha }\end{array}$ \\
\hline $\begin{array}{l}\text { Brazil/ } \\
\text { CEMEX, } \\
\text { Santarem }\end{array}$ & $\begin{array}{l}\text { Tropical } \\
\text { lowland } \\
\text { evergreen } \\
\text { forests. }\end{array}$ & $\begin{array}{l}\text { Pressure of } \\
\text { population low to } \\
\text { medium but } \\
\text { increasing very } \\
\text { rapidly due to } \\
\text { colonisation. No } \\
\text { presence of } \\
\text { Amerindian } \\
\text { communities, some } \\
\text { old settlers. }\end{array}$ & $\begin{array}{l}\text { Privately owned land, } \\
\text { declared as 'farm } \\
\text { land'. Polycyclic } \\
\text { selection system. } \\
\text { Logging in areas which } \\
\text { previously experienced } \\
\text { unrecorded light } \\
\text { logging. }\end{array}$ & $\begin{array}{l}\text { October } 23 \text { - } \\
\text { November } 19 \text {, } \\
1995\end{array}$ \\
\hline $\begin{array}{l}\text { Austria, } \\
\text { Grafenegg, } \\
\text { Langenlois \& } \\
\text { Krems }\end{array}$ & $\begin{array}{l}\text { Mixed } \\
\text { temperate } \\
\text { broadleaf and } \\
\text { coniferous } \\
\text { forests, heavy } \\
\text { human } \\
\text { influence }\end{array}$ & $\begin{array}{l}\text { High demand for } \\
\text { recreation. } \\
\text { Considerable } \\
\text { demand for some } \\
\text { NTFPs. Source of } \\
\text { income to Agrarian } \\
\text { communities }\end{array}$ & $\begin{array}{l}\text { Management favours } \\
\text { regeneration by seed. } \\
\text { However exotics like } \\
\text { Douglas fir were also } \\
\text { introduced. }\end{array}$ & $\begin{array}{l}\text { September } 18 \text { - } \\
\text { November 3, } \\
1995\end{array}$ \\
\hline
\end{tabular}

Table 1: Test Sites

\footnotetext{
${ }^{6}$ Indonesian Selective Cutting and Replanting System. A polycyclic system based on a cutting cycle of 35 years.
} 
of 'above average' forest management for the production of commercial timber, based on natural regeneration. An important criterion in the selection of sites was the willingness of the forest managers at national and local levels to participate and collaborate with the project team. At each of the sites the principal objective of forest management was production of timber. Other objectives, commercial and non-commercial could also be pursued.

Selection of test sites was based on consultations with the relevant government departments in all countries except Brazil. In most cases meetings were also held with interested NGO groups to discuss the selection of sites. In Germany the principal institution involved was the Federal Research Center for Forestry and Forest Products in Hamburg. The final selection of Forstamt Bovenden near Gottingen was the result of over three months consultations within Germany. Similarly in Indonesia the selection of PT Kiani Lestari as the site took place after consultation with the Ministry of Forestry, the concessionaires and NGOs. In the case of Côte d'Ivoire the part- ners in the process of selecting the sites were the ATO, the Ministry of Agriculture and Animal Resources and SODEFOR. Again this choice was discussed also at two meetings with NGOs in Abidjan. Because of the reluctance of Brazilian government institutions to be directly involved in the test, although there was considerable support initially, the site selection took place on the suggestion of Mr. Johan Zweede and Prof. Virgilio Viana, both members of the test team in accordance with the broad guidelines of the project. This was discussed with the owners and at an NGO meeting held in Brasilia. In Austria the sites were selected in a process involving multiple stakeholders and coordinated by Mr. Josef Hack1 of the Federal Environment Agency. As the project is solely concerned with the evaluation of $C \& I$, an evaluation of the management of the forest units at the selected test sites was not an objective of the project.

\section{Selection of Expert Teams}

Consistent with the project plan, special teams were selected for each field test, based on disciplinary

\begin{tabular}{|c|c|c|c|}
\hline Country & Foresters & Social Scientists & Ecologists \\
\hline Germany & $\begin{array}{l}\text { John Palmer-U.K.(team leade } \\
\text { Lukito Daryadi-Indonesia } \\
\text { Peter Boateng-Ghana (ATO) } \\
\text { Eberhard Panitz-Germany }\end{array}$ & & $\begin{array}{l}\text { Per Rosenberg- } \\
\text { Sweden }\end{array}$ \\
\hline Indonesia & $\begin{array}{l}\text { Peter Burgess-U.K. } \\
\text { (team leader) } \\
\text { Elias-Indonesia } \\
\text { Wan Razali Wan Mohd.- } \\
\text { Malaysia }\end{array}$ & P.M.Laksonoa-Indonesia & R.J.Watling-Fiji \\
\hline Côte d'Ivoire & $\begin{array}{l}\text { Patrice Mengin-Lecreulx- } \\
\text { France, (team leader) } \\
\text { Anatole Kanga N'Guessan- } \\
\text { Côte d'Ivoire }\end{array}$ & $\begin{array}{l}\text { Ahui Anvo-Côte d'Ivoire } \\
\text { Heleen van Haaften- } \\
\text { Netherlands }\end{array}$ & $\begin{array}{l}\text { Charles Huttel- } \\
\text { France }\end{array}$ \\
\hline Brazil & $\begin{array}{l}\text { Johan Zweede-U.S.A. } \\
\text { (team leader) } \\
\text { J.N.M.Silva-Brazil } \\
\text { Virgilio M.Viana-Brazil }\end{array}$ & Jan Kressin-Germany & $\begin{array}{l}\text { Rita C.G.Mesquita- } \\
\text { Brazil }\end{array}$ \\
\hline Austria & $\begin{array}{l}\text { E.Senitza-Austria } \\
\text { S .Terzer-Austria } \\
\text { (forest economists) }\end{array}$ & $\begin{array}{l}\text { EGrtinberg-Austria } \\
\text { ERest-Austria }\end{array}$ & $\begin{array}{l}\text { G.Willi-Liechtensteir } \\
\text { (team leader) } \\
\text { F.Reimoser-Austria }\end{array}$ \\
\hline
\end{tabular}

T able 2. Test Teams 
spread and geographical expertise. Each team included at least one forester, one ecologist, and one social scientist. Team members typically included three internationally recruited members and two host country nationals. In all cases considerable effort was made to recruit the best expertise available, both with respect to the discipline and site concerned. An effort was made to ensure that women were represented on the teams. We tried to include differing perspectives (e.g. academics, consultants, NGOs, government officials, etc.) in the teams.

Dr. Ravi Prabhu co-ordinated activities of all four tests, interpreted and explained methods to team members and provided continuity between tests. Dr. Carol Colfer and Dr. Eva Wollenberg joined the team during part of the time, to provide social science support to team members and ensure attention to women's roles in the forest. Mr.
Rinekso Soekmadi, Mr. P. Venkateswarlu and Ms. Lay Cheng Tan provided research and analysis support.

In keeping with CIFOR's philosophy of being a 'center without walls', the research project has been carried out in a collaborative manner with partners. Figure 2 provides an overview of the structure of the project as of January 31, 1996. Further details of this structure, including the principal partners of the project, are to be found in Annex 2.

\subsection{CONCEPTUAL FRAMEWORK}

\subsubsection{NEED FOR A CONCEPTUAL FRAME- WORK}

The need for a conceptual framework in the context of the project was underscored during the test in Germany, where it was found that great concep-

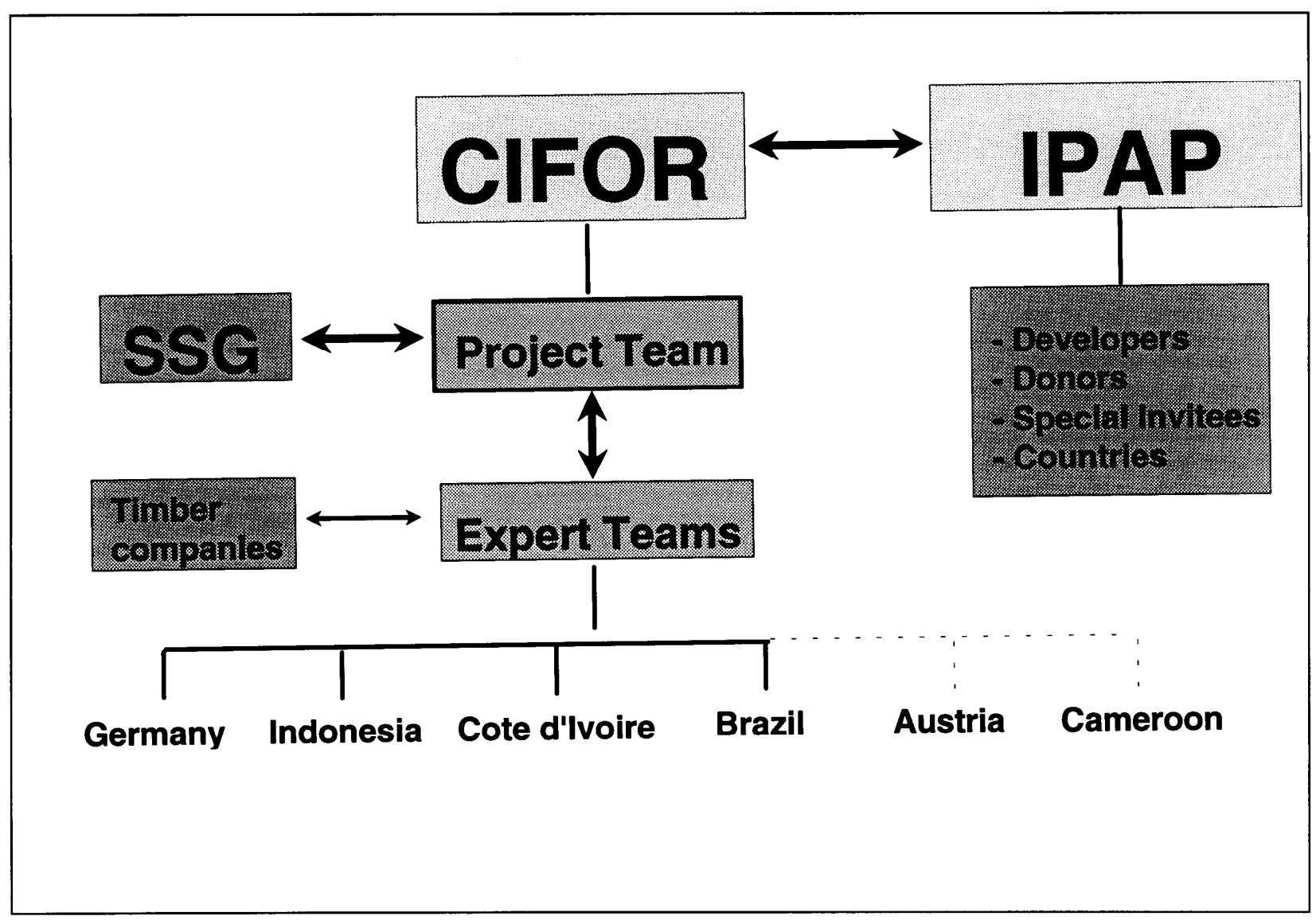

Figure 2: Structure of the Project. IPAP: International Project Advisory Panel; SSG: Scientific Support Group, Developers: representatives of the five base sets, Special Invitees: Both Ends (representing environmental NGOs) ITTO, FAO, FSC. 
tual divergence existed among the various sets of C\&I (Palmer 1995). This was especially true with regard to definitions of principles, criteria and indicators. Such a framework would:

- define the main terms, such as principles, criteria and indicators,

- place them in the context of sustainable forest management,

- define the constraints under which assessment ${ }^{7}$ of sustainability takes place,

- facilitate the operationalisation of the elements by elaborating the hierarchical links and relationships among the elements,

- provide a strategy for developing an operational and cost-effective assessment system, and

- permit the identification of a minimum number of reliable C\&I for each test site.

The conceptual framework was also necessary to provide the teams of experts with a common frame of reference for their work. Without such a frame of reference, interdisciplinary team work would have been even more difficult, and cross-site comparisons would have been more risky.

In developing the conceptual framework the project team built upon the work of FAO (1995), ITTO (1991), FSC (1994), and the proceedings of the International Symposium on Ecological Indicators (McKenzie et al. 1992) among others. Following the German test, it became clear that the social C\&I were particularly problematic as they had received very different attention in the five base sets C\&I. Special attention therefore was devoted to formulating aspects of the conceptual framework that would allow greater clarity and comparability of the social C\&I results from the different test teams and sites.

The development of the project's conceptual framework was an iterative process, responding to interactions during the field tests and the international debate on sustainability. The conceptual framework is bound to change further because sustainability, being an essentially human centered concept, will also continue to evolve in response to society's demands. Thus the proposals in the following sections are not an end product, but rather an iteration of an on-going process.

\subsubsection{ELEMENTS OF THE CONCEPTUAL FRAMEWORK}

In this section we discuss a definition of sustainability, including concepts of ecosystem integrity, human well-being, and continuity/temporal aspects of sustainable forest management. We also provide definitions for principles, criteria and indicators. All tests after the first one in Germany took place within the conceptual framework outlined here.

\subsubsection{SUSTAINABLE FOREST MANAGEMENT}

As Wiersum (1995) notes: "Notwithstanding 200 years of efforts to operationalise the concept of sustainability, its exact application in forestry remains troublesome". Several recent ${ }^{8}$ definitions of sustainable forest management have been proposed (e.g. ITT0 1991). Most have their roots in the concept of sustainable development, e.g. World Commission on Environment and Development 9 For the purpose of developing an assessment system, we have defined sustainable forest management as $\boldsymbol{a}$ set of objectives, activities and outcomes consistent with maintaining or improving the forest's ecological integrity and contributing to people's well-being both now and in the future. This definition represents the common denominator in the other definitions of sustainable forest management that we have examined. The task of a system to evaluate the sustainability of forest management will therefore be to assess the following two conditions:

1. Ecosystem integrity is maintained or enhanced. 2. Well-being of people is maintained or enhanced.

These conditions represent the bio-physical, social and temporal elements of sustainability and are discussed in greater detail below. From a pragmatic and operational point of view, fulfilment of the above two conditions is expected to take place continuously over long but not indefinite periods of time. We also recognise that there may be shortterm and site-specific conflicts between these two goals, and that the determination of the appropriate balance is likely to be problematic for assessors.

Since this project has focused on the forest management unit, it is important to provide a definition of that entity. The definition of what exactly con-

7 See definition of 'assessment' in section 2.3.3.

8 The principle of sustainability has a long history of evolution in Germany and France from the 17th century onwards. The earliest 'modern' definition dates back to Hartig 1804 in Germany '. ..utilise them [the forests] to the greatest possible extent, but still in a way that future generations will have at least as much benefit as the living generation' (quoted in Schmutzenhofer 1992)

9 "Sustainable development seeks to meet the needs and aspirations of the present without compromising the ability to meet those of the future." 
stitutes the FMU has important consequences for the assessment of sustainable forest management. An FMU is defined as a clearly demarcated area of land covered predominantly by forests, managed to a set of explicit objectives and according to a long-term management plan. An FMU can usually be expected to cover a few hundred to several hundred thousand hectares. The entire area of the FMU has to be clearly demarcated on the ground and usually also on a map. Under the broad objectives to which the entire management unit is subjected, sub-units may be managed under different and separate management regimes. The management plan will usually be written and may sometimes be published. However neither are necessary conditions.

Management of the FMU can have implications for people dependent on forest resources and vice versa. These people may or may not reside within the physical boundaries of the FMU, but the impacts of management activities may spill across the formal FMU boundaries. In fact these impacts may be social rather than physical and may affect material, cultural and social values. The team has sought to determine these impacts based on a gradient of importance, using a method under development by Colfer (1995).

\section{Ecosystem Integrity}

Ecosystem Integrity is defined as: the ability to support and maintain a balanced, integrated, adaptive biological community having a species composition, diversity, and functional organisation comparable to that of natural habitat in the region. (Schneider 1992)

An alternative term is Ecosystem Health, which is defined as a comprehensive, multiscale, hierarchical measure of system stability, organisation and vigour (Constanza 1992). These two definitions imply that ecosystem structure, function and resilience should be metrics of concern for ecosystem management. The project's work has been based on the following definitions:

Ecosystem: The biotic and abiotic components of an environment that interact to produce a flow of energy and cycling of nutrients. Ecosystems are extremely difficult to define practically, because of high variation, temporal changes and lack of discreteness. The project has taken the physical boundaries of the FMU as the external limits of the forest ecosystem for which C\&I are tested and developed. As is the case for social spillover impacts, this has not meant ignoring landscape level interactions. Nonetheless the major focus has been on interactions within the physical confines of a forest management unit.

Structure: The species composition, dispersion pattern and organisation of plant and animal species into higher ordered levels, such as trophic levels, food webs, or guilds. The change of structural parameters through time is important for the long-term view of ecosystems (Landres 1992).

Function: The set of processes that results from interactions among biotic and abiotic components of the ecosystem. Three classes of processes are important:

1. processes that affect the rate and total quantity of energy flow,

2. processes that affect the rate and total quantity of nutrient cycling, and

3. processes that influence ecosystem services important to human beings (Landres 1992).

Resilience: A measure of the ability of the system to absorb changes of state variables and parameters and persist or rebound within a given amount of time. It is also defined as the persistence of relationships within a system or the rate of recovery of the ecosystem. Related terms are stability, elasticity and restoration time. Resistance, on the other hand, relates to the extent to which an ecosystem is displaced (Attiwill 1994).

\section{Well-being of People 10}

Well-being encompasses the economic, social and cultural aspects of people's lives, as influenced by forest management. Forest management by its nature is intended to provide benefits to people, although as Colfer (1995) has pointed out, who benefits and by how much is an ongoing debate, especially on lands classified by government as public forest. It is unrealistic to expect forest managers to solve all of society's woes, but on occasion team members, workshop participants, and others have indicated such an expectation.

Careful analysis is needed to determine which of the different social groups requires the attention of forest managers. One critical element is that of proximity. People living in close proximity to the forest have the greatest potential to affect the forest directly. However, other important features

10 Based on Wollenberg and Colfer 1996. 
have emerged in the course of our research. These include pre-existing rights, forest dependence, indigenous knowledge, forest-culture integration, and power deficits. We suspect that a concern for sustainability and poverty may be necessary additions to this list.

Following on these observations, we have begun developing a simple method with which to identify the group of people affected by the management of a particular forest, partially to reduce unfair expectations directed at forest managers, and partially to ensure adequate attention to the relevant populations. A clearer definition of the forest management unit in question, from a 'social' point of view, could be the result of applying this method.

When we first began to investigate the human dimensions of sustainable forest management, we found three distinct aspects of the concept of sustainability to be important. Sustainability can be said to include:

- the maintenance of people's well-being -- often with a focus on forest dwellers,

- the actions of people that affect the sustainability of the forest, and

- the intergenerational distribution of benefits, i.e. the Bruntland Commission definition of meeting the demands of the present without compromising the needs of the future.

Reviewing the existing principles and general literature on forest peoples, there seem to be five essential areas of concern for people's well-being. These could be thought of as a sort of "Bill of Inalienable Sustainability Rights:"

1. security and sufficiency of access to resources - both now and in the future,

2. economic opportunity - forest activities should maintain or enhance people's livelihood opportunities,

3. heritage and identity - people's rights to their cultural values, behaviour, land use and material goods should be respected, both for the present and as a necessary context for the enculturation of the young,

4. justice - there should be fair resolution of conflict and distribution of benefits, rights, responsibilities and incentives, and

5. safety and health - employment, residence in, or use of a forest should not endanger people's safety and health (either physical and mental).

In developing our approach to human well-being, we found the work of Ostrom (1994) to be relevant to understanding how people's actions affect forest management. She refers to the capacity of a group to co-operate effectively as "social capital." Building on her ideas and those of others on common property resource management, we identified nine social conditions as necessary for effective resource management by a group.

1. Boundaries - clearly defined and agreed upon. Rights of use and the distribution of benefits clearly defined and agreed upon.

2. Capacity to protect the resource - the users of the forest have the means to exclude outsiders.

3. Decision-making mechanisms - people affected by a resource have a say in how the resource is managed and how the benefits are distributed. They also have a means within the group of making final decisions.

4. Conflict resolution - closely related to decision-making. People have a means for settling disputes, both internally and externally to the group.

5. Monitoring - information about the quality of the resource is available to the group.

6. Group size - groups are sufficiently small to enable regular contact and communication. Where larger numbers of people are involved, groups are nested to enhance organisational efficiency.

7. Incentives/benefits - the net benefits to people are positive, and may include economic as well as cultural or intangible benefits. Incentives may be positive or negative (e.g., sanctions). Forest management options should be considered in comparison with benefits resulting from other activities (opportunity cost).

8. Inputs - people have the necessary labour, technology, information, capital and other inputs necessary for sustainable management.

9. Conservation value or commitment to sustainability - people using the forest value forest conservation and seek to maintain the quality of the resource.

Intergenerational distribution of benefits focuses on the persistence or improvement of social equity over time. Indicators for assessing intergenerational benefits include the stability of people's well-being, the maintenance of "social capital", equitable inheritance systems, tenurial security, and values of, and opportunities available to, the younger generation. 


\section{Continuity and Temporal Aspects}

Continuity and temporal aspects refer both to the biophysical and the social elements of sustainable forest management. From the biophysical standpoint, it is important to understand that continuity is not taken to mean a flow of goods and services at constant rates. As with any dynamic natural system, outputs from sustainably managed forests will fluctuate. The amplitude of these fluctuations must be controlled to ensure that the system remains stable. These fluctuations must be expected to be controlled over long periods of time.

Social systems also require a balance between stability and change. There is room for fluctuation within a given social system over time; but there are limits beyond which a healthy human system breaks down. One important task in assessing and developing social C\&I is to find indicators that tell us when those limits are being approached or have been transgressed.

The essence of sustainability is the maintenance of a given set of desirable conditions over time and how these conditions are sustained is governed by the principle of inter-generational equity. The reliability of sustainability evaluations is also significant. Such reliability is expected to decrease very rapidly for longer periods due to inherent uncertainties involved in making predictions about such complex social and ecosystem interactions. We therefore recommend five years as the maximum period of validity of any sustainability assessment.

\subsubsection{WHAT ARE CRITERIA AND INDICA- TORS?}

In this section, we define the three main conceptual tools for guiding assessments (principles, criteria and indicators), and discuss verifiers (specifically tolerance levels/performance thresholds and means of verification) and verification procedures. These definitions were used by the test teams in assessing C\&I.

\section{Principle}

The Concise Oxford Dictionary (1990) defines a principle as "a fundamental truth or law as the basis of reasoning or action". This has been the working definition adopted by the project. Principles in the context of sustainable forest management are seen as providing the primary framework for managing forests in a sustainable fashion. They provide the justification for C\&I included in the evaluation system. Examples of principles include "Sustainability of the forest and its multiple functions is a high political priority" (Côte d'Ivoire set), or "Human well-being is assured" (Indonesia set).

\section{Criterion}

A criterion is defined as "a principle or standard that a thing is judged by". Most definitions would seem to agree fairly closely-. with the dictionary definition, as does that of FAO (1995) which defines a criterion as identified elements of sustainability against which forest management can be assessed'. A criterion can therefore be seen as a 'second order' principle, one that adds meaning and operationality to a principle without itself being a direct yardstick of performance. Criteria are the intermediate points to which the information provided by indicators can be integrated and where an interpretable assessment crystallises. Principles form the final point of integration. Examples of criteria include "Forest actors" long term tenure and user rights are secure" (Brazil set) or "The function of water filter of the forest is maintained" (Côte d'Ivoire set).

\section{Indicator}

The transitive verb 'to indicate' is defined in the Concise Oxford Dictionary as:

a) point out, make known, show, or

b) be a sign or symptom of, express the presence of.

Landres (1992) provides a useful definition of ecosystem indicators, which is adopted here in a more generalised form as follows: "An indicator is any variable or component of the forest ecosystem or the relevant management systems used to infer attributes of the sustainability of the resource and its utilisation." Examples from our field tests include: "Absence of ponding behind stream/river crossings" (Indonesia set) or "There are assured compensation benefits in cases of accident" (Brazil set).

\section{Verifier}

In the course of the field tests, it soon became clear that team members 1) felt the need for a fourth level of specificity, 2) wanted more specific details that would indicate or reflect a desired condition and 3) were hesitant to make indicators more specific because they could give rise to controversy that would reduce the value of a valid indicator. The term "verifier" was used to fulfil these perceived needs. Our definition for "verifier" is therefore necessarily broad: "Data or information that enhances the specificity or the ease of assessment of an indicator". This can take the form of a tolerance level or performance threshold, or the means of verification, which is often linked to a verification procedure. In some cases, what was described as a verifier by team members did not fit this definition. In the following discussion, we consider two uses of the term that emerged in our field tests: tolerance levels/performance thresholds, and 
means of verification, both usually linked to verification procedures.

Tolerance levels or performance thresholds (the terms are used analogously) define the limits of a hypothetical zone from which recovery can still safely take place. This assumes that sufficient knowledge about these recovery zones exists. In reality, our current knowledge of the stress to which ecosystems or social systems can be safely subjected is limited. In practice this means adopting an iterative approach towards defining performance thresholds. Consequently, definition of tolerance levels or performance thresholds must follow the precautionary principle.

Tolerance levels add meaning, precision and usually also site-specificity to an indicator. They can be formulated separately from an indicator (e.g., the verifier, "less than 10 percent of marked residuals damaged by tractor blade and rubbing" which refers to harvesting under the Indonesian TPTI system), thereby allowing the indicator (in this case "skidding damage to trees and soil minimised") to maintain a certain generic character. Or they may be integrated within the formulation of an indicator, transforming the indicator into a much more site specific yardstick (e.g., the Brazilian indicator, "cultural and religious sites of special significance to local cultures, traditions and religions of Indians are protected by the FMU in co-operation and co-ordination with local populations, institutions, and authorities" [our italics]). If an indicator is formulated in such a way that more than one performance threshold could apply, a separation of indicator and performance thresholds is useful. Figure illustrates the hierarchical relationship between principles, criteria, indicators and verifiers.

Verification procedures, on the other hand, are procedures needed to determine satisfaction of the conditions postulated in the evaluation system, especially in the indicators or performance thresholds. The verifier in these cases is usually defined as a "means of verification", e.g. "Housing for the staff is appropriate and at least meets the legal minimum." (Brazil set). Verification procedures must fulfil the following demands:

- Cost-effective. Once the C\&I have been identified, the cost of the evaluation depends to a large extent on what procedures are adopted for the means of verification.

- Quick, simple and understandable. This is important if they are to be effectively followed by different evaluation teams and produce consistent results.

- Transparent and plausible, in order to be acceptable.

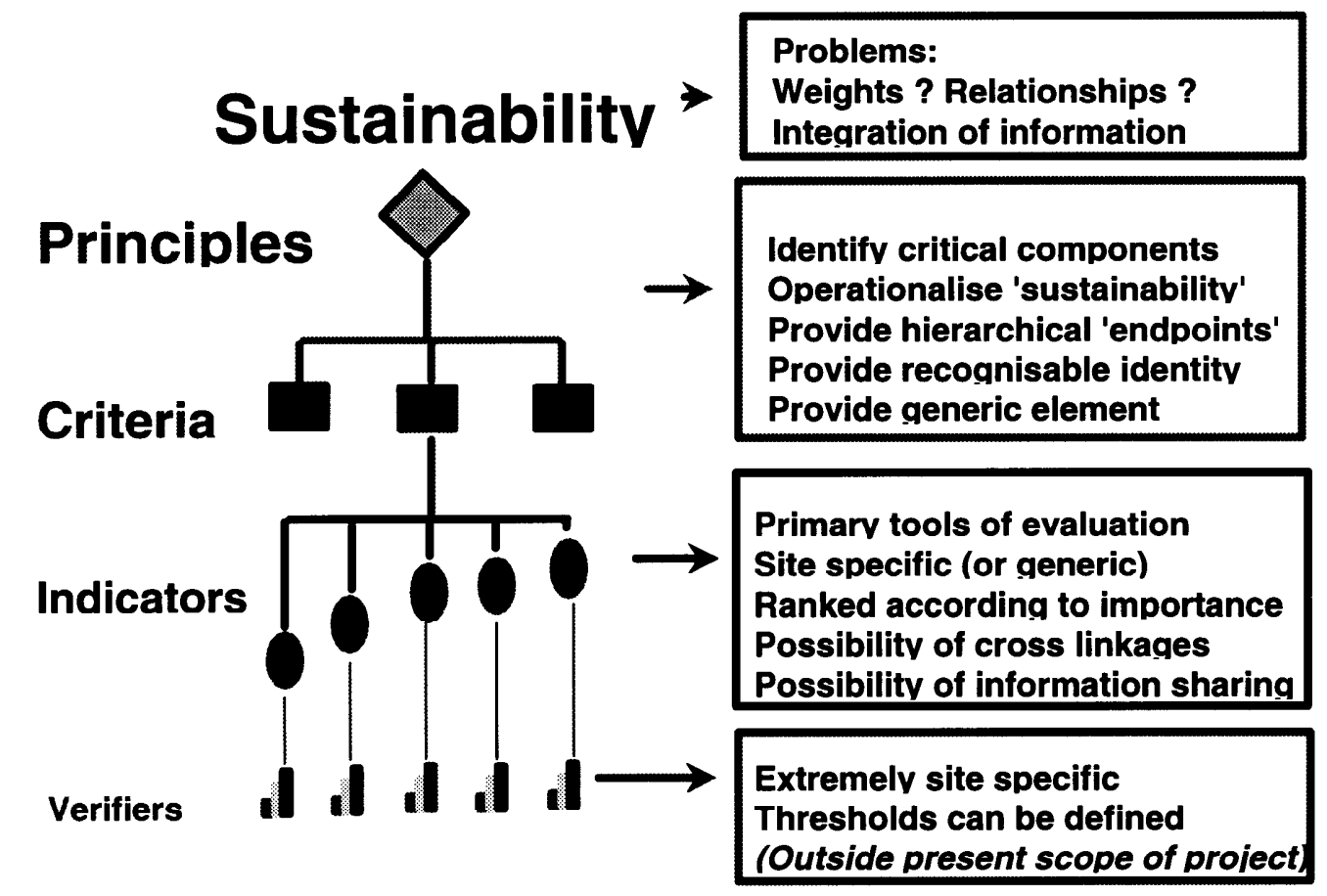

Figure 3. Conceptual Framework 


\subsubsection{METHODS FOR TESTING CRITERIA AND INDICATORS}

Nine attributes were selected for use by team members to judge the C\&I. Team members varied considerably in their perceptions of the utility of the nine primary attributes. Some of the variation can be attributed to differences in disciplinary perspectives. Other modes of evaluation are discussed at the end of this section.

\section{N ine Attributes}

Attributes selected by the project team for use by team members to judge the usefulness of C\&I included:

1) R elevance. All C\&I should be relevant to the issues that define sustainable forest management.

2) Unambiguously related to the assessment goal. Each indicator must be directly related to a criterion and each criterion to a principle. All principles have as their ultimate end-point sustainable forest management. This is similar to, but not the same as, relevance. In the latter case the experts were expected to view a criterion or indicator on its own merits in the context of sustainability. In the case of Attribute 2, it was to view a criterion or indicator within a given logical association. In the process of defining or developing C\&I seemingly logical associations can detract from the fact that a particular indicator actually has little relevance to sustainability on its own. For example, the horsepower of a bulldozer is often linked to the extent of damage it creates, this in turn is linked to the condition of a forest, which is linked to ecosystem integrity. A seemingly logical sequence, it has resulted in the inclusion of some sets of C\&I. This is however misleading as it is not the horsepower of the bulldozer that is relevant to sustainability, but the skill (i.e., training) and commitment of the bulldozer driver. A combination of attributes 1 and 2 with several others listed below would, we believe, help reveal such logical inconsistencies.

3) Precisely defined. The wording for the definition of criteria should be simple and unambiguous.

4) Diagnostically specific. As far as possible indicators should provide information that allows a direct interpretation of the fulfilment of a criterion. For instance the indicator "A permanent forest estate comprising both protection and production forest has been constituted ..." is diagnostically specific to the criterion "Legal and policy framework recognise the benefits occurring from forests and seeks to optimise and maintain them" (Indonesia set). This will however not always be possible due to a lack of information, or the cost of such a direct assessment, among other factors. In such cases proxy indicators will need to be defined. The indicator "Chemicals banned in Europe, America or target country are not used" (Indonesia set) is a proxy indicator that seeks to establish "... no chemical contamination to ... food chains and ecosystem" (Indicator, Brazil set): both indicators are assessing fulfilment of the criterion "Ecosystem function is maintained". However, even such an indirect assessment should strive to fulfil the attribute of diagnostic specificity as far as possible.

5) E asy to detect, record and interpret. In most cases the cost of assessing sustainability has to be borne by the products of the forest management unit. Thus it is important that indicators are selected in such a way that they result in minimum additional costs. Indicators that are easy to detect, record and interpret contribute significantly towards the goal of cost-effectiveness.

6) R eliability. The techniques or methods necessary to ascertain the information specified by the criterion or indicator must be sufficiently reliable, as indicated by replicability.

7) $M$ ust be sensitive to stress on the forest management, ecological or social systems. C\&I need to be defined in such a way that they provide meaningful information under different conditions. Although in some cases a simple yes/no answer may be advantageous, in most cases management impacts will result in varying responses from the underlying systems. An indicator improves its usefulness by being able to provide meaningful information over a wide range of changes in the system.

8) Provides a summary or integrative measure over space and/or time. This essentially looks at the question, how much information does this indicator provide about the system? Indicators defined in relation to "choke-points" in the system would tend to be more informative and cost-effective than 
others (see also "cost-effectiveness" below). For example the indicator (Indonesia) "Potentially dominating secondary successional vegetation is not abundant in loggedover stands" integrates information on the disturbance suffered by a forest during harvesting operations. This includes the amount of canopy opening, disturbance to the soil, tending operations, etc.

9) Appealing to users. This recognises the importance of user preferences in determining the acceptability of C\&I as legitimate measures. Expert team members were asked to consider cost-effectiveness as being particularly important under this attribute. They were also to answer the question "Does it appeal to you?" for themselves.

\section{Other Ways of Judging Criteria and Indicators}

Here we discuss judging $\mathrm{C} \& \mathrm{I}$ according to their causal association with sustainable forest management, temporal classification, classification according to geo-political level, and cost effectiveness. Each criterion or indicator can be defined in different ways. Some of these definitions will only be superficially different, due simply to a different choice of language but expressing the same content. In other cases, however, differences in formulation which have their roots in one of the following causes will result in different types of indicators, with consequences for what is assessed, where, when and how. This applies more to indicators and performance thresholds than it does to criteria. The project has used the following three classifications as aids to identifying and developing better C\&I, and not as ends in themselves.

\section{Causal Association with Sustainable Forest Management}

Two types of causal association are identified. The first type differentiates between physical human inputs or human processes and the outcomes of these two on the forest ecosystem or the social system. A slightly different approach is followed when C\&I are identified as stresses (or pressure), states or responses. These are defined below. The two types of classification are not mutually exclusive. Experience has shown that the input-processoutcome classification was more readily accepted by the expert teams when dealing with human activities.

- Human input: What is put in, or taken in, or operated on by any process or system. E.g. Percentage of revenue re-invested in the forest.
- Human process: A course of human action or proceeding. E.g. "Logging is rationally planned.. ." (criterion, Côte d' Ivoire), "Large canopy gaps are avoided" (indicator, Brazil).

- Outcome: The result or effect of inputs and processes on the three systems concerned. E.g. "Residual stands satisfactorily regenerated" (indicator, Indonesia).

- Stress: An external factor, force or stimulus applied to a system. This is used to classify the causes of change in the status of a system component. E.g. "Maximum five trees to be harvested per hectare" (verifier, Côte d'Ivoire), "Logging prohibited on slopes of over $25^{\circ}$..." (indicator, Indonesia).

- State: The condition or quality of the system component concerned. This classification is to be used when the purpose is to describe a desired condition of a system component, independent of what forces of change are acting on it. E.g. "Forest dependent people are aware of their rights to resources" (indicator, Indonesia).

- Response: The reaction of the system to stress. In other contexts response has been interpreted narrowly to mean human (especially policy) responses to changes in state (e.g. Anon. 1993). In the present context the term is used to classify both human and ecosystem related reactions to pressure or changes in state. "Creepers such as Merremia spp. and Mesoneuron spp. are generally not present within stands" (verifier, Indonesia), "Economic alternatives are increasing because of forestry activities" (indicator, Côte d' Ivoire).

\section{Temporal Classification}

Temporal classification seeks to allocate a criterion or indicator to a particular time period, e.g. an average growth rate is largely a historical (past) indicator, total standing volume is a current (present) indicator and a projection of growth rate would be predictive and therefore attributable to the future.

Classification according to Geo-political Scale. This classification seeks to order a criterion or indicator according to the level at which it mainly influences forest management (e.g. the CITES convention is international in its geo-political influence; definitions of "production" or "conversion" forests in the Indonesian context are of national significance; local taxes, reporting and control instruments are seen to be regional instruments; and decisions taken within the forest management unit or the surrounding population will have a local influence). 
The test in Germany contributed to the identification of these methods for evaluation C\&I (Palmer 1995, Annex 5).

\section{Cost Effectiveness}

The nine attributes and the classification described above are instruments with which the cost-effectiveness of an assessment system can be improved. The cost-effectiveness of the system will depend on whether C\&I have successfully been limited to the key areas of sustainability, how they have been defined, the amount of information they hold potentially, and only lastly, what survey and data collection methods are used.

This project in its current phase has sought to minimise costs associated with an indicator by asking three questions:

1. where to place an indicator within a system in order to sum up a satisfactory amount of information on interactions

2. how to define the indicator such that information is integrated meaningfully and

3 . over what intervals of time should this information be collected, leaving the question of defining the actual field procedures for a later phase.

To be cost-effective, indicators need to be selected in such a way that they provide information on changes at 'choke points' in the system. Such a selection of indicators would ensure that information on systems interactions prior to the "choke point' will be reflected by changes at the choke point itself. Having selected the 'choke points', the second consideration is then actually to define the indicator. This can be descriptive, qualitative or quantitative. In either of these cases it will be important to know what to observe or measure and, in the latter case, what measure to use. Finally some thought must be given to the interval of time over which information is integrated.

In order to achieve information efficiency several conditions need to be met. Some of these have been articulated in the nine attributes described in the previous section. One important condition is the need to build in mechanisms for effective information sharing or multiple linking of C\&I, even across disciplinary boundaries, wherever possible. This can mean that a bio-physical indicator could be used both to indicate fulfilment of a criterion related to ecosystem integrity and to a social criterion. For example, fish yields from streams in logging areas have the potential to be used as an indicator for sound logging practice (maintenance of buffer zones near streams, therefore preventing water temperatures and sediment loads rising unduly, etc.) and can also be used to indicate the economic and social impact of forest management on local ivelihoods (income or income-substitution, source of animal protein, water quality). Similarly some keystone species may be important both to ecological chains and to local people as a source of food.

It is also important to consider the rules related to the integration of information. This must be a transparent and meaningful process. Information is integrated as we move up the hierarchy from verifiers to principles. This process involves a series of 'quantum' jumps. It is not always obvious why certain indicators are grouped under a particular criterion. The rule set is evolving and still retains an essentially intuitive character. We recognise this and have allowed the experts freedom to develop their own models within the agreed conceptual framework. Our expectation is that an analysis of these models will help us to make progress towards a more definitive rule set for associating indicators with criteria and integrating the information they contain. This last step will call for rules to resolve conflicting and incomplete information.

It is also conceivable that information can be integrated without attempting to move up to a higher level of hierarchy. This takes place for instance when the information contained in several indicators is combined to form a new composite indicator or index value. Again we hope that through an intensive analysis of the results of Phase I and activities planned for Phase II, we will make progress towards developing rule sets for this type of integration of information as well.

\subsubsection{USING THE PROPOSED FRAME- WORK}

In this section we focus on how the conceptual framework has been used by the project in an inductive-deductive process of developing a set of tools with which to assess the sustainability of forest management. We lead in to this description by clarifying a few issues related to assessment, and briefly consider that cost-effective assessment of sustainability is intimately linked to how information is treated.

\section{Assessment, Monitoring and Guidelines: a Clarification of Terms}

The assessment of sustainability is often confused with monitoring and guidelines. All three concepts are related inasmuch as they all deal with sustainable forest management, and so share a common guiding principle and probably many similar criteria. 


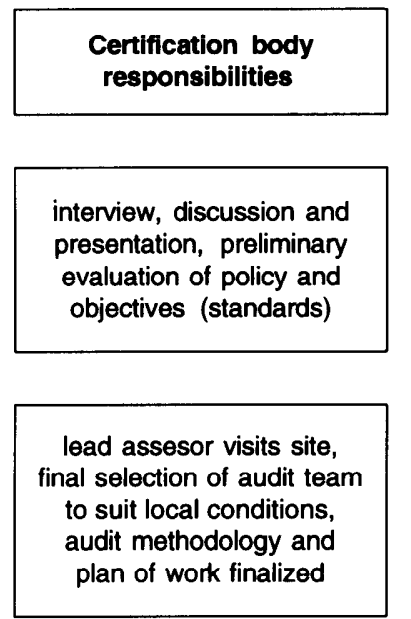

check adequacy and compliance to standards, identify key priorities, evaluate management systems and assess resourcerequirements

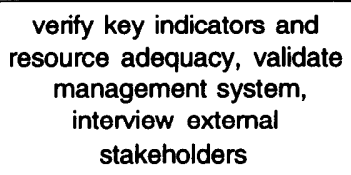

verify key indicators and resource adequacy, validate management system, interview external stakeholders

technical validation of audit procedures and results

issue certificate and explain limitations of usage

organize and implement chain of custody inspections

\footnotetext{
verify continued comliance and non-abuse of certificate. assess progress towards 'continuous improvement'
}

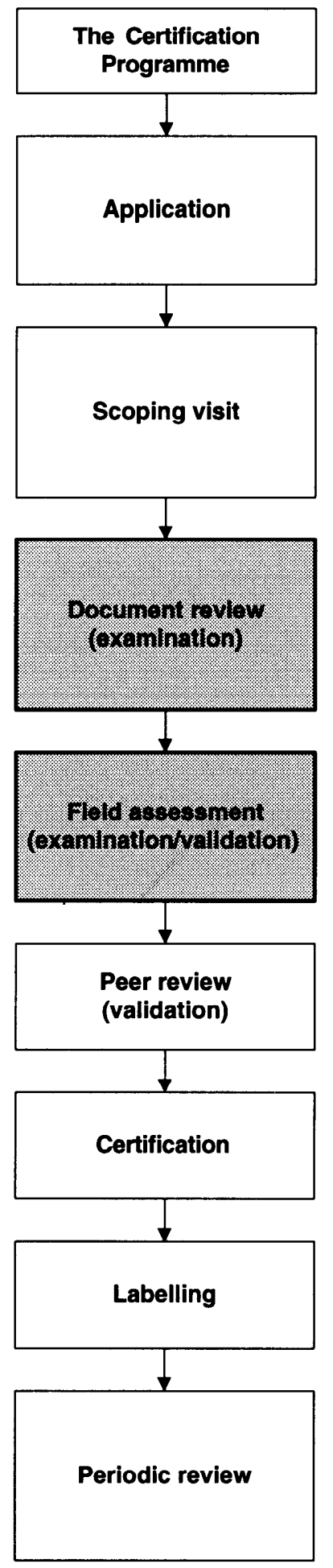

Forest operator/owner responsibilities

provision of basic information description of site and operations, completion of interview questionnaire

meetings with senior staff, understanding of certification process, supply of preliminary management documentation, audit logistics

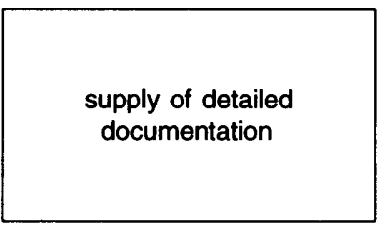

supply access to site, documentation and personnel
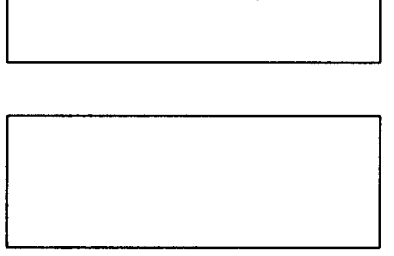

receive certificate and accept conditions of use

undertake not to label without chain of custody inspection

supply access to site documentation and personnel

Figure 4. The Certification Process (from Upton and Bass, 1995). The use of C\&Is takes place only in the highlighted stage. 
An assessment of the sustainability of forest management primarily aims at providing answers to the following three questions:

1. Is forest management committed to sustainability?

2. Is the condition of forests and its users acceptable?

3. Is the response to management interventions positive?

To use the doctor-patient analogy, an assessment should try and reach a diagnosis on whether

- there is an impairment of health, i.e. sustainability,

- which parts of the body have been affected, as in the criterion "structure and diversity aspects of ecosystem-integrity have been affected", and, if possible

- the extent of damage.

The assessment may also give indications of the nature of the illness ("pollination chains have broken down"), however we have not considered this to be a necessary attribute. We do not see it as incumbent upon the assessment system to suggest remedies or monitor recovery ${ }^{11}$. These functions, if desired, will call for additional diagnosis modules and would lead to guidelines for management. This is beyond the scope of the present research project. In a typical certification process, sustainability assessment is only one of several steps, as can be seen in Figure 4. We can view assessment in the context of sustainable forest management as the process by which information about forest management is collected with a view to establishing, within a defined framework of expectations, the current status and probable future direction of the interactions between human beings and forests, using certain criteria and indicators.

In concrete terms the difference between assessment of sustainability and monitoring is that the former attempts to facilitate a spot judgement of management by defining the indicators to compare existing states against pre-defined targets as in the verifier "not more than $\mathrm{X}$ percent of canopy is opened". Indicators in a monitoring process are usually more neutral and procedural in character, and are defined to enable the interpretation of trends over time, based on repeated data collection, e.g, percentage change in forest area.

Guidelines, in contrast, are prescriptions on how to achieve a certain goal. They can be directly interpreted from indicators for assessment especially when the latter are prescriptive in nature, such as "No tractor logging on slopes steeper than $25^{\circ}$ ". However, this will not be the case for descriptive or evaluative indicators (e.g. "Secondary succession species account for less than 10 percent of basal area"). In order to arrive at relevant guidelines, the underlying assumptions of the assessment indicator will require translation into management prescriptions. Interpretation of assessment indicators will be particularly necessary if they are response or outcome oriented.

\section{We suggest it is not productive for either an assess- ment or a monitoring system to aim to provide complete descriptions of the present condition.}

\section{M anagement Systems A pproach vs. Performance Standards}

The conceptual framework presented in the previous section would apply equally to the development of a system to assess sustainability based on evaluation of the presence of process or 'systems' type C\&I such as contained in an environmental management system ${ }^{12}$ or compliance with performance standards. The former stresses the procedural nature of management systems and seeks to establish the presence and quality of these systems. The latter approach seeks to assess sustainability against a set of performance standards or targets. However we believe both approaches have validity and should be reconciled with each other in order to achieve maximum efficiency. This is possible within the conceptual framework defined in the previous section, as both procedural and outcome or target oriented indicators are permissible. This is borne out by the results of the tests: The sets proposed by the teams in Indonesia, Côte d'Ivoire, and Brazil contained C\&I based on performance and process. These results suggest that both process and performance standards are necessary in combination.

\section{"Top-down" and "Bottom-up" Approaches to D eveloping Sustainability A ssessment Systems}

The purpose of the conceptual framework is to facilitate the development of a system to assess sustainable forest management. The important

11 This is not to be confused with a certification process, where it is legitimate to expect management to respond to corrective action requests (CAR) and provide proof of this during surveillance visits.

12 According to Upton and Bass (1995) an environmental management system is defined as 'the organisational structure, responsibilities, practices, processes and resources for implementing environmental management'. 
question is where to begin with this development. The project has taken the view that a sustainability assessment system must be conceptualised from the top-down, i.e. it is important first to define the principles before moving on to the level of criteria and indicators. The principles are defined on the basis of wisdom and knowledge. This ensures that there is a proper focus to the assessment system. In the related field of ecological risk assessment Gentile and Slimak (1992) suggest that the departure point should be from the top-down. The first step, according to them, is to define the highest ecologically valued target and then move downwards to identify a suitable suite of ecological endpoints and indicators. The advantage of proceeding in this fashion, they point out, is that it assures conceptually and scientifically that environmental values are integrated with the selection of ecological endpoints and indicators. Our teams followed this process. This involves using the knowledge, experience and judgement of the experts together with the conceptual framework outlined above to work out the broad intellectual outline of a framework of the critical issues for the subject area concerned.
An important aid to the top-down process was the use of existing frameworks for sustainable forest management such as the Principles and Guidelines of the FSC, and the ITTO criteria and indicators as a development platform.

After arriving at the basic principles and criteria in this fashion, it is necessary to reverse the process and to approach the same question from the bottom-up. Our teams began by considering all 1100 criteria and indicators in the five base sets simply as possible elements of a sustainability assessment tool-box. In a second step, data and information from the field sites were added to these 1100 possible elements. This was then the basis from which an ascent towards the levels of criteria and principles was undertaken.

The minimum set of reliable C\&I was then identified through a confrontation of the top-down and the bottom-up processes in the minds of the expert teams. Mengin-Lecreulx et al. (1995) have depicted this process as shown in Figure 5. This process was not only used by the field teams, it was also

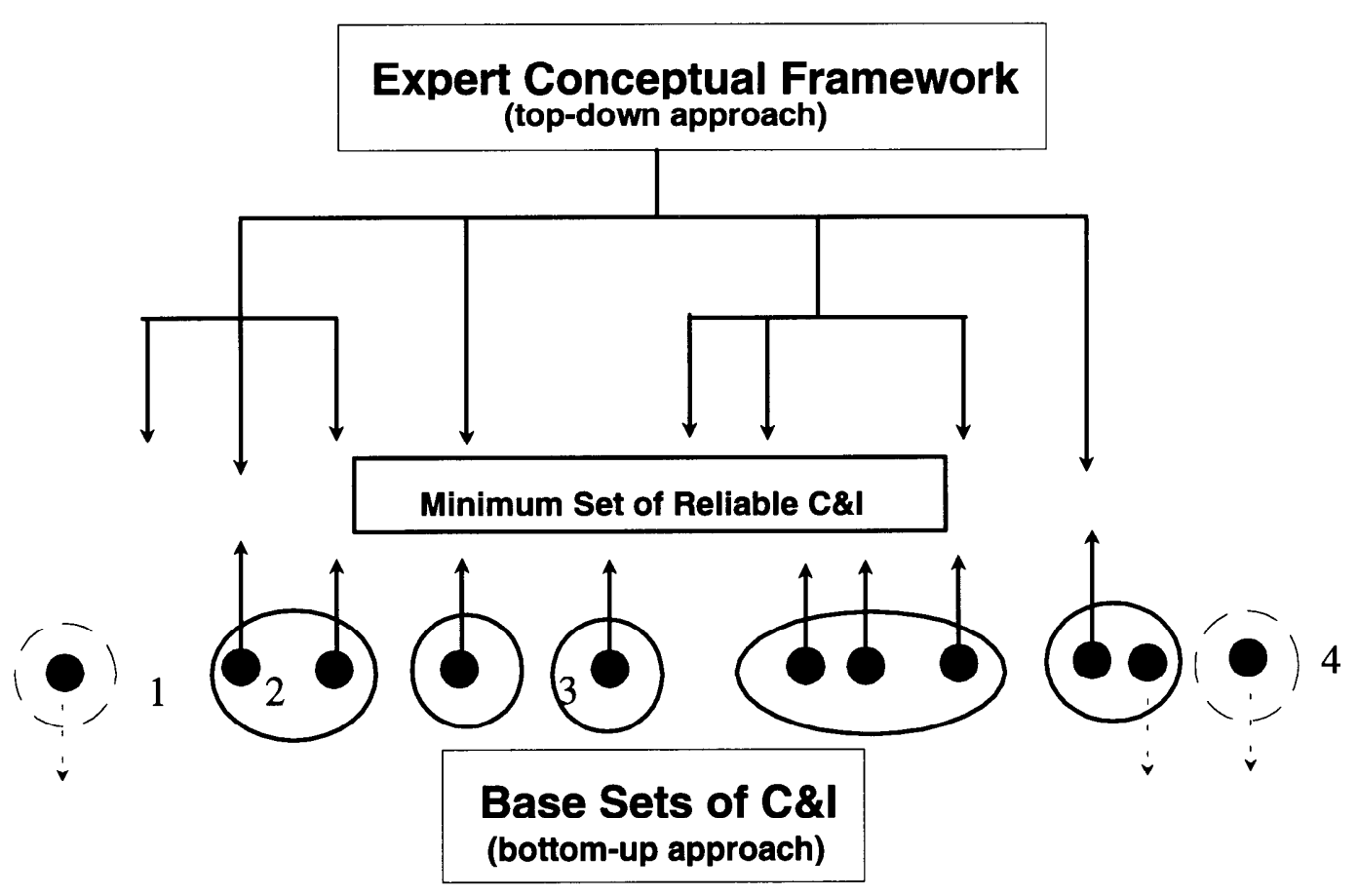

Figure 5. Schematic depiction of the "top-down" and "bottom-up" processes for evaluating C\&I. Dendrite represents an outline of the critical issues manifested as principles and criteria. Dots represent C\&I in base sets. 1: gap in base sets (new C/I to be proposed), 2: gap in expert's conceptual framework, 3: match beween base set and expert's conceptual framework - C/I selected, 4: outside limits of framework - rejected C/I. 
used in our articulation of the conceptual framework for social sustainability (Colfer et al. 1995).

The objective of the bottom-up process is to ensure that information, especially from the fieid, is not lost; the objective of the top-down process is to ensure that the right conceptual information is retained.

It is important to understand that both the topdown and bottom-up approaches have to be integrated into an oscillating process that ensures iterative improvement of the criteria, indicators and verifiers. This is essentially because our current understanding of the underlying processes that drive the interactions between human beings and ecosystems is incomplete. As this understanding improves so will management standards and practices. This new information must find its way into the process of defining sustainability assessment tools. It is important to recognise that this "new" information is not just the result of recent efforts; often it is the inclusion of information that has previously been ignored or under-valued, such as traditional knowledge of local communities. Therefore, in addition to iterations in time, there is a need to iterate these processes spatially, in order to sample the wide variation of forest ecosystems, human societies and their demands on the forests.

The use of the conceptual framework within the top-down and bottom-up processes has thus been the platform for the development of the methods used by the project to evaluate, develop and generate criteria and indicators.

\subsection{FIELD PROCEDURES FOR GENER- ATING AND EVALUATING CRITERIA AND INDICATORS}

\subsubsection{FIELD METHODS}

The development of methods for testing C\&I has been an iterative one, as pointed out in section 1.2. In the first test, the team members were confronted with about $1000 \mathrm{C} \& \mathrm{I}$ to be evaluated on the basis of a 18 point response form. Besides the obvious (in retrospect) difficulties for team members trying to evaluate so many items, the analysis process proved far too unwieldy (Palmer 1995; Prabhu 1995). The process outlined below was developed in response to the problems identified in the German test, and includes all iterative improvements up to, but not including, the last test in Brazil.

By an iterative process, a workable methodology was developed as briefly described in the introductory paragraph above, and in Figure 1. This includ- ed in a preparatory phase the selection of sites, teams, sets of C\&I to assess, development of a conceptual framework (including special attention devoted to social C\&I, see Colfer with Prabhu and Wollenberg 1995) and formal procedures and attributes by which $C \& I$ could be evaluated. An important part of this conceptual framework was the definition of principles, criteria and indicators under a hierarchical framework. This was revealed as necessary during the first test in Germany, where it was clear that the underlying concepts in the sets of C\&I evaluated were unclear and confusing. This was verified at other tests as well. The German test resulted in a significant improvement of methods.

The field testing process involved three phases, conceived as three separate filters (figure 6). It is important to note that this was not simply a mechanical sifting process. It explicitly allowed creative inputs and modifications to criteria and indicators, provided these were also subjected to the evaluation process.

1. Filter No. 1: Pre-fieldwork phase based on use of 'Forml' - During this first filter experts evaluated criteria and indicators on their own, using 'Forml' as their principal tool (see Annex 4 for a description of Fox-ml). Filter No. 1 can thus be seen as essentially being a desk exercise to carry out a preliminary evaluation of all $1100 \mathrm{C} \& \mathrm{I}$ tested. Towards the end of this stage team members met for the first time to organize and classify the results of their evaluation on Form 1.

2. Filter No. 2: Fieldwork phase based on use of 'Form2' - From this point onwards interdisciplinary teamwork at and near commercial logging operations took place. Intellectually, this phase represented an ongoing oscillation between inductive and deductive approaches for the team members, as they applied their existing knowledge to the C\&I at one point, tested these conclusions against field realities, and later returned to their broader experience, in an iterative process. In addition to this kind of analysis, team members filled out assessment forms regarding each selected C\&I (Form2) and exchanged information and views with representatives of other disciplines. A description of Form2 with examples of how it has been used is provided in Annex 4. One of the main tools for evalua- 


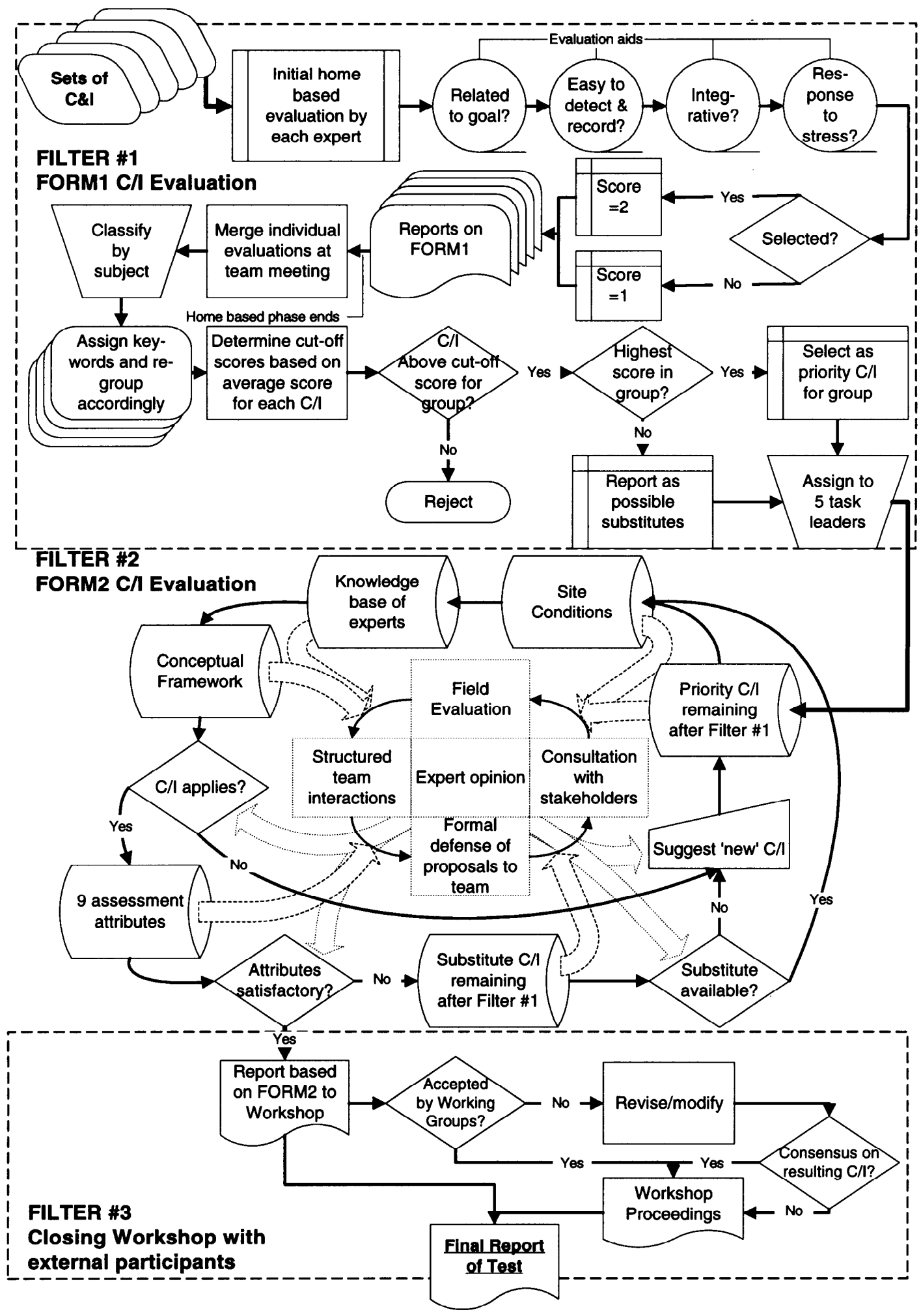

Figure 6. Flow chart of method used to evaluate C\&I during each test. Explanation of processes in main text. 
tion was the set of nine attributes (section 2.3.2.3) with which team members assessed C\&I. However as figure 6 suggests the entire evaluation process was complex with team members calling on "static resources" (the drums in figure 6) to feed dynamic processes (boxes at the centre of the figure) which in turn resulted in the required decisions (depicted as polygons). This is a different and more complete depiction of the process described in figure 5 . The entire process was iterative, with the principal constraint being time. The final test of their conclusions was at the closing workshops.

\section{Filter No, 3: Post-fieldwork phase .}

Participants at the closing workshops were drawn from different institutional and disciplinary backgrounds, but were all characterised by their knowledge and interest in sustainable forest management. These workshops had a duration of between three and five days. Discussions took place in working groups which had the mandate to review the proposals made by the team concerned. This served two purposes: it provided peer review to the team members, but also, because the frame-of-reference of workshop participants was frequently larger in scope than the selected FMU, the workshop provided a first window on the wider applicability of the C\&I proposed by the teams. Finally team members summarised their experience and conclusions into reports, taking into account also the recommendations of the workshops. These results were then passed on to the CIFOR team, to be examined and evaluated, both qualitatively and quantitatively, and then compared. Although a beginning has been made, the CIFOR-based comparative analyses are ongoing, since a considerable quantity of interesting and valuable data were produced in this process.

In Table 3 we present a timeline for the activities related to field testing of C\&I at any one site. The Austrian test showed considerable divergence from this timeline and the methods outlined above (see section 2.4.2).

Generally all tests began with an assessment of the C\&I pertaining to the legal, policy and planning environments within which forest management was taking place. Usually all team members were jointly involved in this phase, which was an interdisciplinary "calibration" process. Often this was the first intensive contact for the ecologists and social scientists with questions related to timber production and forest conservation. The initial stages of the evaluation of policy and planning C\&I helped the teams to find a common idiom. Another point which we considered important was to provide the team with maximum opportunities for interaction with a broad variety of "stakeholders". We then left it to the experts themselves to define the "optimum" number and level of interactions. The number of such interactions was usually quite large and the concomitant risk of inundation in a deluge of information equally high.

Response Form No.2 was an instrument about which everyone had an opinion. It served to focus the teams' efforts, it kept them awake at nights, and it helped CIFOR ensure that the various teams maintained some level of comparability and a systematic approach. Although it was very important, it served as a useful backdrop or support for the real work: the field activities. The field activities were the reality check against which the $\mathrm{C} \& \mathrm{I}$ were being tested.

Fieldwork took place in an interdisciplinary mode. Individual team members selected their own methods - some used rapid rural appraisal methods, some conducted surveys and sampled, others measured and all observed. Interaction among team members was continuous, desired by CIFOR's organisers and unavoidable in the field settings. Team members had considerable freedom and independence to test their C\&I in the ways they felt most appropriate but they also had to present and defend their findings and their perspectives to team co-members.

The final days of fieldwork were devoted to the closing workshop when the results of the field evaluation process were discussed in detail. The objective of the workshop was to review and discuss a clearly defined set of C\&I relevant to the particular site concerned. The selected C\&I were then presented at the workshop attended by participants from government, universities, the private sector and NGOs. At the workshop, the general orientation and goals of the project were presented in plenary sessions. Then participants joined groups (self-selected) where certain C\&I were discussed and suggestions for revisions were made. Group reports were made in the plenary and written versions were provided to the CIFOR team. The optimal duration of a closing workshop was found to be three days, reduced from five days in the first test in Germany and four days in Indonesia. 


\begin{tabular}{|c|c|c|}
\hline Phase & Timeline & Remarks \\
\hline \multirow[t]{7}{*}{ Filter \#l } & $\begin{array}{l}\text { Commencement date: Final } \\
\text { date ('F') - } 65 \text { days }\end{array}$ & $\begin{array}{l}\text { Briefing book contains } \\
\text { methods, TOR and forms. }\end{array}$ \\
\hline & $\begin{array}{l}\text { First briefing of team Approximately F - } 50 \text { days } \\
\text { members by project staff }\end{array}$ & \\
\hline & $\begin{array}{l}\text { Home based evaluation of Approximately F - } 35 \text { days } \\
\text { C\&I in base sets }\end{array}$ & $\begin{array}{l}\text { Objective: mark C\&I for } \\
\text { selection or rejection }\end{array}$ \\
\hline & $\begin{array}{l}\text { Arrival of team members at } \mathrm{F} \text { - } 30 \text { days } \\
\text { assembly point }\end{array}$ & \\
\hline & $\begin{array}{l}\text { Comparison and collation } \mathrm{F}-29 \text { to } \mathrm{F}-28 \\
\text { of results from Form } 1\end{array}$ & \\
\hline & $\begin{array}{l}\text { Assignment of C\&I to each F - } 27 \\
\text { task leader }\end{array}$ & \\
\hline & $\begin{array}{l}\text { Grouping of C\&I according } \mathrm{F}-27 \text { to F - } 26 \\
\text { to key-words, identification } \\
\text { of overlaps, determination } \\
\text { of cut-off scores and } \\
\text { selection of 'priority' C\&I }\end{array}$ & $\begin{array}{l}\text { By this stage about } 25 \% \text { of } \\
\text { the original } 1100 \text { C\&I had } \\
\text { been rejected, about } 10 \% \\
\text { selected as 'priority' and } \\
\text { the rest retained as } \\
\text { 'substitutes' (see Fig. 6) }\end{array}$ \\
\hline \multirow[t]{4}{*}{ Filter \#2 } & $\begin{array}{l}\text { 1. Entry of C\&I on to F-25 to F-22 } \\
\text { Form } 2 \text {. } \\
\text { 2. Meeting with policy } \\
\text { makers, } \\
\text { institutions and policy } \\
\text { 'influencers' }\end{array}$ & $\begin{array}{l}\text { These discussions usually } \\
\text { take place in the national } \\
\text { and relevant state, province } \\
\text { or district capitals. This is } \\
\text { extremely important in } \\
\text { order to clarify the frame- } \\
\text { of-reference for } \\
\text { management and establish } \\
\text { interdisciplinary cooperation }\end{array}$ \\
\hline & $\begin{array}{l}\text { Field evaluations at the F - } 21 \text { to } \mathrm{F}-7 \\
\text { FMU }\end{array}$ & $\begin{array}{l}\text { It is during this phase of the } \\
\text { testing that the C\& I } \\
\text { undergo the most } \\
\text { qualitative changes, } \\
\text { although their quantity may } \\
\text { not change very much. }\end{array}$ \\
\hline & $\begin{array}{ll}\text { Formal team discussions of } & \text { Every third to fourth day } \\
\text { CA } & \text { during F-21 to F-7 }\end{array}$ & $\begin{array}{l}\text { Participation is not } \\
\text { restricted only to expert and } \\
\text { project team members. } \\
\text { Forest managers and other } \\
\text { stakeholders are invited to } \\
\text { participate in small } \\
\text { numbers. }\end{array}$ \\
\hline & $\begin{array}{l}\text { Compilation of results } \mathrm{F}-6 \text { to F - } 4 \\
\text { based on Form } 2 \text { evaluations }\end{array}$ & $\begin{array}{l}\text { Preparation for Closing } \\
\text { Workshop. Only team \& } \\
\text { project members. }\end{array}$ \\
\hline \multirow[t]{4}{*}{ Filter } & Closing workshop & $\begin{array}{l}\text { This is the final phase of } \\
\text { each test and the single } \\
\text { most important review the } \\
\text { C\&I are subjected to. } \\
\text { Modifications and } \\
\text { rejections are permitted. }\end{array}$ \\
\hline & $\begin{array}{l}\text { Review of test, completion } \mathrm{F} \text { (Final day) } \\
\text { of reports }\end{array}$ & $\begin{array}{l}\text { Only team and project } \\
\text { members. }\end{array}$ \\
\hline & Departure of team & \\
\hline & Preparation of final report & By team leader only \\
\hline
\end{tabular}

Table 3. Schedule of activities during a field test 
Taking workshop results into account, team members then wrote their own final reports. These reports include a table showing their selection of the most appropriate $\mathrm{C} \& \mathrm{I}$, their completed evaluation Form2, and a discussion of their experience and conclusions. In addition the format and content of the final report to be prepared subsequently by the team leader was discussed.

Mengin-Lecreulx et al. (1995) provide an excellent and detailed account of the entire evaluation process.

\section{Interdisciplinarity}

The interdisciplinary makeup of the teams has already been described above, but interdisciplinary co-operation does not "just happen." Four techniques were used to encourage effective cooperation among team members. These included:

- Explicit training (by Colfer in the Kalimantan test; and by Prabhu in the remaining tests). This included presentations which focused on the importance of inter-disciplinary cooperation, the different strengths offered by different disciplines, and practical do's and don'ts for team members to keep in mind.

- Pairing of different disciplines. Although success in this endeavour varied from time to time and from team to team, a consistent effort was made to persuade team members to rotate their partners for each day's work among the various disciplines.

- Example. The CIFOR team has established excellent interdisciplinary co-operation and communication, and team members were exposed to this regularly. CIFOR staff supported each other, with appropriate recognition of the differing strengths represented in their respective disciplines.

- Togetherness. The teams were together, in some cases 24 hours a day, every day. In all tests they lived in the same lodging, ate the same food, and looked at the same forest management unit, over the one month period. This kind of continual exposure, in a context encouraging interdisciplinary communication, also functioned to encourage co-operation and sharing of perspectives.

\subsubsection{METHODS USED IN THE AUSTRIAN TEST}

In the Austrian test a pre-selection of C\&I from 14 existing sets (including the five used in the main stream tests) was carried out by an expert committee on sustainability (OFA), which had been established upon recommendation of the timber adviso- ry board, to deal especially with the selection and assessment of the various international set of criteria. This committee selected about 280 C\&I from these 14 sets. They sought to eliminate redundancy, but maintained the original content of the selected C\&I. This constituted the Austrian variant of the "base set". Because this pre-selection of the criteria and indicators reduced the workload of the test team in the first stage of the project a reduction in the duration of the field test could be effected.

After a preparation phase of common meetings and individual work a team of six experts (instead of five) evaluated a selection of $280 \mathrm{C} \& \mathrm{I}$ taken from national and international sets during a field phase of two weeks. Because the test site was relatively close (motoring distance) to team members' home bases it was possible to introduce breaks in the schedule so that team members returned home for some periods in between testing (Willi 1996). Contrary to other CIFOR tests, criteria and indicators were evaluated on Form2 first in individual homework followed by a testing phase.

The Austrian test team developed guidelines in addition to principles, criteria and indicators. This was not an objective in the main CIFOR tests. The Austrian test served the purpose of facilitating a national policy on certification of timber from sustainable forest management.

In order to give due consideration to the structure of forest ownership in Austria, four test enterprises were selected. The Austrian Federal Forests a large private forest estate, an agrarian community, and a farm forest.

Finally, in order to better reflect the specific Austrian situation, Form2 was extended as well (see Annex 4, Form2). The following points were added: "open questions" which could not be answered in the course of the test procedure, the method of verification, suitability with regard to the type of forest (natural forest, semi-natural man-made forests) and size of management unit as well as the assumed range of application (boreal to tropical).

\subsubsection{CRITICAL EVALUATION OF THE METHOD}

The explicitly iterative approach to this task helped to iron out some of the methodological problems in the process (e.g. the need for additional social science input, the improved process for refining the C\&I prior to fieldwork, improvements in the forms used for evaluation, etc.). However, several problems still remain. Evaluation of the method by the four teams of experts has been helpful and their 
comments should be kept in mind in order to reduce these problems in similar exercises in the future.

\section{Procedure and Data Collection}

The work requirements on all the teams were extremely demanding, as unanimously noted in all four test reports. It should be remembered that the objective was not to evaluate the management per se but to evaluate sets of criteria and indicators. Even then, as pointed out by some team members, in the time available it was impossible to test each C\&I methodically. Rather time was used more for the discussion of contentious issues. One team member commented that the orientation time for team members prior to the interviews for data collection was too short and the great amount of information flow too much for absorption in the time allotted. Further simplification of the forms and perhaps further reductions in the number of $C \& I$ tested might help. Conducting four tests within one year in four continents necessitated intensive preparation. Spacing the tests further apart might have facilitated some organisational and logistical matters. Schedules were complicated by the host country's cultural milieu and public holidays in Indonesia and Austria. This caused inconveniences and difficulties in setting up interviews and field visits, but allowances were accordingly made to accommodate such situations.

The first selection of priority $\mathrm{C} \& \mathrm{I}$ was thought to be particularly tedious but it made sure a posteriori that no important C\&I had been overlooked, according to one team member. He also cautioned that grading C\&I was often relative, dependent on a number of factors such as other C\&I, evaluator's field of expertise and personal preferences. These should be considered during weighting of scores. A number of experts pointed out that the next step, consolidating scores from different experts, could have been greatly facilitated if the previous step had been implemented on the basis of a common spreadsheet. This was attempted in later tests and some members had access to such a spreadsheet. Division of the evaluation of C\&I among the experts was sometimes unbalanced, with some experts being overloaded with too many $\mathrm{C} \& \mathrm{I}$.

Differing viewpoints on knowing the results of earlier tests were expressed. Most agreed with the testing methodology of not getting the results so as not to influence their own attempts, but commented that methodological improvements should be shared. In most cases such changes, based on suggestions and recommendations of the expert teams from earlier tests, were made and implemented in the later tests; the process might not have been as transparent as would have been desired by some members. In part, the short intervals between the tests precluded the sharing of results because reports from previous tests were not ready for dissemination. However, the CIFOR Project Coordinator provided a link between tests, communicating previous insights and experiences to new teams. In general, the method used was considered appropriate for the objective of the research, with the field test providing a realistic framework for assessing the C\&I.

\section{Sets of C\&I Selected}

The test in Germany highlighted the need to set the criteria at the highest practicable level of generalisation while retaining applicability at the level of the local forest management unit, complemented by suggested means of verification. However, many principles, criteria, indicators and means of verification proposed do not refer directly to the reference documents, for various reasons according to the Côte d'Ivoire test report. Two parallel approaches - the top-down versus the bottom-up processes as described earlier, based on drawing on the experience of each expert and the five sets of $\mathrm{C} \& \mathrm{I}$ provided - were employed in the selection of C\&I. This dual approach helped to fill in gaps not addressed by the five sets of C\&I used. For example, the LEI set was deemed to be biased toward application in forest concessions which are not as common in Brazil, and the Dutch Standards were considered too generalised for use in that country. Including other sets, such as TCA's C\&I and FSC's Principles and Criteria, might be useful but it was recognised that this would not have changed the output of the work in Brazil substantially. The need for a set of C\&I more suitable for application under Brazilian conditions was voiced. Indeed, the number of C\&I to be tested was considered excessive as it was, and the more common call was for a reduction in number.

The selection of C\&I to be included in the set was not an easy task. One Côte d'Ivoire expert noted the necessity of including aspects of social C\&I in the policy and forest management components (an integration that she termed "horizontal"), and the confounding effects of this on her own attempts to integrate her findings into a tidy hierarchical social C\&I structure ("vertical"). The time available was a limiting factor in integrating the various sets of C\&I. Again, such comments were duly noted and taken into account for the subsequent test in Brazil.

\section{Response Forms}

In retrospect, filling in Form1 was probably a learning exercise. The difficulty for people not familiar with devising or creating C\&I to assume quickly the necessary thought pattern for evaluat- 
ing them in the time given should not be underestimated, as remarked in one report. A further comment on the form was its value as an introduction to C\&I. Certain questions were difficult to comprehend initially. It was suggested that providing guidelines, explanations and examples prior to completing the form would help clarify the meaning and intent of the questions. More time was needed for completing the form than was anticipated. To help reduce the time for this activity, a spreadsheet listing the C\&I, their serial numbers, source documents, abridged version of the text, fields concerned (management, ecology, etc.), and space for possible comments, was suggested as an alternative format. Subsequently, as a result of the iterative approach employed, a spreadsheet was designed and made available in Côte d'Ivoire and Brazil.

Form2 was unpopular among several team members, perhaps partially because of the time required to fill it out in addition to other time constraints. However, it was also seen as a useful vehicle for finalising the selected set, especially if more examples of the attributes were provided. Separating the use of the form as a working sheet from the final descriptive analysis was one consideration. The Justification/Bibliographic references were seen to be important components of the selection, in fact more important than the form itself would suggest. The Austrian team in particular queried the value of maintaining a diary of activities as required in Form2 (see Annex 4). Similar suggestions for standardising Form2 on a spreadsheet in order to eliminate manual entering of serial numbers, source document, fields, and so forth, were put forth. This could also facilitate calculation of scores and levels of consensus. Forms 1 and 2 could be combined in such a format, thus avoiding the use of two record sheets.

\section{Time Allowed for Tests}

As mentioned earlier, all five tests had very tight deadlines. Work was time consuming and demanded great stamina and staying power. Despite the punishing schedules, most members reported that the time for the completion of the forms, field tests and "administrative procedures" was sufficient. The time allowed for working groups was also generally accepted. Most C\&I could be reviewed; however, it was unrealistic to examine every $\mathrm{C} \& \mathrm{I}$ in detail even if more time were available without risking saturation and loss of concentration. Given more time, the expert teams could have filled in the forms more thoroughly, been more prepared for interviews with resource persons, and improved on the sets of C\&I submitted; but realistically, a month's duration is about the maximum length of time for such an intensive and exacting process.
This is reinforced by availability problems due to other professional commitments of all members involved. The level of commitment and dedication to the task at hand manifested-by these team members is unlikely to be reproduced in contexts where assessment is part of a regular job.

\section{Workshops}

In most cases, the workshops were seen as well organised and met most of the objectives. They were viewed as useful by team members in exerting a certain "pressure" to produce a final, minimum set of C\&I. They allowed a wide spectrum of interests to be expressed on the work of the team and the "recommended set", gathering viewpoints from an audience with varied backgrounds and knowledge.

Although deemed desirable by the CIFOR team, a discussion of weights of C\&I did not take place at the workshops. Most participants thought this an important issue, but they tended to consider it relative to a particular region or forest management unit. A case in point is the social C\&I whereby it is acknowledged that social problems in East Kalimantan are very different in nature from those of West Kalimantan.

Information about some test sites, which would have been helpful in setting the scene, was not provided prior to the workshop. In the case of Côte d'Ivoire, the efforts of the working groups would have been facilitated if the list of C\&I had been distributed to participants in two versions, English and French, thus allowing all participants to examine this list before the workshop. Some participants had difficulty in assimilating the objectives of the project, in particular the issue of identifying operational C\&I and not drawing up a comprehensive list of subjects to be considered, prescriptions to be complied with, or research themes to be developed.

As Charles Huttel from the team in Côte d'Ivoire notes (Mengin-Lecreulx et al. 1995):

"The participants experienced great diffi-
culty in assimilating the objectives of the
project, in particular the fact that the issue
was to identify operational C\&I, and not to
draw a comprehensive list of subjects to be
taken into account in forest management,
prescriptions to be complied with, or
research themes to be developed."

The time available was seen to be too short and an appropriate forum to discuss technical points with real experts was absent during the Indonesian test. As a result, the format was changed to address this 
problem in subsequent tests. Inevitably, forceful and articulate speakers were able to drive through certain changes and recommendations which technical experts in a more in-depth analysis might not support. This issue is difficult to overcome: some felt that not all the recommendations of the workshop should be accepted. In general, the comments and suggestions during the workshop were made principally to improve the clarity of the C\&I.

One difficulty faced by the project leadership was to reconcile the case study nature of the C\&I with the more global experience of the workshop. Some of the C\&I suggested by the workshop were not experienced as problems by the team during their stay in the forest, over-hunting is one example. The challenge for the project leadership is to analyse the proposals of the team against the rich information provided by the workshop, at the same time considering that a specific forest management unit was selected as the focus for the evaluation of the criteria and indicators.

\section{Interdisciplinarity}

Additional explicit attention to the issue of interdisciplinary co-operation may be in order. Had the budget been available to provide training to each team, this exercise could have helped team members be more co-operative about changing partners constantly. It could also have been helpful in finding agreement on the meaning of important terms, such as defining the limits of the forest management unit both from the point of view of the social scientist and the forester. This kind of training is particularly important for successful incorporation of input from disciplines such as social sciences and ecology where the $\mathrm{C} \& \mathrm{I}$ are less clear-cut, or are at an earlier stage of development than, for instance, those in forest management per se. Inevitably, some disciplines are more compatible than others, and experts in these fields had less problems in communicating their thoughts and ideas to each other.

Despite the shortcomings, interdisciplinarity was seen quite positively on the whole. One of the main strengths of the working method proposed was to promote maximum synergy between experts of different origins and expertise. Field visits or interviews were conducted by teams of two or three experts of different specialisation, providing an opportunity for mutual input. Informal discussions and presentations facilitated interaction among fellow team members.

\section{Language}

Another issue for consideration is language. It presented the biggest problem in the Côte d'Ivoire test. There, the field team was primarily
French speaking; and no one on the CIFOR team was really fluent in the language. Although it is difficult to know whether this had any significant effect on the team's results, it certainly complicated the co-ordination activities of the CIFOR team. The whole process goes more smoothly when most people understand each other most of the time. In the Indonesian test, participants in working groups debated on issues of language and expression. Although the importance of couching C\&I in simple, unambiguous language was apparent from the outset, it is important to consider cultural dimensions as well when proposals are made in a language not native to an audience.

\section{Concluding Remarks}

As far as possible, the project team noted and considered the comments generated by the expert teams and incorporated their suggestions in subsequent tests. This process has been an ongoing exercise just as the whole procedure of testing C\&I is a learning experience for all concerned. Technical modifications that could be more easily adapted were done so readily. Likewise, organisational and logistical adjustments were made to facilitate the work of the multidisciplinary groups involved whenever possible. Conceptual issues needed more thought and consideration but were also amended when necessary. Nevertheless, some important issues remain unresolved for the time being. They include:

- The number of C\&I from the five sets is too large and needs trimming.

- Simplification of the procedure is desirable but difficult because of the need for transparency. It is the project team's perception that during the first seven days at the test site, most experts understood the concepts and what was expected from them quite easily, but during the later stages most were less successful in applying those concepts.

- Training on application of the concepts was lacking and was a constraint to the success of the project.

- Training on interdisciplinarity was also minimal and needs greater attention.

\subsection{ANALYSIS OF CRITERIA AND INDICATORS}

The analysis of C\&I in the context of this project has been based mainly on their content and the context in which they were developed. This kind of analysis is fundamentally subjective. A pre-requisite to carrying out this analysis is understanding the process by which $C \& I$ were evaluated by team members. The evaluation process has been, fundamentally, cognitive and conceptual in nature. 
Experts, carefully selected for both their disciplinary expertise and their personal experience in the region in question, were asked to try to apply a selection of C\&I to the field reality. They then had to accept, alter or reject the C\&I provided in the initial five sets, based on their qualitative and quantitative judgements. We feel confident that bias in our content analysis of the C\&I proposed by the teams has been reduced to a minimum by the fact that all tests were accompanied by at least one, usually two, of us involved in this analysis.We have thus been in a position to understand the context in which the C\&I have been developed and the issues they aim to address.

The CIFOR team, which had to deal with these assessments in a comparative manner, has had to cope with many of the same issues in trying to understand and explain the process by which the field team members came to their conclusions. We remain uncertain whether the differences in the preferred decision making process pertain to differences of approach/method, subject matter, or the stage reached by the respective sciences in the development of simple, straightforward, cost effective indicators. Indeed, all three may be relevant factors. Since this issue provides a convenient arena for clarifying some of the differences encountered among team members, within both CIFOR and the field teams, further discussion is warranted here.

Just as we have a hierarchy composed of principles, criteria, indicators, and sometimes verifiers, so we have a hierarchy of important questions for these categories in evaluating their utility. At the levels of principles and criteria, the most significant issue in their selection must be the strength of their relevance to sustainability (which includes, according to our definition, human well-being). We must ask ourselves a number of questions about any given principle or criterion:

- Is this a principle or criterion associated with processes which are likely to lead to sustainability?

- Does it represent contributory evidence that a sustainable system already exists?

- Can a causal relationship be demonstrated between the criterion and sustainability (including plausible logical, empirical or chronological evidence of the relationship)?

- Is this condition necessary or sufficient for sustainability to occur?

- Is this principle or criterion unique and/or sufficiently important vis-á-vis other principles and criteria being considered?

As we move down the hierarchy to indicators and verifiers, one important question becomes their relevance for determining the condition specified in the hierarchical level immediately above. Is the indicator, for instance, linked in a causal or associative manner with the criterion whose fulfilment it is designed to ascertain? Again, is there plausible logical, empirical or chronological evidence for a relationship? Is the indicator necessary or sufficient for the condition to occur?

A final stage in selecting C\&I must be some evaluation of confidence in the expected results. Some variables that can affect the results have been pointed out (e.g., ease and cost effectiveness of data collection, need for experience and judgement). Different evaluators will have different resources, different expectations and different needs. The selection of appropriate C\&I will be affected by these differences as well.

There is no way to avoid context-specific decision making altogether. Whereas there are a core of generic C\&I which can be helpful to any evaluator, there are also site specific C\&I that may be much closer to the "ideal type" of indicator than the generic ones for a specific location. In Brazil, for instance, it was possible to substitute one site specific indicator which referred to a comprehensive, local worker safety code for a long series of more generic indicators pertaining to worker safety. Similarly a series of forest management C\&I used on other sites could be subsumed under one, with Indonesia's TPTI system. For this reason, it is difficult to imagine that every potential evaluator of principles, criteria and indicators will not have to spend some time fine tuning the generic set for his or her own use.

\subsection{GENERAL FACTORS INFLUENCING THE SELECTION OF C\&I BY EACH TEAM}

In designing the tests we identified three types of factors which could influence the C\&I proposed by each test team.

- The most fundamental, of course, is the nature and contents of the original, five base sets of C\&I selected for testing by CIFOR.

- The second consideration is the composition, or personal and professional characteristics, of the teams.

- The final set of factors pertains to the site characteristics encountered in the field. These fall into five broad categories: resource ownership and access; history of forest management and the present condition of the forest; forest system ecology; demography and culture. 


\begin{tabular}{|lcc|}
\hline Source Document & No. of C\&I & \% of Pool \\
\hline DDB (Dutch Working Group) & 49 & 4 \\
ITW (Initiative Tropenwald) & 626 & 57 \\
LEI (Lembaga Ecolabel Indonesia) & 127 & 11 \\
SMW (Smart Wood) & 65 & 6 \\
SOI (Soil Association, Woodmark) & 238 & 22 \\
Total & $\mathbf{1 0 9 5}$ & $\mathbf{1 0 0}$ \\
\hline
\end{tabular}

Table 4. Size and Proportions of Five Original C\&I Sets.

We briefly discuss these factors below, based on our observations during the tests and a simple content analysis of the $\mathrm{C} \& \mathrm{I}$ proposed by each team.

\subsubsection{SELECTED BASE SETS OF C\&I}

Major aspects of the base sets that were expected to affect the selection of individual C\&I by the teams included:

- proportion provided by that set to the total pool of C\&I,

- nature of C\&I (performance standard approach vs. environmental management system approach),

- balance among sections (ecology, forestry, social science),

- level of detail, and

- origins of assessment systems.

It is not surprising that the five base sets of C\&I should themselves affect the expert teams' selection, as expert team members began their analyses with a criterion or an indicator from one of these sets. If these five sets had sufficiently reflected a diversity of approaches, they might not have exerted an influence in any particular direction. However four of these five sets have a heavy bias towards the performance standards approach and none of them explicitly follow the environmental management system approach ${ }^{13}$ The differences for the most part are in degree of detail, the manner in which they treat the areas of social and ecological C\&I and the language they use. Within these constraints, the five base sets have different origins and underlying philosophies. Four of them were developed to aid certifi- cation decisions, the fifth from the DDB is more of a conceptual framework.

\subsubsection{COMPOSITION OF THE EXPERT TEAMS}

Major personal and professional characteristics that were expected to affect team members' selection of C\&I include their:

- disciplinary background,

- research interests,

- cultural background,

- work experience, and

- personality.

The project's policy was to include at least one forester, one ecologist and one social scientist in each five person team. Although the selection of C\&I was affected by the personal orientation of team members, a surprising degree of unanimity emerged in team members' assessment. For instance, all team social scientists agreed on the importance of security of land tenure and use rights, fair distribution of forest benefits, local actors' participation in various stages of management (planning, implementation, monitoring and sanctions), and a balance between resources and use.

There were rather predictable differences based on discipline (or perhaps subject matter). Not surprisingly, the foresters, whose history of attention to management practice has included C\&I, fairly quickly identified important C\&I and were able to get down to specifics, including intense discussions of threshold levels and verifiers. Both

13 The performance standards approach basically looks at conditions on the ground, and notes whether a particular forest is meeting specified standards or conditions. The environmental management systems approach, specified in the IS0 14000 series, requires that certain management procedures be implemented, and assume that the result will be an environmentally desirable (sustainable) outcome. The differences are often phrased in terms of whether a criterion or indicator is "prescriptive" or "descriptive." Yet, the teams found in the field that the same wording could be interpreted as both prescriptive and descriptive in many cases (e.g., "Soil disturbance is minimised"). 
the ecologists and the social scientists struggled more with selecting important C\&I, even though there were far fewer from which to choose in these areas than in forestry per se. At the end of the test, the social scientists and ecologists remained more dissatisfied with their results, suggesting either that the problems may have been more intractable and/or the disciplinary experience in this area less advanced.

Other than the contribution of an insider's view, the relationship between host country and expatriate team members did not seem significant for the selection of C\&I.

Current research interests also obviously had an effect. The emphasis in the social C\&I, for instance, in Côte d'Ivoire on stress marginalisation and in Kalimantan on cultural integrity is probably more directly related to the team member's discipline and research interests than to specific conditions at the sites.

Different work backgrounds also seemed to have an effect. An interest in critically evaluating the status quo seemed more apparent with team members from academic settings than with those who normally worked in consulting contexts or government offices. In the latter cases, there seemed to be a greater concern to fit into or mesh with the status quo. Both approaches were useful and valuable in this context.

From the standpoint of personality and teamwork, we can refer to the Myers-Briggs personality index (Myers and Myers 1980). Although we did not administer this instrument to our teams, it was clear, for instance, that team members varied substantially along the "intuitive" - "sensing" continuum. The former tends to learn by intuition, looking for meaning, relationships, possibilities. The latter uses his/her eyes, ears and other senses to find out the realities of the situation (Myers and Myers 1992). Among the teams, the whole spectrum of intuitive-sensing was represented, and resulted in different $\mathrm{C} \& \mathrm{I}$ preferences, different ways of testing, different phrasing of C\&I and perhaps in different levels of detail as well.

Another feature that affected the selection of C\&I was the degree to which the team was able to work effectively together. In one case, interdisciplinary communication was quite thorough and effective; other teams had more trouble with this dimension. Just how this affected the outcome is unclear, but it is undeniable that good communication among team members reduces duplication, improves coverage, and enhances the integrity or consistency of the final result.

\subsubsection{SITE SPECIFIC FACTORS AFFECT- ING CRITERIA AND INDICATORS' SELECTION}

We also expected a series of site specific factors to affect the selection of C\&I. These fell into five broad categories: resource ownership and access; history of forest management; forest system ecology; demography; and culture ${ }^{14}$. These factors do not, so far, lead to predictable differences in C\&I; but they did seem to affect the decisions of team members in their selections.

\section{Resource Ownership and Access}

This was expected to influence the selection of C\&I in terms of :

- unclear ownership and access (with associated confusion about monitoring and control),

- inequities in ownership and access (with resulting concern about people's wellbeing), and

- level of control (too much or too little) by owners or managers, affecting forest sustainability.

The Brazilian team, for example, felt that the fact that the timber company owned its own land severely reduced the government (or anyone else's) ability to affect management of that land. This resulted in four verifiers on issues the team felt might be manipulated under the indicator "land use rights of stakeholders involved and impacted by the FMU area are recognised and upheld." In Côte d'Ivoire, where the human land use pressures on the forest were severe, Anvo and van Haaften differentiated between land tenure and land use rights, allocating one criterion and two indicators on tenure rights, and one criterion, three indicators and two verifiers on use rights. In Indonesia, where abridgement of traditional rights was the major concern, these issues were combined and dealt with in one indicator, with four verifiers (and a fifth level sub-verifier!).

\footnotetext{
14 Because of the many definitions and understandings of "culture" we have some reluctance in using the term. However it represents a convenient shorthand. In general, we refer to a group's total system of knowledge, beliefs and behaviour, which can be viewed as an interconnected whole, significant parts of which tends to be passed from one generation to the next.
} 


\section{History of Forest Management}

The selection of C\&I was expected to be influenced by:

- length of history of forest management,

- current state or nature of forest management (and resultant forest condition) (see also "culture", and

- national context, including policy climate.

For instance, in Brazil and Côte d'Ivoire, where the history of forest management is extremely short, the teams felt a need to be quite specific, including many indicators and verifiers, basically to specify what needed to be done. In Indonesia, on the other hand, where formal forest management ideas have a comparatively long history (though not compared to Germany or Austria), the team could refer to existing regulations or practices in a briefer manner.

\section{Ecology of the Forest Ecosystem}

We expected differences in the forest ecosystems, especially relating to species composition and dynamics of regeneration, among the sites to have an influence on the C\&I. However, results from the tests show that there was considerable overlap in the findings of the three tropical teams, as regards ecology. Important sources of variation, based on site characteristics included:

- interpretations on how to measure biodiversity,

- present condition of the forests (see above), including site specific species composition, and

- the geographical features of the FMU.

The most obvious example is the use in Indonesia of indicator species of creepers (e.g., Merremia spp. and Mesoneuron spp.) and secondary succession (Macaranga spp., Anthocephalus spp.) which were not present on the other sites.

\section{Demography}

We expected population issues would be important on all sites, and expected the teams' selection of C\&I to be affected by site specific variations, such as:

- the balance among land use patterns, number of people and the environment,

- the nature (government sponsored vs. spontaneous, fast vs slow), speed and effects of migration and natural increase on the wellbeing of local populations (e.g., health, economic base, cultural integrity),

- sex ratios (skewed or normal), and

- the stage and speed of environmental and cultural degradation.
Both the Indonesian and Côte d'Ivoire situations were perceived to be demographically explosive. In Indonesia, where the situation was less severe, an indicator ("Demands by stakeholders on environment consistent with the capacity of the forest to accommodate them") and five verifiers were suggested, within the social C\&I. Laksono (and other Indonesia team members) considered this important, feeling that attention to these issues now might forestall further environmental degradation. In Côte d'Ivoire basically the same sentence was considered a criterion in the social C\&I, and cross-referenced to the ecological C\&I. The sense that it was "too late" (at least in Bossematié) may have discouraged further attention in this case. The same issue was addressed at the national level, in both the Côte d'Ivoire and Brazil policy C\&I as well.

\section{Culture}

Several cultural features were expected to affect the selection of C\&I. They are:

- the level of indigenous ecological knowledge and forest management,

- stability and change (including speed and direction) in existing local cultures,

- dependence on, and interaction with, the forest, and

- comparative access to power amongstakeholders from differing cultural traditions.

Considering the last point above, greater acceptability (and perhaps incidence) of violence and conflict, combined with a greater faith in the legal system in the Brazilian context seemed to promote a number of indicators and verifiers dealing with courts, monitoring, conflict resolution, and the like. In the Indonesian context, on the other hand, where open conflict is viewed with distaste and courts are notoriously unsatisfactory for the poor, there was little reliance on such legal mechanisms in the C\&I. 


\section{Cultural Integrity - an Indonesian Example}

Laksono went to the community of Batu Tempau where the timber company's base camp was located. There he found some disturbing conditions. Although many residents worked for the company and had higher than average incomes, he felt there were a number of "social problems. ".

The original Kutai community had practised a riverine lifestyle, including a sustainable form of shifting cultivation, before the arrival of the timber company. But the steady influx of outsiders from many regions of Indonesia and the community's own increasing dependence on the timber company had two undesirable results. First, the intermingling of many ethnic groups within a small geographical area resulted in considerable conflict among residents. Differing cultural patterns and negative cross-ethnic stereotypes made living together difficult and stressful.

Second, there were signs of significant cultural disintegration for the local people. The land surrounding the community had been logged, and then had burned in the 1983 fires. The timber company had the legal right to manage the lands that had previously belonged to the community. The company had "given" the people two hectares each, but most of that land was now covered with Imperata cylindrica. The people's previous economic base was too degraded for their traditional system, and community members were almost completely dependent on wages from the company. Laksono felt that their cultural system was in disarray.

There was a skewed sex ratio, with a considerable number of men who had come alone to work for the company. In response to this, a brothel had been established where women from other areas were working as prostitutes. Their own conditions were disturbing. Many were in debt to their "sponsors" to a degree which left them little personal freedom. Although the company did monitor their health conditions, the women did not understand, for instance, the life threatening nature of AIDS. Many had children who were stigmatised by their mothers' profession. Other community members were unhappy with their presence in the community. The links between the brothel and the company made us realise that, in some sense, these prostitutes are invisible but omnipresent "forest workers" whose well-being needs attention.

These observations prompted the team to consider the significance of cultural integrity for sustainable forest management. Forest people, like all human beings, want to improve their ltfe situation, so change must be possible in a sustainable system. But human well-being also requires a certain, perhaps variable, amount of cultural stability - so that children can be born and raised in a nurturing environment, so that the old can be looked after, so that people havemeaningful and enduring personal ties to other people. These needs suggested to us that cultural integrity is an important element in sustainable forest management. 


\section{SETS OF CRITERIA AND INDICATORS RESULTING OUT OF THE TESTS}

\subsection{CONTRIBUTION OF THE FIVE BASE SETS TO THE C\&I PROPOSED BY THE TEAMS}

In this chapter we consider only the results of the three mainstream CIFOR tests in Indonesia, Côte d'Ivoire and Brazil. The Austrian results are not directly comparable because the selection of 280 $\mathrm{C} \& \mathrm{I}$ as a starting platform was divorced from the actual testing exercise. The Austrian selection was made from 14 sets of C\&I, including the five of the mainstream CIFOR tests, by a different set of experts to those involved in the field testing.

We found that about 80 percent of the $C \& I^{15}$ proposed by the Indonesian team, owed their origin to C\&I in the base sets (Table 5). The remaining 20 percent were new developments by the expert team in reaction to perceived gaps in the base sets and specific site conditions. About 68 percent of the Brazil C\&I came from the base sets. This figure dropped to 62 percent in Côte d'Ivoire. This trend suggests that there may be an inverse relationship between the applicability of "generic" sets of C\&I and the level of development of management practices in commercial timber operations. We look to the results of future tests to confirm this trend. We also find the ecology C\&I across all three tropical sites to show a distinctly higher proportion of references to the base set, with 89 percent. In contrast between 61 percent and 68 percent of the policy, forest management and social C\&I were developed directly out of the base sets. This indicates that a more "generic" approach to evaluating impacts on ecology was applied by the test teams, than was the case for the other disciplinary areas. This we feel is due to the fact that C\&I for ecology were based on generally applicable ecological principles, such as maintenance of ecosystem processes and functions.

We have found that in some cases some experts have different interpretations for the same base set indicator. While this may indicate a certain ambiguity in its definition, it also indicates that interpretation is an important factor. Some caution is therefore necessary when interpreting the "origins" of a C or I, as both language and personal preferences have an influence on the selection of a criterion or indicator from a base set as a starting point for development. In Table 6 we show that upto 24 percent of all LEI C\&I quoted in the sets proposed by the tests teams as being the model or starting point for the final $\mathrm{C}$ or I were used by more than one of the four "disciplines": ecology, social science, policy and "production". This would indicate that the $\mathrm{C}$ or I concerned was not precisely defined. The following subsections provide brief analyses of the emphases of the five sets, as perceived by team members.

\section{Deskundigenwerkgroep Duurzaam Bosbeheer Standards (DDB)}

This set had a more conceptual orientation than the other sets. Burgess noted that it differed from the others also in emphasising "forest function" as a central concept. Zweede found it difficult to use in the field mainly because it reflects mainly political and policy standards and does not get down to FMU level. Mengin-Lecreulx noted that it was the shortest document, with the fewest C\&I. However, perhaps because of its more conceptual orientation and the small number of C\&I it contains, the $32 \mathrm{C} \& \mathrm{I}$ used by team members in the three tests represented

\begin{tabular}{|lllllllll|}
\hline Set & \multicolumn{2}{c}{ Indonesia } & \multicolumn{2}{c}{ Côte d'Ivoire } & \multicolumn{2}{c|}{ Brazil } & \multicolumn{2}{c|}{ Total } \\
\hline & $\begin{array}{l}\text { C\&I in } \\
\text { set* }\end{array}$ & $\begin{array}{l}\text { Origin } \\
\text { in base } \\
\text { sets } \%\end{array}$ & $\begin{array}{l}\text { C\&I in } \\
\text { set* }\end{array}$ & $\begin{array}{l}\text { Origin } \\
\text { in base } \\
\text { sets \% }\end{array}$ & $\begin{array}{l}\text { C\&I in Origin } \\
\text { set* }\end{array}$ & $\begin{array}{l}\text { C\&I in base } \\
\text { sets } \%\end{array}$ & $\begin{array}{l}\text { Origin } \\
\text { set* base } \\
\text { sets \% }\end{array}$ \\
\hline Policy & 24 & 66.6 & 14 & 50.0 & 27 & 74.1 & 65 & 66.1 \\
Ecology & 17 & 76.5 & 18 & 100.0 & 19 & 89.5 & 54 & 88.9 \\
Social & 28 & 78.6 & 22 & 40.9 & 37 & 59.5 & 87 & 60.9 \\
'Production' & 28 & 96.4 & 78 & 61.5 & 20 & 55.0 & 126 & 68.3 \\
Total & 97 & 80.4 & 132 & 62.1 & 103 & 68.0 & 332 & 69.3 \\
\hline
\end{tabular}

Table 5. Influence of the five base sets of C\&I proposed by expert teams. * does not include verifiers.

15 None of the following estimates includes verifiers 


\begin{tabular}{|c|c|c|c|c|c|}
\hline Set & $\begin{array}{l}\text { Number of } \\
\text { C\&I used by } \\
\text { teams as } \\
\text { 'origin' (O) } \\
\text { of final C\&I* }\end{array}$ & $\begin{array}{l}\text { Proportion of } \\
(\mathrm{O}) \text { to } \mathrm{C} \& \mathrm{I} \text { in } \\
\text { base set+ }(\%)\end{array}$ & $\begin{array}{l}\text { Proportion } \\
\text { of }(\mathrm{O}) \text { to } \\
\text { total C\&P } \\
\text { proposed by } \\
\text { by teams }(\%)\end{array}$ & $\begin{array}{l}\text { Proportion of } \\
\text { (O) used } \\
\text { across disci- } \\
\text { plines }(\%)\end{array}$ & $\begin{array}{l}\text { Proportion } \\
\text { of }(\mathrm{O}) \text { used } \\
\text { in all } \\
\text { three tests } \\
(\%)\end{array}$ \\
\hline DDB & 32 & 65 & 20 & 13 & 9 \\
\hline ITW & 233 & 37 & 49 & 6 & 3 \\
\hline LEI & 50 & 39 & 33 & 24 & 4 \\
\hline Smart Wood & 61 & 94 & 34 & 23 & 30 \\
\hline Woodmark & 103 & 43 & 43 & 19 & 17 \\
\hline
\end{tabular}

Table 6: Characteristics of use of base sets. 'Origin' $(\mathrm{O})$ refers to $\mathrm{C} \& \mathrm{I}$ in the base sets that were used as a 'model' or starting point for the C\&I finally proposed by team members. *Multiple 'origins' involving C\&I from more that one set are possible. + See Table 4 for total number of C\&I in the base sets. \# See Table 5 for total number of C\&I proposed by each team.

65 percent of all C\&I in the set. However they were used for only 20 percent of all C\&I proposed by the three teams.

\section{Initiative Tropenwald (ITW)}

Teams were unanimous in their conclusions that the ITW set was the most comprehensive, in terms of conventional forest management. Palmer, Burgess and Mengin-Lecreulx all suggested that it made an excellent checklist, ensuring that nothing was overlooked. MenginLecreulx noted its detailed analysis, particularly of forest exploitation issues (as well as some duplication) with 626 references. Both Zweede and Mesquita also commented on its exhaustive coverage but noted that it does not leave much room for flexibility in situations different from the framework thought of when it was developed. In addition, Zweede suggested that in its present form it would not be cost effective to utilize in many regions, especially in the tropics. From the social perspective, it was among the least comprehensive. Nonetheless the 233 C\&I from the ITW set were used by the teams for 49 percent of all the C\&I proposed by them. C\&I from this set were also the most precisely defined, only six percent were used as a basis for C\&I from different disciplines.

\section{Lembaga Ekolabel Indonesia (LEI)}

Mengin-Lecreulx found it rather difficult to understand, partially because of references to Indonesian conditions. An additional constraint was the rather indifferent quality of the unofficial translation available to the teams. This may have resulted in the high proportion of C\&I being used as an "origin" for different disciplines. Zweede considered it very situation specific thus making it hard to use on private forest land as is usual in the case of Brazil. The relevant figures in Table 6 of four percent generic content and 33 percent utility to teams would seem to support this view.

\section{Smart Wood (Rainforest Alliance, USA)}

The teams expressed the greatest satisfaction with this set. Palmer considered it the closest to an environmental management systems approach. Burgess considered this set much easier to deal with, and Mengin-Lecreulx considered it a "welloptimised set of C\&I". We find this is borne out by the fact that about 94 percent of the original Smart Wood set was used by team members as models or starting points for the sets of C\&I proposed by them. About 34 percent of all C\&I proposed by the three teams were based at least in part on the Smart Wood set. It also showed the highest "generic" content in that of the C\&I used by the teams 30 percent appeared as "origins" in the proposals of all three teams. However, this may have been in part because of more "imprecise" definitions as the figure of 23 percent would indicate.

\section{Woodmark (Soil Association, UK)}

This set of C\&I was generally considered more prescriptive than those in the other sets. Palmer, Burgess and Mengin-Lecreulx noted the lack of attention to policy, planning and national level administrative concerns. Mengin-Lecreulx pointed out the comparative balance among forestry, ecology and social issues. He felt there is an unwarranted bias in favour of local farmers and a bias against plantations and the use of chemicals. Palmer considered the treatment of social issues to be weak but "morally fervent". Mesquita noted that this set has a good representation of all the components and linkages relevant to forest man- 
Figure 7: Dendrites depicting structure of the sets of C\&I proposed by the teams in Indonesia, Côte d'Ivoire, and Brazil.

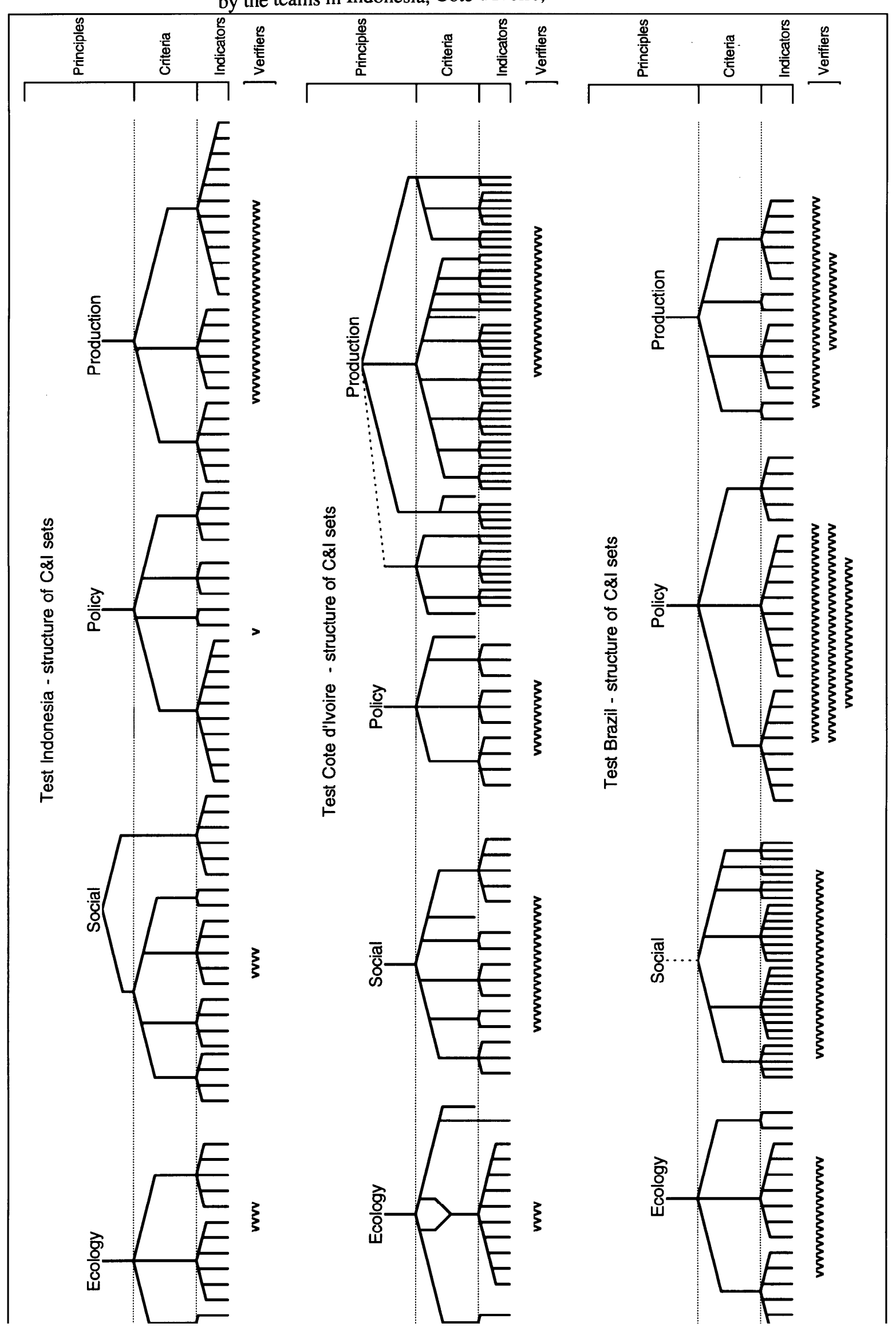


agement, but thought that many important C\&I "are very hard to be verified in the field". Still, she suggested since it better represents an ideal set, it could guide future research in generating verifiers. In absolute terms it followed only ITW in providing the most number of C\&I (103) used by teams, 17 percent of which were used in all three sets of proposed C\&I.

These analyses give us some idea of the relative merits of the C\&I in aggregate from each base set. However, it should be remembered that each set has its own strengths, which are not reflected in this gross analysis of retained C\&I. As stated earlier, we have begun, not completed, the process of analysis.

\subsection{OVERVIEW OF C\&I PROPOSED BY TEST TEAMS}

The organization of the C\&I proposed as a result of three tropical tests was fairly similar. This is not surprising given that the conceptual framework under which they were developed was the same. The Austrian set shows marked differences to the mainstream sets. This is because the conceptual framework under which it was developed diverged on several points from the mainstream tests. Another important difference was that the Austrian test was geared specifically to the development of a certification scheme, whereas the mainstream CIFOR tests were focussed solely on the developing C\&I. As a result, the Austrian team also investigated general and organizational requirements for certification. Furthermore, financial productivity and investment capital were included under the purview of C\&I in the Austrian test, whereas these were not treated during the tropical tests, mainly because of methodological and conceptual problems of dealing with these aspects within the framework of sustainability. Examples of such problems are the influence of currency valuation, fluctuations in energy prices and the difficulties of properly valuing all economic benefits. Finally the lack of access to relevant data from the managers of the FMUs concerned has also been an important deterrent.

As compared with the three tropical tests (Table 6) the C\&I proposed by the Austrian team are 48 for ecology, 47 for the social aspects and 58 for management of forests for production of goods and services ("production"). Although there is not a separate category for $\mathrm{C} \& \mathrm{I}$ related to policy aspects three were identified as addressing these issues in the section on "General and Organizational Requirements" (see Annex 8). This reflects the tight net of official and mandatory regulations influencing management at the FMU level in Austria. In the following sections guidelines, verifiers and general administrative requirements have been excluded.

The structure of the sets of C\&I proposed by the three tropical teams are depicted as dendrites in figure 7. As can be seen, the tendency to include verifiers in the proposed sets of C\&I increased from Indonesia to Brazil. Interestingly, experts in the field of ecology consistently proposed C\&I with the simplest overall structure. C\&I addressing the aspect of policy were also fairly clearly and simply structured. This is not as true for the social C\&I and was certainly not true for C\&I related to "production" in Côte d'Ivoire. Particularly the latter seems overly complex: A "pruning" to a simpler and clearer structure seems warranted. Several criteria with only single indicators can be noticed in the case of the Côte d'Ivoire set. This suggests the need to reexamine these criteria and restructure the set.

We draw attention to the fact that Figure 7 is a two-dimensional depiction of multi-dimensional linkages. Thus links between ecology and "production" or between "production" and policy have not been shown. Nonetheless a schematic depiction of this nature is of help in identifying redundancies and optimising the flow of information.

\subsection{CRITERIA AND INDICATORS RELATED TO THE POLICY, PLANNING AND LEGAL ENVIRONMENTS WITHIN WHICH FOREST MANAGEMENT TAKES PLACE}

\subsubsection{MAJOR CONCLUSIONS}

One common principle and six common C\&I for policy were found. These focus on issues of planning, co-ordination, access to/use of information, permanent forest estates and adequate funding.

The most important factor accounting for differences in policy C\&I was the history of management. Resource ownership/access and culture were also important, with a few C\&I related to composition of the expert team.

The differences among C\&I fell into six topics: number of verifiers, human well-being, forest service and extension functions, environmental institutions as implementors of forest policy, bottomup approach, and making access to forest benefits more transparent.

The level of attention to policy matters increased with each field test, culminating in the Brazil test 
where one team member spent all his time on this issue. Although our emphasis has been on the FMU level, we have been compelled by field realities to address policy issues. This resulted in some conceptual tension, both during the fieldwork and in the workshops, about the level and nature of attention appropriate for policy within this project context. We have tried to keep it to a minimum, recognising the already overwhelming task of dealing adequately with FMU level C\&I. In the Austrian test no specific attention was given to policy matters, although some of the C\&I did address this issue (see section 3.2).

\section{PRINCIPLE: POLICY, PLANNING AND INSTITUTIONAL FRAMEWORK ARE CONDUCIVE TO SUSTAINABLE FOR- EST MANAGEMENT.}

CRITERION: THERE IS SUSTAINED AND ADEQUATE FUNDING FOR THE MANAGEMENT OF FORESTS.

\section{Indicators:}

- Policy and planning are based on recent and accurate information.

- Effective instruments for inter-sectoral coordination on land use and land management exist.

- There is a permanent forest estate (PFE), adequately protected by law, which is the basis for sustainable management, including both protection and production forest.

- There is a regional land use plan (or PFE) which reflects the different forested land uses, including attention to such matters as population, agricultural uses, conservation, environmental, economic and cultural values.

- Institutions responsible for forest management and research are adequately funded and staffed.

The teams unanimously felt that the policy C\&I were good summary/integrative measures and that they were closely related to the assessment goals. The Indonesia and Brazil teams gave them high scores on relevance, and the Côte d'Ivoire team considered them to be appealing to users and precisely defined.

The Indonesian and Brazil teams did not find the policy C\&I to be appealing to users, although the
Côte d'Ivoire team disagreed dramatically. Côte d'Ivoire and Brazil teams agreed that they were difficult to detect, record and interpret; the Indonesian and Côte d'Ivoire teams considered them unreliable. The Côte d'Ivoire team also felt their response range to stress was inadequate. No immediate future steps on policy $\mathrm{C} \& \mathrm{I}$ are planned.

\subsubsection{COMMONALITIES}

One of the major goals of this project has been to identify C\&I that hold up or apply in a variety of circumstances. In a series of matrices (Annex 6) we have placed the C\&I selected by each of the tropical field teams together, to show where the teams agreed and where they differed in their selection of C\&I. Inevitably we have had to be flexible in interpreting the three teams' different phrasing when we felt that the same issue was being addressed.

In the policy realm, seven items, including one principle, were common to all three tropical sites. This comprised 38 percent of Indonesia's policy C\&I; 73 percent of Côte d'Ivoire's; and 63 percent of Brazil's (Figure 8). One interesting difference between this set of C\&I and some of the others is the general agreement on the hierarchical level of the item in question. If one team considered something an indicator, they were all likely to.

\section{PRINCIPLE: POLICY: PLANNING AND INSTI- TUTIONAL FRAMEWORK ARE CONDUCIVE TO SUSTAINABLE FOREST MANAGEMENT.}

This was a principle on all three sites. In addition the Brazil set contained three criteria on the subject (Annex 6).

CRITERION: THERE IS SUSTAINED AND ADEQUATE FUNDING FOR THE MANAGEMENT OF FORESTS.

In Côte d'Ivoire this was specified at both criterion and indicator levels; in the other two sites, at the indicator level. All teams felt this was the important pre-requisite for sustainable forest management. It also indicated a sustained interest on the part of government in the maintenance and enhancement of benefits from forests.

Indicator: Policy and planning are based on recent and accurate information.

These were indicators on all three sites. All three teams were confronted repeatedly with policy documents based on information that was out of date. As a result the relevance of the document itself was questionable. On the other hand where information was accurate and up to date the analysis of the relevance of the policy document was essen- 


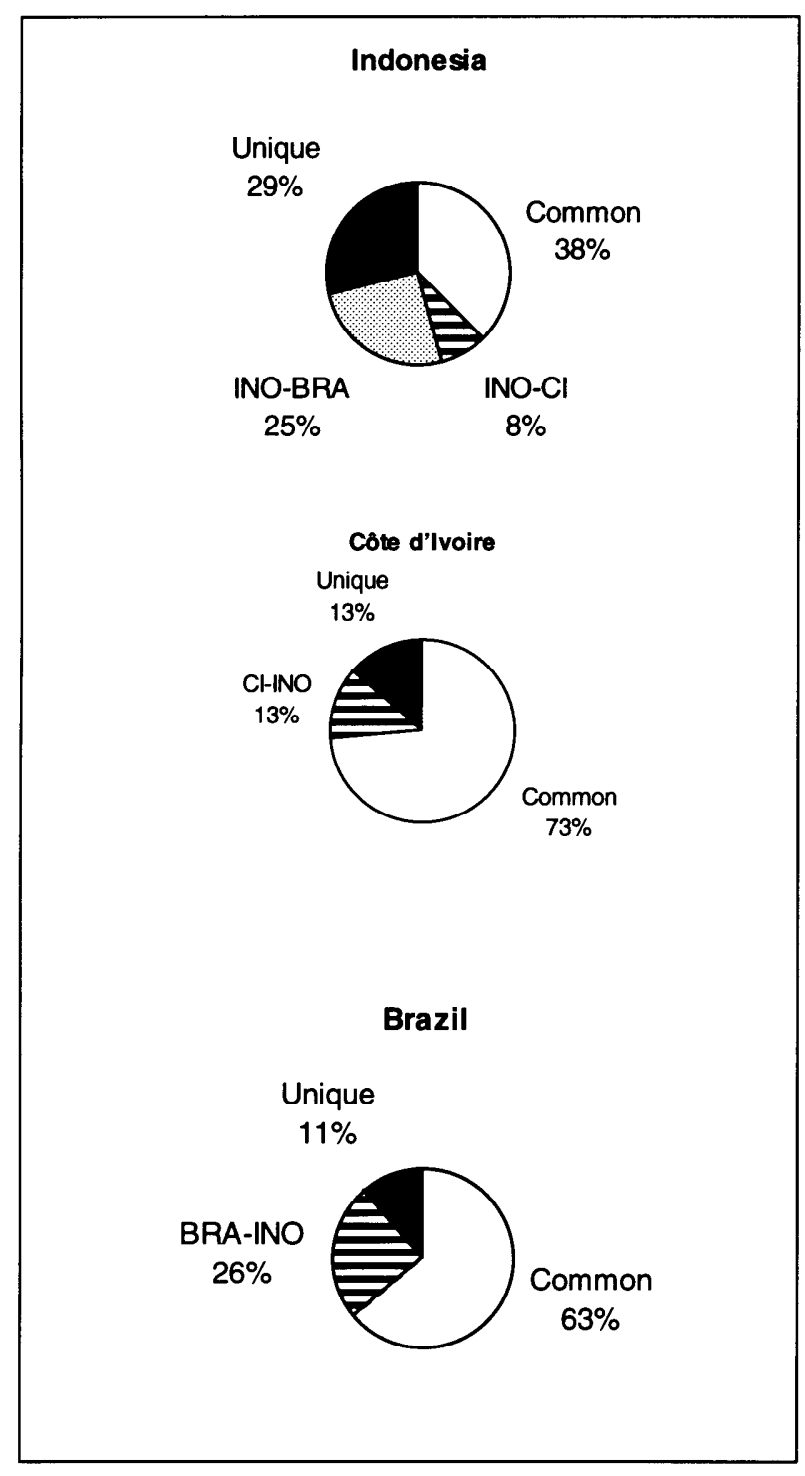

Figure 8. Policy indicators - commonalities and differences. Common: occurs in all three proposals. Unique: only to be found in one set. CI: Côte d'Ivoire,INO: Indonesia: BRA: Brazil.

tially reduced to an understanding of the interpretation of data. Furthermore the likelihood of the policy itself being relevant was expected to be much higher in the latter case.

Indicator: Effective instruments for inter-sectoral co-ordination on land use and land management exist.

The Brazil set contains four indicators, Côte d'Ivoire has one criterion and one indicator, and the Indonesian set has one indicator. The teams felt that a lack of inter-sectoral coordination has been a major stumbling block for sustainable forest management in the three countries. Evidence of this was apparent in Brazil for instance in the allocation of land earmarked for colonization for forest management, tax incentives for conversion of this land to agriculture etc.

Indicator: There is a permanent forest estate $(P F E)$, adequately protected by law, which is the basis for sustainable management, including both protection and production forest.

This was an indicator on all three sites. This is related directly to the principle above. All teams felt that this was a very important pre-requisite for sustainable forest management and therefore to be spelled out in law and policy. There are relevant references to this issue also in the "production" portion of the Brazil set.

Indicator: There is a regional land use plan (or $P F E)$ which reflects the different forested land uses, including attention to such matters as population, agricultural uses, conservation, environmental, economic and cultural values.

This was an indicator on all three sites (dealt with in two in Brazil). Closely related to the previous indicator, this one examines the content of the PFE. All teams felt that without adequate attention to the nature of the forests included in the PFE and their potential uses the goal of sustainable forest management was unlikely to be met.

Indicator: Institutions responsible for forest management and research are adequately funded and staffed.

This is covered by one criterion and two indicators in Indonesia, two indicators in Côte d'Ivoire and four indicators in Brazil. The question of training and capacity building addressed here have also been adressed in the "production" sets.

\subsubsection{DIFFERENCES}

In the previous section, we dealt with commonalities that spanned all three countries. We also analysed the commonalities among individual countries and consequently their differences. For Indonesia, 21 percent of its $C \& I$ were shared with Brazil and 8 percent with Côte d'Ivoire. 33 percent of its C\&I were unique. Côte d'Ivoire had 13 percent commonality with Indonesia, and had another 13 percent which were unique. Brazil shared 26 percent with Indonesia and had 11 percent which were unique.

In the following discussion, we have categorised these differences among selected C\&I into six topics: number of verifiers, human well-being, forest service and extension functions, environmental institutions as implementors of forest policy, recognition of diversity, and making access to forest benefits more transparent. The most common factor that differentiates C\&I selections in many of the following is the history of manage- 
ment and the present condition of the forests. Resource ownership and access and culture are also important, with a few C\&I related to composition of the expert team.

\section{Number of Verifiers}

One feature that stands out is the dramatically greater number of verifiers in the Brazil set, vis-ávis the others. This derives partly from the history of management and the present condition of the forests, and perhaps partly from culture. There was a sense among the team that something should be done quickly, and the more specific their findings, the more helpful they would be to future assessors. This same attitude was manifest in the closing workshop in Belem. There was a greater concern perhaps reflecting Brazilian culture at the macrolevel - with legality, or solving problems by legal means, than on the other sites. There is a correspondingly greater number of verifiers dealing with issues like court cases, appeals, damages, and conflict resolution (Annex 8).

\section{Human Well-being}

The inclusion of so many human well-being issues in the policy $\mathrm{C} \& \mathrm{I}$ in Brazil represents a marked departure from the other sites. This derives from differing resource ownership and access, culture and composition of the team. Many of the issues that were not dealt with, or were dealt with marginally, at the FMU level in Brazil, were included in the policy $\mathrm{C} \& \mathrm{I}$ as indicators and verifiers (at least two indicators and 15 verifiers) primarily because Viana16 felt these issues were important and should appear somewhere in the overall set. Brazil's policy set included C\&I on land tenure, division of forest benefits, participation, conflict resolution, indigenous knowledge, human rights, balance between people and resources, and cultural diversity. The Indonesian team's policy set also included indicators on land tenure, division of forest benefits, participation and conflict resolution. In the Indonesian case, these were also included because of the recognition that the problems were severe enough to need attention at all levels.

Another reason they were addressed in Brazil's set was the pervasive sense that private land owners, such as CEMEX, could do as they liked with their land, that only policy could effect the changes required for sustainable forest management. Finally, the legalistic cultural orientation mentioned earlier, seems to have had some impact on this choice.

\section{Forest Service and Extension Functions}

Only in Côte d'Ivoire was the Forest Service truly highlighted as a focus of C\&I (though the Brazilian set has some comparable functions for forest extension agencies, NGOs and consulting firms, reflected in one indicator and two verifiers). Côte d'Ivoire had two indicators and three verifiers dealing with this issue. This derives from the history of forest management and the present condition of the forests and the composition of the team. The current form of forest management has a short history in Côte d'Ivoire (Mengin-Lecreulx et al. 1995), and the team wanted to highlight the positive functions intended for forest services' employees. Mengin-Lecreulx ${ }^{17}$ had also worked with SODEFOR, the recently created agency responsible for management of the Ivoirean gazetted forest reserves, and therefore had a special interest in and knowledge of that organisation.

\section{Environmental Institutions as Implementors of Forest Policy}

This occurs in Brazil because of the relatively short history of forest management for timber production. Forests in the Amazon region were not managed in a planned manner for timber production until a few decades ago, and are now under the jurisdiction of IBAMA. The indicator dealing with this issue is supplemented by twelve verifiers. Some of the functions are similar to those listed for the forest service in Côte d'Ivoire.

\section{Recognition of Diversity}

Both the Indonesian and Brazilian teams emphasise the importance of attending to local variation. The Indonesian policy set has one indicator on this and Brazil one indicator with five verifiers under it, plus a variety of verifiers pertaining to public participation which should measure similar issues. Culture may be the most important factor in these selections. In Brazil, there is a strong emphasis on democracy; and in Indonesia there is an increasing recognition in policy circles that the cultural diversity that characterizes the country requires improved mechanisms for feedback to the centre. This is particularly true for forest people. Both countries are large, and undoubtedly require more explicit attention to feedback to the centre for that reason.

\section{Making Access to Forest Benefits More Transparent}

This was a particular Indonesian interest (with five indicators and one verifier), focusing on such things as making clear policies for harvesting for-

\footnotetext{
16 Brazil team's expert on policy and NTFF

17 Team leader, policy and forestry expert of the Côte d'Ivoire team
} 
est products, licensing of harvesting, making legal frameworks transparent, and so on. The primary factors in this selection are the history of forest management and resource ownership and access. Indonesian forests have been subject to both traditional (indigenous) ownership and management and formal (governmental) ownership and management. Access to forest benefits has gone disproportionately to the latter, to the disadvantage of the former. These indicators are designed to assess whether this practice continues or not.

\subsubsection{FIELD EXPERIENCE vs WORKSHOP EXPERIENCE}

The field experience in East Kalimantan persuaded the CIFOR team that we needed to address policy issues. Although the intent of our tests has been to focus on FMU, we could not escape the significance of national policies sponsoring transmigration, expanding industrial tree crop plantations, and other government-sponsored development activities on Kalimantan's forests and the people there. Burgess drafted the policy C\&I, with input from all team members.

At the Samarinda workshop, policy was discussed in three working groups on the first day. The rapporteur of each session was given a list of the characteristics of an ideal criterion or indicator (see next section), and asked to address these issues with regard to a specific subset of the selected C\&I in the discussion. Participants made specific suggestions for inclusion (such as explicit attention to the Indonesian industrial tree crop programme) and raised problems they perceived with regard to words like "adequate, appropriate, effective." They made a thorough and careful critique of the policy C\&I. The interdisciplinary groups that characterised the Samarinda workshop probably worked best with regard to the policy issues, since to some extent anyone could contribute productively from a variety of perspectives.

In Côte d'Ivoire, again we found important effects of policies on the situation in the forest. Agricultural, migration and forestry policies were not well integrated; and the result was steady pressure on the forests. Mengin-Lecreulx compiled the team's views on policy issues.

At the Abidjan meeting, we discussed policy issues in a plenary session. There was considerable sharing of perspectives from various African countries, with very different forest management regimes. Unlike the other topics, policy issues were discussed in broad terms in a plenary session.

In Brazil, Viana focused on the policy issues, and spent much of his time in Santarem and Belém researching them. The lack of congruence between government policies and sustainable forest management was most striking in Brazil. Team members and other interested parties reviewed Viana's lists and suggested rewordings and additions.

Following the request of a group of workshop participants, a special working group was constituted on the policy C\&I. They went through the proposed C\&I carefully, one by one, and provided the same kind of feedback that had been given to the other topics in the other two workshops. Such input was useful for fine tuning, but - as with most workshop input - no drastic changes were made. The sharing of perspectives and airing of issues were useful, as was the goodwill generated by providing a forum for such discussion.

\subsubsection{COST EFFECTIVENESS, RELIABILI- TY AND UTILITY}

Although we had hoped to be able to provide more detailed information on the costs of using individual C\&I, both the CIFOR team and the field teams were unable to do this during the time available. Instead, we are counting on the teams' assessments as a proxy for the more general statements on cost effectiveness that we had hoped to make. We asked each consulting team member to rate the C\&I selected on nine attributes of a good criterion or indicator.

The data collected are complex and we have not completed our analyses yet, but we can offer some preliminary findings. The C\&I that were selected by each team were evaluated using nine characteristics of an ideal indicator, as shown below. This formal evaluation was made on a 1-5 scale, with 5 being the most positive.

1. summary or integrative measure,

2. closely and unambiguously related to the assessment goal,

3. adequate response range to stress (sensitive),

4. diagnostically specific,

5. appealing to users,

6. easy to detect, record and interpret (feasible),

7. precisely defined (clear),

8. produces replicable results (reliable), and

9. relevant.

We have pulled out the teams' assessments, using these attributes for all four areas on which C\&I were evaluated and selected (policy, ecosystem, social, and forestry). Although the assessments are by no means conclusive, they do identify areas where the teams felt the C\&I were strong or weak.

In order to provide some sense of the differing assessment patterns of the three team members 


\begin{tabular}{|llccc|}
\hline tem\# & Characteristic of C/I & Indonesia & Côte d'Ivoire & Brazil \\
\hline $\mathbf{1}$ & Summary/integrative measure & 4.9 & 4.5 & 5.0 \\
$\mathbf{2}$ & Closely related to assess. goal & 4.7 & 4.7 & 5.0 \\
$\mathbf{3}$ & Response range to stress & 4.6 & 3.9 & 4.8 \\
$\mathbf{4}$ & Diagnostically specific & 4.6 & 4.1 & 4.8 \\
$\mathbf{5}$ & Appealing to users & 4.4 & 4.5 & 4.7 \\
$\mathbf{6}$ & Easy to detect, record, interpret & 4.5 & 3.9 & 4.4 \\
$\mathbf{7}$ & Precisely defined & 4.5 & 4.5 & 4.9 \\
$\mathbf{8}$ & Produces replicable results & 4.3 & 3.9 & 5.0 \\
$\mathbf{9}$ & Relevant & 4.7 & 4.4 & $\mathbf{4 . 8}$ \\
& & & 4.3 & \\
& OVERALL MEAN SCORE & $\mathbf{4 . 6}$ & $\mathbf{4 . 3}$ & \\
\hline
\end{tabular}

Table 7. Comparison of Average Evaluation Scores (Policy - Indonesia, Côte d'Ivoire, and Brazil)

who focused on policy, we provide Table 7 which summarises the average scores for each of the nine characteristics, across all selected policy C\&I, for each site.

In interpreting these scores, it is sensible to note the overall mean score given by each team. Due to the obvious variation in scoring among different team members, we have selected cut-off figures for "high" and "low" which identify the top and bottom two or three attributes, rather than selecting one cut-off for the entire data set.

In Indonesia, the policy C\&I scored quite high in comparison, for instance, with social C\&I. Of the 24 policy C\&I selected, only two received scores $<4$, and the overall average score was 4.6 (range: 2.9 - 5). Those attributes which received comparatively low scores, on average, included:

- "appealing to users" 4.4; and

- "produces replicable results", 4.3.

High scorers (>4.6) included:

- "summary/integrative measure" (4.9),

- "closely related to assessment goal"(4.7),

- "relevant" (4.7).

In Côte d'Ivoire, where 14 policy C\&I were selected and evaluated, the average score was lower (4.3), with a range from 3.9 to 4.7. The low scorers $(<4)$ were:

- "response range to stress" (3.9),

- " "easy to detect, record, interpret"(3.9), and

- "produces replicable results" (3.9).

The high scorers $(=>4.5)$ were
- "summary/integrative measure" (4.5),

- "closely related to assessment goal" (4.7),

- "appealing to users" (4.5), and

- "precisely defined" (4.5).

The Brazil team, which selected and evaluated 27 policy C\&I, gave them the highest score (4.8), with a range from 4.4 to 5 . Those attributes with the lowest scores $(\sim 4.8)$ were:

- "appealing to users" (4.7), and

- "easy to detect, record, and interpret" (4.4).

The high scorers $(5 \mathrm{~s})$ were:

- "summary/integrative measure",

- "closely related to the assessment goal",

- "relevant".

In summary, the teams were happier with the policy C\&I than with any of the other sets. Only in Côte d' Ivoire's forest management C\&I did the average $\mathrm{C} \& \mathrm{I}$ score equal the policy $\mathrm{C} \& \mathrm{I}$ average score in that country.

Although we do not have further steps planned in investigating policy issues, we recognise the importance of such activities. Byron (personal communication) has argued, for instance, that a simultaneous field and policy study of contiguous forest, managed by governments with differing forest policies (such as Papua New Guinea and Indonesia or Brazil and Bolivia) could tell us much use in sustainable forest management. This kind of study interests us, were funding, time and personnel available.

In our future work, we will be guided by a principle similar to what has guided us during this phase. 
We will address policy considerations if they influence what we are investigating at the FMU level and we have access to the competence to address them.

\subsubsection{RESULTS FROM THE TEST IN AUSTRIA}

In analysing the Austrian C\&I we will concentrate only on commonalities with all three tropical tests. The C\&I proposed by the Austrian team do not contain a section devoted to policy. However under the section on "General and Organizational Requirements" (see Annex 8), sub-section 6.1.1.2 deals with compliance with legal standards. Three items $(5 / 14,6 / 14,7 / 14)$ deal with legal requirements, including compliance with the forestry laws, land use planning and property rights.

\subsection{CRITERIA AND INDICATORS RELATED TO THE MAINTENANCE OF ECOSYSTEM INTEGRITY}

\subsubsection{MAJOR CONCLUSIONS}

Based on an analysis of the underlying thinking, a number of commonalities among the principles, criteria and indicators proposed for three tropical test sites emerged, although the wording in most cases differed among them.

The Indonesia, C\&e d'Ivoire, and Brazil ecology sets also contained $13 \mathrm{C} \& \mathrm{I}$ that were unique to one of these sets. We believe the inclusion of these C\&I in the ecology sets was influenced mainly by factors related to the expertise and experience of the experts concerned and only to a lesser degree by site specific factors. Most commonahties in the tropical sets are also reflected in the Austrian results.

Although the proposals made by the expert teams were generally accepted at the closing workshops, three important gaps were identified:

- the absence of an indicator on the impact of hunting (Indonesia set),

failure to include an indicator based on ecological monitoring (Côte d'Ivoire set),

- inadequate treatment of landscape and trans-FMU level interactions (Brazil set).

In their own assessment of their proposals, the teams were consistently less satisfied with the appeal of the principles, criteria, indicators and verifiers to users and their response range to stress. On the other hand they were confident that the principles, criteria, indicators and verifiers were

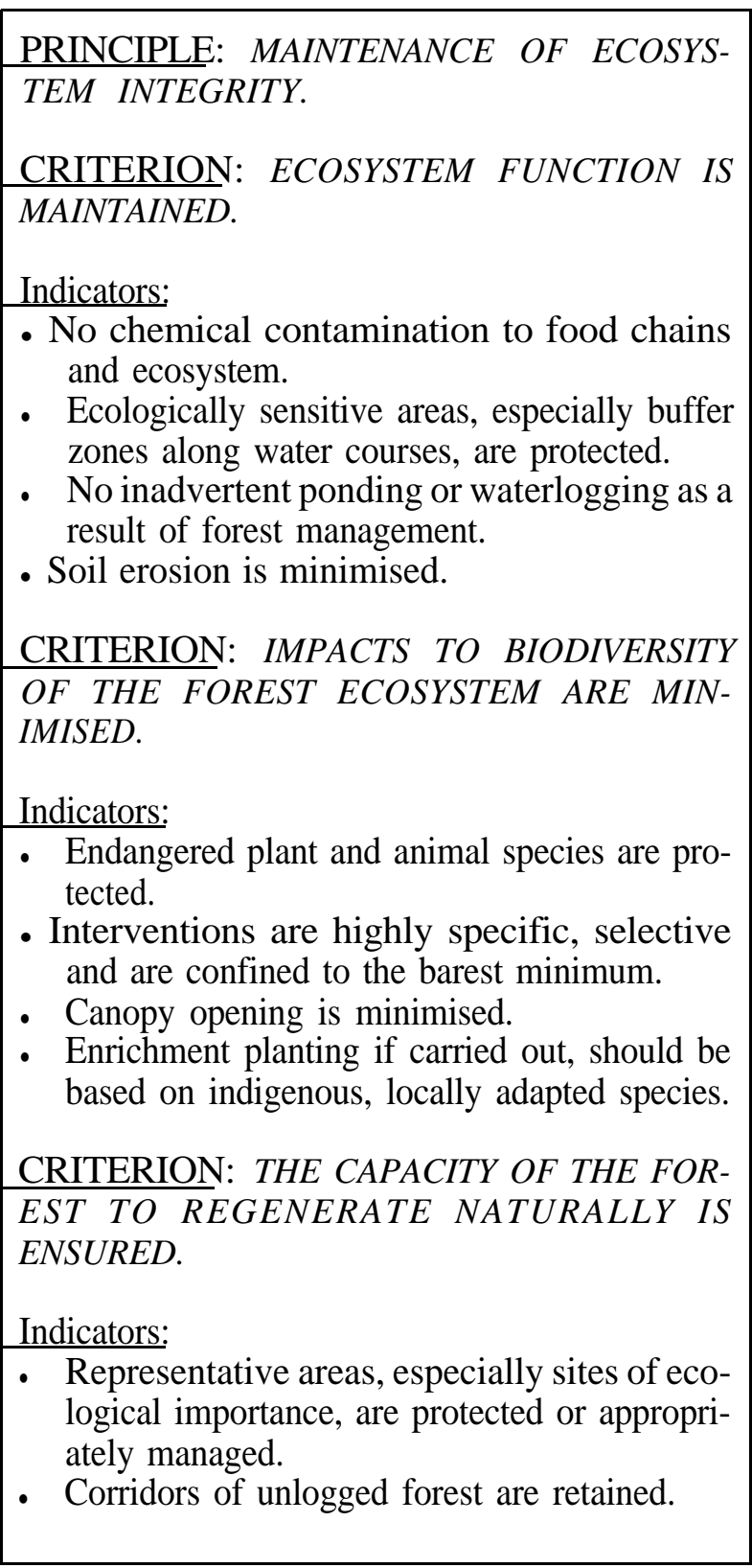

relevant, unambiguously related to the assessment goal and succeeded in integrating information in a summary fashion. Our conclusion is that they form a good platform and template for further development. They also reveal weaknesses, especially in assessing the impact of forest management on biodiversity and environmental services.

\subsubsection{COMMONALITIES}

We analysed the degree of commonality between the C\&I relevant to assessing the maintenance of ecosystem integrity based on the cross tabulation of all ecology related C\&I in Annex 6. We mainly considered principles, criteria and indicators. Verifiers were included only where they have been cross tabulated with indicators or criteria from another set. We also included C\&I from the relevant management, policy and social sets, where appropriate. 


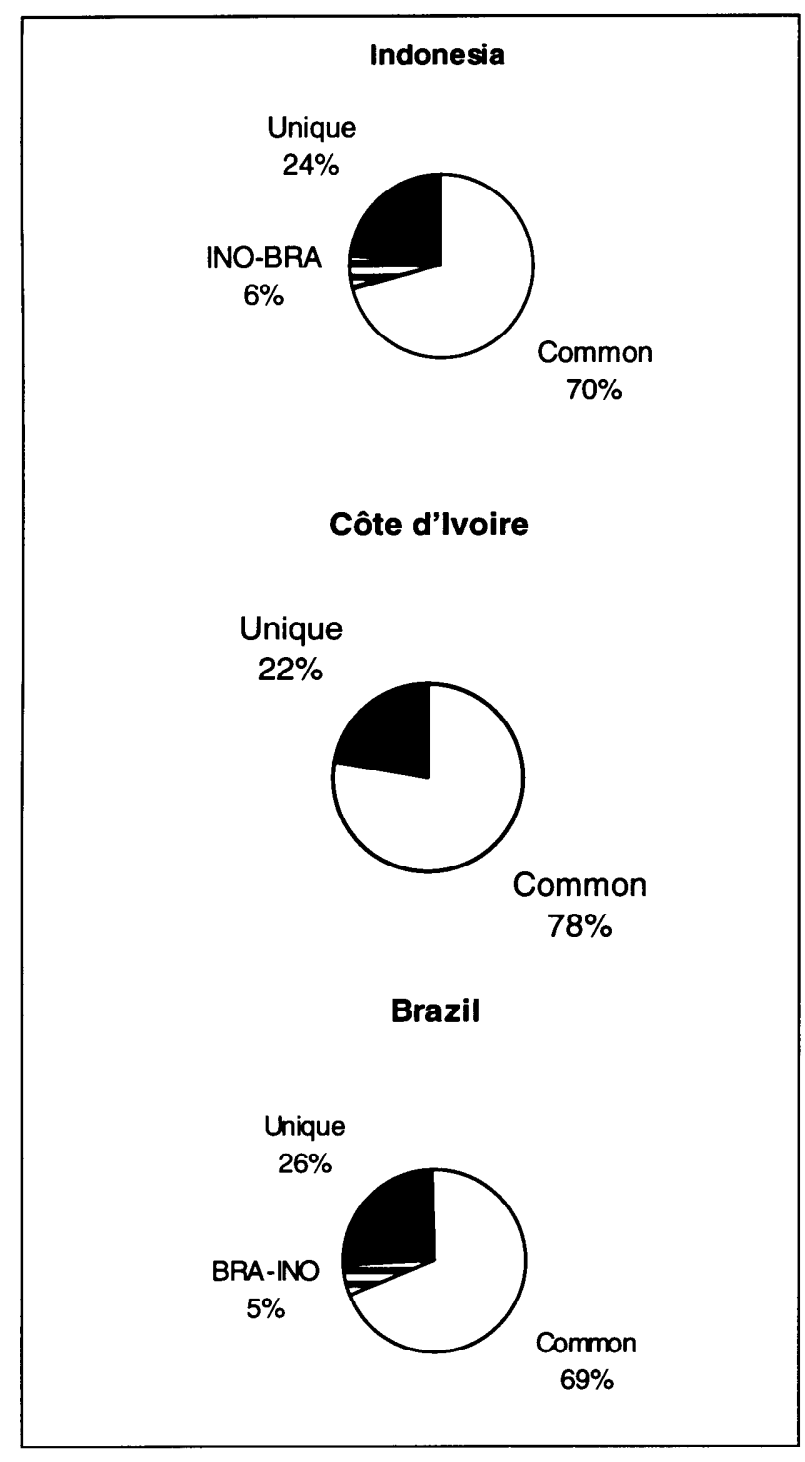

Figure 9: Ecosystem integrity indicators - commonalities and differences. Common: occurs in all three proposals. Unique: only to be found in one set. CI: Côte d'Ivoire, INO: Indonesia, BRA: Brazil

The ecological principles, criteria and indicators recommended for each site show a high degree of commonality: between 78 percent for Côte d'Ivoire and 68 percent in Brazil (Figure 9). This is surprising considering that the forests and sites are very different. One reason for this high degree of commonality is perhaps that the expert teams have sought principles, criteria and to some extent indicators that address issues related to impacts on ecosystem processes and functions. Adoption of such an approach leads to the sets having an inherently high generic element, as similar processes and functions apply to forest ecosystems independent of the sites concerned.

As in previous sections we present the common principles, criteria and indicators based on our analysis and wording that tries to convey only the underlying thinking.

\section{PRINCIPLE: MAINTENANCE OF ECOSYS- TEM INTEGRITY.}

This was a principle in the Indonesia and Brazil sets of C\&I. We have included it as a "common" principle here despite the fact that "ecosystem integrity" does not appear in the Côte d'Ivoire set. This is because on comparing the list of C\&I in the Côte d'Ivoire set with the definition of ecosystem integrity in Chapter 2 we found a remarkable degree of overlap. Both ecosystem integrity and resilience are jargon terms quite commonly used among English speaking ecologists. However, these may not be the terms used in other languages, which is why both terms were almost always questioned by ecologists who were not familiar with ecological terms in English. At the same time, there was general agreement on the content of the definition, and its importance.

\section{CRITERION: ECOSYSTEM FUNCTION IS MAINTAINED}

This was defined as a principle in Côte d'Ivoire and as a criterion in the other two sets. There was a common understanding amongst the ecologists that maintenance of forest ecosystem functions is critical for the sustainability of the forests.

Indicator: No chemical contamination to food chains and ecosystem.

All three proposals contain references to the prevention of chemical contamination to flora, fauna, water and people. In Brazil, Mesquita identified three verifiers for this indicator, two of which were prescriptive.

Indicator: Ecologically sensitive areas, especially buffer zones along water courses are protected.

Although worded differently in each case, the protection of buffer zones along water courses, highly erodible areas and other ecologically sensitive areas was considered to be a good indicator that management was aiming to maintain ecosystem functions. Several references to this issue can be found also in the "production" sets proposed by the teams.

Indicator: No inadvertent ponding or waterlogging as a result of forest management.

The Indonesia and Brazil sets of ecological criteria and indicators list this as an indicator and verifier, respectively. The Côte d'Ivoire set deals with this issue in the forest management set (e.g. as a verifier "No fill dumped into stream beds"). In both the Côte d'Ivoire and Brazil sets this was classified a verifier and not an indicator, of proper management techniques in the former case and of mainte- 
nance of water and soil quality in the latter. We have classified it as an indicator here. In the Brazil "production" set there are several prescriptions aimed at preventing ponding.

\section{CRITERION: IMPACTS TO BIODIVERSITY OF} THE FOREST ECOSYSTEM ARE MINIMISED.

Although this criterion is worded differently in each of the three sets, the wording above captures the underlying thinking. In the Côte d'Ivoire set, Huttel split this criterion into two "sub-criteria" (a category the project does not recognise), one of which dealt with negative impacts on biodiversity and the other with biological reserves. Biological reserves were a recognised management option within the two gazetted forests used by the Côte d'Ivoire team for its test.

\section{Indicator: Endangered plant and animal species are protected.}

Whereas in Indonesia the indicator was defined to include the protection of "key" and "rare" species as well, in Côte d'Ivoire it was considered sufficient to protect locally rare or endangered tree species. The Brazil set simply stipulates protection in accordance with CITES. It is difficult to assess the relevance of this indicator to sustainability. In most cases the view is that protection of endangered species is intimately connected with sustainability. However locally rare species may not be common because, for instance, they may be:

1. endemics, with local presence only, in which case protection seems warranted,

2. poorly adapted to new conditions and therefore heading for local extinction, and

3. aggressive colonisers making a first appearance in the area.

All the expert teams wrestled with this problem. Based on an application of the precautionary principle we believe the inclusion of this indicator is justified.

Indicator: Interventions are highly specijic, selective and are confned to the barest minimum.

In the case of the Côte d'Ivoire set this indicator is referred to indirectly and only in the "forest management" set as "Standards for silvicultural and other work [are] adapted to the specific ecology of the forest...". The need for validation of the silvicultural standards is stressed. This indicator reflects the generally accepted view that "blanket treatments" are detrimental to the maintenance of biodiversity.

\section{Indicator: Canopy opening is minimised.}

This indicator is worded similarly in both the Indonesian and Brazil sets. The Côte d'Ivoire set focuses on the vertical structure of the forest and deals with canopy opening only in the first verifi- er. This difference in focus was the result of the degraded condition of the forest in Côte d'Ivoire. The underlying assumption is that relatively few canopy openings of small- sizes have a lower impact on the forest, than several large ones. It is important to recall that this indicator was developed in the context of polycyclic, selective cutting systems in tropical moist forests.

Indicator: Enrichment planting, if carried out, should be based on indigenous, locally adapted species.

This is a prescription contained in all three sets to cover enrichment and other kinds of planting. It also stipulated that planting was to be restricted to degraded areas and only be carried out if necessary. In Indonesia this was an indicator under the management set. It would probably have been better placed in the forest management section of the Côte d'Ivoire and Brazil sets as well, as we feel that the ecology section should mainly cover the impacts of management, and not the interventions themselves. This means defining indicators mainly as outcomes of human processes or as ecosystem responses (see Chapter 2).

\section{CRITERION: THE CAPACITY OF THE FOREST} TO REGENERATE NATURALLY IS ENSURED.

This is an edited version of an indicator in the Côte d'Ivoire set. In the Indonesian set this was a criterion that referred to the resilience of the forest ecosystem. The Brazil set refers to two indicators (and one verifier) which deal with the ability of animal (1.2.6) and plant (1.2.7) species to recover (see Annex 8).

Indicator: Representative areas, especially sites of ecological importance, are protected or appropriately managed.

In the case of the Indonesian and Brazil sets, this was a prescriptive indicator. In both cases however the indicator contained multiple conditions, making an assessment of compliance difficult. In the case of the Côte d'Ivoire set, this was one "sub-criterion" and one indicator, both prescriptive. In the Indonesia C\&I, setting aside 10 percent of the area for this purpose was considered appropriate. Interestingly each of the three sets saw this as being associated with a different criterion. In the case of Indonesia, the criterion dealt with resilience, in the Côte d'Ivoire set it was biodiversity, and in the Brazil set it was maintenance of ecosystem process and function. This illustrates an indicator which contributed to several areas, i.e. had multiple linkages.

Indicator: Corridors of unlogged forest are retained.

This indicator appears in the Côte d'Ivoire and Brazil sets, but not in the Indonesian set. In the for- 
mer case this refers to corridors between biological reserves. In the case of Brazil the corridors are to be based on stream sides with links up slopes and across ridges. This is a proxy indicator that seeks to ascertain the potential for species to recolonise an area after disturbance has ceased.

\subsubsection{DIFFERENCES}

Besides comparing the C\&I across all three sites, comparisons were also made between individual sites. Identifying a number of C\&I common in two sites naturally also reveals $C \& I$ which are unique. The Indonesia team had 6 percent in common with Brazil, with 28 percent of its C\&I being unique. Côte d'Ivoire had 5 percent of its C\&I in common with Brazil, and 32 percent were unique; and Brazil shared 5 percent with both Côte d'Ivoire and Indonesia, with 15 percent of its C\&I being unique. There are a number of differences among the ecological C\&I proposed by the experts. It is interesting to note that the factor ecology of the forests contributed to the development of a 'unique' indicator in one case only.

Indicators which owe their origin principallv to the composition of the expert teams:

1) Overmature trees are maintained as habitat (Indonesia).

2) Minimum diameter at cutting considers age of reproductive maturity or maximum size reached for a given species (Brazil).

3) Hunting, even when legal, is controlled (Brazil).

4) Shape, location and design of forest compartments attempts to minimise current and future edge effects due to forest fragmentation (Brazil).

5) Management plan recognises variability in the forest... and has monitoring mechanisms sensitive enough to detect change (Brazil).

6) Much sought after non-timber forest products should be the object of conservative management and domestication trials (Côte d'Ivoire).

Although none of the indicators listed above is fully free of site influence, we believe that by changing the composition of the team, they could have been proposed at other sites as well. The first indicator, for instance, is probably a result of Watling's specialisation in ornithology and work experience in setting up national parks. None of the other ecologists had this experience. It also reflects the intensity of logging in Indonesia. The site had an influence on the development of indicator 6 above, inasmuch as the fragmentation of the CEMEX forests into seven "Fazendas" or farms prompted Mesquita to develop this indicator in Brazil. Her background of work experience on forest fragmentation issues, probably sensitised her to this problem. We believe, however, that this indicator could be relevant elsewhere. We discuss hunting and monitoring in section 3.4.4 below.

\section{Criteria and indicators owing their origin to preferences in wording}

1) Conservation of biomass and nutrients (criterion, Côte d'Ivoire).

This criterion is important for sustainability, but is difficult to assess. It serves to flag important issues dealt mainly in the Côte d'Ivoire "production" set. It was the choice of words rather than the underlying thinking that caused it to be treated as "unique" or site-specific.

Indicators resulting from historv of management and condition of the forests:

1) Residual living basal area after logging is not less than $15 \mathrm{~m}^{2 / \mathrm{ha}}$ (Indonesia).

2) Less than 35 percent damaged trees in residual stand (> $20 \mathrm{~cm} \mathrm{DBH}$ ) (Indonesia).

3) The size of biological reserves is adapted to the object of preservation (Côte d 'Ivoire).

4) Selection of biological preservation areas should take into account their potential for efficient protection(Côte d'Ivoire).

5) Management plans... only provide for single species or exotic species plantations... (Côte d'Ivoire).

6) Producers and processors respect the environmental laws (Brazil).

The first two indicators are a direct result of the higher intensity of logging in Indonesia. There is no reason why they should not apply at the other two sites, however the performance thresholds would probably be more stringent to take into account lower harvesting volumes and different regeneration patterns. The concern in Côte d'Ivoire with biological reserves arises out of the fact that management plans explicitly foresee the declaration of such reserves. This is not yet the case in Indonesia and Brazil. Plantations (indicator 5 ) were outside the mandate of the expert teams. However the Côte d'Ivoire team successfully argued the case that, given the present degraded condition of forests in Côte d'Ivoire and the intimate way in which small scale plantations were interspersed with regenerating logged-over natural forest, it would be expedient to include them.

\section{Indicator resulting from special site character-} istics:

1) Logging prohibited on slopes of over $2.5^{\circ}$ measured over a terrestrial distance of $100 \mathrm{~m}$.

The one reason, we believe, this indicator was included only in the Indonesia set was because all 
other sites had flat terrain. As the experts were expected to develop C\&I within the specific context of "their" sites, they dropped slope limits as a consideration in C\&e d'Ivoire and Brazil.

\subsubsection{FIELD EXPERIENCE vs WORKSHOP EXPERIENCE}

In the three closing workshops there was little controversy about the C\&I proposed by the expert teams; they were accepted with few modifications. However, three important gaps were identified:

1) Absence of hunting in the Indonesia set. This was accepted as an oversight by the team.

2) Lack of an indicator on ecological monitoring during the C\&e d'Ivoire closing workshop. Huttel argued against the inclusion of such an indicator, pointing out that the costs of ecological monitoring systems would be prohibitive given the present condition of Côte d'Ivoire forestry. He felt that the proposed set was adequate to assess maintenance of forest ecosystem functions, and did so in a cost-effective manner. No consensus was achieved.

3) The working group on ecological $\mathrm{C} \& \mathrm{I}$ at the Brazil workshop was unanimous in their concern that landscane level ecological interactions were being inadequately addressed at present. Although in many cases an FMU extends across a landscape, the feeling was that by limiting the focus to an FMU, there was a danger that "cross-FMU" interactions may be ignored. This was an important consideration, but was not developed into concrete recommendations.

\subsubsection{COST EFFECTIVENESS, RELIABILI- TY AND UTILITY}

Again, as with the policy set, we have made use of the teams' assessments using the nine attributes in Section 2.3.2.3 as a proxy for the cost evaluations that we were unable to make. Here we evaluate principles, criteria, indicators and verifiers. The nine attributes were evaluated by each team member on a scale of $1-5$, with 1 being the less desirable end of the scale.

The principles, criteria, indicators and verifiers pertaining to ecological matters were second only to the social set in their difficulty. This is reflected in the comparatively low scores given to ecological indicators (Table 8).

In Indonesia, the overall average for the 17 ecology principles, criteria, indicators and verifiers was 3.9 , with a range from 3.5 to 4.3 . Those scoring lower than 3.8 included:

- "summary or integrative measure" (3.6), and

- "response range to stress" (3.5).

The high scorers $(>4.2)$ included:

- "precisely defined" (4.3), and

- "relevant" (4.3).

In C\&e d'Ivoire, there were 18 ecology $\mathrm{C} \& \mathrm{I}$. The average score (4) was only slightly higher, but the range was peculiar, with the lowest value being 1.4 , and the next lowest value being 4 . The highest value was 4.9. The average without the 1.4 outlierts is

\begin{tabular}{|llccc|}
\hline [tem\# & Characteristic of C/I & Indonesia & Côte d'Ivoire & Brazil \\
\hline $\mathbf{1}$ & Summary/integrative measure & 3.6 & 4.6 & 4.2 \\
$\mathbf{2}$ & Closely related to assess. goal & 4.2 & 4.6 & 4.6 \\
$\mathbf{3}$ & Response range to stress & 3.5 & 1.4 & 3.7 \\
$\mathbf{4}$ & Diagnostically specific & 3.8 & 4.3 & 4.0 \\
$\mathbf{5}$ & Appealing to users & 4.2 & 4.0 & 3.7 \\
$\mathbf{6}$ & Easy to detect, record, interpret & 3.8 & 4.1 & 4.0 \\
$\mathbf{7}$ & Clear & 4.3 & 4.3 & 3.8 \\
$\mathbf{8}$ & Reliable & 3.8 & 4.2 & 4.8 \\
$\mathbf{9}$ & Relevant & 4.3 & 4.9 & $\mathbf{4 . 1}$ \\
& OVERALL MEAN SCORE & $\mathbf{3 . 9}$ & $\mathbf{4 . 0}$ & \\
\hline
\end{tabular}

Liable 8. Comparison of Average Evaluation Scores (Ecosytem Integrity - Indonesia, Côte d'Ivoire, and Brazil)

18 This strange score came from the fact that the team member had a hard time applying this attribute ("response range to stress" to his C\&I, resulting in many empty cells. If the empty cells are disregarded, the average assessment of this attribute is 5 !. 
4.4. Ignoring the outlier, the low scorers $(<4.2)$ in Côte d'Ivoire include:

- "appealing to users" (4), and

- "easy to detect, record, interpret" (4.1).

The high scorers $(>4.5)$ were:

- "summary or integrative measure" (4.6),

- "closely related to the assessment goal" (4.6), and

- "relevant" (4.9).

In Brazil, the average score for the 19 ecology C\&I was 4.1 , with a range from 3.7 to 4.8 . The low scorers $(<3.8)$ were:

- "response range to stress" (3.7), and

- "appealing to users" (3.7).

High scorers (>4) included:

- "summary or integrative measure" (4.2),

- "closely related to the assessment goal" (4.6)

- "relevant" (4.8).

If we look at the cross-site average evaluations, we find considerable continuity, with the range being from 3.9 in Kalimantan to 4.1 in Brazil.

The ecological principles, criteria, indicators and verifiers are extremely economical in terms of their total number per site. When we compare among sites it becomes apparent that Watling (Indonesia) was more critical of that set than Huttel (Côte d' Ivoire) or Mesquita (Brazil). However we believe this is not a reflection of the intrinsic value of the Indonesia set but more a reflection of higher expectations.

In all sets the ecologists were relatively less satisfied with the ability of C\&I to respond to changes in stress. This is certainly a difficult attribute to fulfil, but one that has a great deal of influence on the quality and cost of information being retrieved from an indicator or verifier. Interestingly, they were also uncertain whether the ecology principles, criteria, indicators and verifiers would be appealing to users. There may have been a feeling that some of the principles, criteria, indicators and verifiers were not directly interpretable without a suitable introduction. In other cases, e.g. "Decrease in water quality in the watershed or subwatershed" Côte d'Ivoire), there may have been a lack of specificity, making it less "easy to detect, record or interpret".

There was general agreement that the ecology sets were relevant, closely related to the assessment goal and integrated a great deal of "up-stream" information. The teams' assessments concurred that the ecological principles, criteria, indicators and verifiers were adequate to assess the maintenance of ecosystem integrity. We generally agree

The ecology sets reveal some weaknesses, particularly with respect to assessment of impacts on biodiversity.

- None of the existing sets of C\&I has actually attempted to define C\&I that directly assess the impacts of forest management on biodiversity and key environmental services.

- Perhaps rightly, the underlying assumption in all the sets is by assessing compliance with "good forest stewardship" we can assess maintenance of biodiversity, water quality and soil conservation. The teams have therefore worked with proxy indicators, which particularly in the case of biodiversity are quite weak. In our search for better indicators for biodiversity, we need to consider that there may not yet be an affordable method of directly assessing forest management's impact on biodiversity. In this case proxy indicators are the only solution. However a better and clearer link between "good forest stewardship" and maintenance of biodiversity needs to be established, before we can be confident that this is indeed a proper way to proceed.

- Development of better indicators for impacts on biodiversity will not free us from the thorny normative question of "how much and what kind of biodiversity do we wish to preserve?" Once this question has been clarified it will be easier to develop appropriate indicators. This is, however, not a question to which we have seriously sought an answer during the first phase of the project.

In our view the ecology principles, criteria, indicators and verifiers from the three tropical sites are a good platform for further development. The potentially high generic character of the principles, criteria and indicators allows us to expect them to be potentially useful as templates for the development of more site specific sets, especially once some of the problems listed above have been ironed out.

\subsubsection{RESULTS FROM THE TEST IN AUSTRIA}

The Austrian results show some degree of overlap with all but two of the commonalities identified above for the three tropical tests (see Annex 6). In the case of the indicator "Enrichment planting if carried out, should be based on indigenous, locally adapted species" the Austrian equivalents (Nos. 62/14 and 310 in Annex 8) do not refer to "enrichment planting" as such as this is not a common forestry practice. However the underlying issue in 
the tropical sets is the introduction of exotic species or provenances by means of planting. This is addressed in the Austrian set. In common with the need to maintain ecosystem function in the tropical sets, the Austrian set calls for:

"In forest management the maintenance and improvement of the functional capacity of ecosystems, their dynamics as well as their vitality and stability have to be guaranteed.

- Maintaining the capacity of ecosystems to react upon external impacts and processes.

- Especially forest stands adapted to the local conditions must be maintained and supported in order to profit to a maximum from natural control mechanisms."

The two exceptions are the principle "Maintenance of ecosystem integrity" and the indicator "Corridors of unlogged forest retained". In the Austrian set the term "ecosystem integrity" is not used at all, the reason is perhaps the same as is the case for Côte d'Ivoire - the term is ecological jargon. In the context of Austrian forestry it would be difficult to maintain corridors of "unlogged" forest because all forests have already been logged. There is however a demand in the Austrian C\&I to set aside representative areas that will not be logged in future. However these presumably will not form corridors.

Due mainly to the late arrival of the Austrian results, we have only been able to analyse $C \& I$ held in common with all three tropical sites. Superficial examination of the Austrian results reveals however that such limited commonalities are present, e.g. hunting is an issue in both the Brazilian and Austrian sets (1.2.2 and 49/4 respectively in Annex 8).

\subsection{CRITERIA AND INDICATORS RELATED TO THE SOCIAL ENVIRON- MENT WITHIN WHICH FOREST MAN- AGEMENT TAKES PLACE}

\subsubsection{MAJOR CONCLUSIONS}

There are at least eight common social C\&I selected by all three tropical teams. The same issue is assigned to a different hierarchical level, in many cases.

All teams scored the social C\&I generally as deficient on the characteristic, "reliable." Two gave low scores on "diagnostically specific" and "precisely defined". One gave a low score for "relevant", one for "feasible", and one for "appealing to users".

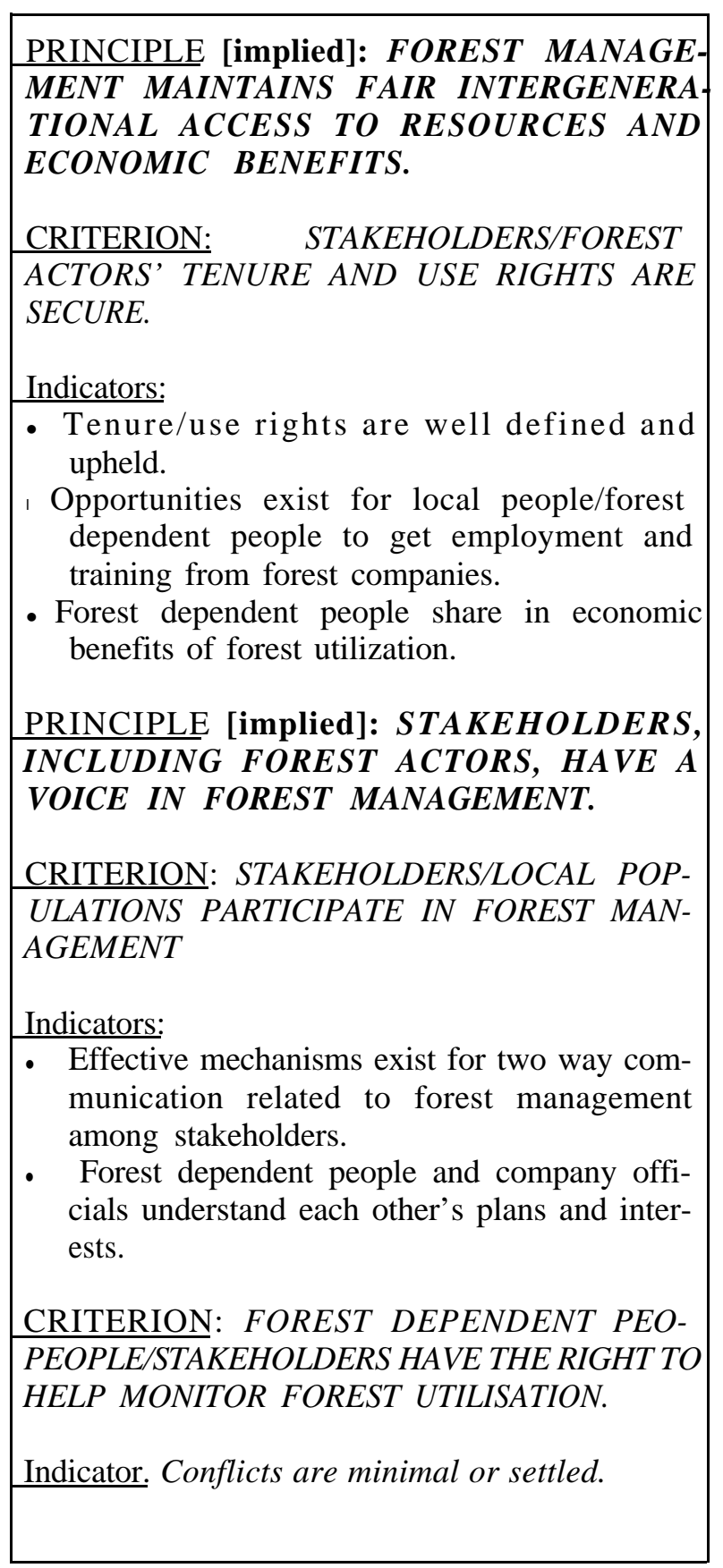

Social C\&I, on average, scored high on "close/unambiguously related to assessment goal" from all teams. Two social scientists gave high scores on "summary/integrative measure" and "relevant". One each gave high scores on "appealing to users", "diagnostically specific" and "precisely defined".

The social C\&I, not surprisingly had the smallest percentages of common C\&I, with Brazil having as many as 54 percent unique C\&I. However, the fact that there were, on average, about 34 percent common social C\&I was gratifying to the team, in providing a tested "starting point". Although common- 
alities with the Austrian set were established, differences in the testing methods severely constrain comparability.

\subsubsection{COMMONALITIES}

We found nine common C\&I, each of which is described below (see Annex 6, for the matrix comparing the social C\&I). For Indonesia, this represented 43 percent of the team's social C\&I; for Côte d'Ivoire, 32 percent; and for Brazil, 27 percent. Not surprisingly, the social C\&I had the lowest range of common C\&I of any of the four major topics (Figure 10).

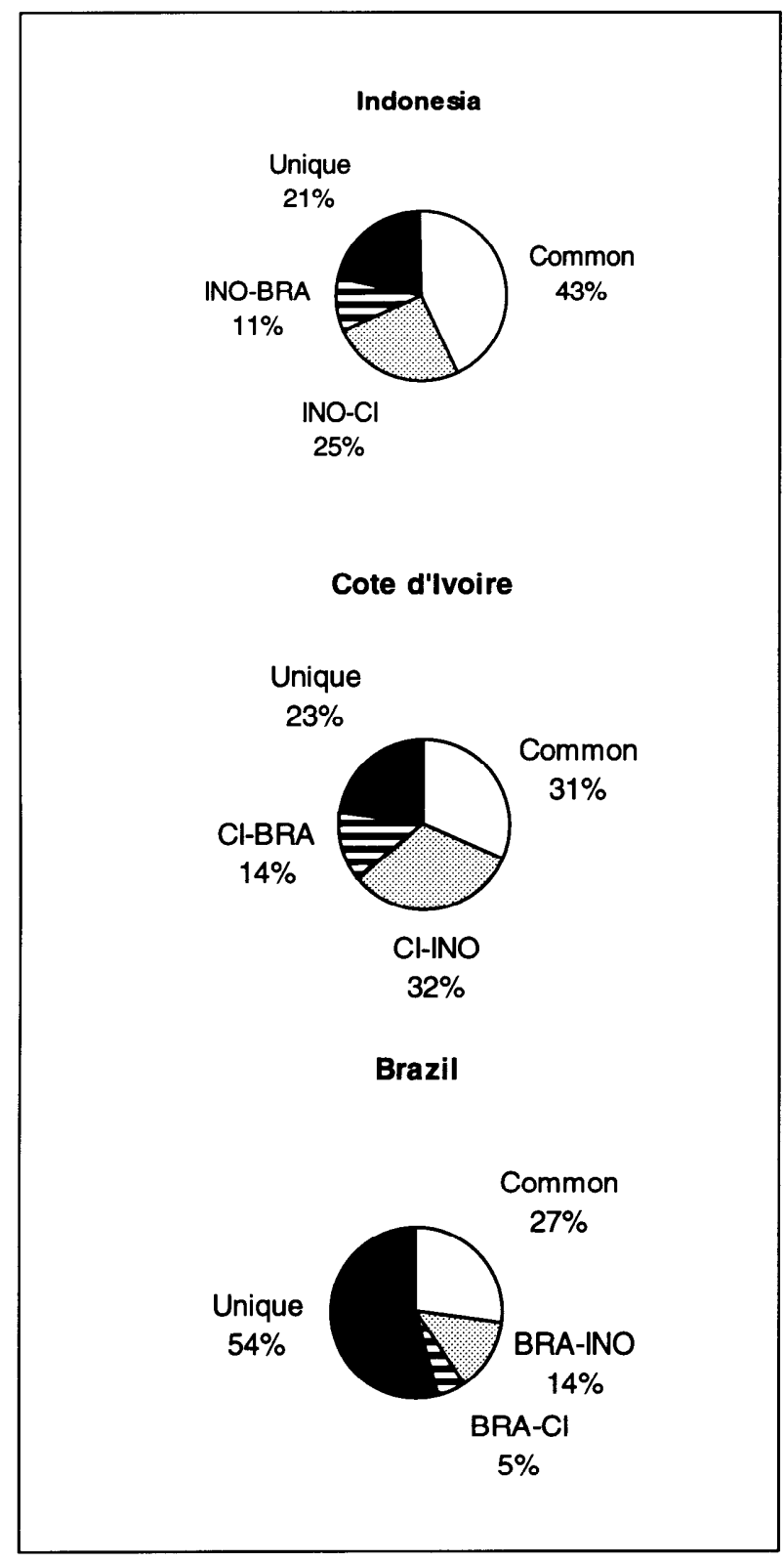

Figure 10: Social Indicators - commonalities and differences. Common: occurs in all three proposals. Unique: only to be found in one set. CI: Côte d'Ivoire, INO: Indonesia, BRA: Brazil
We have put the number used in our conceptual framework paper (Annex 7), for a corresponding criterion or indicator, in parentheses, to show the congruencies. The three major issues dealt with below include mechanisms to secure local people's livelihood both now and in the future, mechanisms to ensure that people in the area have a voice in forest management; and mechanisms to monitor and control access to resources.

PRINCIPLE [implied]: FOREST MANAGEMENT MAINTAINS FAIR INTERGENERATIONAL ACCESS TO RESOURCES AND ECONOMIC BENEFITS.

In Brazil, no principles were specified, but a series of C\&I pertaining to this issue and comparable to those on the other sites suggests that this is indeed a shared principle.

CRITERION:STAKEHOLDERS/FOREST ACTORS' TENURE AND USE RIGHTS ARE SECURE.

In Côte d'Ivoire, this formed one principle and one criterion and in Brazil and Indonesia one criterion each. The Côte d'Ivoire team considered the differentiation between ownership and use rights to be very important; the other teams, less so. In Indonesia this was considered to be an indicator (Criterion 1.1, "Forest actors" current and intergenerational access to resources is secure").

Indicator: Tenure/use rights are well defined and upheld.

In Côte d'Ivoire this was dealt with in one criterion (again emphasising the differentiation between tenure and use). In Brazil, it was one indicator, and in Indonesia, one verifier. (Indicators 1.1.1 and 1.1.2 under Criterion 1.1 above).

Indicator: Forest dependent people share in economic benefits of forest utilization

This was a criterion and an indicator in Indonesia, and was represented by one indicator each in Côte d'Ivoire and Brazil. (Indicator 1.2.4 under Criterion 1.2 , "Forest actors have a reasonable share in the economic benefits derived from forest use").

Indicator: Opportunities exist for local people/forest dependent people to get employment and training from forest companies.

In Côte d'Ivoire and Brazil, this was considered an indicator; in Indonesia, a verifier. (Indicator 1.2.4 under Criterion 1.2, "Forest actors have a reasonable share in the economic benefits derived from forest use").

PRINCIPLE [implied]: STAKEHOLDERS, INCLUDING FOREST ACTORS, HAVE A VOICE IN FOREST MANAGEMENT. 
All teams developed C\&I that addressed this issue, though none used this exact phrasing. Team members wrote C\&I on two-way communication, mutual monitoring, conflict resolution mechanisms, and other specifics that can be subsumed under this principle, and they tended to use the term "participation" only at lower hierarchical levels.

CRITERION: STAKEHOLDERS/LOCAL POPULATIONS PARTICIPATE IN FOREST MANAGEMENT.

In Côte d'Ivoire this was considered a criterion; in Indonesia and Brazil, an indicator. (Criterion 2.1 "All stakeholders have an acknowledged right and means to participate in equitable forest management"). Although the term is used here, we should mention that there was considerable distaste among non-native English speakers for the term, "participation", which was felt to imply a patronising attitude. This seemed to interfere with the development of comparable phrasing among sites, as no alternative proved acceptable.

Indicator: Effective mechanisms exist for two way communication related to forest management among stakeholders.

This was an indicator in all three locations (Indicator 2.1.1 under Criterion 2.1 above).

Indicator: Forest dependent people and company officials understand each other 's plans and interests.

In Brazil, this was seen as an indicator. In both Indonesia and Côte d'Ivoire, it was dealt with by using two verifiers each (Indicator 2.2.2 under Criterion 2.2, "Resource managers co-operate to assimilate differing management models").

Indicator: Forest dependent people/stakeholders have the right to help monitor forest utilisation.

In Brazil, this was considered a criterion, whereas in Côte d'Ivoire and Indonesia, it was a verifier (Indicator 2.2.3 under Criterion 2.2 above, and verifier 2.3.2.2 under Criterion 2.3, "Mechanisms for control of access to desired local resources are supported by all stakeholders").

Indicator: Conflicts are minimal or settled.

This was an indicator in Brazil, and a verifier in Indonesia and Côte d'Ivoire. (Verifier 2.3.1 .1 under Criterion 2.3 above; also Indicator 1.3.3 under Criterion 1.3, "The health of forest actors (see Colfer 1995 for a discussion of forest actors), cultures and the forest is acceptable to all stakeholders").

Interestingly the only criterion specified in our conceptual framework for which there is not at least one common criterion, indicator or verifier

\section{PARTICIPATION - AN AUSTRIAN EXAMPLE}

Colfer only spent three days in the forests oj Austria, but she was accompanied by a conglomeration of (sometimes antagonistic) stakeholders in the forest management process. It became quite clear during that time that Austrian forest farmers have considerable voice in forest management compared to local people in the other project sites.

When Colfer examined why she was so confident that Austrian farmers had a significant voice, she found the following indicators:

- a farmer was included (under the auspices of the Ministry of the Environment) on the team evaluating $C \& I$,

- both forest farmers and their representatives were invited to participate and came to the closing workshop,

- Austria has a legally mandated forest owners' group, which was mentioned in a positive way on the forest/farm as a source of consultation, a forestry official was able to describe a series of clear; legal steps, in cases of conflict about forest uses and rights,

- forest farmers and their representatives at the workshop freely expressed a variety of opinions, including scepticism, about aspects of certification, demonstrating their freedom to express opinions contrary to those of the government,

- a formalised negotiation process was outlined, again by a government official, regarding the union activities of forest workers.

One significant category of people seemed to have their voice muted: women. The farmers' representative and government officials said that the majority of Austrian farmers are part timers. A typical pattern is the men work off farm for wages, while the women stay home and manage the farm. Indeed, when the team visited a small forest farm, the woman of the household could be seen in the distance operating a tractor. The only woman examining the $C \& I$ was working for a shorter period of time on an issue that was not being locally tested (the situation of indigenous people in the Third World). The workshop itself had four women participants (out of about 35-40 people).

Another factor that influenced Colfer's conclusion that the level of farmer participation was comparatively high in Austria (and her willingness to come to a conclusion at all in that short a space of time) derived from similarities to the Pacific Northwest coast of United States (an area about which she had more in-depth knowledge). 
specified above by all teams, was Criterion 1.3, "The health of forest actors, cultures and the forest is acceptable to all stakeholders". In fact, all teams did deal with these matters, but they put them in different parts of their overall sets or used different words. In Côte d'Ivoire and Brazil, for instance, though the social science team dealt at length with issues of human health, they left the health of the forest to the ecologists. The Indonesia team emphasised balance between people and land uses. We have juggled the phrasing of this matter repeatedly ourselves. It is a node that links people with their environment in a very direct way and includes demographic, cultural and land use matters.

One of the interesting findings is the lack of agreement among teams about the hierarchical level of these issues. Determining the level of an issue that all agreed was important was a problem with which the CIFOR team also contemplated. In the field setting, it was not always clear which item was the indicator and which the criterion - even though the formal definitions of these were known and understood. This derives from the interrelationships among systems and their elements, and the possibility of defining a criterion relevant to sustainable forest management at various levels of generality (resulting in different hierarchical levels for the subordinate topics, see also discussion in section 3.7 ).

For instance, participation of forest actors in forest management is a condition (i.e., criterion) that many researchers consider important for sustainable forest management. Nevertheless, participation levels and quality can also be indicators or verifiers showing effective monitoring or mechanisms for joint planning, conflict resolution, or accessing indigenous knowledge. Similarly, we have identified the health of forest actors as a criterion (a condition pertaining to the well-being of people); yet it can also be an indicator that forest actors are getting a reasonable share of economic benefits from forest use. We have found no simple way to identify the level of importance of social issues. Our understanding outlines broad spheres; but undoubtedly important, site specific variations that must be taken into account in future assessments exist. In the next section, we discuss the kinds of differences in selected C\&I on the different sites, to give some insights into this issue.

\subsubsection{DIFFERENCES}

As with the other topics, each team shared a certain number of common C\&I with one other country. Indonesia, for instance, had 25 percent of similar social C\&I with Côte d'Ivoire and 11 percent with Brazil. 21 percent of its C\&I were unique for Indonesia. Côte d'Ivoire had 32 percent common- ality with Indonesia and 14 percent with Brazil, and revealed 23 percent unique C\&I. Brazil's C\&I had 14 percent commonality with Indonesia, 5 percent with Côte d'Ivoire; and had an unusual 54 percent unique $\mathrm{C} \& \mathrm{I}$.

In looking at the differences in the three sets of indicators, the basis of difference is, by and large, clear. To illustrate the kinds of factors that affected team members in their choices, we discuss seven broad, illustrative categories: worker safety and benefits, community health, balance between human demands and the capacity of the forest to accommodate them, ethic of sustainable land use, spiritual/sacred sites, conflicts and monitoring, and forestry personnel as links to local communities.

\section{Worker Safety and Benefits}

This issue was much more fully treated in the Brazil set than in the other two, although all three sites had forest workers. Primary reasons for this Brazilian emphasis included the history of management, the composition of the team, and possibly language.

The most obvious reason was the inclusion of forestry workers in the quite strict definition of "forest management unit" adopted by the team leadership. There was considerable pressure from team-mates for the social scientist to minimise attention to the communities adjacent to CEMEX lands. The communities in the area were adjacent to, rather than inside, the FMU (as defined by traditional forestry). Kressin, as a sociologist, probably also had more experience than the other social scientists with worker issues.

This brings up a recurrent issue that also seemed to play a role - the differential status of social as opposed to biological sciences. If great care is not taken, the social science input can be marginalised because of the necessity for social sciences to attend to "soft" and "fuzzy" matters like cultural values and other difficult-to-quantify topics. When this occurs, social phenomena with important impacts on sustainability may be neglected (such as, in this case, the potential effects of settlers on remaining forests, or conflicting claims on river people's forest lands). Interdisciplinary collaboration was probably most problematic for the Brazil team.

On the other sites, the brief time and the glaring community problems required team members to focus their attention on the apparently most disadvantaged forest actors. In Brazil, where this was discouraged by other team members, the forestry workers received needed attention that they had not received on the other sites. 


\section{Community Health}

The Côte d'Ivoire set is strikingly more detailed in this sphere than the other sites. Primary factors leading to this result include local demography, culture and the composition of the team. From the standpoint of demography and culture, the Côte d'Ivoire sites were plagued by a variety of problems with health implications, including dramatic levels of in-migration, reductions in land/person ratios, high rates of $\mathrm{HIV}+$ individuals, malaria, sleeping sickness and recurrent hunger during part of the year. The health situation appeared to be significantly worse than on the other sites.

Another factor was van Haaften's professional interest in health, both mental and physical. Her primary research interest at the time was the measurement of stress and marginalisation. Her general interest in this theme undoubtedly carried over into her examination of $\mathrm{C} \& \mathrm{I}$.

As with the previous example, the overall project benefited from this emphasis. Team members on other sites agreed that health was important, but simply did not have time, energy and expertise to pursue that focus.

Balance between Human Demands and the Capacity of the Forest to Accommodate Them Although both the Côte d'Ivoire and Brazil teams addressed this issue, they assigned it to the policy level. The Indonesia team specified social C\&I at the FMU level. Factors which led the team to identify this criterion on this level included resource ownership and access, demography, culture, and history of management. Indeed, in this case, ownership and tenure and history of management are closely connected. The disturbing process observed was one in which the indigenous people (with a low population density and a long fallow agroforestry system) had managed the surrounding forests sustainably for a very long time. The more recent claim by the national government, and management by timber concessionaires, along with the introduction of industrial tree crop estates and transmigration programmes into the area were having obviously deleterious effects on the local ecosystem and human well-being.

Although similar processes were occurring in Brazil and Côte d'Ivoire, two possible explanations for the Indonesia team's decision to address these issues at the FMU level come to mind. First, in Indonesia, expressing concern for the poor is part of the national ethic (cf. Pancasila, gotong royong, bapakism $)^{19}$. The inclusion of human well-being in forest management is more of an assumption in Indonesia than on the other sites. Another possible explanation is Laksono's recognition of the comparative lack of control of the FMU, on a day-to-day basis, by the government; and his concomitant recognition that these problems would have to be worked out on site. Conflicts and negotiations regularly occur in Indonesia between timber companies and local populations to resolve problems of resource use, "encroachment," damages, etc.

\section{Ethic of Sustainable Land Use}

This criterion emerged in the Brazil test and is, again, based on issues of resource ownership and access, ecology of the forest system, demography, and culture, and history of management. The nearabsence of an ethic of sustainability in the Brazil context was striking, as was the pace of forest destruction. We found the same tenure situation Hecht (1992:38) describes for Amazonia in general:

“...overlapping forms of land rights make competing ownership claims common, possession is nine-tenths of the law, and the law is $O$ lei do mais fort - the law of the jungle. To secure land in Amazonia is to clear it."

Although ownership and use rights were unclear and subject to conflicting claims (as in the other two test sites), there was a greater sense in Brazil that private ownership granted the owner freedom to do whatever he/she liked with the land.

Further, the government's claim to much of the land allowed it to determine policies that were followed to varying degrees, but that, in large measure, encouraged further destruction of the forests. The in-migrating settlers were from other regions, and had an agricultural rather than a forestry orientation. There seemed to be very few actors in the CEMEX setting with values that would contribute to forest sustainability 20 .

The inclusion of this concept in the $\mathrm{C} \& \mathrm{I}$ has raised interesting questions for the CIFOR team. In retrospect, on the other two sites there was variation on this dimension among forest actors. In Indonesia,

\footnotetext{
19 Pancasila is the national 'creed', and has five principles pertaining to human well-being. Gotong royong is a pan-Indonesian ideal of co-operative work for community betterment, and bapakism (though involving less benevolent components as well) refers to the generally acknowledged paternalism of government officials.

20 Colfer found some indications of a sustainability ethic in the three riverine (ribereino) communities on the Tapajos, which she visited briefly; but these were not considered part of the FMU.
} 
resettled farmers from Java show less of an ethic of forest sustainability than do the indigenous dayaks. Allochtones in Côte d'Ivoire may also have fewer such concerns than autochtones. In many places, individuals with a strong sustainability ethic have made their views known and influenced forest management from afar.

\section{Spiritual/Sacred Sites}

Ironically, the team working at CEMEX, which had no Indian communities or others with spiritual/sacred sites, had the most thorough coverage of this feature. The factors affecting this decision include resource ownership and access, demography, culture, history of management and possibly team composition. The most important reason for emphasising this criterion was probably information, provided at the workshop, that there had in fact been Indians on the CEMEX site some 15-20 years earlier, but that they had fled. The acceptance in the international and national communities of the gravity of the cultural and other problems of Brazilian Indians, its politicisation, and the presence at the workshop of an articulate Indian representative may also have contributed to the emphasis given to these sites.

The Indonesian team also included this criterion, recognising that many ethnic groups in Indonesia have cultural links to the forest which are not, but should be, recognised in forest management. Its absence in the Côte d'Ivoire set may have been related to the still widespread feeling there that indigenous cultures are inferior and the consequent muting of their expression generally, and the particular interests of the two social scientists. Spiritual significance of the forest was mentioned in one verifier there.

\section{Conflicts and Monitoring}

Kressin dealt with this issue considerably more than did the other teams, though all devoted some attention to it. Important factors in the Brazil team's emphasis included culture and the ecology of the forest system. The primary factor seemed to be the ubiquity and acceptability of conflict in the Brazilian cultural context (in marked contrast, for instance, with its unacceptability in Indonesia). Beyond that, the dramatic way in which forest degradation and destruction were occurring may have pushed the team toward emphasising the importance of monitoring and conflict resolution.

\section{Forestry Personnel as Links to Local Communities}

The role of forestry officials was only addressed in the Côte d'Ivoire set where it received considerable attention, as a means for improved communication with local communities. The primary factor seemed to be the history of management and culture. The effects of Côte d'Ivoire's colonial background were much more obvious than in the other two sites, including the muting of local cultures discussed above and a top-down approach to forest management. It was felt that an effective forest service whose personnel could communicate with local people could do much to educate local people (particularly about improved agricultural methods) and inform the forestry officials about local cultures and conditions, thus improving the chances for mutually acceptable forest management strategies to emerge. The availability of good roads in Côte d'Ivoire may have rendered this an option which did not exist in Brazil and Indonesia and was thus not considered by the teams.

\subsubsection{FIELD EXPERIENCE vs WORKSHOP EXPERIENCE}

This section is organised by test site, in the order in which they were conducted, so that the iterative nature of the processes IS clearer. In each, we highlight unique or important aspects of the field and workshop experiences.

\section{P.T. Kiani Lestari Concession in East Kalimantan, Indonesia}

- We noted the possibility that the team was overly influenced by Colfer's conceptual framework (though we also recognised that her experience in that setting may have resulted in the similar results). We stressed the tentative nature of the conceptual framework more in subsequent tests.

- The concessionaire's personnel insisted on accompanying the team wherever they went. When sensitive questions arose, this reduced people's willingness to speak frankly. This will be a recurring problem in assessing the sustainability of forests.

- The interdisciplinary co-operation that occurred on this team was outstanding. The explicit training the team received in interdisciplinarity and their willingness to change partners and try to understand other disciplines were important factors in this success.

- At the Samarinda closing workshop, we structured the working groups in an interdisciplinary way. Discussion lagged in some of the working groups; in others red herrings were raised that did not contribute significantly to the work at hand (such as whether social C\&I should be included in eco-labelling). Subsequent workshops involved self-selection in working groups for which people had training/experience. 
Foréts Classées Haut Sassandra and Bossematié, Côte d'Ivoire

- Interdisciplinary communication was a problem. Although overall intra-team communication improved over time, two members were unable to resolve their differences: one brought along a critical, academic perspective; the other worked within a bureaucracy which held his allegiance. It is hard to know how this affected the outcome in terms of selected C\&I.

- Very few NGO representatives came to the Abidjan closing workshop, but the self-selected social working group was productive and efficient. The social working group comprised a diverse mixture of interested and focused individuals. Excellent suggestions were made, though again no fundamental changes were made. This was accomplished with English and French speakers, without benefit of professional translators - quite a feat in itself.

\section{CEMEX Company, near Santarem, Brazil}

- Again interdisciplinary co-operation was problematic. Two members (burdened by the heaviest workload) spent all their time together; one person was frequently away from the team, leaving only the very junior ecologist and the social scientist to try to work together.

- The lack of agreement on what constituted the FMU - this was the first test in which the definition of the FMU was unclear - and which people were the legitimate reference for testing the social C\&I were serious problems.

- The social scientist needed an interpreter, which had not been anticipated, and his teammates were unwilling to accompany him.

- The Belém closing workshop's social working group was one of the most controversial. The self-selected working group had problems during its second session, resulting in the alienation of many group members, including the team social scientist. A third meeting was held, attended almost exclusively- by NGO representatives, with the resulting C\&I not truly reflecting the range of opinion in the original group. The discussions were useful and wide-ranging, including Indian and settler issues which had only marginally been addressed. Workshop participants wanted to address the real and vital issues that characterised many of their Brazilian forests. Yet the FMU definition had precluded this. The working group's contribution was counterproductive from the standpoint of defining a minimum set, but it raised important issues in Brazil's forests, and, as with the other workshop results, did not alter the fundamental focus of the C\&I.

\subsection{COST EFFECTIVENESS, RELIABILI- TY AND UTILITY}

Prior to the first field test of C\&I, project personnel identified 170 separate C\&I pertaining to social issues. These were not tested systematically in the first test in Germany because of the lack of access to social science expertise at that stage; but they were carefully considered in the three subsequent tests.

The C\&I that were selected by each team were also evaluated using the nine characteristics of an ideal indicator (refer to section 2.3.2.3). This formal evaluation was made on a $1-5$ scale, with 5 being the most positive. In order to provide some sense of the differing assessment patterns of the four social scientists, Table 9 summarises the average scores for each of the nine characteristics, across all selected social C\&I, for each site. In interpreting these scores, the overall mean score given by each team should be noted.

\begin{tabular}{|llccc|}
\hline Item\# & Characteristic of C/I & Indonesia & Côte d'Ivoire & Brazil \\
\hline $\mathbf{1}$ & Summary/integrative measure & 4.4 & 4.0 & 3.7 \\
$\mathbf{2}$ & Closely related to assess. goal & 4.6 & 4.0 & 3.9 \\
$\mathbf{3}$ & Response range to stress & 4.5 & 3.8 & 3.3 \\
$\mathbf{4}$ & Diagnostically specific & 4.6 & 3.6 & 2.8 \\
$\mathbf{5}$ & Appealing to users & 4.1 & 4.1 & 2.2 \\
$\mathbf{6}$ & Easy to detect, record, interpret & 3.7 & 3.9 & 3.3 \\
$\mathbf{7}$ & Precisely defined & 3.6 & 3.4 & 3.6 \\
$\mathbf{8}$ & Produces replicable results & 3.4 & 3.6 & 3.0 \\
$\mathbf{9}$ & Relevant & 4.8 & 4.1 & 3.8 \\
& & & & $\mathbf{3 . 1}$ \\
\hline
\end{tabular}

Table 9. Comparison of Average Evaluation Scores (Social - Indonesia, Côte d'Ivoire and Brazil) 
Turning first to the Indonesian results, $28 \mathrm{C} \& \mathrm{I}$ were selected and evaluated. The average score given by Laksono was 4.2, ranging from 3.7 to 5 . Of the 34 selected C\&I, the mean evaluation across all nine ideal characteristics only fell below 4 for seven C\&I (20 percent). The characteristics on which social C\&I fairly consistently received low marks (an average $<4$, across the $\mathrm{C} \& \mathrm{I}$ ) were:

- "easy to detect" (average of 3.7),

. "precisely defined"(3.6), and

. "produces replicable results" (3.4), above.

Those with "high marks" (>4.5) included

- "closely and unambiguously related to assessment goal" (average 4.6),

- "diagnostically specific" (4.6), and

- "relevant"(4.8).

Our Côte d'Ivoire test represents the only team on which there were two social scientists (van Haaften and Anvo). Between them, they selected and evaluated $22 \mathrm{C} \& \mathrm{I}$. The overall average score (including all selected C\&I and all nine characteristics) was 3.8, ranging from 2.4 to 5. Anvo and van Haaften found social C\&I to be less than ideal $(<=3.6)$ for the following characteristics:

. "diagnostically specific" (3.6),

- "precisely defined" (3.4), and

- "produces replicable results" (3.6).

On the other hand, they gave high marks $(>=4)$ to the social C\&I, with regard to these characteristics:

"summary/integrative measure" (4),

"closely/unambiguously related to assessment goal" (4),

"appealing to user" (4.1), and

"relevant" (4.1).

In this data set, we also examined the team's views with regard to categories of C\&I. From the standpoint of the above nine positive characteristics of C\&I, they viewed the four pertaining to monitoring and control as the most problematic (with an average overall score of 3.4 ), with the ten C\&I focusing on tenure issues only slightly better (3.6).

The "best" of their selected and evaluated C\&I, from this standpoint, were the ten on benefits that people might obtain from commercial forest use (with an overall average score of 4.0), the human/ecological balance and human health that obtained (14 C\&I, with an average score of 4.0), and issues of people's participation $(15 \mathrm{C} \& \mathrm{I}$, with a 3.9 average).

In Brazil, $37 \mathrm{C} \& \mathrm{I}$ were selected in the final set. Kressin's overall average score was 3.1, consider- ably lower than that of Laksono. Also in sharp contrast to Laksono, none of Kressin's criteria averaged as high as 4. His average scores ranged from 2.2 to 3.9. In Kressin's estimation, most social C\&I scored low $(=<3)$ on the following characteristics:

- "appealing to users" (2.2),

- "diagnostically specific" (2.8), and

- "produces replicable results" (3.0).

The characteristics on which social C\&I consistently received the highest average scores (>3.5) were:

- "summary/integrative measure" (average of 3.7),

"closely and unambiguously related to assessment goal" (3.9),

- "precisely defined" (3.6), and "relevant" (3.8).

In the case of Brazil, we have also been able to make assessments by criterion. By averaging the nine scores (characteristics) for all C\&I in that category, we obtained a rough idea of the consultant's perception of the difficulty of assessing that condition vis-a-vis the other important conditions in the field. Those criteria for which the C\&I were deemed most difficult included "interaction and co-ordination" (Criterion 3, with an average score of 2.7) and "cultural inheritance" (Criterion 5, average 2.6). "Land tenure", "labour relations" and "concern for sustainability" were deemed to be equally good indicators (average score, 3.3). Social and economic contribution represented an intermediate condition to assess (3.1).

These evaluations reflect the reality that developing straightforward, cost-effective, replicable indicators pertaining to people's roles in forest management must be a research priority. As we think about future steps, numerous needs present themselves. The unanimity with which the teams addressed issues of intergenerational access to resources and participation of forest actors has convinced us that these are important issues in sustainable forest management. The teams' dissatisfaction with the C\&I's reliability and other ideal characteristics of C\&I, combined with the general inability to settle on the appropriate level (principle, criterion, indicator or verifier) for any given issue also point to the need to clarify these matters further.

Issues pertaining to the identification of significant stakeholders and the definition of an FMU as it relates to local communities/workers prompt us to continue our investigations into these topics. We plan to extend these investigations in field-based, interdisciplinary and international teams, co-ordinated from CIFOR, but implemented largely by collaborators in host countries in Africa, South 
America and Asia. Our goal will be to specify more clearly the causal links between people's behaviour, knowledge and beliefs on the one hand, and sustainable forest management on the other. These plans are outlined in more detail in Section 4 (Future Steps).

From the standpoint of assessment teams, we recommend using the commonly agreed upon, or close approximation of, C\&I supplemented by a site specific set to be determined locally by the team in co-operation with timber managers, community members and local officials. It is our view, at this point, that this is the only way to adequately address the tremendous variation that exists in forest management.

\subsubsection{RESULTS FROM THE TEST IN AUSTRIA}

Apart from the implied principles in the list of commonalities above one criterion and one indicator have no match in the Austrian test results (Annex 6). These two are the indicator "Forest dependent people and company officials understand each others" plans and interests' and the criterion "Forest dependent people/stakeholders have the right to help monitor forest utilisation".

Given that the tendency is for social C\&I to be more site-specific, this result may come as a surprise. We suggest two explanations. Firstly, the list of common C\&I for the tropical tests is fairly short, so that it probably reflects something of a "core set". Secondly the Austrian team included one expert on social aspects, Ms. Grünberg, who was given the responsibility to develop C\&I especially for "indigenous people" in tropical conditions. This is a very significant departure from our test methods as she operated outside the frame-of-reference provided by a specific FMU. As such the C\&I related to issues that do not apply to Austrian conditions cannot be considered to have been tested in the sense we are using the term, and are strictly speaking not comparable. This is a severe limitation to our analysis of the social C\&I in the Austrian set.

However the social C\&I in the Austrian set also include C\&I which would seem to apply under Austrian conditions as well, such as working conditions, safety provisions and health insurance (Annex 8 section 6.4.2.1).

Through centuries of forestry practice in Austria the questions of ownership and land use rights have been settled. This is also reflected in a detailed and well implemented legal and institutional frame work that regulates the interests of the parties concerned. As a result the C\&I pertaining to social aspects can be limited in number.

\subsection{CRITERIA AND INDICATORS RELATED TO THE SUSTAINABLE PRO- DUCTION OF GOODS AND SERVICES FROM THE FOREST}

\subsubsection{MAJOR CONCLUSIONS}

Eighteen common principles, criteria and indicators were selected among the three tropical field teams. These were:

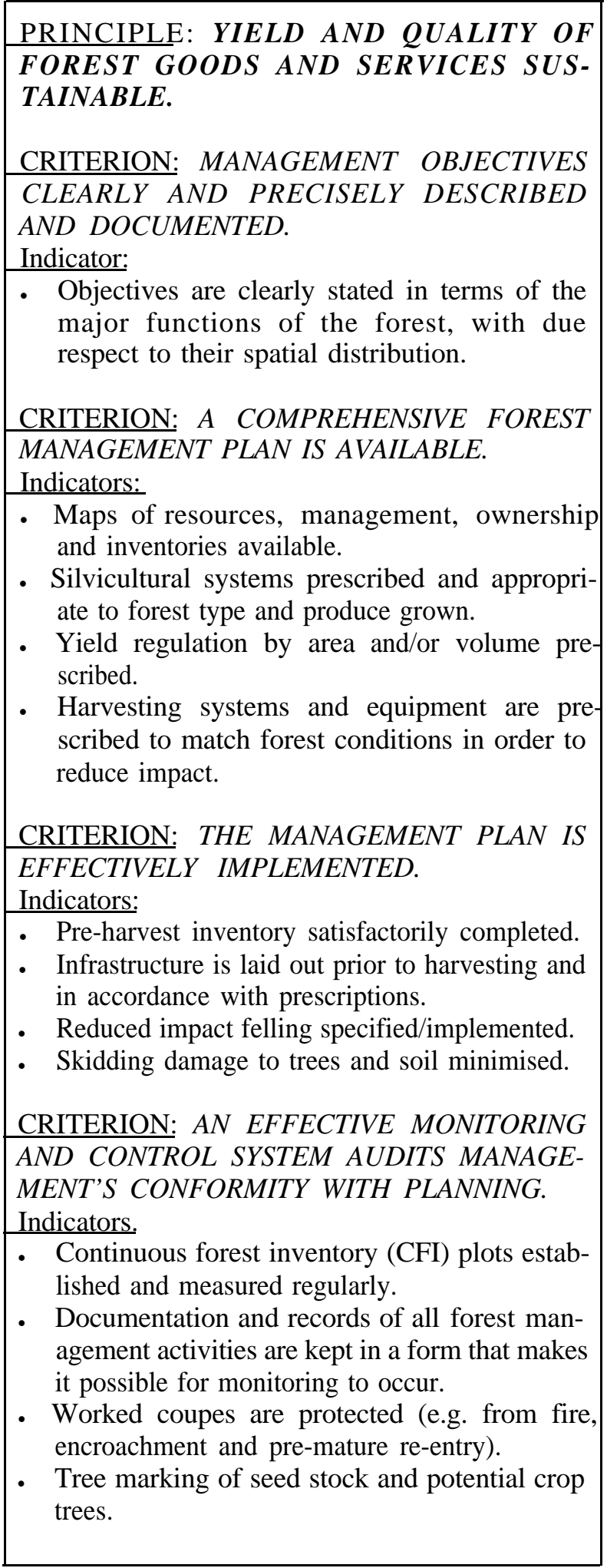


The management sets contained 11 areas in which differences were noted. One important difference was in the degree of detail contained in the sets and the relative importance accorded to C\&I. We found that where the history of management was relatively short, the tendency of the experts was to provide more details, thus giving the C\&I a more prescriptive character.

The foresters were in agreement about the value of their proposals, and were generally more satisfied with them than others, according them an average score of 4.3 from a best score of 5 . Despite this we feel that there is still room to reduce the numbers of C\&I and optimise this set in other ways as well. The management set is, however, the best developed of all the sets and provides a good template for further development.

\subsubsection{COMMONALITIES}

This topic produced the largest set of C\&I in the initial sets, as well as the largest final set in each field test. The degree of commonality ranged between about 51 percent in Côte d'Ivoire to 64 percent in Indonesia (Figure 11). We included verifiers in this analysis only where they were cross tabulated with principles, criteria or indicators (Annex 6). As with the social sets, we found considerable differences in the hierarchical classification of an issue. A criterion in one set might be an indicator or verifier in another. Considering the large number of C\&I dealing with "production" issues in the base sets and the flood of information the experts were confronted with, the time provided for the evaluation process was most critical for this area. As a result the structures had not fully matured during the month in the field.

The broad intellectual approach used by the teams was fairly similar, and is illustrated (Figure 12). The C\&I in this set are based on the assumption that a polycyclic selective logging system is best suited to producing timber and other forest products sustainably. There is a common understanding that assessment of the sustainability of the forest management system only makes sense if the security of the FMU is assured. This is the basic condition stipulated in each of the test proposals, albeit often in different sections. The remaining C\&I are organised then to assess whether a commitment to sustainability (as revealed in the objectives) is evident, and whether the three major stages in the process of management, planning, implementation and control are effective in interpreting these objectives (Figure 12).
Forest management, with 18 common principles, criteria and indicators (plus six others if crosstopic commonalities are included), surpasses the other three categories, by a considerable margin ${ }^{21}$ We include principles, criteria and indicators related to security of the FMU under the Section 3.3.

\section{PRINCIPLE: YIELD AND QUALITY OF FOR-} EST GOODS AND SERVICES SUSTAINABLE. Although this was treated as a single principle in Indonesia and Brazil and three principles in Côte d'Ivoire, we find a common understanding among the three sets.

\section{CRITERION: MANAGEMENT OBJECTIVES CLEARLY AND PRECISELY DESCRIBED AND DOCUMENTED.}

An indicator in Indonesia and Côte d'Ivoire, this was a verifier in Brazil that followed the criterion: "Forest management is clearly committed to sustainability". Although no such link was made in the Indonesia and Côte d'Ivoire sets, we believe it was implied. In our context therefore, the objectives must reveal a clear commitment to sustainable forest management.

Indicator: Objectives are clearly stated in terms of the major functions of the forest, with due respect to their spatial distribution.

This is a paraphrasing of a similar indicator in the Côte d'Ivoire set. The Indonesia and Brazil sets also include this issue, but as verifiers. Though this is written as a prescriptive indicator, it does reveal whether adequate thought has been given to the fact that, especially for large scale FMUs, the objectives will usually need function and site specific interpretation.

\section{CRITERION: A COMPREHENSIVE FOREST MANAGEMENT PLAN IS AVAILABLE.}

There was agreement that this was a key issue for assessment. The wording is from the Indonesia set. The Côte d'Ivoire criterion stipulates that the management plan should cover a period of 10-20 years. Although only the relevant indicator in the Brazil set explicitly demands that this should be a written document, there was a similar implicit understanding in the other two sets as well. In all three sets this was a criterion preceding indicators dealing with objectives.

Verifier: Maps of resources, management, ownership and inventories available.

This is a demand in all three sets. However only in the Côte d'Ivoire set is this treated as an indicator. On examining its content we recommend that this

21 Cross-topic commonalities are those which are specific in, for instance, the forest management section in Côte d'Ivoire, but the ecology section in Brazil. 


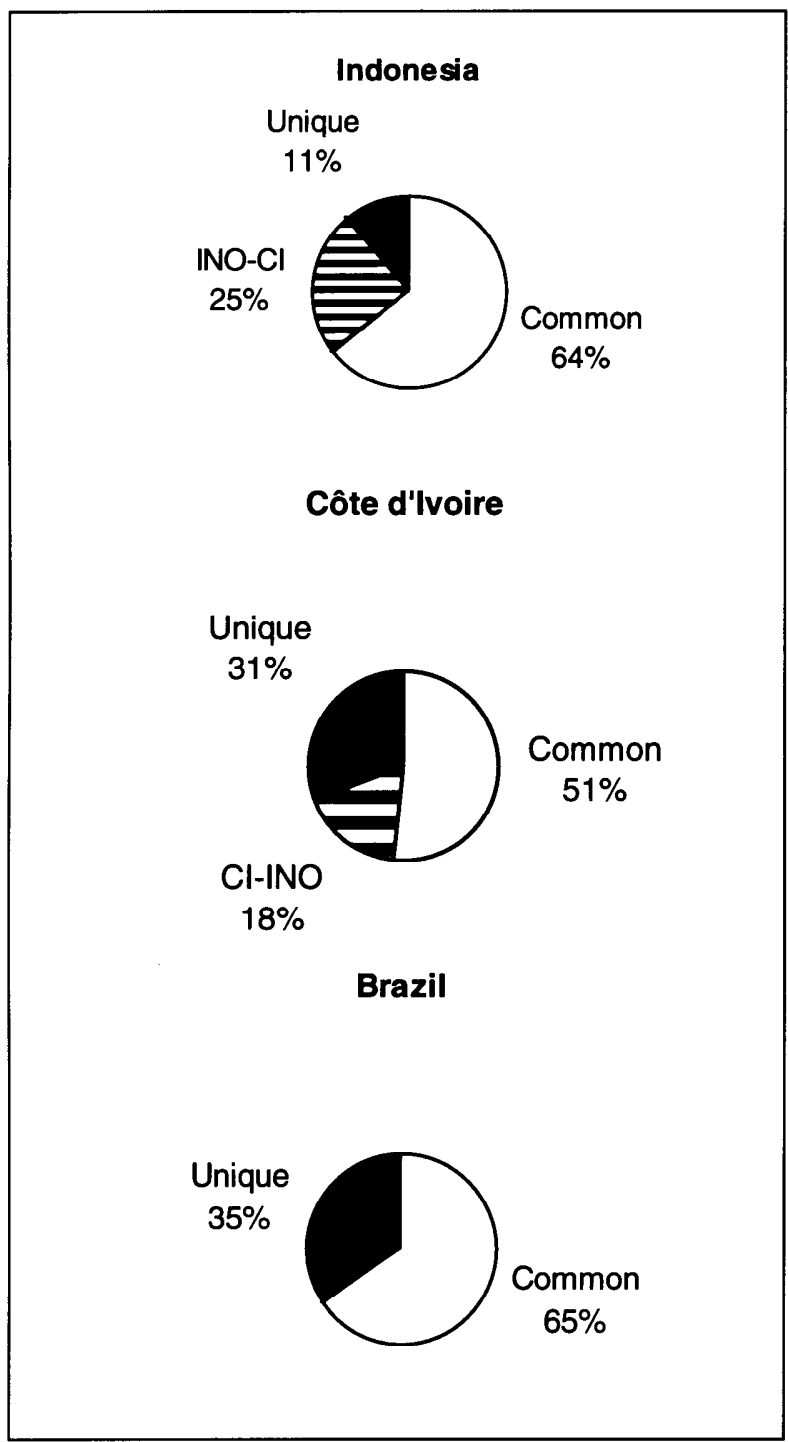

Figure 11: Management Indicators - commonalities and differences. Common: occurs in all three proposals. Unique: only to be found in one set. CI: Côte d'Ivoire, INO: Indonesia, BRA: Brazil.

Figure 12: Underlying structure and assumptions of C\&I related to sustainable production of goods and services from the forest

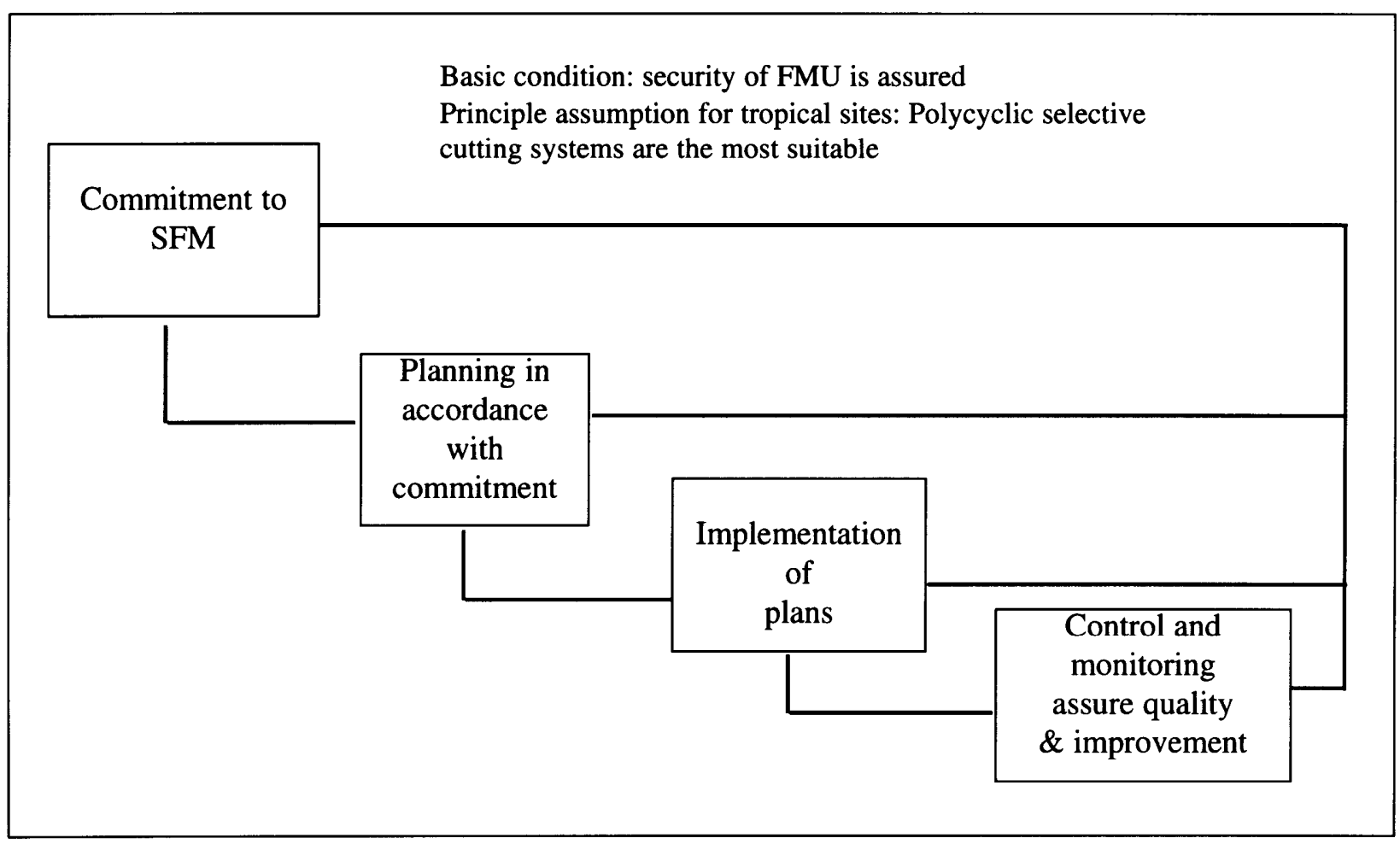


be treated as a verifier, as the documents concerned are all essentially means of verification.

Indicator: Silvicultural systems prescribed and appropriate to forest type and produce grown. This is an interesting example of the different perceptions of the importance of an issue. This was two criteria in Côte d'Ivoire, one indicator in Indonesia, and one verifier in Brazil. In C\&e d'Ivoire the perception was that silvicultural systems had not yet been adequately spelt out for forest managers, and that this was a pressing need if the heavily logged forests were to recover within a shorter period of time. In the Brazil set the issue was treated as a verifier because of the insertion of the criterion on "commitment to sustainability", consequently the management plan was "demoted" to the level of an indicator, and silvicultural systems as a component of the planning process to a verifier. We believe it is significant that the Brazil team should have been so concerned about a commitment to sustainability as to mention it explicitly as a criterion.

\section{Indicator: Yield regulation by area and/or volume} prescribed.

This issue was treated in two indicators in Indonesia, one in C\&e d'Ivoire, and three verifiers in Brazil. All teams wished to see a clear expression of how yields would be regulated. Burgess made a strong case for having a yield regulation system which is amenable to external control. Mengin-Lecreulx provided a detailed prescription on the conditions applicable to the calculation of the allowable cut. All these indicate the importance ascribed to this issue by the three test teams.

Indicator: Harvesting systems and equipment are prescribed to match forest conditions in order to reduce impact.

The Côte d'Ivoire team considered this matter in two criteria and one indicator, Indonesia had one indicator, and Brazil had two verifiers. Zweede 22 provided a number of examples to illustrate how he interpreted this, which we believe is an appropriate reaction to the relatively young history of natural forest management in the Amazon. This stresses the point that principles, criteria, indicators and verifiers must be adapted to the needs and culture of the context in which they will be used. At the same time it is important that, as far as possible, they provide a level playing field for regional or international comparisons.
CRITERION: THE MANAGEMENT PLAN IS EFFECTIVELY IMPLEMENTED.

In Indonesia, this relevant criterion included control as well. In the Brazil set this is a criterion and two indicators and refers to a written annual operating plan, which is the annual operational interpretation of the forest management plan. In the Indonesia and Brazil sets this criterion marked the beginning of the assessment of the implementation phase of forest management procedures. This was addressed by one criterion and two indicators in the C\&e d'Ivoire set.

\section{Indicator: Pre-harvest inventory satisfactorily completed.}

This is an indicator in Côte d'Ivoire, and a verifier in Indonesia and Brazil. It is a prescription based on the assumption that if the information on timber stocks is available and accurate, a wise utilisation of the resource is more likely. An interesting parallel can be found in the policy set where the need for up to date and relevant information is explicitly demanded.

Indicator: Infrastructure is laid out prior to harvesting and in accordance with prescriptions.

This was covered in two indicators in Indonesia, one criterion and three indicators in Côte d'Ivoire and three verifiers in Brazil. These were supplemented with other road building issues in Indonesia by two additional indicators; and in Côte d'Ivoire by one more indicator. Infrastructure should be taken to mean roads, bridges, firebreaks and skid trails. In Côte d'Ivoire the two criteria stipulate that negative impact on the environment should be reduced to a minimum, and that the infrastructure should be permanent. This is echoed in the Brazil set, in which the following performance thresholds are also defined:

- primary roads, secondary roads and log decks should not cover more than 2.5 percent of the productive forest area, and

- road construction should take place a minimum of twelve months prior to use.

In the case of the second point, it is not clear whether all roads are meant or only primary roads. The relevant verifiers in the Indonesia set contain the following additional performance thresholds:

- "daylighting" width not more than $15 \mathrm{~m}$ for roads running in the North-South direction; no "daylighting" for roads running East-West,

- maximum width of main roads $10 \mathrm{~m}$, branch roads $8 \mathrm{~m}$ and skid trails $4.5 \mathrm{~m}$, 
- maximum allowable road grades: main roads 10 percent, branch roads 15 percent, skid trails 30 percent.

Although issues related to harvesting maps and tree marking appear a number of times in all three sets, they are not dealt with here as they were almost always verifiers.

Indicator: Reduced-impact felling specifed and implemented.

Although there was no consensus among the sets on the hierarchical level at which this issue should be addressed, all three sets are in agreement that "operational low-impact felling techniques" (Côte d'Ivoire) should be evident.

Indicator: Skidding damage to trees and soil minimised.

Treated as one indicator in Côte d'Ivoire, this was an indicator in Indonesia and four prescriptive verifiers in Brazil. This addresses an extremely important cause of damage to the residual stand. Again the fact that the Brazil set lays out specific prescriptions is probably indicative of a lower level of awareness on proper skidding techniques in the Amazon area, a situation Zweede and Silva sought to redress by being very specific.

Issues related to replanting of areas have been dealt with in Section 3.4 and will not be repeated here.

CRITERION: AN EFFECTIVE MONITORING AND CONTROL SYSTEM AUDITS MANAGEMENT'S CONFORMITY WITH PLANNING

With this criterion, assessment of the control function of management was opened in the three sets. In all three sets there was agreement on the need for effective control systems, although wording and importance accorded to the issue varied.

Indicator: Continuous forest inventory (CFI) plots established and measured regularly

This was treated by one indicator each in the Indonesian, Côte d'Ivoire and Brazilian sets. There is a strong parallel to the indicator in the policy set which documents the need for up to date and relevant information.

Indicator: Documentation and records of all forest management activities are kept in a form that makes it possible for monitoring to occur.

Another relatively rare example of consensus among the three teams, this was an indicator on all three sites. Each site addressed this issue with additional indicators and verifiers. With this indicator, assessment of the control function of management was opened in the three sets.
Indicator: Worked coupes are protected (e.g., from fire, encroachment and pre-mature re-entry).

A criterion in Côte d'Ivoire, this was an indicator in Indonesia and two verifiers in Brazil. This gradient in the hierarchy reflects closely the reality that confronted the teams at the three sites. This demonstrates once more that there may be utility in deliberately elevating an issue to a higher level in order to address its importance within a given context more appropriately. It brings home the point that although it was important for the teams to follow the definitions of principles, criteria, indicators and verifiers in the conceptual framework (Section 2.2.2), it was equally important to remind team members that these were tools and not ends in themselves. For future development of $\mathrm{C} \& \mathrm{I}$ we recommend that the experts concerned should be allowed a certain amount of "creative licence" with the conceptual framework, if their expertise is to be fully used. This was the case during the Phase I field tests.

Indicator: Tree marking of seed stock and potential crop trees.

As part of management controls, all teams felt the need to prescribe the marking of trees to be retained either as seed stock or as potential crop trees. This was to reduce the risk of damage to those trees which would be the source of future harvests.

The other forest management C\&I, which were covered by all three sites, by means of cross-topic references included:

1. the dedication of the land to natural forest management (under Policy in Indonesia),

2. protection of the area against erosion and hydrological problems (under Ecology in Indonesia),

3. appropriate water diversions exist to direct runoff into the forest (under Ecology in Indonesia),

4. residual stands satisfactory (under Ecology in Côte d' Ivoire'

5. adequate number and quality of forest staff (under Policy in Indonesia),

6. adequate training and incentives for forest staff (under Policy in Indonesia).

Although there was obviously considerable agreement among the teams on the important issues in sustainable forest management from a forestry perspective, the lack of congruity of levels at which these issues were addressed among the sites was something of a surprise to us. Prior to the field tests we had expected the greatest agreement among experts and the greatest clarity in problem 
definition on the C\&I in this realm, feeling that this was the most well defined of the topics investigated. Both these expectations have been met, but in a manner that we had not expected. Although the base sets were the same and the conceptual forest management system ${ }^{23}$ which formed the frameof-reference used by the forestry experts was very similar, the hierarchical level of importance accorded to them also varied, because common problems often varied in their degree of severity. Additionally foresters' assignments of similar issues to different hierarchical levels may derive from inter-team differences in interpretation of the hierarchical levels.

The continued existence of a large number of forest management C\&I confirms our sense that further refinement is needed.

\subsubsection{DIFFERENCES}

As with the other topics investigated, we look at the clusters of C\&I that are not common in all three sites, in this section. These differences are then interpreted in light of the factors discussed in Section 3.2. When we look at the percentages of C\&I which were common to two of the three sets and those which were unique (see Figure 11) we find the following: in the Indonesia set, 25 percent were common with Côte d'Ivoire (but not Brazil), and 11 percent were unique. In Côte d'Ivoire, 18 percent were similar with Indonesia, and 31 percent were unique. For Brazil, there were no commonalities with Indonesia and Côte d'Ivoire and 35 percent were unique.

\section{Land Tenure}

In Brazil, land tenure was dealt with explicitly under "production of goods and services", as well as in the policy and social sections, primarily because of its perceived importance in sustainable forest management and the confusion that surrounds it, both at the policy level and on the ground. The same issues were dealt with in Indonesia and in Côte d'Ivoire in the policy and social sections.

\section{Contents of the Management Plan}

In Côte d'Ivoire the specifics of the management plan were'spelled out in more detail than in the other two sites. This was probably influenced by the history of management in that country. The Brazil set had a similar degree of detail, and it is an artefact of our present level of analysis that this fact does not appear here, because most of the issues for assessment had been assigned to the level of verifiers in that set. The history of sustainable management of the dry-land forests of the Amazon is at least as short and uncertain as in Côte d'Ivoire. In Indonesia, on the -other hand, many of the details that needed specification elsewhere are part of the TPTI system, with which forest managers must comply.

\section{Research and its Use}

As with the management plan, the Côte d'Ivoire team spelled out research requirements and indicators relating to the use of research results in considerable detail, perhaps because there was a perception amongst team members that this was a weak point in the system. The Indonesian and Brazil teams might have found more reassurance in the several interactions they had with researchers.

\section{Third Party Contractors}

Although third party contractors were present on all sites, only in Brazil was their behaviour singled out in an indicator. This is probably because of the comparatively free hand that timber companies have had and the resultant absence of other institutions which might control such third party contractors.

\section{Use of FAO and Other Guidelines}

Both Indonesia and Côte d'Ivoire selected indicators regarding the use of such guidelines in forest management, because they felt reference to them in management documents revealed an interest in keeping up with the "state of the art". They also used this as a precautionary measure, which ensured that nothing of importance had been missed out. Finally and perhaps most importantly, they felt this was a quick and efficient method of assessing the amount of knowledge and awareness managers at least theoretically had about reducing the impacts of forestry operations. The prevailing political mood of "self-reliance" in Brazil may have contributed to this issue being ignored in the set.

\section{Forest Coupes and their Demarcation}

In both Indonesia (one indicator and four verifiers) and Côte d'Ivoire (one criterion, three indicators), the issue of forest boundaries was emphasised. Interestingly the Brazil team did not feel the need to include this issue in their set. This was possibly due to the very few infringements of the FMU's boundary. Indeed, the FMU operations extended outside their boundary. In Indonesia and Côte d'Ivoire, on the other hand, this was an extremely important

23 In the present context this is taken to mean the objectives, inputs, processes and outcomes necessary to produce timber and other forest products. 
issue. We believe that this will prove to be a common issue, in all forest areas where the pressure of population is high and the history of management is long.

\section{Harvesting Limits}

The Indonesia team specified one indicator and one verifier pertaining to harvesting limits. The Côte d'Ivoire team specified two indicators with four indicators related to harvesting limits. At first glance it is a little puzzling that the Brazil team did not suggest harvesting limits for commercial tree species, although Silva is an acknowledged expert on the topic of growth and yield in Brazil. It was, however, possibly because of his awareness of the state of knowledge harvesting limits for tree species in the Amazon that he was hesitant to suggest untenable standards, and perhaps so compromise ongoing research. Both the length of the history of management and the lack of knowledge of the ecology of the systems seem to have been major factors in the selection of these C\&I.

\section{Reduced-impact harvesting measures}

For example, "Pre-harvest vine cutting" and "Skidding regulations" were specified with different degrees of detail in the three sets. In the Indonesian set this was because several of these measures are stipulated anyway in the mandatory TPTI guidelines. In the case of Brazil the degree of detail reflects to an extent Zweede's expertise in this field. Mengin-Lecreulx and Kanga N'Guessan in Côte d'Ivoire were reacting largely to the weakness of existing guidelines.

\section{Continuity of Resource Flow}

This criterion in Indonesia subsumed six indicators and four verifiers. Comparable issues were mentioned in Côte d'Ivoire, as one criterion, three indicators and one verifier.

\section{Penalties}

Only in Côte d'Ivoire were penalties specified for non-compliance, specifically with regulations on NTFP harvesting. It seems probable that the conflicting views of ownership and access, the decline in environmental quality, the rapid growth of population, and the prior absence of governmental management, together prompted the team to specify the existence of penalties as a criterion for sustainable forest management. This also reflected a confidence in the management approach of SODEFOR, which was much less laissez-faire than managers in the past.

\section{Maintenance of Forest Area and Plantations}

Although the Indonesia team recognised the importance of maintaining the forest area (with two indicators), there was a much more thorough attention to this in Côte d'Ivoire with one criterion, three indicators, and three verifiers. In Côte d'Ivoire, a considerable component of this attention deals with plantations (something the project generally eschewed). The absence of prior governmental management combined with the obvious environmental degradation rendered such C\&I necessary in the team's view. In Indonesia, while there was concern about "encroachment", the degradation has not proceeded so far and the demographic pressure is less. In Brazil there was no general interest in maintaining the forest area. Rather the interest was in slowing the deforestation process and more rationally controlling it.

\section{Staff Monitoring and Farmer Impacts}

Although all teams dealt with staff monitoring and farmers in one way or another, Côte d'Ivoire's forest management set dealt with these issues in greatest detail. Of the three tropical sites, governmental management was most evident in Côte d'Ivoire and least evident in Brazil. If private owners (Brazil) and concessionaires (Indonesia) are included, then our perception would be that management intensity in terms of field presence of trained professionals would be similar in Indonesia and Côte d'Ivoire but still very much less in Brazil.

\subsubsection{FIELD EXPERIENCE vS WORKSHOP EXPERIENCE}

The foresters in general had the least discontinuity between the fieldwork and workshop experience. They seemed to realise more quickly that they were in general agreement, and proceed to discuss lower level issues like tolerance levels and verification procedures. This agreement is reflected in the large number of common C\&I selected by all three tropical teams. In Brazil an interesting discussion on what was "long term" management occurred. Views diverged between one or more rotations (usually espoused by the scientists in the group) to 10-20 years (championed by representatives of the industry). In Côte d'Ivoire there was a similar discussion on the need to mark and plot trees for harvesting and retention. Neither discussion was resolved to the satisfaction of all present; however in both cases, workshop participants agreed to err on the side of caution. The reports of the tests in Indonesia (Burgess et al. 1995), Côte d'Ivoire (Mengin-Lecreulx et al. 1995) and Brazil (Zweede et al. 1996) contain a more detailed report on the workshop.

\subsubsection{COST EFFECTIVENESS, RELIABILI- TY AND UTILITY}

We had assumed that the foresters would find more cost effective, reliable and useful C\&I than team members from other disciplines because of their greater experience in managing forests. 
Interestingly, the scores they give are slightly higher than the ecology and social ones, but not dramatically so; the experts identify some of the same problems with C\&I as were encountered by the social and ecological scientists.

One interesting and unique feature was that the average score on forest management issues, by all teams, was 4.3 (Table 10). There was then greatest agreement about the quality of the C\&I, on average, among the foresters.

In Indonesia, on the 28 selected and evaluated C\&I, the overall average was 4.3 , with a range from 3.9 to 4.6. Those attributes which scored low $(<4)$ included:

- "response range to stress" (3.9),

"easy to detect, record, and interpret" (3.9),

- "produces replicable results" (3.9).

High scoring attributes (>4.5) included:

- "appealing to users" (4.6), and

- "relevant" (4.6).

In Côte d' Ivoire, the team also gave an average score of 4.3 to all 78 of their C\&I, with a range from 3.7 to 4.8 . The low scoring attributes $(<4)$ for the forest management C\&I were:

- "response range to stress" (3.7), and

- "easy to detect, record, and interpret" (3.9).

The high scorers $(>4.5)$ included:

- "closely related to assessment goal" (4.8),

- "precisely defined" (4.7).

In Brazil, the average score was also 4.3, with a range from 3.5 to 5 , for the $20 \mathrm{C} \& \mathrm{I}$ selected and evaluated. Those attributes ranking < 4 included:
- “summary/integrative measures" (3.8),

"response range to stress" (3.5), and

"produces replicable results" (3.7).

Those ranking high (>4.6) were:

"closely related to the assessment goal" (4.9),

- "precisely defined (4.7), and

"relevant" (5).

In conclusion, we note that there is potentially a high degree of commonality among the sets. We also found that in all three sets both issues of performance and of process have been addressed. In some cases process was addressed obliquely through performance related indicators. All three sets contained a high degree of prescriptive C\&I, although the Indonesian set contained fewer of these than the others. This, we feel, is largely due to the fact that most of these prescriptions are already contained in the existing guidelines, especially TPTI. This was not the case in the other two sites. This persuaded the experts in Côte d'Ivoire and Brazil to include such prescriptions in their sets, along with more descriptive indicators. As forest management is in different stages of development, we recommend that flexibility in the interpretation of principles, criteria, indicators and verifiers be maintained, to accommodate shifts in emphasis.

We find that there is still considerable scope to reduce the number of $\mathrm{C} \& \mathrm{I}$ in the management set, and concur with Mengin-Lecreulx et al. (1995) that these still do not represent the "optimal" set. The management set is however the best developed of all the sets and provides a good template for further development. Of the four sets, we are most confident of the management set's utility in assessing the sustainability of management.

\begin{tabular}{|llccc|}
\hline Item\# & Characteristic of C/I & Indonesia & Côte d'Ivoire & Brazil \\
\hline 1 & Summary/integrative measure & 4.2 & 4.1 & 3.8 \\
2 & Closely related to assess. goal & 4.4 & 4.8 & 4.9 \\
3 & Response range to stress & 3.9 & 3.7 & 3.5 \\
4 & Diagnostically specific & 4.4 & 4.4 & 4.6 \\
5 & Appealing to users & 4.6 & 4.4 & 4.2 \\
6 & Easy to detect, record, interpret & 3.9 & 3.9 & 4.5 \\
7 & Precisely defined & 4.5 & 4.7 & 3.7 \\
8 & Produces repicable results & 3.9 & 4.2 & 5.7 \\
9 & Relevant & 4.6 & 4.4 & 4.3 \\
& & & 4.3 & \\
\hline
\end{tabular}

Table 10. Comparison of Average Evaluation Scores ('Production' - Indonesia, Côte d'Ivoire, and Brazil) 


\subsubsection{RESULTS FROM THE TEST IN AUSTRIA}

Of the 18 commonalities among the tropical tests only two were analysed as lacking any degree of overlap with C\&I from the Austrian set. These are the criterion "Management plan is effectively implemented" and the indicator "Tree marking of seed stock and potential crop trees". The issue of management plans is not directly addressed at all in the Austrian set, the closest are:

"25/14: In order to guarantee the sustainability of forest management systems over the long term, an appropriate management concept adapted to the size of the enterprise has to be provided. In this connection, management measures traditionally carried out in coppices, which are often not recorded in writing, are being taken into consideration.

26/14 a): The legal rules and regulations on which the management concept is based have to be cited."

And in the section on socio-economic C\&I:

"241/ 2/F: All agreements and especially those with regard to land titles and rights of use as well as conservation regulations are clearly laid down in the respective forest management plans and they are recognized."

This is probably because the Austrian test took place at different sites with different, sizes of holdings or units. For small holders no management plans have to be drawn up, however all larger management units must draw up management plans.

The need to retain seed trees is explicitly recognized in the Austrian set (Annex 8, section 6.3.2.4.3), the issue of whether they should be marked for retention is therefore of lesser consequence. This prescription may not be necessary under Austrian conditions. However, no mention of the need to mark potential crop trees is made, although or perhaps because this is standard practice.

In the case of some of the commonalities the Austrian equivalent have to be interpreted in the context of management in that country. For instance the various types of inventory such as pre-harvest and CFI are summed up by a single indicator in the Austrian case. Another example is the issue of minimisation of damage to soil and vegetation which is addressed by $190 / 5 / C$ and 190a/5/C in the Austrian set (Annex 8).

\subsection{USING THE CRITERIA AND INDICATORS}

Throughout this document, we have tried to show, by explanation and example, how our teams used the C\&I. In this section, we would like to address some important lessons that we learned in the process and provide a summary of the practical implications that emerge from our research.

We believe that the method we developed has wide applicability. We have shown that interdisciplinary teams of experts can use, develop, and evaluate C\&I in field settings, and select and defend those most appropriate for that setting, to the satisfaction of a wider audience. We are optimistic about the prospects of assessing sustainable forest management, with continuing methodological improvements building on this project experience.

There is utility in starting from other existing sets of C\&I, as the analysis of references in Section 2.6 showed. However, we would not recommend using a large number of C\&I to start from, as the benefits of starting from a very large set would be marginal and disproportionately expensive. Future teams can and should take the common C\&I the teams have identified as a starting point for their own work - with one caveat or warning. The common C\&I that we have identified across the three to five tests should not be taken as a monolithic, eternal set, already proven to be suitable everywhere. Nonetheless the degree of commonality among the sets encourages us in the belief this is an efficient way to begin development of regionally relevant sets of $C \& I$.

This warning derives from a fundamental feature which we have discovered about our conceptual framework - a framework we share with many actors in this field - which specifies the hierarchical levels of principle, criterion, indicator, verifier. We found that although all team members were able to put the C\&I into a hierarchical framework, the levels of any individual item could vary from criterion to verifier, from one site to another. As we examined these examples, we realised that the experts, when they looked at the field realities, identified a) important areas of concern, and b) important gaps in the chain or mesh that constitutes sustainable forest management (including at least some notion of "best practice" and "human well being"). Those areas/gaps, identified locally, were then likely to be granted a higher place in the hierarchy than were areas which were progressing smoothly in that same location. 
In trying to interpret this variation, we tried to understand how site conditions affected interpretation of the hierarchy. The sets of C\&I can be thought of as a cloth, thrown over varying real world landscapes. The presence of hills and valleys produced lumps in the cloth (hierarchies of C\&I). Where the landscape was flat, C\&I tended not to be selected or were granted minimal importance. When the cloth was taken to another place, it covered different hills and vales, and produced hierarchies of different depths in different parts of the landscape. The cloth was stretched in different places and to different degrees.

We realise that more work needs to take place in achieving consistency in the use of our hierarchy of principles, criteria, indicators and verifiers. In this context we suggest that a basic entity model of information and information processing described by Liang (1994) could be a potentially useful aid. He identifies four basic entities in ascending order of hierarchy: data, information, knowledge and wisdom ${ }^{24}$. If we attempt to fit the elements of the conceptual framework into the categories of the basic entity model, we will find that principles and criteria reflect wisdom and knowledge, whereas indicators and particularly verifiers can be classified as information or data following Liang's hierarchy. Although this offers an interesting new insight into the elements of the conceptual framework, we are aware there is a danger in stretching the comparison. However we intend testing the use of these concepts as tools to achieve more consistency. This excursion into the basic entity model also serves to underscore that the basic currency of sustainability assessment is information. We are also analysing the "nine attributes" (section 2.3.2.3) to see whether they reveal useful patterns of scoring which could help us further identify typical characterstics of each of the elements in our hierarchy.

Although the inconsistencies in the assignment of principles, criteria, indicators and verifiers in the tests do not negate the usefulness of hierarchies in assessment, they do alter the monolithic nature we had originally envisioned for such hierarchies. It means that there will be a tendency for hierarchies to change to fit the location to which they are applied. What was a criterion may become a veri- fier, and vice versa depending on the perceived critical points in the field setting. Although in some sense, the C\&I sets remain "of one cloth" they get moulded by the experts - more than we expected - to the topography of the real world.

This raises the second issue important for potential users of our findings. Those C\&I which were unique to only one site in our sample should not be flatly rejected for wider use. To some extent, this follows from what we have said before. In new contexts, new "hills" and "valleys" will emerge, and may require hierarchical depth not encountered in our sample. But another element enters as well: the influence of individual team members and their different perceptions and perspectives on the selection of C\&I.

\begin{abstract}
Although the selection of many C\&I could be attributed to site specific conditions, in some cases the interests of one team member resulted in the selection of certain C\&I which another person would have vetoed. This is not a methodological criticism. Each team member brought new insights which someone else would have omitted. With our present understanding of sustainability, we readily admit we harbour uncertainties about the scientific relevance of many issues to sustainability. As mentioned at the beginning of this document, C\&I of "best practice" are all we can hope to achieve at this point. In this context, diversity of opinion is unavoidable and probably desirable.
\end{abstract}

Thus, the related practical implication for potential assessors is that assessor teams will require a period to fine tune the set of C\&I they begin with, to tailor it to their setting ${ }^{25}$. It is our belief that involving local stakeholders in the identification of appropriate C\&I (contents, weighting, information sources, etc.) just prior to fieldwork will be a cost-effective way to reduce the time and money needed in making a preliminary selection. Involvement of such stakeholders can make two important kinds of contribution by providing a) sources of information needed by assessors, and b) a mechanism for facilitating input from local communities, workers and other forest actors whose well-being is a requisite for sustainability of the forests. This latter contribution is particularly important because of the difftculty of assessing social issues in sustainability.

24 Liang (loc cit.) in the strict sense of his model maintains that "Information conveys a 'single message' compared to a data element, which conveys a "single value." Knowledge on the other hand is a large-scale selective combination of related pieces of information, e.g. the science of physics. Finally wisdom is perceived as a small increment in knowledge created by a person's intellectual deductive ability after attaining a sufficient level of understanding of a knowledge area.

25 SCS has an elaborate procedure for determining the weights of their C\&I in particular contexts (see e.g., Seymour, Hrubes and Hammel 1995, or McNulty and Cashwell 1995). 
Our results also suggest that the C\&I related to aspects of social sustainability will tend to have a smaller degree of commonality than those for the other aspects. We will be seeking to verify and understand this phenomenon in our future work.

In a small exercise in analysis we examined how the C\&I from the three tropical tests would fit under the 'umbrellas' of the ITTO criteria and indicators and the FSC principles and criteria. In both cases we found that the distribution of C\&I from the tests covered the entire range of issues covered in those two documents, with the exception of C\&I related to plantations. Plantations were outside the purview of our test teams, except in Côte d'Ivoire where it was felt that pockets of planted trees within natural forest areas should be included in the mandate of the team.

Finally, we suggest that, in general, the level of expertise required for good assessment has been underestimated. Field and CIFOR team members tried to keep in mind the probability that assessors would have to be generalists, operating within a short time frame. However, all teams (including the CIFOR team) remain doubtful that many of the C\&I, as they stand now, could be reliably applied by non-specialists. This was particularly true of the ecological and social C\&I. This problem, as much as any other, makes the continuation of our work necessary. The costs of sustainability assessments need to be reduced and without simpler C\&I they are unlikely to do so. 


\section{FUTURE STEPS}

In the previous sections we have been able to establish that progress made towards achieving our first two objectives, development of a methodology and indentification of "minimum sets" of C\&I, has been good. We are equally certain that there is still room for improvement, and we have tried to identify what this should be. Our progress towards developing a system to evaluate sustainability as a whole, our third objective, has been less satisfactory. However, we were aware that this was an extremely ambitious target for a phase of only 18 months duration.

In considering what our future steps should be during the second phase of the project, we are planning to build upon the lessons we have learnt during the first phase. There are several areas of weakness that we have identified, assessment of forest management's impacts on biodiversity being one, that cannot possibly be addressed with CIFOR's resources alone. We would hope that our analysis of potential future courses of action could also be a platform for others interested in developing the assessment of sustainable forest management further.

We have identified a large number of possible future steps in the course of Phase I of this project. Some of the more interesting ones include:

- Harmonisation of concepts, terms and definitions. Considerable confusion remains about the exact meanings of criteria, indicators, performance thresholds, etc., and how to use them in an effective manner.

- Improvements in quality and use of current $\mathbf{C \& I}$. This can include quantification of currently qualitative indicators, improvements in standardising measurement and monitoring, development of improved RRA or PRA methods.

- C\&I pertaining to ecological integrity. C\&I for assessing biodiversity, for instance, at the FMU level, are in their infancy [see below]. Similar problems exist for such issues as carbon sequestration, water yields, soil erosion, etc.

- C\&I pertaining to social issues. Understanding the role that local communities play in sustainable forest management is very much an ongoing process [see below]. Important questions that have arisen include: Who affects and is affected by forest management? How do indigenous forest management and formal forestry complement each other? What do different actors consider sustainable forest management? How do we balance the needs of local people with the needs of more distant stakeholders?

- Differences in forest type as they affect C\&I. Important issues that need resolution include variations in natural forest type, degrees of human impact, functions ascribed to the forest in land-use planning processes, and various geo-political levels of relevance for FMUs.

- Transparent decision making tools. These are needed to help resolve conflicts arising out of partial fulfilment of C\&I requirements and to help forest managers to benefit from our results in implementing improved management practices [see below].

- Development of linking mechanisms. This can include exchange of information, experience and know-how, as well as links among the various levels and bodies (national policy to FMU; community forestry)

From this grand range of possible activities, we have selected a smaller number which we feel we can realistically address during the next two years.

Our next steps (for which funding is partially secured) will involve five major foci:

1. The development of tools based on appropriate $\mathrm{C} \& \mathrm{I}$.

2. Improving $\mathrm{C} \& \mathrm{I}$ for assessing impacts on social sustainability.

3. Improving deficient C\&I for assessing impacts on key ecological areas.

4. Testing C\&I within the context of forests managed by local communities.

5. Developing decision making methods for holistic evaluation of sustainability of forest management.

These are each discussed in turn below. Before we begin work on the development of tools based on appropriate criteria and indicators, one of our first steps will be to develop a training module on how to assess and develop C\&I. Building on our experience with the expert teams we aim to develop a simple training manual on how to go about assessing and generating criteria and indicators for sustainable forest management.

\section{The development of tools based on appropri- ate $C \& I$}

Although significant progress has been made during this phase, there remains considerable confusion about methods and terminology. The main goal of this activity is to develop an acceptable standardisation of methods and terminology which will in turn enhance transparency, comparability and acceptability of the results of such evaluations. 
Special emphasis will be directed toward the development of indices and the standardisation of survey and other assessment procedures. Substantively, we will focus on assessment tools for the following:

- changes in forest cover,

- changes in volumes of standing timber,

- logging damage,

- post-harvest regeneration of forests, impacts on growth and yield, impact of forest opening, and

- determination of the quality of management systems.

This will involve desk study, iterative, interdisciplinary field trials on three continents, workshops to analyse and refine results and methods, and replications.

\section{Improving $\mathrm{C} \& I$ for assessing impacts on social sustainability}

This component was planned in recognition of the shortcomings of existing C\&I pertaining to social dimensions of sustainability. The relevance and importance of social factors is widely acknowledged, but the lack of reliable, efficient and cost effective methods has plagued all assessment efforts to date.

In this component we expect to conduct field investigations on three major topics. The role played by participation will be clarified, along with the significance of varying tenure and use rights arrangements. Finally, our work on defining forest actors will continue, specifically with efforts to clarify the meaning and comparative importance of the dimensions we have so far identified (proximity, pre-existing rights, dependency, forest-culture link, indigenous knowledge, and power deficit). These investigations will occur in South America, Africa, and Asia.

We expect this process to allow us to fine tune existing C\&I and to identify new ones characterised by greater simplicity, reliability and cost effectiveness. Our output will include an academic book on our research findings, and a user manual, suitable for use by forest managers, policy makers and others interested in sustainable forest management on a practical basis.

\section{Improving deficient $\mathrm{C} \& \mathrm{I}$ for assessing impacts on key ecological areas}

We have found problems, similar to those mentioned above with regard to social dimensions, in our attempts to deal with ecological factors in sustainable forest management. For this reason, we have planned more intensive investigation into two distinct methods for assessing ecosystem integrity in sustainable forest management more effectively. The first approach examines changes in biodiversity at the genetic level, in the belief that levels of genetic diversity are potentially useful early warning indicators of changes in biodiversity as a whole. There are unlikely to be changes in population size or age structure, for instance, without attendant changes in measures of genetic diversity. A major advantage to this approach is the comparative ease with which such changes can be monitored. First steps in this direction were taken recently (Namkoong et al. 1996).

We will also address the development of C\&I at the levels of species and ecosystems. This will include use of plant functional attributes (PFAs) (Gillison 1994). These attributes have already been used experimentally as indicators of biodiversity response to logging impact and for forecasting the impact of different land uses on forest lands. The next step will be to expand the testing of this approach in several locations, to determine its appropriateness for assessing ecosystem integrity.

\section{Testing C\&I within the context of forests managed by local communities}

This project was originally intended to include a component testing C\&I on community-managed forests, but time and funding constraints precluded our doing so. These problems have now been overcome, and the process initiated during Phase I will be adapted and implemented during this coming year in Asia, Africa and South America. The main changes from the current approach include the following:

- The teams will be composed of three national scientists (forester, ecologist and social scientist).

- Each team member will select 20 of the most relevant criteria within his/her own field for testing, prior to fieldwork (based on experience and discussion with other team members) .

- Team members will assess their criteria, two per day, for their relevance to sustainability and feasibility of measurement.

- Team members will interview stakeholders regarding the acceptability of these criteria.

\section{Developing decision making methods for holistic evaluation of sustainability of forest management}

In order to evaluate sustainability at the forest management unit level, it is necessary to assess the degree to which production, conservation and social C\&I jointly contribute towards high present and future net benefits to society. There are a variety of techniques available which purport to deal with such complexity, such as Analytic Hierarchy 
Process (Saaty 1980), the AMOEBA approach (Brink 1991), and various other multi-criteria analysis techniques (Munasinghe 1993; Kangas and Kuusipalo 1993; Faith 1995). We expect to commission a review of the state of the art of decision making methods under fuzzy environments, including an evaluation of their applicability to sustainabilility assessment. These findings will then be used in a "virtual" working group (e-mail, Internet) whose deliberations will be followed by a traditional workshop. The goal of this activity will be to select the most practical decision making tools for use in field level assessments of sustainability. These methods will then be field-tested, refined, and the results analysed. Revisions are anticipated, and these will be further tested during the project's replication field tests. The subsequent analysis is expected to result in usable decision support software by the end of the project.

In addition to the four broad themes listed above we intend looking at the issue of developing C\&I on economic sustainability, including financial aspects which we have not addressed so far. We will continue to work on improving the consistency of our conceptual framework and methos for developing and testing C\&I. We will also explore ways and means to link C\&I at the FMU level with appropriate C\&I at the national level. All these proposed steps are encompassed by our intention to contribute to the development of a "tool-box" for the assessment of sustainability at the FMU level. As our project has developed we have become convinced that such a "tool-box" approach is the appropriate interpretation of our third objective contribution to the development of "a system to assess sustainability of forest management as a whole". Thus Phase 2 of the project will be oriented towards making significant contributions towards the third objective of developing a tool-box.

We were encouraged to believe that this approach and the activities we have envisaged for Phase 2 are correct by the results of the CIFOR/CATIE workshop on sustainability assessment (Tan 1996). 


\section{REFERENCES}

Anonymous (1993). OECD core set of indicators for environmental performance review.

Environment Monograph No 83, Paris.

Attiwill, P.M. (1994). The disturbance of forest ecosystems: the ecological basis for conservative management. Forest. Ecology and Management. 63, pp. 247-300.

Brink, B. (1991) . The AMOEBA approach as a useful tool for establishing sustainable development? In: Kuik, O., Verbruggen, H. (eds.) In search of indicators of sustainable development. Kluwer Academic, Dordrecht, pp 71-87.

Burgess, Peter with Elias, Laksono, PM., Walting R.J., Wan Razali Wan Mohd. (1995). Final Report, Test Indonesia March 5 - April 2, 1995. CIFOR Project on Testing Criteria and Indicators for Sustainable Management of Forests.

Colfer, Carol J. Pierce (1995). Who Counts Most in Sustainable Forest Management? CIFOR Working Paper No. 7.

Colfer, Carol J. Pierce with Ravi Prabhu and Eva Wollenberg (1995). Principles, Criteria and 1ndicators:Applying Ockam's Razor to the People - Forest Link. CIFOR Working Paper No. 8.

Concise Oxford Dictionary of Current English (1990). Clarendon Press, Oxford.

Constanza, R. (1992). Ecological economic issues and considerations in indicator development, selection and use: Towards an operational definition of ecosystem health. In: McKenzie, D.H., Hyatt, D.E., McDonald, J.E. (eds.), Ecological Indicators, Vol. 2. Elsevier Applied Science, London.

FAO (1995). Expert meeting on harmonisation of criteria and indicators for sustainable forest managemenf. Background Note 2/95. (Unpublished)

Faith, Daniel P., (1995) Biodiversity and Regional Sustainability Analysis. CSIRO Division of Wildlife and Ecology, Canberra.

FSC (1994): Forest Stewardship Principles and Criteria for Natural Forest Management. Forest Stewardship Council, Oaxaca, Mexico.
Gentile, J.H. and Slimak, M.W. (1992). Endpoints and indicators in ecological risk assessments. In: McKenzie, D.H., Hyatt, D.E., McDonald, J.E. (eds.), Ecological Indicators, Vol. 2. Elsevier Applied Science, London.

Gillison, A.N. (1994). A generic Plant Functional Attribute set and grammer for vegetation description and analysis. CIFOR Working Paper No.3.

Grayson, A.J., Ed. (1995). The World's Forests: International Initiatives since Rio. Special publication by the Commonwealth Forestry Association. (Available from Oxford Forestry Institute, South Parks Road, OX1 3RB Oxford, UK).

Hahn-Schilling, B., Heuveldop, J. and Palmer, J. (1994). A comparative study of evaluation systems for sustainable forest management (including Principles, Criteria, and Indicators). Arbeitsbericht, Bundesforschungs-anstalt für Forst- und Holzwirtschaft, Hamburg.

Hecht, Susanna (1992). Valueing Land Uses in Amazonia: Colonist Agriculture, Cattle, and Petty Extraction in Comparative Perspective. In Kent H. Redford and Christine Padoch, (eds). Conservation of Neotropical Forests: Working with Traditional Resource Use. New York: Columbia University Press, pp. 379399.

Huttel, Charles (1995). Rapport Final "Écologie" pour le Test Côte d'Ivoire. CIFOR Project on Testing Criteria and Indicators for Sustainable Mangement of Forests.

ITTO (1991). Criteria for the Measurement of Sustainable Tropical Forest Mangement. International Tropical Timber Organization, Yokohama.

Kangas, J and Kuusipalo, J. (1993) Integrating biodiversity into forest management planning and decision making. Forest Ecology and Management, 61 : pp 1-15.

Kressin, Jan (1995). Social Evaluation Summary: Report on Testing Social Criteria and Indicators for Sustainable Forest Management. CIFOR Project on Testing Criteria and Indicators for Sustainable Mangement of Forests. 
Laksono, PM. (1995). Report on Evaluation of Methodology for Testing Criteria and Indicators of Sustainable Management of Forests (SocioAnthropological Aspects).

Landres, PB. (1992). Ecological indicators: Panacea or liability?. In: McKenzie, D.H., Hyatt, D.E., McDonald, J.E. (eds.), Ecological Indicators, Vol. 2. Elsevier Applied Science, London.

Liang, T.Y. (1994). The Basic Entity Model: A Fundamental Theoretical Model of Information and Information Processing. Information and Management 30(5): 647-661.

McKenzie, D.H., Hyatt, D.E. and McDonald, V.J. (eds.) (1992). Ecological Indicators, Volumes 1 \& 2. Elsevier Applied Science, London.

McNulty, John W. and John H. Cashwell (1995). The Land Manager's Perspective on Certification. Journal of Forestry 93, No.4:22-25.

Mengin-Lecreulx, Patrice, with Ahui Anvo, Charles Huttel, Heleen van Haaften, an d N'Guessan K. Anatole ( 1995). Final Report: Test Côte d'Ivoire June 2-30, 1995. CIFOR Project on Testing Criteria and Indicators for Sustainable Mangement of Forests. (English translation by Guy Ferlin).

Mesquita, Rita de Cássia G. (1995). Ecological Evaluation Summary: Report on the Methodological Procedures During Selection and Testing of Criteria and Indicators relevant for Sustainable Forest Management, Brazil. CIFOR Project on Testing Criteria and Indicators for Sustainable Management of Forests.

Munasinghe, M. (1993). Environmental economics and sustainable development. World Bank Environment Paper No. 3. The World Bank, Washington, D.C.

Myers, Isabel1 Briggs with Peter B. Myers (1980). Gifts Differing. Palo Alto, CA: Consulting Psychologists Press, Inc.

(1992). Introduction to Type: A Description of the Theory and Applications of the Myers-Briggs Type Indicator. Palo Alto, California: Consulting Psychologists Press, Inc.
Namkoong, G., Boyle, T., Gregorius, H.R., Joly, H., Savolainen, O., Ratnam, W., Young, A. (1996). Criteria and Indicators for Impacts of Forest Management on Genetic Variation. Testing Criteria and Indicators for Sustainable Management of Forests. CIFOR Working Paper No. 10.

Ostrom, Elinor (1994). Neither Market Nor State: Governance of Common-Pool Resources in the Twenty-first Century. Washington, DC, International Food Policy Research Institute.

Palmer, John, (1995). Final Report, Test Germany November 12-28, 1994. (With Peter Boateng, Lukito Daryadi, Eberhard Panitz, and Per Rosenberg). CIFOR Project on Testing Criteria and Indicators for Sustainable Management of Forests. Unpublished. CIFOR, Bogor.

Prabhu, Ravi (1994). Assessing Criteria for Sustainable Forestry. ITTO Tropical Forest Update 4 (5), pp 5-8.

Prabhu, Ravi (1995). Interim report. Unpublished report, May 1995.

Saaty, T.L. (1980). The Analytic Hierarchy Process. Planning, Priority Setting, Resource Allocation. McGraw-Hill, New York, pp 283.

Schmutzenhofer, H. (1992). IUFRO's birthday. IUFRO News 21 (1 \& 2): 3

Schneider, E.D. (1992). Monitoring for ecological integrity: The state of the art. In: McKenzie, D.H., Hyatt, D.E. and McDonald, V.J. (eds.), Ecological Indicators, Vol. 2. Elsevier Applied Science, London.

Seymour, Robert S., Robert J. Hrubes, and Debbie Hammel (1995). Certifying Sustainable Forestry. Journal of Forestry 93, No.4:26-29.

Tan, L.C. (ed.) (1996). Initiatives on Assessing Sustainability: Status and Future Directions. Summary of the open session of the third international project advisory panel (IPAP) meeting on 'Testing criteria and indicators for sustainable management of forests, Turrialba, Costa Rica, February 29 - March 1, 1996. CIFOR, Bogor (In preparation). 
Upton, C. Bass, S. (1995). The Forest Certification Handbook. Earthscan Publications, London. pp 217.

van Haaften, Heleen (1995a). Final Report/Diary. CIFOR Project on Testing Criteria and Indicators for Sustainable Mangement of Forests. Wageningen, the Netherlands (21 July).

(1995b). Stress and Marginalisation around the Forests HautSassandra and Bossematié. Draft project paper, CIFOR Project on Testing Criteria and Indicators for Sustainable Management of Forests. Wageningen, the Netherlands.

Venkateswarlu, P. and Ravi Prabhu (1996). Methodological Investigations into Evaluation of Criteria and Indicators for the Sustainable Management of Forests. CIFOR Project on Testing Criteria and Indicators for the Sustainable Management of Forests, working paper.

Viana, Virgilio (1995). Component I: Policy, Planning and Institutional Framework. Final Report, CIFOR Project on Testing Criteria and Indicators for the Sustainable Management of Forests. Piracicaba, Brazil (24 November).

Wiersum, K.F. (1995). 200 Years of Sustainability in Forestry: Lessons from History. Environmental Management 19(3): pp 32 1-329.

Willi, Georg (1996). Endbericht: Testung von Kriterien und Indikatoren einer nachhaltigen Waldbewirtschaftung in Osterreich im Rahmen des internationalen CIFOR Projektes. CIFOR Project on Testing Criteria and Indicators for the Sustainable Management of Forests.

Wollenberg, Eva and Carol J. Pierce Colfer (1996). Social Sustainability in the Forest: A progress report of a project aiming to test criteria and indicators for the social dimensions of sustainable forest management. ITTO Tropical Forest Update.
Zweede, J., with Kressin, J., Silva, J.N.M., Viana, V.M. (1996). Consolidated Final Report Brazil. CIFOR Project on Testing Criteria and Indicators for the Sustainable Management of Forests. Belem, Para, Brazil, 27 December 1995.

\section{Source Documents for the Five Base Sets}

Hahn-Schilling, B., Heuveldop, J. and Palmer, J. (1994). Criteria for an evaluation of sustainable management of tropical forests. In: A comparative study of evaluation systems for sustainable forest management (including Principles, Criteria, and Indicators). Arbeitsbericht, Bundesforschun-gsanstalt für Forst- und Holzwirtschaft, Hamburg. ITW

Kelompok Kerja Ekolabel (1995) Kriteria SUSTAINABLE FOREST MANAGEMENT Hutan Produksi Alam. Penyempumaan. Ringkasan. Jakarta, February 1995. [English translation by Rinekso Soekmadi] LEI

Rainforest Alliance (revised draft October 1993). Smart Wood Certification: Generic guidlines for assessing natural forest management. New York, New York. Smart Wood

Schotveld, A., Stortenbeker, C.W. (1994) Evaluating Sustainable Forest Management. Report of Deskindigenwerkgroep Duurzaam Bodbeheer (DBB), Ministry of Environment, Netherlands, pp. 26. DDB

Soil Association Marketing Company Ltd. (1994). Responsible Forestry Standards. Bristol/UK. Woodmark 


\section{AN NEX 1 \\ EXCERPT FROM PROJECT PROPOSAL}

\section{SHORT DESCRIPTION OF THE PROJECT}

The project aims at contributing towards the development of a system to evaluate the sustainability of natural forest management, by generating and evaluating criteria relevant to such management in forests of different climatic zones. The output of this project would be an instrument for the development of an unbiased and objective certification of forest products from sustainably managed forests. It is recognised that certification itself is only one element of the global effort to introduce and maintain sustainability of management of natural forests. It must be understood that probably all criteria in existence today have been designed to test whether management is potentially sustainable and not sustainability itself. As such they are designed to test good forest stewardship.

Within the framework of a consultative process with participating countries in Asia, Africa, Latin America, and Europe it is envisaged national and international standards for sustainable management of forests would be evaluated as to their relevance and cost-effectiveness in a series of tests. The expected final output would be recommended sets of regionally relevant criteria incorporated within a system to evaluate the sustainability of forest management.

The total project duration is to be 18 months.

\section{PROJECT PURPOSE AND RATIONALE}

\subsection{Context (Problem Analysis)}

International concern about the widescale destruction and degradation of forest areas, especially in tropical countries, has led to a plethora of national and international initiatives aiming to stem this negative development. Notable among these are the ITTO declaration of Target 2000, the UNCED resolution on Global Forest Principles, the CSCE workshop on environmental criteria/indicators for the sustainable development of Boreal and Temperate forests, the Ministerial Conference on the Protection of Forests in Europe and more recently in the latest draft of the Forest Stewardship Council's Principles and Criteria for Natural Forest Management. As the discussion paper for the CanadaMalaysia Inter-Governmental Working Group on forests (IWGF) also recognises, there is a need to formulate internationally acceptable and scientifically testable criteria to characterise sustainable forestry; a need also identified in Agenda 21. The ITTO has, in a similar vein, called on member countries to work on developing such criteria.

In recent years, a lot of effort has gone into the development of standards to evaluate the sustainability of forest management. Most of this development initially took place in North America. More recently a significant part of it has concentrated on tropical forests, some of which have their origin within governments, as in Indonesia and Cameroon, while others are the result of inter-governmental negotiations, such as the African Timber Organisation's certification scheme, or the list of quantitative indicators for sustainable forest management of the Ministerial Conference on the Protection of Forests in Europe. Parallel to governmental initiatives, many non-governmental organisations have introduced their own sets of standards for sustainable management. Prominent among these are the Smart Wood scheme of the Rainforest Alliance, the Responsible Forestry Standards of the Soil Association (SA) and the criteria proposed by the Initiative Tropenwald (ITW).

Although these numerous efforts indicate positive global concern for the sustainability of forest management, they lack a capacity for rigorous scientific testing. In some cases, bias threatens the acceptance of certification in the market place. There is a need to harmonise the different standards, to test them with respect to their relevance to sustainability and effectiveness as criteria thereof. This has to be done in a fair, transparent and scientific manner, if certification of timber from sustainable production is at all to become an instrument to further sustainable management of forests and ensure better markets for products from such management. Indeed the usefulness of such criteria, goes beyond their incorporation in a certification system. They can play an important role as general guidelines for improving forest management practices.

There is also a need to develop and define criteria specific to the different forest conditions prevailing within each country. This process, which is already taking place in some countries, would benefit from a standardised methodology to evaluate the relevance and cost-effectiveness of criteria.

\subsection{CIFOR' s R ole as Project Co-ordinator}

The Centre for International Forestry Research (CIFOR) was established in response to global concerns about the social, environmental and economic consequences of loss and degradation of forests. CIFOR's mission is to provide a global research partnership to enhance and sustain the contribution of forests to human well being. At the 
end of its first year, CIFOR has progressed significantly towards an international global partnership for strategic research aimed at improving the management of forests for the benefit of the international community and especially the poor people in tropical developing countries.

Operational collaboration with CIFOR's research partners is already well developed. A strong relationship has been established with national forestry research systems of CIFOR's constituency - governments, universities, industry, NGOs and other development agencies including FAO, UNDP, the World Bank and regional development banks, UNEP, UNESCO and IUFRO.

\subsection{Project Purpose}

The aim of the project is to develop a regionally adaptable set of criteria and indicators, incorporated within an objective evaluation system for the sustainable management of natural forests, within the framework of a co-operative and participative process involving producers and consumers of forest products.

It is anticipated that this research project would also deliver an objective methodology to evaluate criteria - potentially a useful tool for the development of criteria.

\section{PROJECT DESIGN}

\subsection{Background}

Forestry experts from Great Britain, The Netherlands and Germany met in Weilburg (Germany) in February 1994 to call for comparative field tests of the 'most developed certification systems currently available for tropical forests'. At this meeting the standards of the Rainforest Alliance (Smart Wood scheme), Soil Association (Responsible Forestry Standards) and ITW (Criteria for an evaluation of sustainable management of tropical forests) and national criteria, wherever feasible, were singled out for testing. This selection was based on a cross sectional analysis of the criteria and guidelines of eight organisations and seven certifying bodies*.

At a subsequent, informal co-ordination meeting attended by representatives from France, Denmark, Austria, Great Britain, The Netherlands, the European Commission and Germany held in June 1994 in Eschborn (Germany) it was agreed the project should:

- test relevant criteria from national and international sources in different climatic zones

- be conceived as an integrated part of ongoing international political initiatives on sustainable management of forests

- underline the concern for sustainable management of forests in all countries.

- be carried out by international forestry organisation with accepted neutrality and high scientific credibiilty. CIFOR was identified as the ideal platform for this project and

- be evolved in dialogue with potential participating countries.

At this meeting it was made clear that most criteria available for testing would probably test good forest stewardship rather than sustainability.

\footnotetext{
* Hahn-Schilling, B., Heuveldop, J., Palmer, J. (1994) A comparative study of evaluation systems for sustainable forest management (including Principles, Criteria, and Indicators). Arbeitsbericht, Bundesforschungs-anstalt fur Forst- und Holzwirtschaft, Hamburg.
} 
ANNEX 2

\section{STRUCTURE OF THE PROJECT}

The figure below provides an overview of the structure of the project as on January 31, 1996.

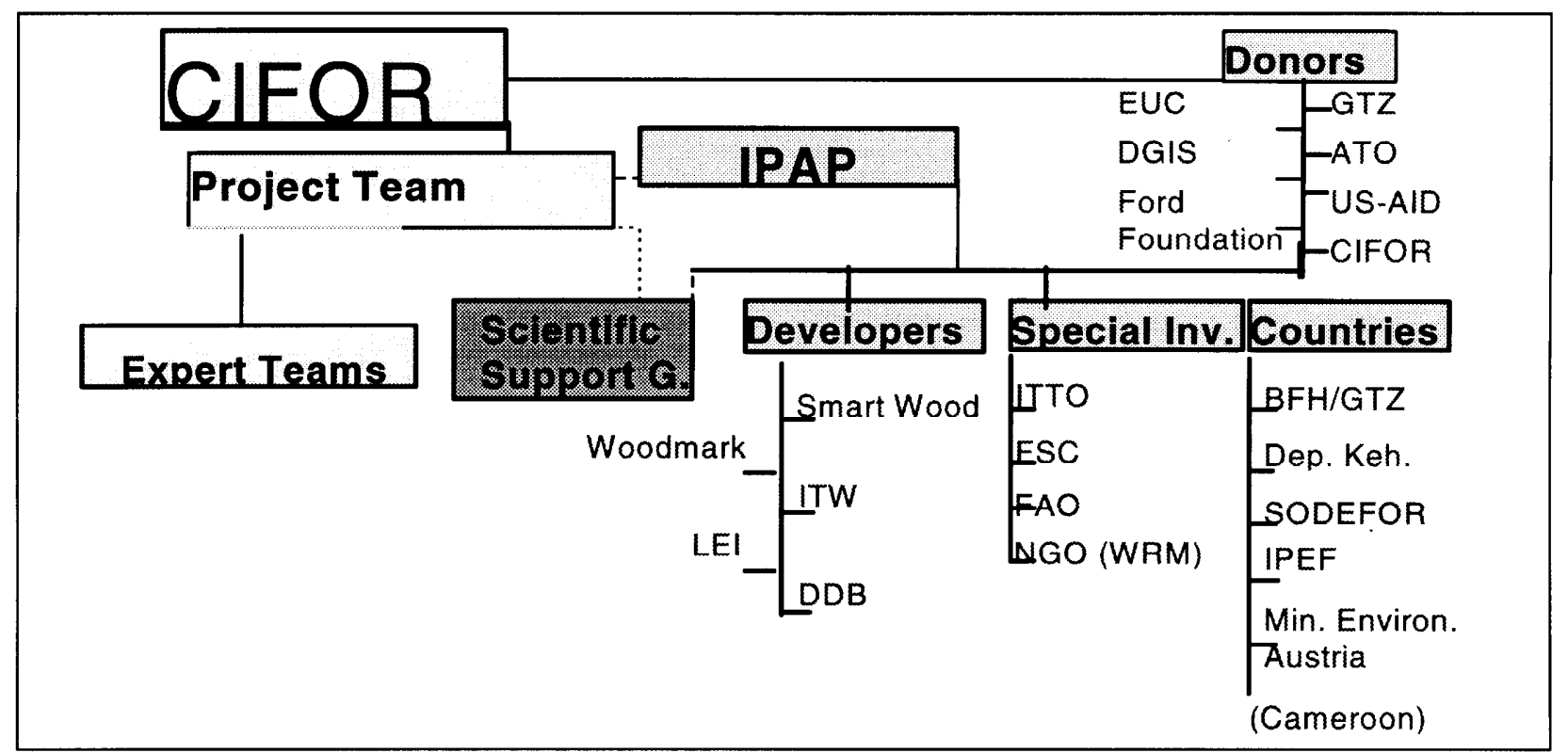

Figure 1: Structure of the project.

\section{Project Team}

The CIFOR project team consists of Dr. Ravi Prabhu, (forester) as project coordinator. Initial analysis of the sets of criteria and indicators selected for the research project revealed weaknesses in the area of social criteria and indicators. In response Dr. Eva Wollenberg (natural resources social scientist), and Dr. Carol Pierce Colfer (anthropologist), joined the team as social science coordinator the principal research scientist respectively. Dr. Dennis Dykstra (forester) and Dr. Neil Byron (forest economist) were the senior advisors to the project team. The project team's responsibility has been to develop the conceptual and methodological aspects of the research project, to coordinate with external collaborators and to organise the field testing. Project team members played key roles in facilitatating and guiding the work of the expert teams.

\section{Expert Teams}

For each tests site, these are five-member teams of experts in forestry, ecology and sociology/social anthropology who have a specialist knowledge of the area in which tests will take place. It is important to note that different teams are constituted for each site.

\section{International Project Advisory Panel (IPAP)}

This is the body in which all partners of the project find representation. The IPAP in its constituting meeting on December 8, 1994 gave itself a mandate and a set of guidelines for its constitution. Elected Chairperson of IPAP is Mr. Lukito Daryadi (Ministry of Forestry, Indonesia), the Dr. Prabhu was appointed the Ex-Officio Secretary. As can be seen in Figure 1, there are four main categories of members.

\section{Donors}

Principal donors are the European Union and GTZ, followed by CIFOR and the African Timber Organization. The Dutch Agency for Cooperation (DGIS) has provided support for activities scheduled for the second phase. Additional support during the closing months of the first phase has come from the Ford Foundation and USAID.

\section{Developers}

These are organizations that have developed the five base sets of criteria and indicators. Two of the five organizations listed have carried out more than one certification, although four of the five intend to do so at some stage. Smart Wood is one of the certification schemes of the Rainforest Alliance. Woodmark is the forestry certification scheme of the Soil Association, U.K.. ITW refers to the Initiative Tropenwald, an initiative of German timber importers and the Wood and Plastic Workers Union. The Lembaga Ekolabel Indonesia is an independent Indonesian institute being 
set up to oversee certification by the Government of Indonesia. DDB stands for the Dutch working group of experts on the evaluation of sustainable forest management.

\section{Countries}

This category refers to organizations that are national collaborators for this project in the countries where tests have or will take place. The Institute for World Forestry, Hamburg (BFH) and GTZ are the German partner organizations on the panel. The Ministry of Forestry (Departemen Kehutanan) is the principal partner in Indonesia. In Côte d'Ivoire this is SODEFOR. The Brazilian partner organization is IPEF, which has been named by IBAMA as the national coordinating agency. In Austria our main counterpart has been the Federal Environment Agency operating under the Ministry of Environment. An additional case study is proposed for Cameroon in 1996, which explains the parentheses around its name.

\section{Special Invitees}

The debate on criteria and indicators for the sustainable management of forests has also been carried forward by a small number of international organizations. Such organizations, it was felt, should also be represented on the IPAP to provide guidance to the project. These organizations are the International Tropical Timber Organization (ITTO), the Forest Stewardship Council (FSC) and the Food and Agriculture Organization of the United Nations (FAO). It was also felt that representation from international non-governmental organizations (NGO) and private industry should also find a place in the IPAP. It has been possible to identify the World Rainforest Movement (WRM) as the NGO representative. This was done through a process initiated by the IPAP and carried out by Forest Movement Europe, an Amsterdam based NGO. WRM has been represened at IPAP meetigs by Both Ends a Netrherlands based NGO. A suitable private industry representative has not yet been identified.

\section{Scientific Support Group}

The magnitude of this project and the complexity of the issues it covers has called for the identification of additional scientists outside CIFOR to assist the project team. Current members of this group are Prof. J. Heuveldop from the Institute of World Forestry, Hamburg, Dr. Jean-Guy Bertault from CIRAD-Forêt, Montpellier, Mr. Erik Lammerts van Bueren from TROPENBOS, Wageningen, Dr. Riga Adiwoso Suprapto from the University of Indonesia, Jakarta, Dr. Barbara Weber from the USDA-Forest Service, Washington D.C. and Prof. P.R.O. Kio from the University of Benin, Nigeria (Professor of Forestry). Scientific Support Group members have an observer status at the IPAP. 


\section{ANNEX 3 \\ PUBLICATIONS AND PAPERS RELATED TO THE PROJECT}

Burgess, Peter with Elias, Laksono, PM., Watling, R.J., Wan Razali Wan Mohd. 1995. Final Report, Test Indonesia March 5 - April 2, 1995. CIFOR Project on Testing Criteria and Indicators for Sustainable Management of Forests.

Colfer, Carol J. Pierce (1995). Who Counts Most in Sustainable Forest Management? CIFOR Working Paper No. 7.

Colfer, Carol J. Pierce with Ravi Prabhu and Eva Wollenberg (1995). Principles, Criteria and Indicators: Applying Ockam's Razor to the People - Forest Link. CIFOR Working Paper No. 8.

Mengin-Lecreulx, Patrice, with Ahui Anvo, Charles Huttel, Heleen van Haaften, and N'Guessan K. Anatole (1995). Final Report: Test Côte d'Ivoire June 2-30, 1995. CIFOR Project on Testing Criteria and Indicators for Sustainable Management of Forests. (English translation by Guy Ferlin).

Namkoong, G., Boyle, T., Gregorius, H.R., Joly, H., Savolainen, O., Ratnam, W., Young, A. (1996). Criteria and Indicators for Impacts of Forest Management on Genetic Variation. Testing Criteria and Indicators for Sustainable Management of Forests. CIFOR Working Paper (in preparation)

Palmer, John, with Peter Boateng, Lukito Daryadi, Eberhard Panitz, and Per Rosenberg (1994). Final Report, Test Germany November 12-28, 1994. CIFOR Project on Testing Criteria and Indicators for Sustainable Management of Forests.

Prabhu, Ravi (1994). Assessing Criteria for Sustainable Forestry. ITTO Tropical Forest Update 4 (5), pp 5-8.

Prabhu, R., Colfer, C.J.P., Venkateswarlu, P., Tan, L.C., Soekmadi, R., Wollenberg, E. (1996). Testing Criteria and Indicators for Sustainable Management of Forests: Final Report of Phase I. CIFOR, Bogor (In preparation).

Tan, L.C. (1996). Initiatives on Assessing Sustainability: Status and Future Directions. Summary of the open session of the third international project advisory panel (IPAP) meeting on 'Testing criteria and indicators for sustainable management of forests, Turrialba, Costa Rica, February 29 - March 1, 1996. CATIE/CIFOR Special publication. CIFOR, Bogor (In preparation).

van Haaften, H. (1995). Stress and Marginalisation around the Forests Haut-Sassandra and Bossematie. Draft project paper, CIFOR Project on Testing Criteria and Indicators for Sustainable Management of Forests. Wageningen, the Netherlands.

Willi, Georg (1996). Endbericht: Testung von Kriterien und Indikatoren einer nachhaltigen Waldbewirtschaftung in Osterreich im Rahmen des internationalen CIFOR Projektes. CIFOR Project on Testing Criteria and Indicators for the Sustainable Management of Forests.

Wollenberg, Eva and Carol J. Pierce Colfer (in press). Social Sustainability in the Forest: A progress report of a project aiming to test criteria and indicators for the social dimensions of sustainable forest management. ITT0 Tropical Forest Update.

Zweede, Johann (1995). Consolidated Final Report - Brazil. CIFOR Project on Testing Criteria and Indicators for the Sustainable Management of Forests. Belem, Para, Brazil, 27 December 1995. 


\section{AN NEX 4 \\ FORM1 AND FORM2}

TESTING CRITERIA AND INDICATORS FOR THE SUSTAINABLE MANAGEMENT OF FORESTS

Response Form No. 1: Evaluation of all criteria and indicators

Instructions for users

\section{Purpose of the form}

The objective of the response form is to enable a preliminarv evaluation of all criteria and indicators to determine, based on best professional judgement, the most important ones for assessing sustainability of the ecosystem, the management and social systems. This first examination should concentrate on eliminating only the most obviously defi cient criteria and indicators. The results of this first evaluation will be discussed with other panel members in Abidjan, to determine the sub-set considered by the team to be 'priority' criteria meriting further and more detailed evaluation.

\section{M ethod}

The criteria and indicators are to be evaluated in the context of conditions in at the FMU/country.

The task of a system to evaluate sustainability is to assess the satisfaction of the following two conditions:

1. Ecosystem integrity is ensured/maintained, and

2. Well being of people (primarily local people) is maintained or enhanced

These conditions represent the bio-physical, social and temporal elements of sustainability and are discussed in greater detail in the Briefing Book. Fulfilment of the above two conditions is expected to takes place continuously over long but not infinite periods of time.

The following five questions have been designed as an aid to focus on important attributes of criteria and indicators and enable the elimination of obviously deficient criteria and indicators.

1. Closely and unambiguously related to the assessment goal? = directly/obviously/intuitively/logically linked to criterion or to sustainability

2. E asy to detect, record \& interpret? = easy to get the information, straightforward?

3. Provides a summary or integrative measure? summarizes/integrates a lot of information, is it information efficient?

4. Adequate response range to stresses? $=$ does the indicator continue to give you useful and meaningful information over a wide range of situations?

5. I mportant and therefore selected as 'priority'? = Is it relevant and appropriate? Is it useful ? Is it worth further investigation during the field phase?

- Please use a scale of 1-5 in answering the five questions listed on Response Form No. 1.

- Please photocopy the form as required.

Please try and record your responses on the attached simple program to record data. Remember to make print outs for safety! 
Response Form No. 1: Evaluation of all criteria and indicators

Please use a scale of 1-5, where 1='no' and 5='yes'. Codes: Smart Wood=1; Initiative

Tropenwald=2; Soil Association=3; Lembaga Ekolabel=4, ATO=5, Dutch=6

\begin{tabular}{|c|c|c|c|c|c|c|}
\hline Source & $\begin{array}{l}\text { No. of C/I as } \\
\text { printed in } \\
\text { source } \\
\text { document. }\end{array}$ & $\begin{array}{l}\text { Closely and } \\
\text { unambiguously } \\
\text { related to the } \\
\text { assessment } \\
\text { goal? }\end{array}$ & $\begin{array}{l}\text { Easy to } \\
\text { detect, } \\
\text { record \& } \\
\text { interpret? }\end{array}$ & $\begin{array}{l}\text { Provides a } \\
\text { summary } \\
\text { or } \\
\text { integrative } \\
\text { measure? }\end{array}$ & $\begin{array}{l}\text { Adequate } \\
\text { response } \\
\text { range to } \\
\text { stresses? }\end{array}$ & $\begin{array}{l}\text { Important } \\
\text { and } \\
\text { therefore } \\
\text { selected as } \\
\text { 'priority'? } \\
\text { Yes=2 } \\
\text { No=1 } \\
\end{array}$ \\
\hline & & & & & & \\
\hline & & & & & & \\
\hline & & & & & & \\
\hline & & & & & & \\
\hline & & & & & & \\
\hline & & & & & & \\
\hline & & & & & & \\
\hline & & & & & & \\
\hline & & & & & & \\
\hline & & & & & & \\
\hline & & & & & & \\
\hline & & & & & & \\
\hline & & & & & & \\
\hline & & & & & & \\
\hline & & & & & & \\
\hline & & & & & & \\
\hline & & & & & & \\
\hline & & & & & & \\
\hline & & & & & & \\
\hline & & & & & & \\
\hline & & & & & & \\
\hline & & & & & & \\
\hline & & & & & & \\
\hline & & & & & & \\
\hline & & & & & & \\
\hline & & & & & & \\
\hline & & & & & & \\
\hline & & & & & & \\
\hline & & & & & & \\
\hline
\end{tabular}




\section{TESTING CRITERIA AND INDICATORS FOR THE SUSTAINABLE MANAGEMENT OF FORESTS Response Form 2 \\ Instructions for users}

1. This form has been designed to record assessments of criteria and indicators selected for more intensive evaluation, after analysis of Form 1. It has also been designed to provide a transparent record of how you reached your conclusions.

2. Filling in the form.

a) The first six unnumbered boxes on page 1 identify which panel member is primarily responsible for the evaluation of the criterion or indicator ('CONSULTANTS INITIALS'), which of the sets it originated from ('SOURCE'), its number or reference as recorded in the source (CRITERIA NO OR INDICATOR), its subject matter ('CLASS') and whether after completion of the field phase it was recommended or not ('RECOMMENDATION'),

b) Attributes, Box A:

General: Two entry boxes have been provided for each question in this and subsequent sections. The first box (d) refers to the criterion or indicator as listed in Box D, which is the initial selection. If the initial selection has to be modified, this will be recorded in Box 0 on page 4. This final version must be subjected to a renewed evaluation (o). By comparing evaluations (d) and (o) the reader can assess whether the final version is significantly better than the initial version.

1) Provides a summary or integrative measure? Does it sum up or integrate a lot of information? Is it information efficient?

2) Closely and unambiguously related to the assessment goal? Is it closely related to its assessment goal? Is it diagnostically specific? Is the criterion or indicator easy to detect, record and interpret?

3) Adequate response range to stresses? Is it sensitive to changes in the environment or the system? Does it provide meaningful information over these changes?

4) Diagnostically specific? Does the indicator (or criterion) tell us something about the criterion it relates to? Or is it more general, relating perhaps to more than one criterion or area?

5) A ppealing to users? Does it appeal? Would a potential user feel invited to use it? Is it cost-effective?

6) E asy to detect, record and interpret? How feasible is the criterion/indicator? Will it produce repeatable results?

7) Precisely defined? Is the meaning clear? Is the definition precise? Would two different people understand it the same way? (Test this on your fellow panel members.)

8) W ill it produce replicable results? Is it reliable and repeatable? How robust are predictions based on this indicator or criterion?

9) H ow relevant is this criterion or indicator? Your opinion on the relevance of this criterion or indicator to sustainability.

10)0 ther: e.g. Is an absolute or a relative measure better?

c) Box B: Provide an estimate of how much it would cost (in terms of person-hours or US\$) what the total cost would be if this criterion or indicator were to be used to evaluate sustainability of a forest management unit.

d) Box C: Based on your experience, published documents, ongoing research etc. can you suggest a value or a range of values that could make this indicator or criterion more precise?

e) Box D: Please enter the original text of the criterion or indicator, you have selected as being the most worth evaluating from amongst the sets provided. Please refer to relevant Response Forms No 1 of all panel members, before effecting your selection.

f) Box E: Justify your selection of this criterion or indicator, giving the main arguments.

g) Box F: Give bibliographic references to provide additional weight to your justification, if you can.

h) Box G: Give the references, wherever possible, of similar criteria and indicators from the other sets.

i) Box H: Record additional notes in this space. If a criterion or indicator is rejected, please provide the reasons here. 
j) Box I: Maintain a daily diary of your efforts to evaluate the criterion or indicator. This will be of help to you in justifying to the workshop your reasons for selecting or rejecting it. It will also be of help to CIFOR staff for the analysis of your recommendations after the field phase. Please feel free to add additional pages if desired.

k) Box J: The consultant selected as task leader for 'time' will tick the appropriate box to indicate whether a criterion or indicator has a primarily backward looking or historical nature (Past), is a snapshot of conditions as they exist at the moment (Present) or has a predictive character (Future).

1) Box K: The responsible task leader will evaluate the geo-political scale on which a criterion or indicator operates. Multiple entries are possible, but care should be taken to determine the primary thrust of a criterion or indicator.

m) Box L: In this box the responsible task leader will determine whether the criterion or indicator belongs to the category of 'human inputs' (e.g. capital, labour) or 'human processes' (as opposed to natural processes) such as the various planning processes or whether it is an 'outcome' of either of the first two categories in the bio-physical or social systems. The difference between a human input and a human process is often a very fine one. an indicator such as "Annual, 5 year and twenty year management plans exist" would be an input resulting out of the process "Management is based on appropriate planning horizons.. .". Inputs are generally easier to record, predict and interpret. Processes on the other hand are often more revealing of how committed management is to achieving its goals.

n) Box M: A classification of criteria and indicators according to whether they refer to a 'stress' on the system (biophysical, social or management), describe its 'state' or how the system 'responds' to stress or strain, is an effective way of looking at causes and effects. Examining whether the major sources of stress, and the systems' responses to these stresses, have been captured in criteria and indicators facilitates objective conclusions on their effectiveness and reliability.

o) Box N: Criteria and indicators constitute a network or web to capture information. The boxes above have attempted to examine whether the right strands have been woven into this web, and that the mesh is neither too small nor too large for the information we want to capture. In this box we are looking for linkages between criteria and indicators, to ensure that the same or similar information is not collected twice and to ascertain whether the necessary feedback loops exist between criteria and indicators. Examples of important feedback loops in forestry are between regeneration and growth on the one hand and silvicultural prescriptions and cutting cycles on the other. An effective system of criteria and indicators needs to reflect such information loops.

p) Box O: If the criterion or indicator selected in Box D has undergone changes in its definition, the final version of this criterion or indicator should be recorded here. It is assumed that justification for these changes can be found in pages $2 \& 3$.

q) Box P: The workshop notes will be used to record the most important conclusions of the workshop on the criterion or indicator. 
Testing Criteria and Indicatora: Test Braxil

Response Form No. 2: Field responses
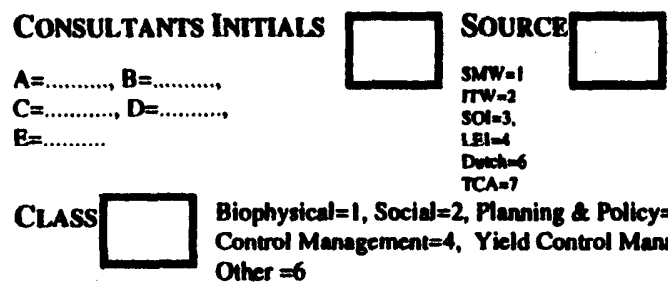

$S M N=1$

$\min _{s \rightarrow 2}$

LEl=1

DCA=7

Biophysical=1, Social=2, Planning a Policy=3, Damare

Control Management $=4$, Yield Control Management $=5$,

Other $=6$

Criteria

No.

OR

INDICATOR

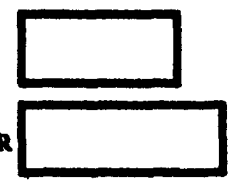

RECOMMENDATION

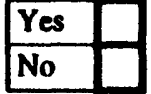

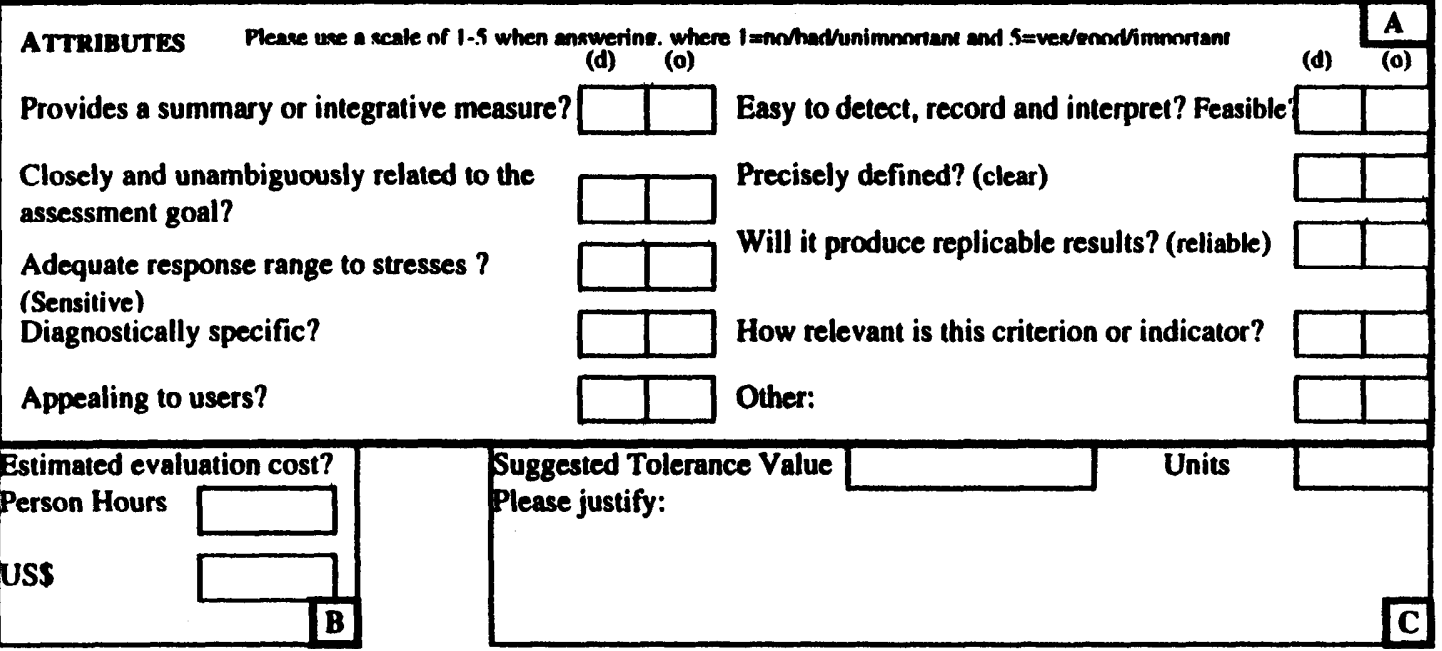

Enter the selected criterion or indicator as stated in the source document in this space:

Justify your selection of this criterion or indicator:

Provide bibliographic references (if any):

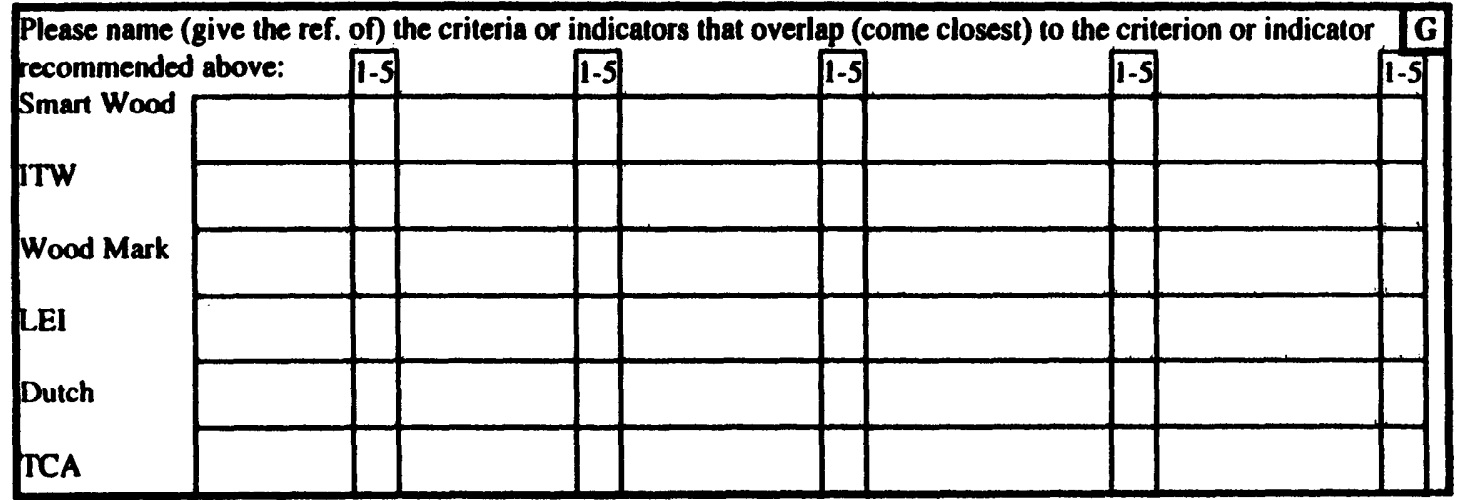

Page 1 (20.10.95) 
NOTES: Please record your notes on evaluating the criterion/indicator (Box D) here: $\mathbf{H}$

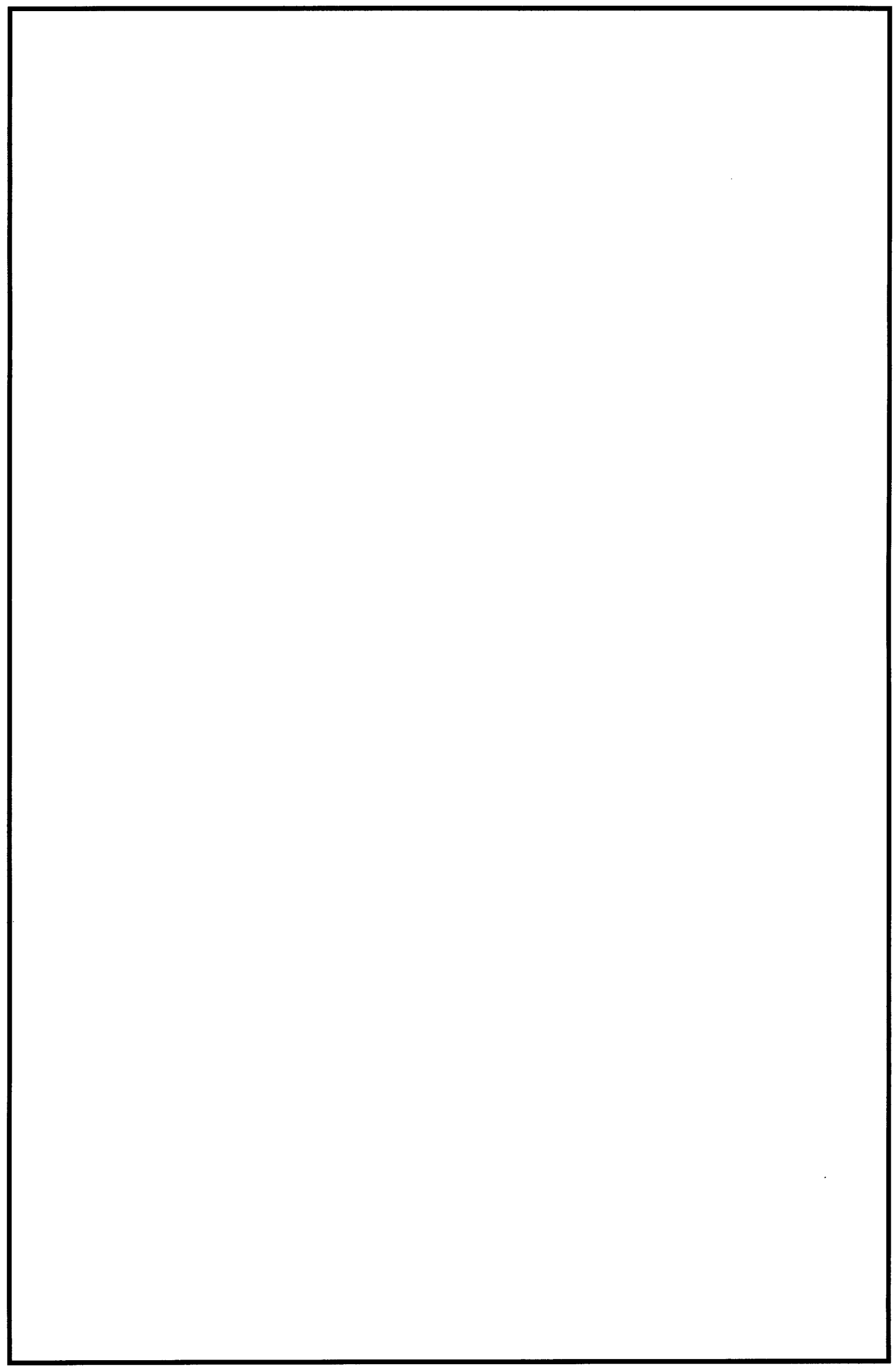


Daily Diary

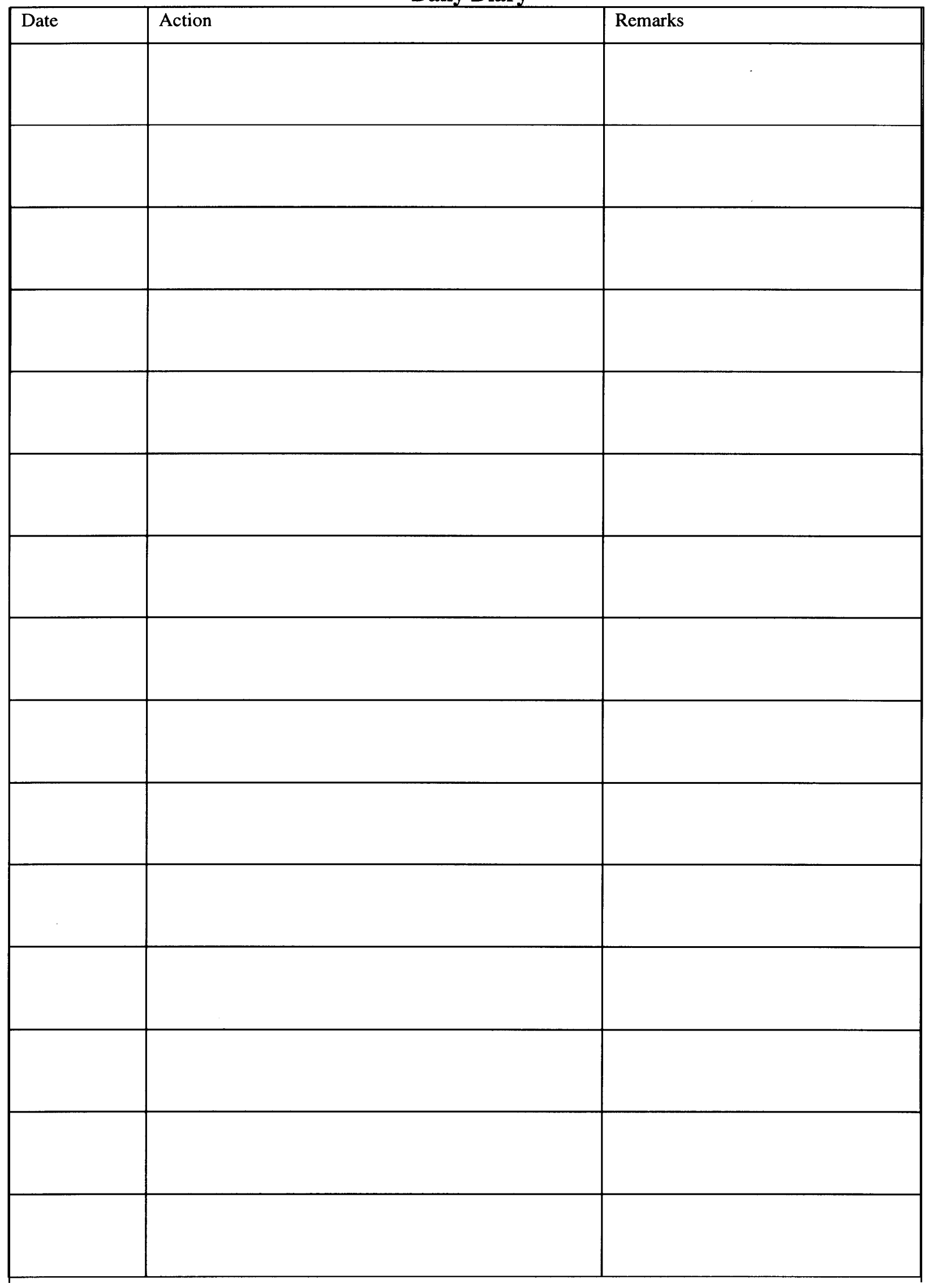

Response Form 2, Page 3 


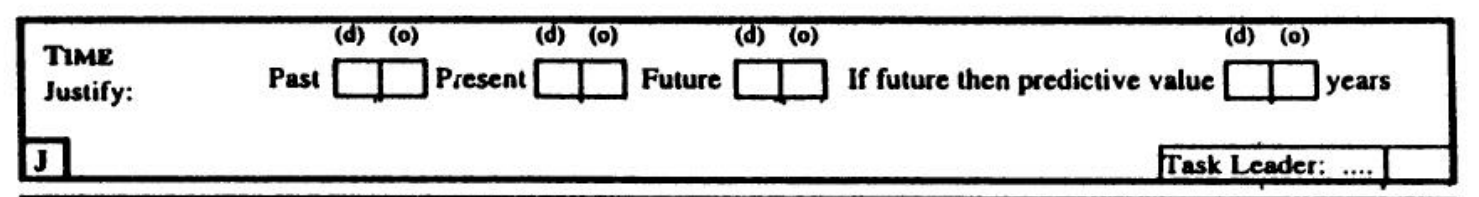

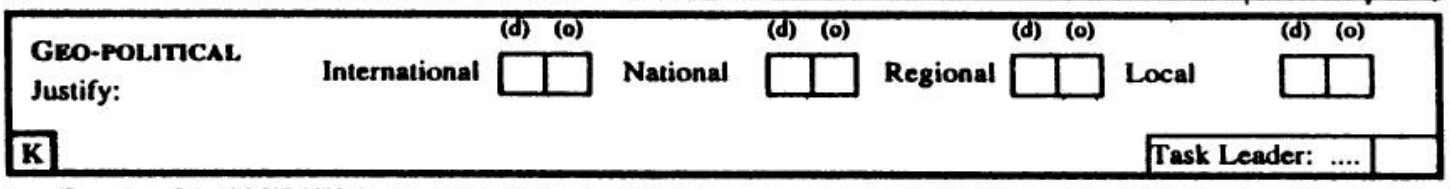

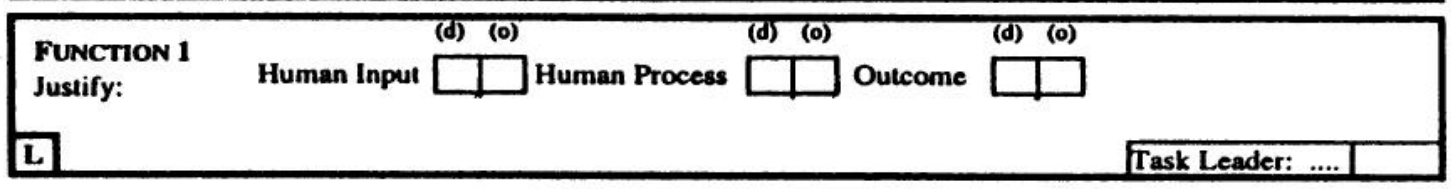

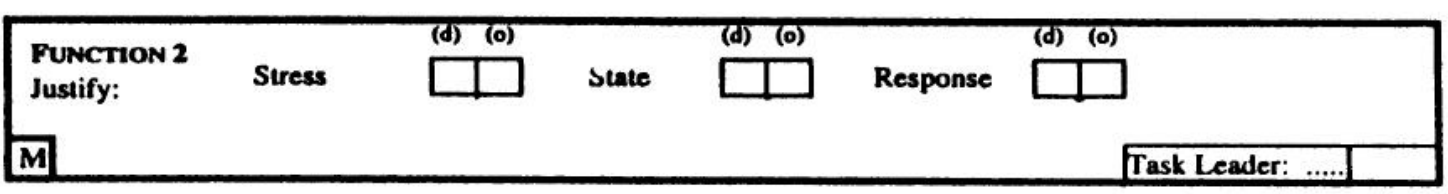

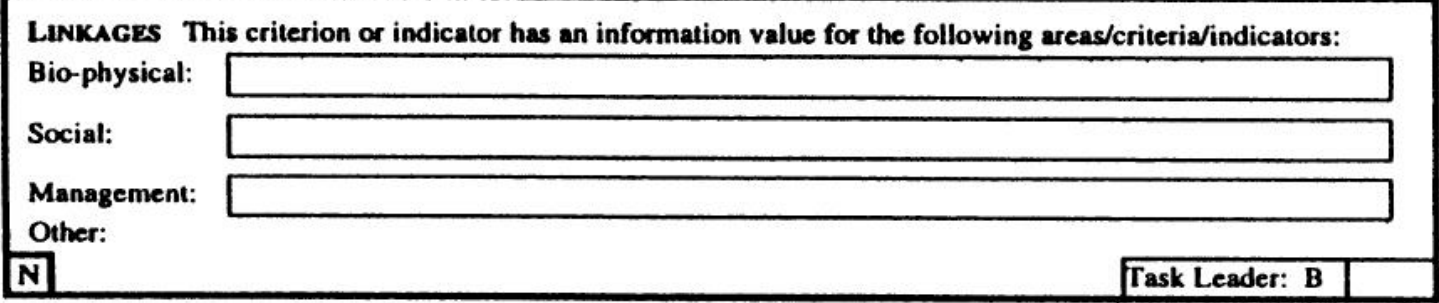

\begin{tabular}{l} 
Final version of criterion/indicator, state enly if differenule definition on pare 1 (Box D): \\
\hline
\end{tabular}

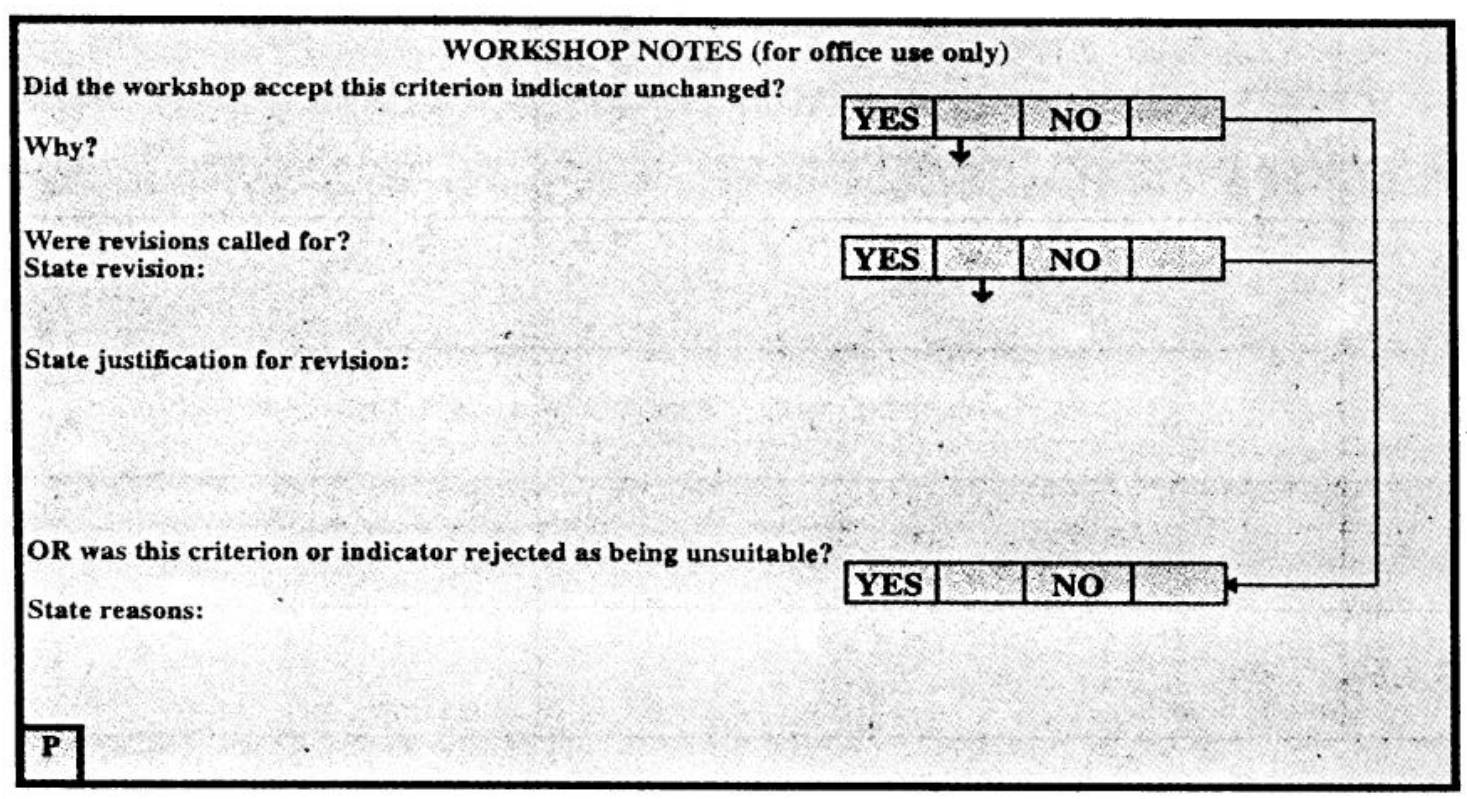

Response Form 2, page 4 (5.4.95) 


\section{AN NEX 5 \\ STATISTICAL ANALYSIS AND THE TEST IN GERMANY}

The test, which took place in Forstamt Bovenden in the Lower Saxony State had three main objectives:

- provision of sufficient information about the forest management system in use at the test site, and its context, to enable the test team to test the $\mathrm{C} \& \mathrm{I}$,

- establishment of a database at CIFOR to show the variations among team members in their application of standard field techniques for assessment of issues related to sustainable forest management, and

- provision of a testing ground for the development of methods to be used in subsequent tests. This was done together with partners from subsequent test sites.

Evaluation of C\&I took place through an interdisciplinary team consisting of foresters and ecologists. The evaluation of C\&I in the German test was based on an 18 point response form, filled in by all the experts to evaluate each indicator. Evaluations focused on such information as importance for maintenance of forest production, ecosystem, biodiversity, well-being of people, relevance to sustainability, whether or not the criteria are measurable and are precisely and objectively defined. Significant constraints were identified in the German test, some of which were partially rectified in the subsequent tests. They were:

1. Sample size. The sample size was only four (since the data was received from only four experts).

2. Uniformity of distribution. The distribution of disciplines was not uniform as the team consisted of three foresters and only one ecologist - a factor likely to have introduced some disciplinary bias. This was true too of the work experience of the respondents: two members were over 60 years old and two over 40 years old. The absence of adequate social science input was also regretted (and subsequently corrected).

Our objective in evaluating these responses for each indicator was to conclude whether or not all the experts were in perfect agreement and had applied essentially the same standard in ranking of these responses. The hypothesis, then, could be put in the form: $H_{0}$ =agreement among experts against $H_{\mid}=$no agreement among experts.

The sequence of computational procedures involved in analysing the data from testing of C\&I for sustainable management of forests are presented in detail in Annex 1.

\section{Results}

In the German test, four sets of C\&I were tested: Smart Wood, Woodmark, ITW and the C\&I of the Ministerial Conference for the Protection of Forests in Europe ('Helsinki Initiative'). The Helsinki C\&I were not included in the analysis because they were conceived for the national rather than FMU level. The evaluation of C\&I from these sets was carried out using an 18 point response form comprising various attributes explained above. These responses were broken down into two categories, substance and operational for each set. The substance and operational categories contained six and seven responses respectively. The remaining were descriptive and not considered for analysis.

\section{Substance Category}

Since the responses to the questions were measured on the nominal scale, all the responses from the four experts were initially ranked. We used the "Rank Correlation Test for agreement in Multiple Judgements" and Factor analysis (see Annex 1) to identify the principal factors affecting selection of C\&I by the experts. Whereas for the Smart Wood and Woodmark sets the two principal factors were "maintaining forest resource/production base" and "overall relevance to sustainable management", in the case of the ITW set these were "maintaining biodiversity" and "maintaining ecosystem". Factor 3 was difficult to interpret. We present the 20 percent most 'important' C\&I from each of these three sets in Annex 1. Our expectation is that these C\&I will be revealed as being important in other tests as well. However as the analysis of subsequent tests is still underway, we cannot yet provide evidence that this was indeed the case. We anticipate being in a position to conclude this discussion in the final version of this report when the analysis of the 'references' from the base sets listed by experts in their proposals is completed.

\section{O perational Category}

Characteristics such as objectivity, measurability and quantifiability, demand on time, requirement for professionals to assess the indicator, precise definition and period of time needed for the indicator to have an effect, were found to be important by the experts in evaluating the indicators. According to this analysis the top three factors ranked by experts were "objectivity", "measurability" and "how precisely a criterion or indicator had been defined". Another important factor in the case of the Smart Wood set was whether it was necessary to use a professional to assess a particular criterion or indicator. For the Woodmark set the "period of time to have effect" accounted for 25 percent of the total variance and the others together, 69 percent. Similar results were noted for the ITW set. 
Since the common factors considered represented most of the operational characteristics, weighted factor scores were calculated and ranked to evaluate the importance of the criteria. The C\&I that were found important were presented for all the three modules in Annex 1.

The analysis of data from the German test revealed that all the experts essentially applied the same standard in ranking the responses. The analysis of the 'operational' conditions that effective C\&I were expected to fulfil, provided us also with a ranking, which was an aid to developing the nine attributes of C\&I (discussed in sections 3.3 - 3.6). Although our efforts were hampered by the small sample size and a skewing of data due to the preponderance of foresters on the team, we were still able to derive meaningful results.

We will report these results in greater detail in a paper currently under preparation. 


\section{ANNEX 6 \\ ANALYSIS OF COMMONALITIES}

Tables showing commonalities and differences between the principles, criteria and indicators in the Indonesia, Côte d'Ivoire, and Brazil sets. Austrian results have been analysed for broad agreements with the commonalities of the three tropical tests. Results are presented in the following order:
1) Policy
2) Ecology
3) Social
4) 'Production'

For further details on the principles, criteria and indicators listed please see Annex 8. 
Annex 6: Analysis of Commonalities

\begin{tabular}{|c|c|c|c|c|c|c|}
\hline P.C.I.V & $\begin{array}{c}\text { Policy } \\
\text { Indonesia }\end{array}$ & P.C.I.V & $\begin{array}{c}\text { Policy } \\
\text { Côte d'Ivoire }\end{array}$ & P.C.I.V & $\begin{array}{l}\text { Policy } \\
\text { Brazil }\end{array}$ & Remarks \\
\hline principle & \multicolumn{6}{|c|}{ POLICY, PLANNING AND INSTITUTIONAL FRAMEWORKS ARE CONDUCIVE TO SUSTAINABLE FOREST MANAGEMENT. } \\
\hline D & $\begin{array}{l}\text { Policy, planning \& institutional } \\
\text { framework effective and committed to } \\
\text { sustainability } \\
\text { NOTE: These are national level } \\
\text { criteria and indicators }\end{array}$ & 0 & $\begin{array}{l}\text { Sustainability of the forest and its } \\
\text { multiple functions is a high political } \\
\text { priority. }\end{array}$ & $\begin{array}{l}0 . \\
0.1 \\
0.2 \\
0.3 .\end{array}$ & $\begin{array}{l}\text { Environmental and non } \\
\text { environmental policies and } \\
\text { planning create an environment } \\
\text { conducive to sustainable forest } \\
\text { management. } \\
\text { Environmental policies are } \\
\text { conducive to sustainable forest } \\
\text { management. } \\
\text { Non-environmental policies and } \\
\text { institutions are conducive to } \\
\text { sustainable forest management. } \\
\text { Regional development planning } \\
\text { creates a broad framework for the } \\
\text { design and implementation of } \\
\text { environmental and non- } \\
\text { environmental policies that are } \\
\text { conducive to sustainable forest } \\
\text { management. }\end{array}$ & $\begin{array}{l}\text { AUSTRIAN TEST: See 6.1.1.2 } \\
\text { Compliance with legal standards } \\
\text { points } \\
5 / 14,6 / 14, \text { and } 7 / 14 \text { and } \\
\text { specific items in the sections on } \\
\text { ecology, economy and } \\
\text { socio-economy. }\end{array}$ \\
\hline criterion & \multicolumn{6}{|c|}{ There is sustained and adequate funding for the management of forests. } \\
\hline D.1.5 & $\begin{array}{l}\text { An adequate percentage of the total } \\
\text { revenue from forest is re-invested in } \\
\text { maintaining the PFE. }\end{array}$ & 0.2 .1 & $\begin{array}{l}\text { The Government allocates adequate } \\
\text { means for sustainable management of } \\
\text { the State forests. } \\
\text { There is a mechanism for sustained and } \\
\text { adequate funding for the management } \\
\text { of State forests. }\end{array}$ & {$[0.1 .5]$} & $\begin{array}{l}\text { [Environmental policies have } \\
\text { instruments to pay forest producers for } \\
\text { the value of forest goods and services } \\
\text { from sustainably managed forests.] }\end{array}$ & \\
\hline indicator & \multicolumn{6}{|c|}{ Policy and planning are based on recent and accurate information. } \\
\hline D.3.1 & $\begin{array}{l}\text { Policy and planning is based on recent } \\
\& \text { accurate information }\end{array}$ & 0.1 .6 & $\begin{array}{l}\text { The Government has a system for } \\
\text { reliable, adequate and updated } \\
\text { information on the forestry sector. } \\
\text { Consequently, while maintaining the }\end{array}$ & 0.3 .4 & $\begin{array}{l}\text { Planning of location of production } \\
\text { forest lands is based on up to date } \\
\text { information on current production } \\
\text { systems, stocks and potentials of }\end{array}$ & \\
\hline
\end{tabular}


Annex 6: Analysis of Commonalities

\begin{tabular}{|c|c|c|c|c|c|c|}
\hline P.C.I.V & $\begin{array}{l}\text { Policy } \\
\text { Indonesia }\end{array}$ & P.C.I.V & $\begin{array}{l}\text { Policy } \\
\text { Côte d'Ivoire }\end{array}$ & P.C.I.V & $\begin{array}{l}\text { Policy } \\
\text { Brazil }\end{array}$ & Remarks \\
\hline & & 0.1 .5 & $\begin{array}{l}\text { objective of sustainable forest } \\
\text { development, the Government can } \\
\text { update its action plans and adjust the } \\
\text { means involved according to } \\
\text { developments in the sector. } \\
\text { There is a continuous forest inventory, } \\
\text { in particular: an updated map of forest } \\
\text { cover: a quantiative (volume, } \\
\text { increment) and qualitative (species, } \\
\text { quality) assessment of present timber } \\
\text { resources }\end{array}$ & & $\begin{array}{l}\text { multiple forest products (e.g. non- } \\
\text { timber, timber, fish, game) and } \\
\text { services (e.g. carbon, watersheds). }\end{array}$ & \\
\hline indicator & \multicolumn{6}{|c|}{ Effective instruments for inter-sectoral co-ordination on land use and land management exist. } \\
\hline D.3.2 & $\begin{array}{l}\text { Effective instruments for inter-sectoral } \\
\text { co-ordination on land use \& land } \\
\text { management exist. }\end{array}$ & 0.3 .2 & $\begin{array}{l}\text { Action is taken by Government to } \\
\text { reduce all types of pressure on the } \\
\text { forest. } \\
\text { The Government implements } \\
\text { appropriate programmes to stabilize } \\
\text { agriculture. In particular: } \\
\text { - Efficient and economically viable } \\
\text { technical packages are developed and } \\
\text { massively disseminated among small } \\
\text { farmers; } \\
\quad \text { Funding mechanisms allowing } \\
\text { small farmers to achieve such } \\
\text { intensification are established (e.g. } \\
\text { preferential loans). }\end{array}$ & $\begin{array}{l}0.2 .1 \\
0.2 .6\end{array}$ & $\begin{array}{l}\text { Inter-sectoral policies are integrated } \\
\text { and in tune with the goal of promoting } \\
\text { sustainable forest management } \\
\text { Agricultural policies do not encourage } \\
\text { deforestation in areas with clear } \\
\text { suitability to forestry activities (e.g. } \\
\text { hilly topography) } \\
\text { Transpor policies take into account } \\
\text { their positive and negative impacts on } \\
\text { SFM and existing lannd use plan } \\
\text { Agricultural policies encourage } \\
\text { sustainable agricultural land use } \\
\text { systems, reducing the pressure for } \\
\text { deforestation }\end{array}$ & - \\
\hline indicator & \multicolumn{6}{|c|}{$\begin{array}{l}\text { There is a permanent forest estate (PFE), adequately protected by law, which is the basis for sustainable management, including both protection and } \\
\text { production forest. }\end{array}$} \\
\hline D.1.1 & $\begin{array}{l}\text { A permanent forest estate (PFE) } \\
\text { comprising both protection and } \\
\text { production forest has been constituted, }\end{array}$ & 0.1 .2 & $\begin{array}{l}\text { There is a permanent forest estate } \\
\text { governed by laws and regulations, not } \\
\text { subject to changes, which are the basis }\end{array}$ & 0.1 .6 & $\begin{array}{l}\text { Environmental policies promote } \\
\text { effective protection of representative } \\
\text { ecosystems, endangered species and } \\
\text { watersheds. }\end{array}$ & \\
\hline
\end{tabular}


Annex 6: Analysis of Commonalities

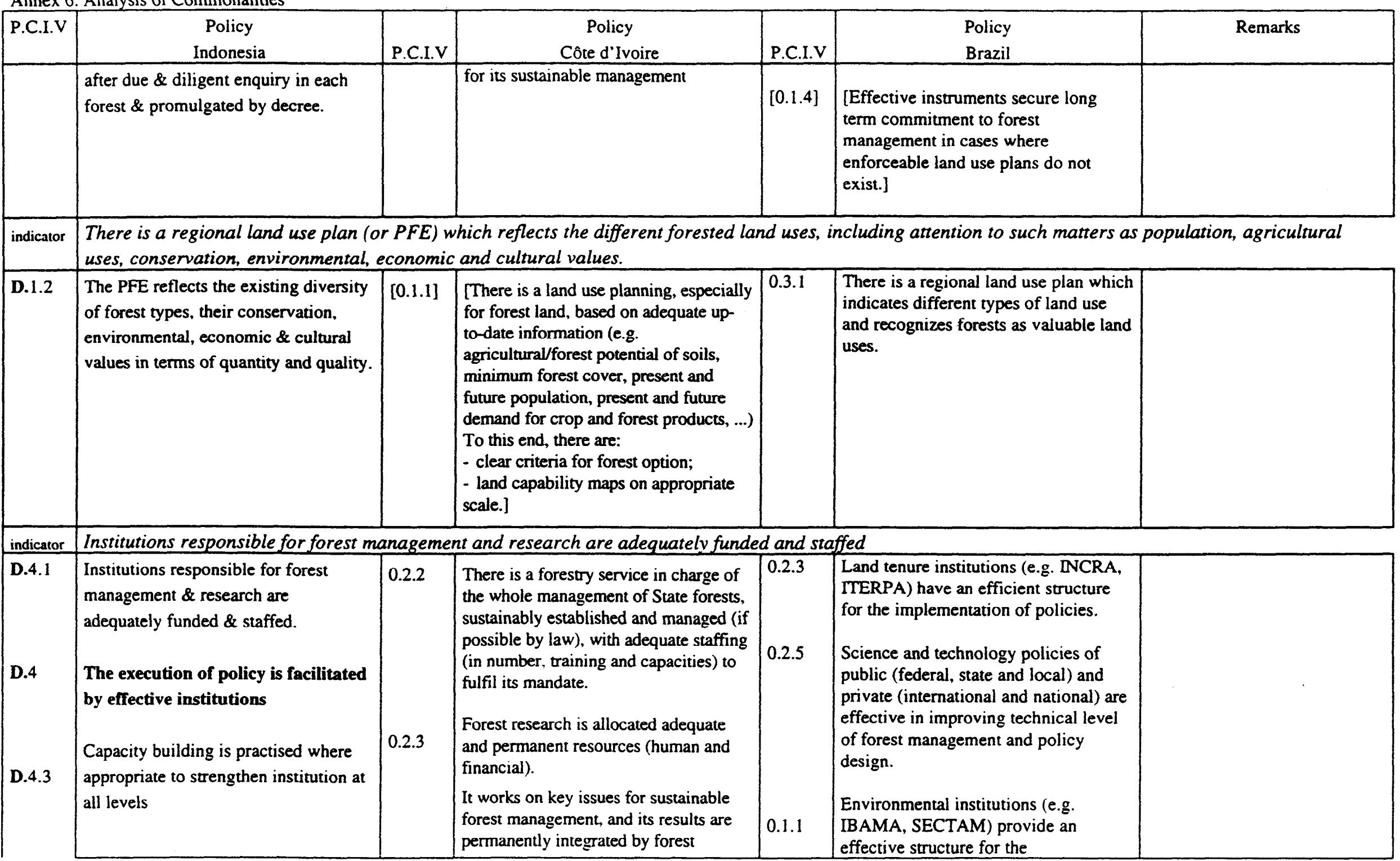


Annex 6: Analysis of Commonalities

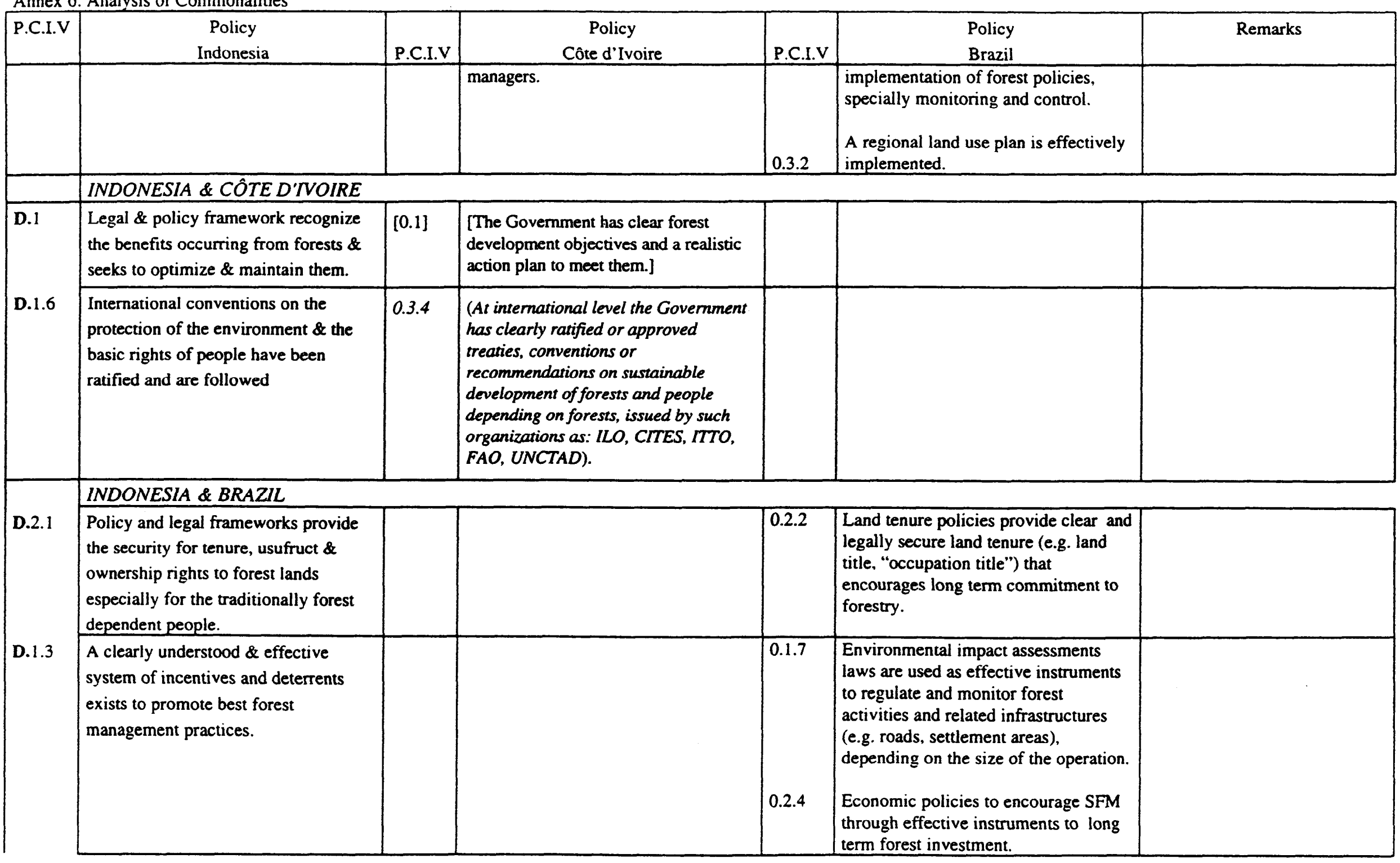




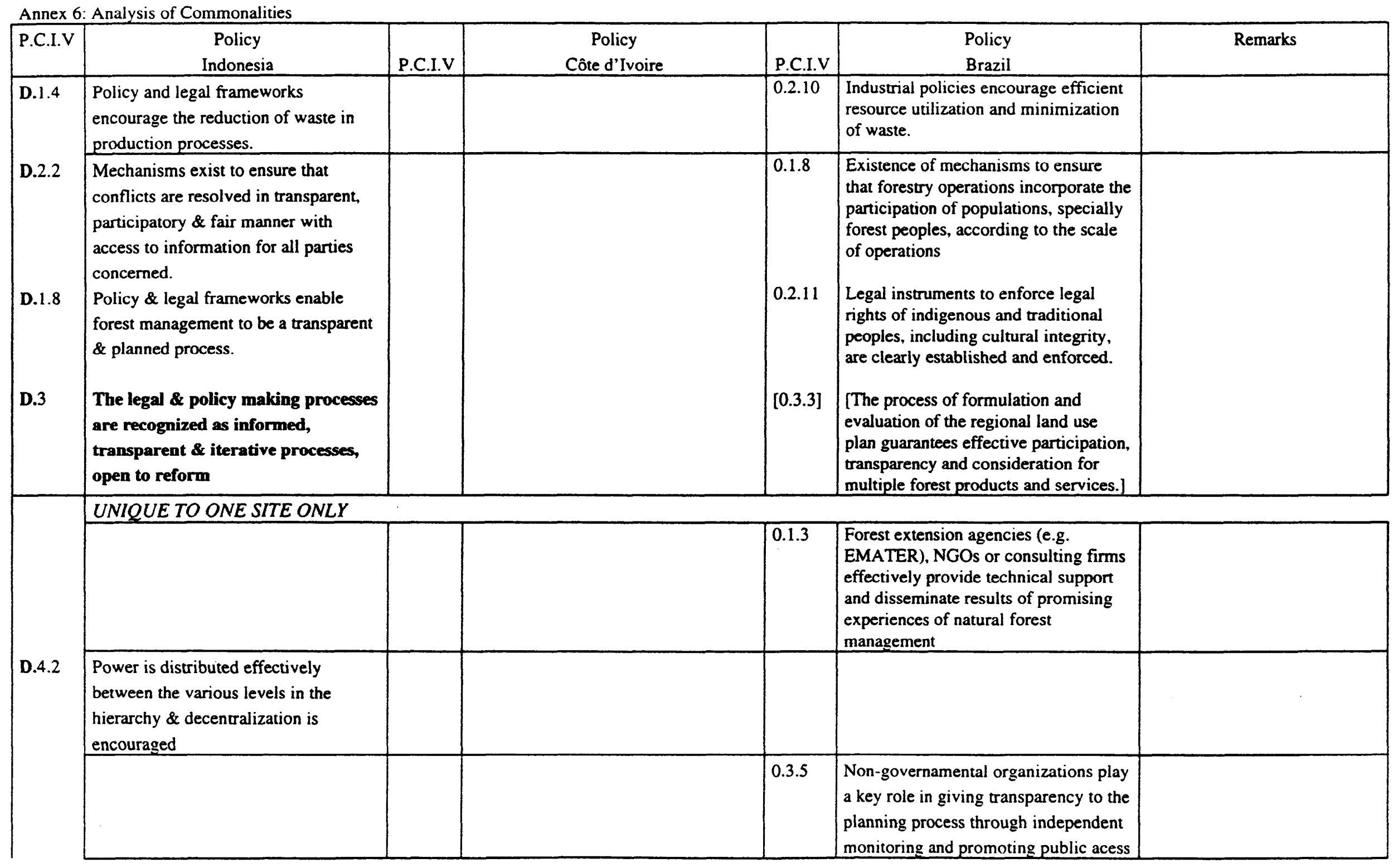




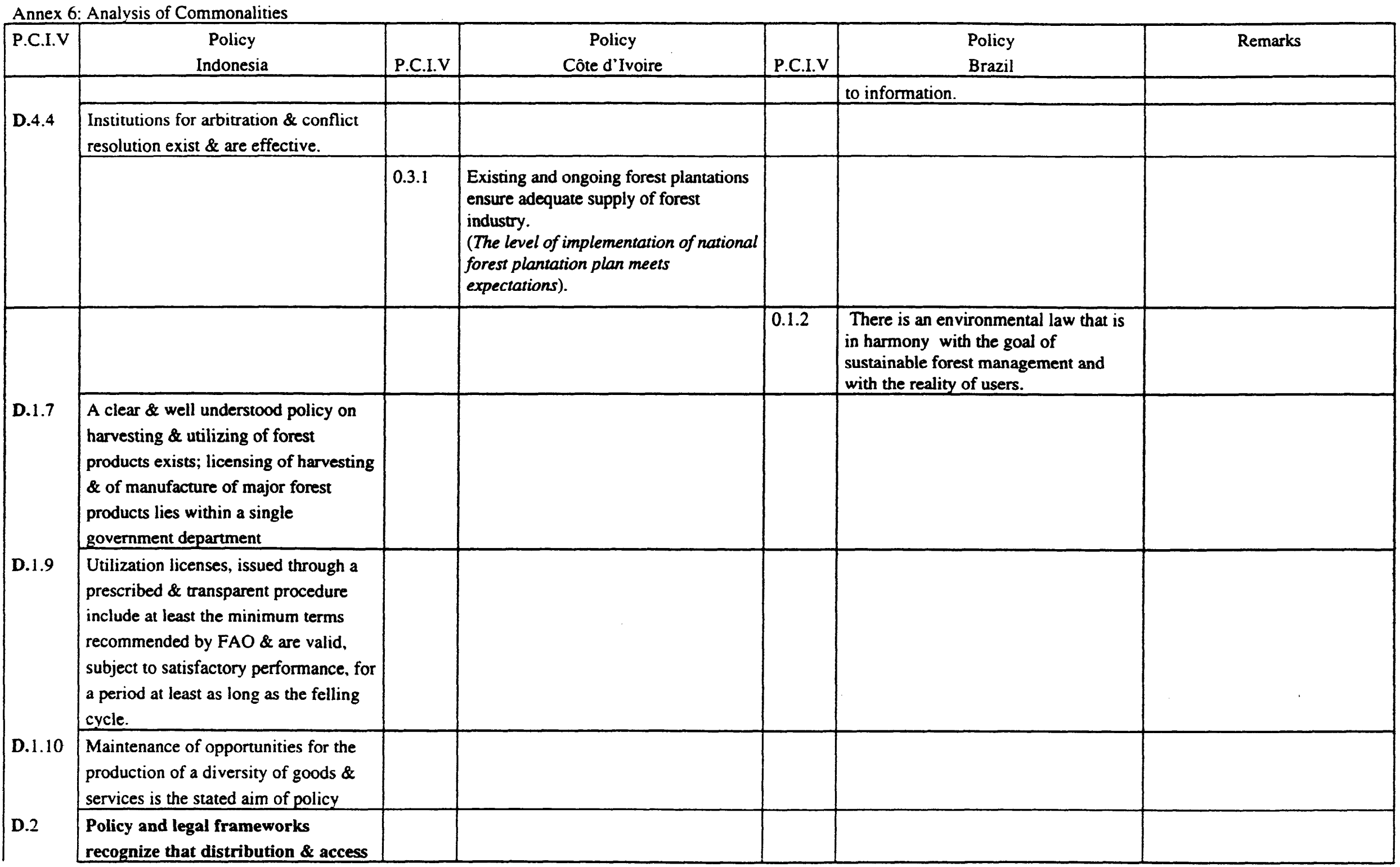


Annex 6: Analysis of Commonalities

\begin{tabular}{|c|c|c|c|c|c|c|}
\hline P.C.I.V & $\begin{array}{c}\text { Policy } \\
\text { Indonesia }\end{array}$ & P.C.I.V & $\begin{array}{c}\text { Policy } \\
\text { Côte d'Ivoire } \\
\end{array}$ & P.C.I.V & $\begin{array}{l}\text { Policy } \\
\text { Brazil }\end{array}$ & Remarks \\
\hline D.3.3 & & 0.3 .3 & $\begin{array}{l}\text { The population increase (birth rate and } \\
\text { immigration) does not lead to demand } \\
\text { of subsistence crop products exceeding } \\
\text { productive capacity of the rural sector. }\end{array}$ & & & \\
\hline
\end{tabular}


Annex 6: Analysis of Commonalities

\begin{tabular}{|c|c|c|c|c|c|c|}
\hline P.C.I.V & $\begin{array}{l}\text { Ecology } \\
\text { Indonesia }\end{array}$ & P.C.I.V & $\begin{array}{l}\text { Ecology } \\
\text { Côte d'Ivoire }\end{array}$ & P.C.I.V & $\begin{array}{l}\text { Ecology } \\
\text { Brazil }\end{array}$ & Remarks \\
\hline & \multicolumn{6}{|c|}{ MAINTENANCE OF ECOSYSTEM INTEGRITY } \\
\hline I. & Ecosystem integrity is maintained & & "Function preferred" & I. & $\begin{array}{l}\text { A sustainable forest management can } \\
\text { only be reached if the ecosystem's } \\
\text { integrity is maintained. }\end{array}$ & Common to Indonesia \& bra \\
\hline \multirow[b]{2}{*}{1.3.} & \multicolumn{6}{|l|}{ ECOSYSTEM FUNCTION IS MAINTAINED } \\
\hline & Ecosystem function is maintained & III. & $\begin{array}{l}\text { The main ecological functions of the } \\
\text { forest are maintained. }\end{array}$ & I.1. & $\begin{array}{l}\text { Maintenance of critical ecosystem } \\
\text { functions and processes is secured at } \\
\text { all stages of forest management } \\
\text { (spatial and temporal). }\end{array}$ & $\begin{array}{l}\text { COMMON CI } \\
\text { AUSTRIAN TEST: Principle under } \\
\text { section 6.2.2.1 }\end{array}$ \\
\hline \multirow[b]{2}{*}{ I.3.1. } & \multicolumn{6}{|c|}{ No chemical contamination to food chains and ecosystem } \\
\hline & $\begin{array}{l}\text { Chemicals banned in Europe, } \\
\text { America or target country are not } \\
\text { used. }\end{array}$ & III. & $\begin{array}{l}\text { Flora, fauna, water and people should be } \\
\text { protected against chemical } \\
\text { contamination. }\end{array}$ & [1.3.2.] & $\begin{array}{l}\text { [There is no chemical contamination } \\
\text { (quantities above the level established } \\
\text { by pertinent legislation) to food chains } \\
\text { and ecosystem] }\end{array}$ & $\begin{array}{l}\text { COMMON CI } \\
\text { AUSTRIAN TEST: C68/14, 306, } \\
\text { 120/3, Principle under 6.2.1.2.4 }\end{array}$ \\
\hline \multirow[b]{2}{*}{ 1.3.2. } & \multicolumn{6}{|c|}{ Ecologically sensitive areas, especially buffer zones along water courses, are protected } \\
\hline & $\begin{array}{l}\text { Appropriately sized stream//ake } \\
\text { buffers not disturbed }\end{array}$ & $\begin{array}{l}\text { III.3.5 } \\
\text { m. } 4 \\
\text { m. } 4.1\end{array}$ & $\begin{array}{l}\text { Sensitive areas, flats, stream banks, steep } \\
\text { slopes are excluded from working plans } \\
\text { and considered biological reserves } \\
\text { The function of water filter of the forest } \\
\text { is maintained } \\
\text { Decrease in water quality in the } \\
\text { watershed or sub-watershed }\end{array}$ & I.1.1 & $\begin{array}{l}\text { Water and soil quality is maintained to } \\
\text { secure ecosystem's sustainability }\end{array}$ & $\begin{array}{l}\text { COMMON C/ } \\
\text { AUSTRIAN TEST: Principle under } \\
6.2 .1 .2,111 / 2\end{array}$ \\
\hline \multirow[b]{2}{*}{ 1.3.4. } & \multicolumn{6}{|c|}{ No inadvertent ponding or waterlogging as a result of forest management } \\
\hline & $\begin{array}{l}\text { Absence of ponding behind } \\
\text { stream/river crossings }\end{array}$ & & [Covered under management IIA.11, IIA I1.4] & I.1.1.1 & $\begin{array}{l}\text { Ponds and swamps are not formed by } \\
\text { improper logging techniques or poor } \\
\text { drainage (verifier) }\end{array}$ & $\begin{array}{l}\text { COMMON CI } \\
\text { AUSTRIAN TEST: } 114 / 3,119 / 8 . \\
\text { Principle under } 6.2 .1 .2 .3\end{array}$ \\
\hline & \multicolumn{6}{|c|}{ IMPACTS TO BIODIVERSITY OF THE FOREST ECOSYSTEM ARE MINIMISED } \\
\hline 1.2. & Structure \& diversity of forest & [m.3] & [Biodiversity is preserved.] & 1.3. & Forest management minimizes & COMMON Cll \\
\hline
\end{tabular}


Annex 6: Analysis of Commonalities

\begin{tabular}{|c|c|c|c|c|c|c|}
\hline P.C.I.V & $\begin{array}{l}\text { Ecology } \\
\text { Indonesia }\end{array}$ & P.C.I.V & $\begin{array}{c}\text { Ecology } \\
\text { Côte d'Ivoire }\end{array}$ & P.C.I.V & $\begin{array}{c}\text { Ecology } \\
\text { Brazil }\end{array}$ & Remarks \\
\hline & $\begin{array}{l}\text { ecosystem resembles original } \\
\text { forest }\end{array}$ & m.3b & $\begin{array}{l}\text { Negative impacts on biodiversity should } \\
\text { be minimized. }\end{array}$ & [1.2.] & $\begin{array}{l}\text { impacts of logging on forest's } \\
\text { structure and biodiversity } \\
\text { [Forest management recognizes the } \\
\text { importance of biodiversity services] }\end{array}$ & $\begin{array}{l}\text { (Note III. } 3 \mathrm{a} \text { and III. } 3 \mathrm{~b} \text { counted as } \\
\text { integral pars of III.3) } \\
\text { AUSTRIAN TEST: } 58 / 14,59 / 14\end{array}$ \\
\hline \multirow[b]{2}{*}{ 1.2.1. } & \multicolumn{6}{|c|}{ Endangered plant and animal species are protected } \\
\hline & $\begin{array}{l}\text { There are prescribed measures for } \\
\text { the protection of key, rare and } \\
\text { endangered species, of both national } \\
\text { and international significance. }\end{array}$ & II. & $\begin{array}{l}\text { No tree of locally rare or endangered } \\
\text { species or species included in lists of } \\
\text { sensitive species is felled. }\end{array}$ & 1.2.1. & $\begin{array}{l}\text { Endangered plant and animal species } \\
\text { are protected according to CITES } \\
\text { agreement or national legislation on } \\
\text { endangered species }\end{array}$ & $\begin{array}{l}\text { COMMON CI } \\
\text { AUSTRIAN TEST: 29/14 }\end{array}$ \\
\hline \multirow[b]{2}{*}{ 1.2.3. } & \multicolumn{6}{|c|}{ Interventions are highly specific, selective and are confined to the barest minimum } \\
\hline & $\begin{array}{l}\text { Silvicultural treatments (including } \\
\text { climber cutting) are highly specific } \\
\text { and selective and are confined to the } \\
\text { barest minimum. }\end{array}$ & & $\begin{array}{l}\text { [Implicit in managementt IIA.1.2. IIA.1.3, } \\
\text { IIA.1.5] }\end{array}$ & 1.2.4. & $\begin{array}{l}\text { Interventions, if applied, are highly } \\
\text { specific to the individual tree level, } \\
\text { instead of to species or whole stands }\end{array}$ & $\begin{array}{l}\text { COMMON CII } \\
\text { AUSTRIAN TEST: } 77 / 8,67 / 14\end{array}$ \\
\hline \multirow{2}{*}{ I.1.2. } & \multicolumn{6}{|c|}{ Enrichment planting if carried out, should be based on indigenous, locally adapted species } \\
\hline & $\begin{array}{l}\text { [Covered in management } \\
\text { IIC.3.11] }\end{array}$ & III.3.9 & $\begin{array}{l}\text { If enrichment plantations are carried out } \\
\text { in logged-over forests, preference will be } \\
\text { given to species that were actually } \\
\text { harvested in these forests }\end{array}$ & I.2.3. & $\begin{array}{l}\text { Enrichment planting or restoration of } \\
\text { degraded areas is performed with } \\
\text { indigenous, locally adequate species }\end{array}$ & $\begin{array}{l}\text { COMMON CI } \\
\text { AUSTRIAN TEST: } 62114,310 \text { (broad } \\
\text { interpretation) }\end{array}$ \\
\hline & \multicolumn{6}{|c|}{ THE CAPACITY OF THE FOREST TO REGENERATE NATURALLY IS ENSURED } \\
\hline I.1. & Resilience of forest ecosystem is & [III.1.] & [The capacity of the forest for natural & 1.2.6. & Animal species which are negatively & COMMON C/1 \\
\hline
\end{tabular}




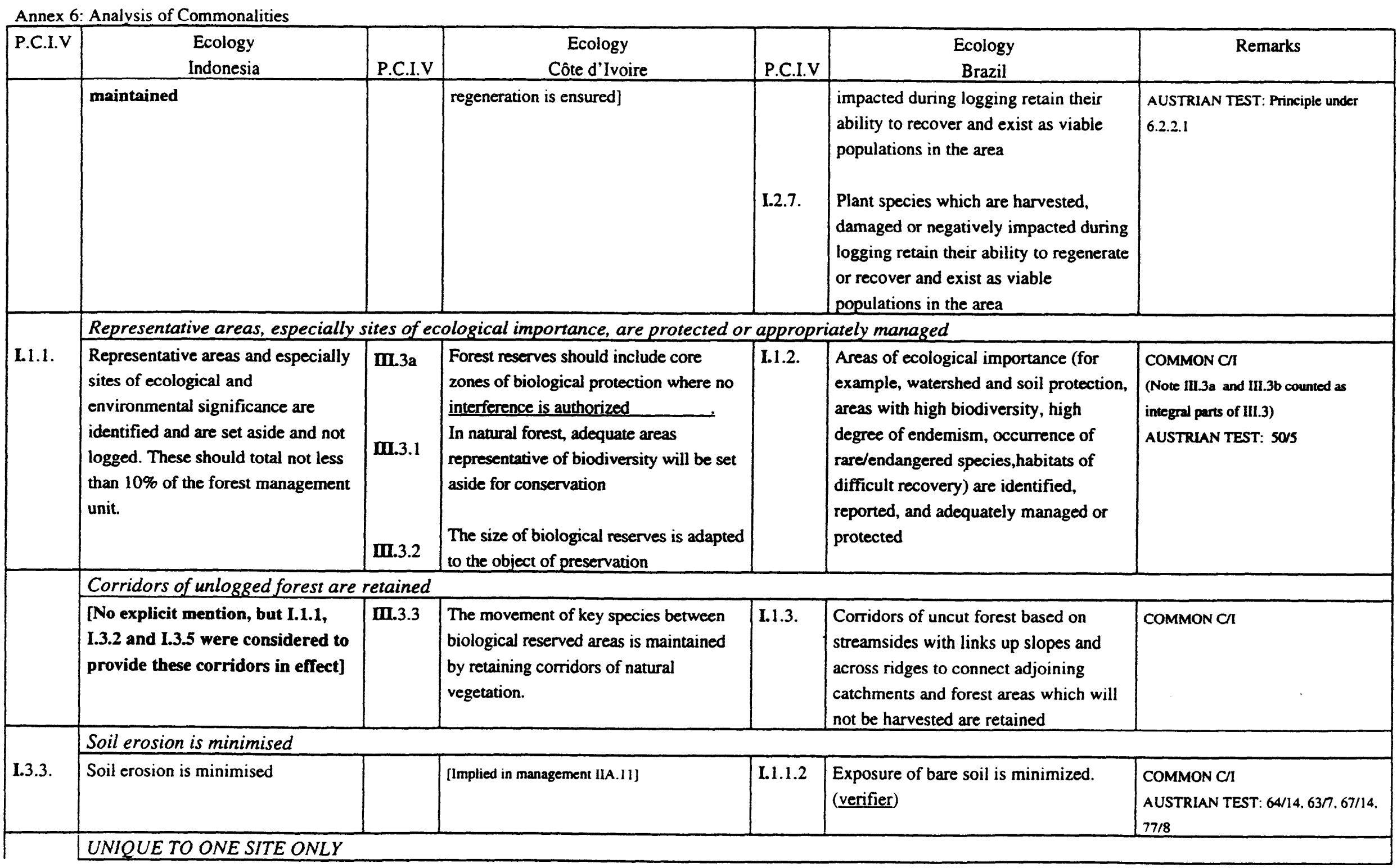




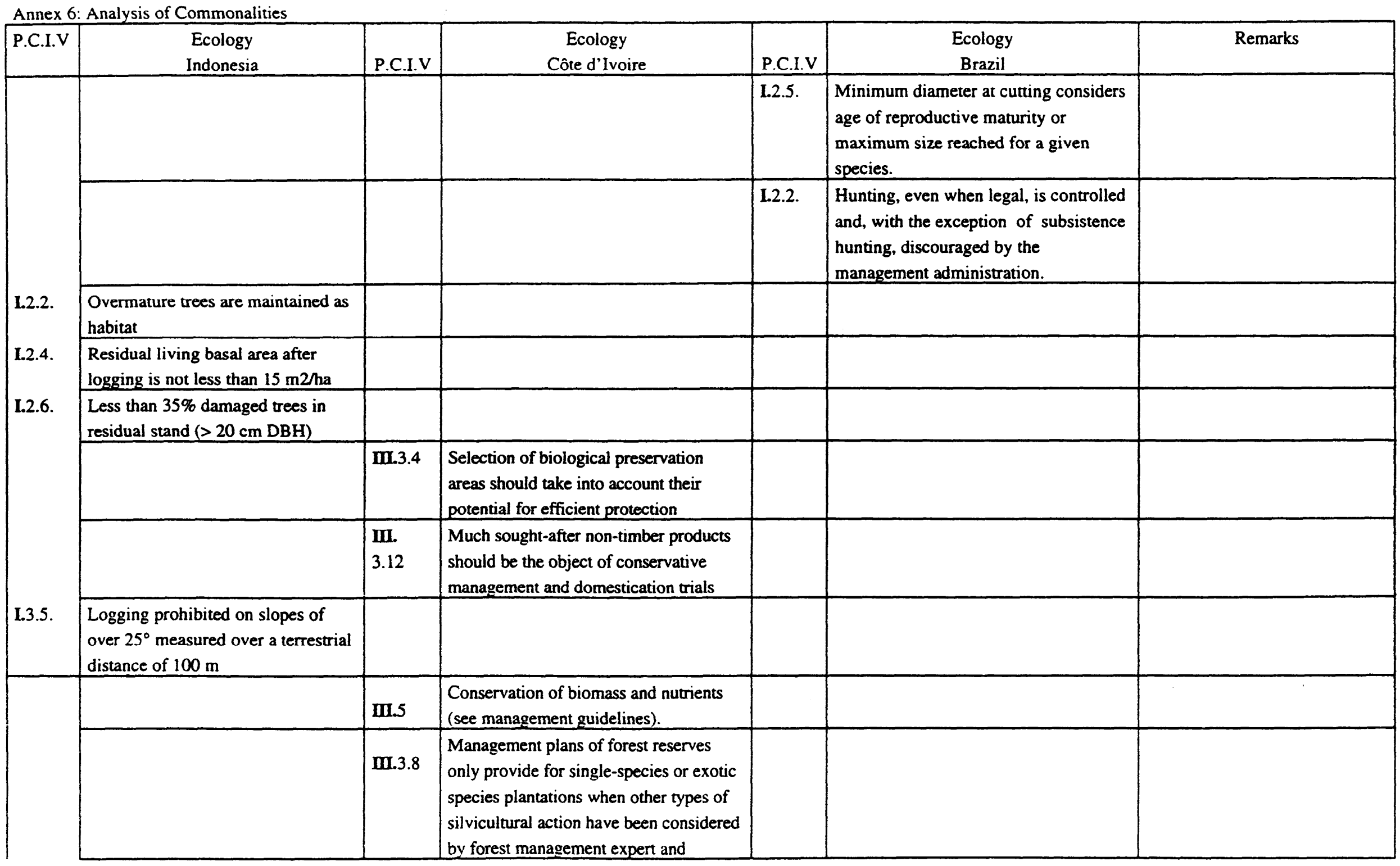




\begin{tabular}{|c|c|c|c|c|c|c|}
\hline P.C.I.V & $\begin{array}{c}\text { Ecology } \\
\text { Indonesia } \\
\end{array}$ & P.C.I.V & $\begin{array}{c}\text { Ecology } \\
\text { Côte d'Ivoire }\end{array}$ & P.C.I.V & $\begin{array}{c}\text { Ecology } \\
\text { Brazil }\end{array}$ & Remarks \\
\hline & & & abandoned for justified reasons. & & & \\
\hline & & & & I.1.4. & $\begin{array}{l}\text { Shape, location, and design of forest } \\
\text { compartments attempt to minimize } \\
\text { current and future edge effects due to } \\
\text { forest fragmentation }\end{array}$ & \\
\hline & & & & L.1.5. & $\begin{array}{l}\text { The management plan recognizes the } \\
\text { natural variability in the forest and } \\
\text { differences in rates of recovery (stand } \\
\text { productivity and vegetation structure), } \\
\text { and has monitoring mechanisms } \\
\text { sensitive enough to detect these } \\
\text { differences. }\end{array}$ & \\
\hline & & & & I.1.6. & $\begin{array}{l}\text { Producers and processors respect the } \\
\text { environmental laws }\end{array}$ & \\
\hline
\end{tabular}


Annex 6: Analysis of Commonalities

\begin{tabular}{|c|c|c|c|c|c|c|}
\hline P.C.I.V & $\begin{array}{c}\text { Social } \\
\text { Indonesia }\end{array}$ & P.C.I.V & $\begin{array}{c}\text { Social } \\
\text { Côte d'Ivoire }\end{array}$ & P.C.I.V & $\begin{array}{l}\text { Social } \\
\text { Brazil }\end{array}$ & Remarks \\
\hline & \multicolumn{6}{|c|}{ [implied]:FOREST MANAGEMENT MAINTAINS FAIR INTERGENERATIONAL ACCESS TO RESOURCES AND ECONOMIC BENEFITS. } \\
\hline \multirow[b]{2}{*}{ IIA.1 } & \multicolumn{6}{|c|}{ STAKEHOLDERS/FOREST ACTORS' TENURE AND USE RIGHTS ARE SECURE } \\
\hline & $\begin{array}{l}\text { Stakeholders' long term tenure and } \\
\text { user rights are secure }\end{array}$ & IV.2 & $\begin{array}{l}\text { The rights of all stakeholders } \\
\text { should be clearly defined and } \\
\text { perceived by all } \\
\text { Stakeholders' tenure rights are clear } \\
\text { to all parties and are secure }\end{array}$ & 0.1 & $\begin{array}{l}\text { Forest actors' long term tenure and } \\
\text { user rights are secure }\end{array}$ & $\begin{array}{l}\text { AUSTRIAN TEST: First three } \\
\text { principles under } 6.4 .1 .1\end{array}$ \\
\hline \multirow[b]{2}{*}{ IIA.1.1 } & \multicolumn{6}{|c|}{ Tenure/use rights are well defined and upheld } \\
\hline & $\begin{array}{l}\text { Long term tenure/use rights have } \\
\text { been legally settled }\end{array}$ & IV.1 & $\begin{array}{l}\text { All stakeholders have their user } \\
\text { rights well defined and secure }\end{array}$ & 0.1 .3 & $\begin{array}{l}\text { Land use rights of stakeholders } \\
\text { involved and impacted by the FMU } \\
\text { area are recognized and upheld. }\end{array}$ & $\begin{array}{l}\text { AUSTRIAN TEST: } 235 \mathrm{a} / 14 / \mathrm{F} \text {, } \\
\text { 234/13/F }\end{array}$ \\
\hline \multirow[b]{2}{*}{$\begin{array}{l}\text { IIA.2 } \\
\text { IIA.2.2 }\end{array}$} & \multicolumn{6}{|c|}{ Forest dependent people share in economic benefits of forest utilization } \\
\hline & $\begin{array}{l}\text { Forest dependent people share in } \\
\text { economic benefits of forest } \\
\text { utilization } \\
\text { Fair and effective mechanisms for } \\
\text { sharing forest revenues with forest } \\
\text { dependent people }\end{array}$ & IV.6 & $\begin{array}{l}\text { Sharing of benefits from the forest is } \\
\text { perceived as just. }\end{array}$ & 0.4 & $\begin{array}{l}\text { There are contributions to social } \\
\text { and/or economic development of } \\
\text { local population by the FMU. }\end{array}$ & $\begin{array}{l}\text { AUSTRIAN TEST: 236/14/F (broad } \\
\text { interpretation) }\end{array}$ \\
\hline \multirow{3}{*}{ IIA.2.4 } & \multicolumn{6}{|c|}{ Opportunities exist for local people/forest dependent people to get employment and training from forest companies } \\
\hline & $\begin{array}{l}\text { Forest dependent people have } \\
\text { significant opportunities to work } \\
\text { and be trained in company without } \\
\text { discrimination }\end{array}$ & IV.6.4 & $\begin{array}{l}\text { Forest dependent people have } \\
\text { opportunity to get employment and } \\
\text { training from forest companies }\end{array}$ & 0.4 .2 & $\begin{array}{l}\text { Local populations have priority in } \\
\text { opportunities for education, } \\
\text { employment, training, services and } \\
\text { support for community } \\
\text { organization. }\end{array}$ & AUSTRIAN TEST: $225 / 5,252 / 2,611$ \\
\hline & \multicolumn{6}{|c|}{ [implied]:STAKEHOLDERS, INCLUDING FOREST ACTORS, HAVE A VOICE IN FOREST MANAGEMENT } \\
\hline \multirow[b]{2}{*}{ IIB.5 } & \multicolumn{6}{|c|}{ STAKEHOLDERS/LOCAL POPULATIONS PARTICIPATE IN FOREST MANAGEMENT } \\
\hline & All stakeholders participate in & IV.3 & All stakeholders participate in forest & 0.3 .8 & Local populations are guaranteed & AUSTRIAN TEST: 606 \\
\hline
\end{tabular}




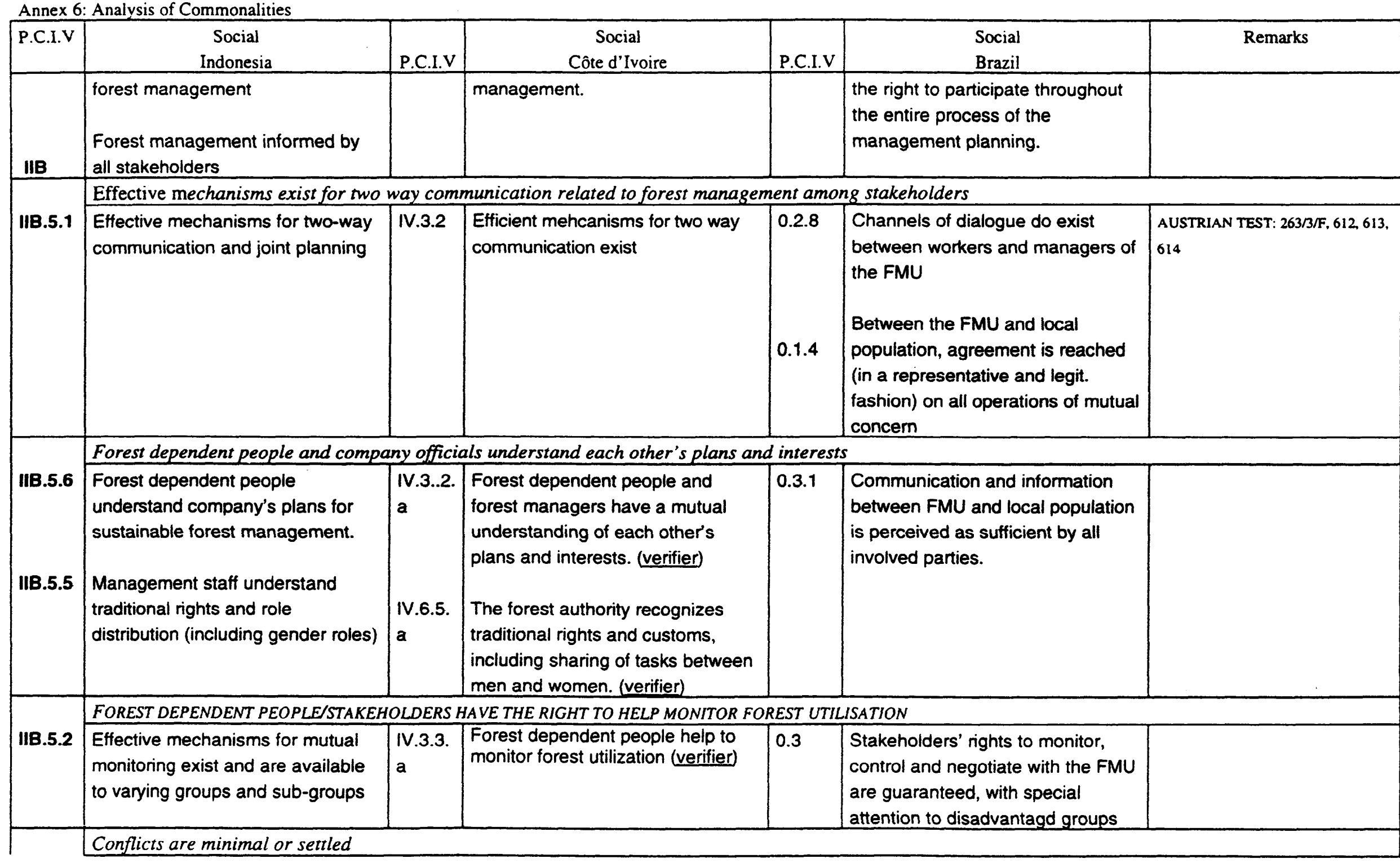




\begin{tabular}{|c|c|c|c|c|c|c|}
\hline 114.3 .2 & $\begin{array}{l}\text { Little or no conflict among } \\
\text { stakeholders re natural resources }\end{array}$ & $\begin{array}{l}\text { IV.3.3. } \\
\mathrm{b}\end{array}$ & $\begin{array}{l}\text { Chronic conflicts should be finally } \\
\text { settled. (verifier) }\end{array}$ & 0.1 .2 & $\begin{array}{l}\text { There are no significant conflicts, } \\
\text { disputes or significant claims on } \\
\text { property and use rights }\end{array}$ & AUSTRIAN TEST: $235 / 14 \mathrm{~h} / \mathrm{F}$ \\
\hline & \multicolumn{6}{|c|}{ CI COMMON TO INDONESIA AND CÔTE D'IVOIRE } \\
\hline II.A & $\begin{array}{l}\text { Access to benefits from forest is } \\
\text { perceived as just }\end{array}$ & IV.1.2 & $\begin{array}{l}\text { The definition of access to forest- } \\
\text { based natural resources is } \\
\text { accepted by all stakeholders. }\end{array}$ & & & \\
\hline ||A.1.4 & $\begin{array}{l}\text { No significant informed concem by } \\
\text { forest dependent people over } \\
\text { security of rights. }\end{array}$ & IV.1.3 & $\begin{array}{l}\text { No significant concern among } \\
\text { stakeholders on security of rights of } \\
\text { access to forest-based natural } \\
\text { resources. }\end{array}$ & & & \\
\hline HA.3 & $\begin{array}{l}\text { Demands by stakeholders on } \\
\text { environment consistent with the } \\
\text { capacity of the forest to } \\
\text { accommodate them }\end{array}$ & IV.5 & $\begin{array}{l}\text { Demand by stakeholders on the } \\
\text { forest is consistent with its } \\
\text { capacity to meet it. [referred to } \\
\text { ecology C\&l] }\end{array}$ & & & \\
\hline IIA.3.4 & $\begin{array}{l}\text { Cycle of shifting cultivation } \\
\text { adequate. }\end{array}$ & $\begin{array}{l}\text { IV.4.1. } \\
\text { C }\end{array}$ & $\begin{array}{l}\text { Agriculture is stabilized and } \\
\text { intensified to prevent food deficit } \\
\text { among local populations. (verifier) }\end{array}$ & & & \\
\hline IIB.5.4 & $\begin{array}{l}\text { Resource managers cooperate to } \\
\text { assimilate differing management } \\
\text { models }\end{array}$ & IV.6.5 & $\begin{array}{l}\text { Forest utilization reflects the } \\
\text { necessary compromises and } \\
\text { complementarities. }\end{array}$ & & & \\
\hline
\end{tabular}




\begin{tabular}{|c|c|c|c|c|c|c|}
\hline $\begin{array}{l}\text { IIA.1.3 } \\
\text { \|A.4.2 }\end{array}$ & $\begin{array}{l}\text { Fair and effective mechanisms for } \\
\text { resource management and conflict } \\
\text { resolution exist which include all } \\
\text { relevant groups } \\
\text { Effective mechanisms for trial \& } \\
\text { punishment of offenders }\end{array}$ & & & 0.3 .4 & $\begin{array}{l}\text { Conflicts are resolved in order to } \\
\text { facilitate the participation of all } \\
\text { relevant stakeholders, and includes } \\
\text { mutually acceptable neutral } \\
\text { arbitration. }\end{array}$ & \\
\hline IIA.3.3 & $\begin{array}{l}\text { Historically, culturally and } \\
\text { ecologically important } \\
\text { characteristics of forest } \\
\text { distinguished and appropriately } \\
\text { appraised }\end{array}$ & & & $\begin{array}{l}0.5 \\
0.5 .1 \\
0.5 .2\end{array}$ & $\begin{array}{l}\text { Respect for and protection of } \\
\text { cultural and religious sites of } \\
\text { special significance has priority } \\
\text { over any utilization. } \\
\text { Cultural and religious sites of } \\
\text { special significance to local } \\
\text { cultures, traditions and religions of } \\
\text { indians are protected by the FMU } \\
\text { in cooperation and coordination } \\
\text { with local populations, institutions, } \\
\text { and authorities. } \\
\text { When archaeological sites or } \\
\text { artifacts are located during } \\
\text { operations, all relevant authorities } \\
\text { must be notified immediately and } \\
\text { the sites recorded prior to further } \\
\text { disturbance. }\end{array}$ & \\
\hline
\end{tabular}




\begin{tabular}{|c|c|c|c|c|c|c|}
\hline & & IV.6.2 & $\begin{array}{l}\text { Damages are compensated in a } \\
\text { fair manner }\end{array}$ & 0.1 .5 & $\begin{array}{l}\text { Damages to resources of local } \\
\text { population or FMU are } \\
\text { compensated in a manner which is } \\
\text { perceived as sataisfactory and just } \\
\text { by the victim. }\end{array}$ & \\
\hline & & IV.6.3 & $\begin{array}{l}\text { Wages and other benefits conform } \\
\text { to national standards }\end{array}$ & 0.2 .1 & $\begin{array}{l}\text { Wages and other benefits (health } \\
\text { care, retirement, compensation, } \\
\text { education, housing, food) at least } \\
\text { fulfill legal requirements and are } \\
\text { equal to or better than prevailing } \\
\text { local and regional standards. }\end{array}$ & \\
\hline & & IV.4.2 & $\begin{array}{l}\text { Forest employers take care of } \\
\text { forest-related health risks for } \\
\text { workers. }\end{array}$ & 0.2 .1 .3 & $\begin{array}{l}\text { Health care and safety are at least } \\
\text { the legal minimum. (verifier) }\end{array}$ & \\
\hline IIA.3.1 & $\begin{array}{l}\text { Population increase, either natural } \\
\text { or thru in-migration, is in harmony } \\
\text { with maintaining the permanent } \\
\text { natural forest estate. }\end{array}$ & & & & & \\
\hline \multirow[t]{2}{*}{ IIA.4.1 } & $\begin{array}{l}\text { Agreement exists between } \\
\text { stakeholders on rights and } \\
\text { responsibilities }\end{array}$ & & & & & \\
\hline & & IV.3.3 & $\begin{array}{l}\text { Control mechanisms are supported } \\
\text { by all stakeholders. }\end{array}$ & & & \\
\hline IIA.4 & Access to forest resources & & & & & \\
\hline
\end{tabular}




\begin{tabular}{|c|c|c|c|c|c|c|}
\hline P.C.I.V & $\begin{array}{c}\text { Social } \\
\text { Indonesia } \\
\end{array}$ & P.C.I.V & $\begin{array}{c}\text { Social } \\
\text { Côte d'Ivoire }\end{array}$ & P.C.I.V & $\begin{array}{l}\text { Social } \\
\text { Brazil } \\
\end{array}$ & Remarks \\
\hline & effectively controlled & & & & & \\
\hline & & & & 0.1 .1 & $\begin{array}{l}\text { Forest management unit is } \\
\text { implementing forest management } \\
\text { on the basis of a legal title to the } \\
\text { land, recognized customary rights } \\
\text { or lease agreements }\end{array}$ & \\
\hline & & IV.1.1 & $\begin{array}{l}\text { Access to forest-based natural } \\
\text { resources is described. }\end{array}$ & & & \\
\hline & & IV..2.1 & $\begin{array}{l}\text { Tenure rights have been } \\
\text { delineated. }\end{array}$ & & & \\
\hline & & & & 0.2 & $\begin{array}{l}\text { Income and security of life } \\
\text { conditions are mandatory } \\
\text { preconditions for all parties } \\
\text { involved in the forest management } \\
\text { unit. }\end{array}$ & \\
\hline & & IV.4.1 & $\begin{array}{l}\text { The relationship between public } \\
\text { health and forestry is } \\
\text { acknowledged }\end{array}$ & & & \\
\hline & & & & 0.2 .2 & $\begin{array}{l}\text { Worker safety fulfills legal } \\
\text { requirements }\end{array}$ & \\
\hline & & & & 0.2 .3 & $\begin{array}{l}\text { Training corresponds to necessary } \\
\text { skills required for type of work }\end{array}$ & \\
\hline & & & & 0.2 .4 & $\begin{array}{l}\text { Temporary workers' labour rights } \\
\text { and benefits are respected as } \\
\text { required by law. }\end{array}$ & \\
\hline & & & & 0.2 .5 & $\begin{array}{l}\text { There are assured compensation } \\
\text { benefits in cases of accident. }\end{array}$ & \\
\hline & & & & 0.2 .6 & $\begin{array}{l}\text { Workers have the right to organize } \\
\text { guaranteed. }\end{array}$ & \\
\hline & & & & 0.2 .7 & Workers have the right to collective & \\
\hline
\end{tabular}




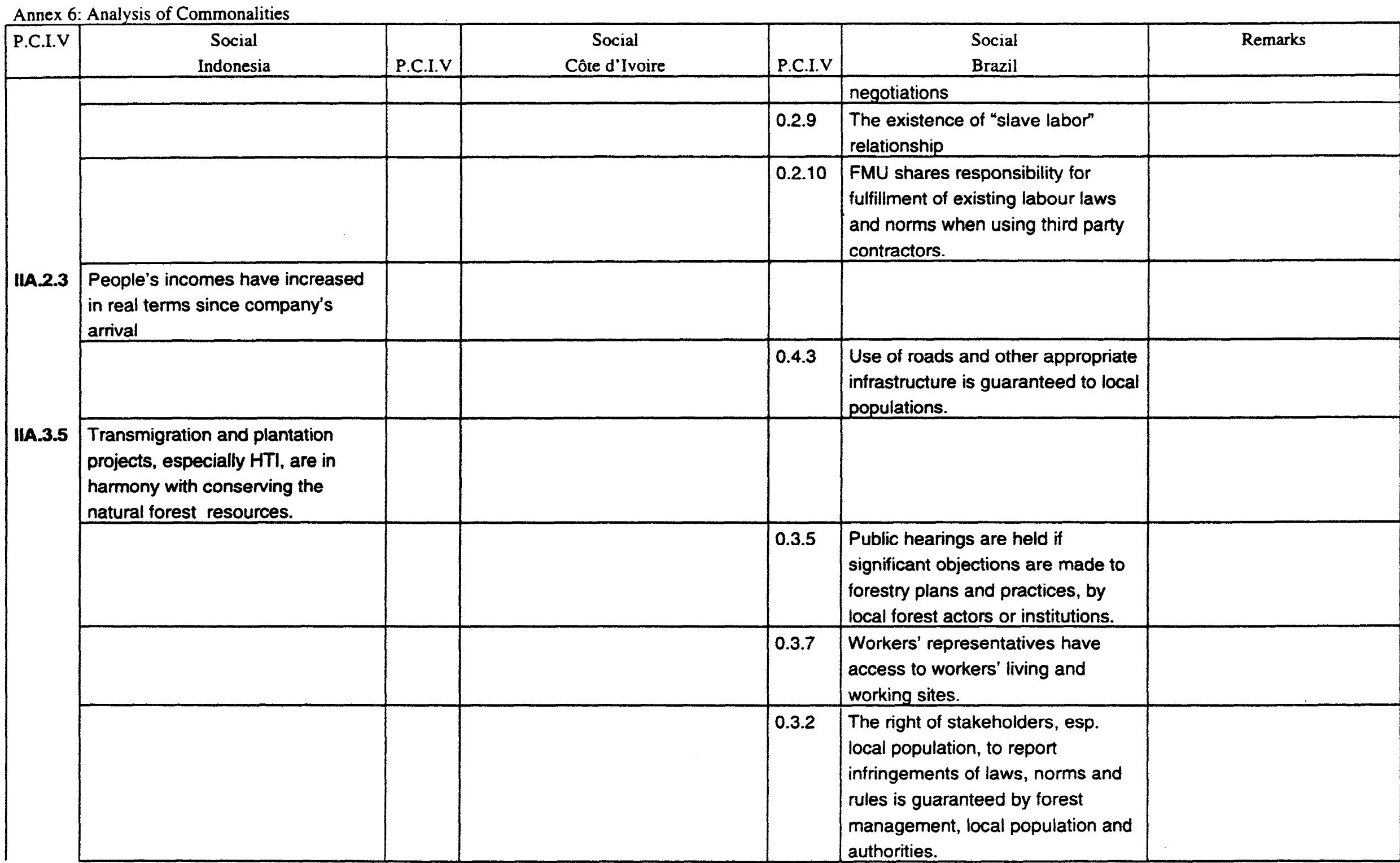




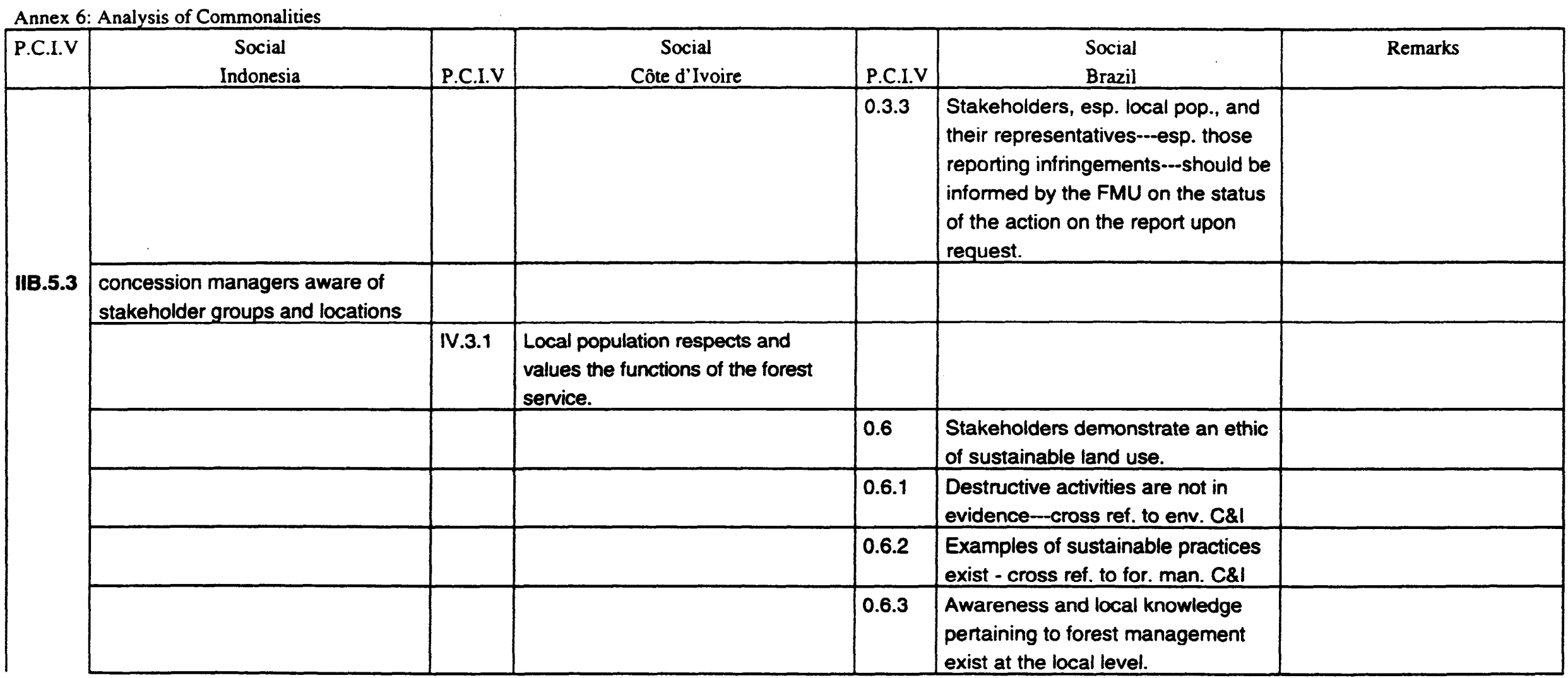


Annex 6: Analysis of Commonalities

\begin{tabular}{|c|c|c|c|c|c|c|}
\hline P.C.I.V & $\begin{array}{l}\text { 'Production' } \\
\text { Indonesia }\end{array}$ & P.C.I.V & $\begin{array}{l}\text { 'Production' } \\
\text { Côte d'Ivoire }\end{array}$ & P.C.I.V & $\begin{array}{c}\text { 'Production' } \\
\text { Brazil }\end{array}$ & Remarks \\
\hline & \multicolumn{6}{|c|}{ YIELD AND QUALITY OF FOREST GOODS AND SERVICES SUSTAVNABLE } \\
\hline C. & $\begin{array}{l}\text { Yield and quality of forest goods \& } \\
\text { services sustainable }\end{array}$ & $\begin{array}{l}\text { IIA. } \\
\text { [II.] } \\
\text { [IIB] }\end{array}$ & $\begin{array}{l}\text { Sustainable timber production is } \\
\text { possible in adequate quantity and } \\
\text { quality through patrimonial } \\
\text { management. } \\
\text { [The forest is adequately managed] } \\
\text { [Sustainable production of non- } \\
\text { timber forest products is ensured] }\end{array}$ & IIB. & $\begin{array}{l}\text { Sustained yield forest management is } \\
\text { assured }\end{array}$ & $\begin{array}{l}\text { AUSTRIAN TEST: Princple under } \\
6.3 .1\end{array}$ \\
\hline \multirow[b]{2}{*}{ C.1.1 } & \multicolumn{6}{|c|}{ MANAGEMENT OBJECTIVES CLEARLY AND PRECISELY DESCRIBED AND DOCUMENTED } \\
\hline & $\begin{array}{l}\text { Management objectives clearly \& } \\
\text { precisely described and documented }\end{array}$ & II.1.1 & $\begin{array}{l}\text { The managernent plan, established for a } \\
\text { period of } 10-20 \text { years, includes the } \\
\text { following: } \\
\text { - definition of the forest area submitted } \\
\text { to sustainable management; } \\
\text { - key findings of studies and analyses } \\
\text { on all functions and uses of the forest } \\
\text { (timber production, other forest } \\
\text { products, farmer-forest relationship, } \\
\text { forest ecosystem); } \\
\text { - identification of objectives and } \\
\text { priorities in these various fields; } \\
\text { - relevant action plans to meet these } \\
\text { objectives; } \\
\text { - reference to laws and regulations } \\
\text { governing such actions; } \\
\text { - economic and financial evaluation; } \\
\text { - } \\
\text { a set of maps allowing a clear } \\
\text { synthetic overview of the results of } \\
\text { studies (vegetation map, forest } \\
\text { settlement map, etc.), the objectives } \\
\text { (map of working circles) and the action } \\
\text { plans (map of blocks for harvesting, }\end{array}$ & $\begin{array}{l}\text { IIB.2 } \\
\text { IIB. } \\
2.1 .1\end{array}$ & $\begin{array}{l}\text { Forest management is clearly } \\
\text { committed to sustainability } \\
\text { A clear statement of unambiguous long } \\
\text { term management objectives for the } \\
\text { Forest Management Unit (FMU) } \\
\text { (verifier) }\end{array}$ & AUSTRIAN TEST: $27 / 14,28 / 14$ \\
\hline
\end{tabular}




\begin{tabular}{|c|c|c|c|c|c|c|}
\hline P.C.I.V & $\begin{array}{l}\text { 'Production' } \\
\text { Indonesia }\end{array}$ & P.C.I.V & $\begin{array}{l}\text { 'Production' } \\
\text { Côte d'Ivoire } \\
\end{array}$ & P.C.I.V & $\begin{array}{l}\text { 'Production' } \\
\text { Brazil } \\
\end{array}$ & Remarks \\
\hline & & & replanting, etc.). & & & \\
\hline \multirow[b]{2}{*}{ C.1.1 } & \multicolumn{6}{|c|}{ Objectives are clearly stated in terms of the major functions of the forest, with due respect to their spatial distribution } \\
\hline & $\begin{array}{l}\text { DESCRIPTION OF OBJECTIVE BY MAJOR } \\
\text { FOREST TYPES \& NTFP (NON-TIMBER } \\
\text { FOREST PRODUCTS) AVALABLE }\end{array}$ & II.1.2 & $\begin{array}{l}\text { The objectives related to the various } \\
\text { functions of the forest (timber } \\
\text { production, other forest products, social } \\
\text { objectives, objective of ecosystem } \\
\text { preservation), their spatial disuribution } \\
\text { (series), respective priorities (within the } \\
\text { series) and resulting action plans are } \\
\text { clearly stated and documented: } \\
\text { - on the basis of preliminary studies, the } \\
\text { key findings of which are shown; } \\
\text { in compliance with national } \\
\text { management standards }\end{array}$ & $\begin{array}{l}\text { IIB. } \\
2.1 .3 \\
\text { IIB. } \\
2.1 .4\end{array}$ & $\begin{array}{l}\text { A description of the main forest types } \\
\text { in the FMU. (verifier) } \\
\text { A description of protected areas of } \\
\text { sufficient size and distribution, in } \\
\text { accordance with forest laws, to } \\
\text { safeguard basic ecosystem functions } \\
\text { which have been designated within the } \\
\text { FMU. (verifier) } \\
\text { A description of the socioeconomic } \\
\text { environment within which the forest } \\
\text { management unit is located. (verifier) }\end{array}$ & AUSTRIAN TEST: $172 / 2 / \mathrm{C}$ \\
\hline & \multicolumn{6}{|c|}{ A COMPREHENSIVE FOREST MANAGEMENT PLAN IS AVAILABLE } \\
\hline \multirow[t]{2}{*}{ C.1. } & $\begin{array}{l}\text { A vailability of comprehensive forest } \\
\text { management plan. }\end{array}$ & II.1 & $\begin{array}{l}\text { A management plan has been } \\
\text { established for a period of } 10 \text { to } 20 \\
\text { years in a perspective of sustainable } \\
\text { management. All forest components and } \\
\text { functions are taken into account: timber } \\
\text { production, other forest products, } \\
\text { contribution to well-being of local } \\
\text { people, ecology }\end{array}$ & IIB.2.1. & $\begin{array}{l}\text { A written long term forest } \\
\text { management plan, which complies } \\
\text { with the law, is available. } \\
\text { All forest operations are guided and } \\
\text { directed by an annual operation plan in } \\
\text { accordance with the owner's } \\
\text { commitment to sustainable forest } \\
\text { management. }\end{array}$ & $\begin{array}{l}\text { AUSTRIAN TEST: } 25 / 14,26 / 14 \\
\text { (broad interpretation) }\end{array}$ \\
\hline & \multicolumn{6}{|c|}{ Maps of resources, management, ownership and inventories available } \\
\hline C.1.2 & $\begin{array}{l}\text { Description of timber \& non-timber } \\
\text { resources \& their limit clear } \\
\text { Maps of resources, management, }\end{array}$ & IIA.3.1 & $\begin{array}{l}\text { Fully consistent with silvicultural } \\
\text { standards, and based on preliminary } \\
\text { inventory, the area to be harvested over } \\
\text { the management plan period is assessed }\end{array}$ & $\begin{array}{l}\text { IIB. } \\
2.1 .6\end{array}$ & $\begin{array}{l}\text { Forest inventory data of the FMU, } \\
\text { especially: } \\
\text { - list of species occurring in the FMU, } \\
\text { - number of trees per ha. Per species }\end{array}$ & AUSTRIAN TEST: $401 / \mathrm{C}$ \\
\hline
\end{tabular}


Annex 6: Analysis of Commonalities

\begin{tabular}{|c|c|c|c|c|c|c|}
\hline P.C.I.V & $\begin{array}{l}\text { 'Production' } \\
\text { Indonesia } \\
\end{array}$ & P.C.I.V & $\begin{array}{l}\text { 'Production' } \\
\text { Côte d'Ivoire } \\
\end{array}$ & P.C.I.V & $\begin{array}{c}\text { 'Production' } \\
\text { Brazil } \\
\end{array}$ & Remarks \\
\hline & $\begin{array}{l}\text { ownership, together with inventories } \\
\text { available (verifier) }\end{array}$ & IIB.3.2 & $\begin{array}{l}\text { and mapped } \\
\text { Location and representation on a map } \\
\text { [NTFP] }\end{array}$ & $\begin{array}{l}\text { IIB. } \\
2.1 .9\end{array}$ & $\begin{array}{l}\text { and size classes, } \\
\text { - basal area and volume per ha. Per } \\
\text { species and size classes. (verifier) } \\
\text { Maps at an adequate scale providing } \\
\text { detailed information for management } \\
\text { activities such as: location and access } \\
\text { to the FMU, forest types, hydrology, } \\
\text { annual coupes, etc. (verifier) } \\
\end{array}$ & \\
\hline \multirow[b]{2}{*}{ C.1.3 } & \multicolumn{6}{|c|}{ Silvicultural systems prescribed and appropriate to forest type and produce grown } \\
\hline & $\begin{array}{l}\text { Silvicultural systems prescribed and } \\
\text { appropriate to forest type \& produce } \\
\text { grown }\end{array}$ & IIA.3 & $\begin{array}{l}\text { Standards for silvicultural and other } \\
\text { work adapted to the specific ecology of } \\
\text { the forest and ensuring sustainable } \\
\text { management have been developed and } \\
\text { are operational } \\
\text { The management plan includes a } \\
\text { working plan and a silvicultural } \\
\text { programme clearly derived from } \\
\text { preliminary studies and consistent with } \\
\text { silvicultural and other work standards }\end{array}$ & $\begin{array}{l}\text { IIB. } \\
2.1 .12\end{array}$ & $\begin{array}{l}\text { A sequence of operations of a suitable } \\
\text { silvicultural system is given, } \\
\text { describing the timing and type of } \\
\text { silvicultural treatments to be applied } \\
\text { during the cutting cycle such as: } \\
\text { - Pre-harvest vine cutting } \\
\text { - Low impact logging } \\
\text { - Post-harvest vine cutting } \\
\text { - Thinnings } \\
\text { (verifier) }\end{array}$ & AUSTRIAN TEST: $413 / \mathrm{C}$ \\
\hline \multirow[b]{2}{*}{ C.1.4 } & \multicolumn{6}{|c|}{ Yield regulation by area and/or volume prescribed } \\
\hline & $\begin{array}{l}\text { Yield regulation by area and/or } \\
\text { volume prescribed } \\
\text { Annual Allowable Cut regulated \& } \\
\text { controlled by area \&/or volume }\end{array}$ & IIA. & $\begin{array}{l}\text { Calculations of allowable cut and } \\
\text { rotation period are clearly detailed in } \\
\text { mamagement plan, are consistent with } \\
\text { silvicultural standards, increment data } \\
\text { and preliminary inventory, and are } \\
\text { established at levels considered } \\
\text { compatible with sustainable yield of the } \\
\text { forest. Allowable cut includes two } \\
\text { categories of species: slow-growing } \\
\text { (redwoods), and fast-growing }\end{array}$ & $\begin{array}{l}\text { IIB.2.1. } \\
10\end{array}$ & $\begin{array}{l}\text { Based on reliable data on growth, } \\
\text { cutting cycles are long enough to } \\
\text { recover the volume harvested and } \\
\text { maintain the forest's composition and } \\
\text { structure. (verifier) } \\
\text { A description of the methodology to } \\
\text { collect data on growth and yield, } \\
\text { giving details of variables to be } \\
\text { surveyed and timing for }\end{array}$ & AUSTRIAN TEST: $208 / 5 / C$ \\
\hline
\end{tabular}




\begin{tabular}{|c|c|c|c|c|c|c|}
\hline P.C.I.V & $\begin{array}{c}\begin{array}{c}\text { 'Production' } \\
\text { Indonesia }\end{array} \\
\end{array}$ & P.C.I.V & $\begin{array}{l}\text { 'Production' } \\
\text { Côte d'Ivoire } \\
\end{array}$ & P.C.I.V & $\begin{array}{c}\text { 'Production' } \\
\text { Brazil } \\
\end{array}$ & Remarks \\
\hline & & & (whitewoods). & $\begin{array}{l}\text { IIB. } \\
2.1 .11\end{array}$ & $\begin{array}{l}\text { remeasurements. (verifier) } \\
\text { The AAC has been clearly expressed } \\
\text { in the forest management plan, and is } \\
\text { based on reliable published growth } \\
\text { data. (verifier) }\end{array}$ & \\
\hline \multirow[b]{2}{*}{ C.1.5 } & \multicolumn{6}{|c|}{ Harvesting systems and equipment are prescribed to match forest conditions in order to reduce impact } \\
\hline & $\begin{array}{l}\text { Harvesting plan and methods are } \\
\text { appropriate \& take account of NTFP }\end{array}$ & $\begin{array}{l}\text { IIA.6 } \\
\text { IIA.5 } \\
\text { IIA.2.3 }\end{array}$ & $\begin{array}{l}\text { Logging is rationally planned on the } \\
\text { base of maps. } \\
\text { There are technical and financial } \\
\text { specifications for logging } \\
\text { Operational guidelines exist for } \\
\text { infrastructure (roads, bridges, etc.) to } \\
\text { minimize environmental damage. }\end{array}$ & \begin{tabular}{|l|} 
IIB. \\
3.1 .2 \\
\\
IIB.2.1. \\
2
\end{tabular} & $\begin{array}{l}\text { Harvesting systems and equipment } \\
\text { applications are specified to match the } \\
\text { forest conditions in order to reduce } \\
\text { harvest impact, e.g., Manual road } \\
\text { building and simple truck with cable } \\
\text { loading system, to fully mechanized } \\
\text { harvesting systems. (verifier) } \\
\text { Management is committed to reducing } \\
\text { negative impacts on the FMU to a } \\
\text { minimum. (verifier) }\end{array}$ & AUSTRLAN TEST: $169 / 5 / C$ \\
\hline \multirow[b]{2}{*}{ C.2. } & \multicolumn{6}{|c|}{ THE MANAGEMENT PLAN IS EFFECTIVELY IMPLEMENTED } \\
\hline & $\begin{array}{l}\text { Implementation \& control of forest } \\
\text { management plan (as detailed } \\
\text { above) is effective }\end{array}$ & $\begin{array}{l}\text { II. } 1.5 \\
\text { IIA. } 7 \\
\text { IIA.3.4 }\end{array}$ & $\begin{array}{l}\text { The management plan is fully } \\
\text { implemented } \\
\text { Logging operations in compliance with } \\
\text { technical specificstions } \\
\text { The felling and work programme is } \\
\text { operational: } \\
\text { - clear and unambiguous; } \\
\text { - realistic (means for } \\
\text { implementation). }\end{array}$ & IIB.3.2. & $\begin{array}{l}\text { The written operating plan is followed } \\
\text { in the field. }\end{array}$ & \\
\hline
\end{tabular}


Annex 6: Analysis of Commonalities

\begin{tabular}{|c|c|c|c|c|c|c|}
\hline P.C.I.V & $\begin{array}{l}\text { 'Production' } \\
\text { Indonesia }\end{array}$ & P.C.I.V & $\begin{array}{l}\text { 'Production' } \\
\text { Côte d'Ivoire } \\
\end{array}$ & P.C.I.V & $\begin{array}{c}\text { 'Production' } \\
\text { Brazil } \\
\end{array}$ & Remarks \\
\hline C.2.2.1 & $\begin{array}{l}\text { PRE-HARVEST INVENTORY } \\
\text { SATISFACTORILY COMPLETED }\end{array}$ & IIA.4.1 & $\begin{array}{l}\text { Prior to any designation of harvest, an } \\
\text { inventory/diagnosis should confirm that } \\
\text { harvesting is feasible in compliance } \\
\text { with silvicultural standards and } \\
\text { management plan. }\end{array}$ & $\begin{array}{l}\text { IIB. } \\
3.1 .1 \\
\text { a } \\
\text { b } \\
\text { c } \\
\text { d }\end{array}$ & $\begin{array}{l}\text { A pre-harvest inventory performed } 12 \\
\text { months prior to the harvest is available } \\
\text { and provides the following data: } \\
\text { - full enumeration and mapping of all } \\
\text { potential crop trees of commercial and } \\
\text { intermediate size classes. } \\
\text { - full enumeration and mapping of } \\
\text { commercial harvest trees } \\
\text { - enumeration and mapping of } \\
\text { protected trees } \\
\text { - notation and mapping of special bio- } \\
\text { physical features (verifier) }\end{array}$ & AUSTRIAN TEST: $221 / 8 / C$ \\
\hline & \multicolumn{6}{|c|}{ Infrastructure is laid out prior to harvesting and in accordance with prescriptions } \\
\hline C.2.3 & $\begin{array}{l}\text { Forest infrastructure established in } \\
\text { accordance with prescription. } \\
\text { Road and skid trails laid out prior to } \\
\text { harvesting in accordance with } \\
\text { prescriptions }\end{array}$ & $\begin{array}{l}\text { IIA. } \\
11.5 \\
\text { IIA.11 } \\
\text { IIA. } \\
11.1 \\
\text { IIA. } \\
11.3\end{array}$ & $\begin{array}{l}\text { Infrastructure (primary and secondary } \\
\text { roads, timber yards, skidding tracks) } \\
\text { should be planned prior to } \\
\text { implementation, taking into account the } \\
\text { terrain and the requirements of logging. } \\
\text { Infrastructure (roads, bridges, } \\
\text { firebreaks, etc.) is designed, established } \\
\text { and maintained in such a way that } \\
\text { negative impact on the environment } \\
\text { (forest, soil, water course network) is } \\
\text { reduced to a strict minimum. } \\
\text { Width cleared for road construction is } \\
\text { reduced to the minimum achievable. } \\
\text { Minimum infrastructure required for } \\
\text { logging is made permanent (skidding } \\
\text { racks in particular). }\end{array}$ & $\begin{array}{l}\text { IIB } \\
3.1 .3\end{array}$ & $\begin{array}{l}\text { Planning of primary roads, secondary } \\
\text { roads, log decks, and stream crossings } \\
\text { is based on the following } \\
\text { considerations: } \\
\text { - They are permanent infrastructure in } \\
\text { the FMU } \\
\text { - They have pre-established written } \\
\text { specifications either in accordance } \\
\text { with national forest regulations or } \\
\text { other recognized guidelines, e.g., } \\
\text { FAO's forest infrastructure guidelines } \\
\text { - These structures should not occupy } \\
\text { more than } 2.5 \% \text { of the productive } \\
\text { forest area. } \\
\text { - The design and layout of this } \\
\text { infrastructure is matched to the chosen } \\
\text { harvesting systems. } \\
\text { - Timing of road construction should }\end{array}$ & AUSTRIAN TEST: $195 / 5 / C$ \\
\hline
\end{tabular}




\begin{tabular}{|c|c|c|c|c|c|c|}
\hline P.C.I.V & $\begin{array}{c}\begin{array}{c}\text { 'Production' } \\
\text { Indonesia }\end{array} \\
\end{array}$ & P.C.I.V & $\begin{array}{c}\text { 'Production' } \\
\text { Côte d'lvoire } \\
\end{array}$ & P.C.I.V & $\begin{array}{c}\text { 'Production' } \\
\text { Brazil } \\
\end{array}$ & Remarks \\
\hline & & & & $\begin{array}{l}\text { IIB. } \\
3.2 .2 \\
\text { IIB.3.1. } \\
3\end{array}$ & $\begin{array}{l}\text { be a minimum of } 12 \text { months prior to } \\
\text { use for the proper consolidation. } \\
\text { (verifier) } \\
\text { All forest infrastructure is well } \\
\text { maintained and all road surfaces are } \\
\text { well drained (verifier) } \\
\text { Planning of primary roads, secondary } \\
\text { roads, log decks, and stream crossings } \\
\text { is based on the following } \\
\text { considerations: } \\
\text { - They are permanent infrastructure in } \\
\text { the FMU } \\
\text { - They have pre-established written } \\
\text { specifications either in accordance } \\
\text { with national forest regulations or } \\
\text { other recognized guidelines, e.g., } \\
\text { FAO's forest infrastructure guidelines } \\
\text { - These structures should not occupy } \\
\text { more than } 2.5 \% \text { of the productive } \\
\text { forest area. } \\
\text { - The design and layout of this } \\
\text { infrastructure is matched to the chosen } \\
\text { harvesting systems. } \\
\text { - Timing of road construction should } \\
\text { be a minimum of } 12 \text { months prior to } \\
\text { use for the proper consolidation. } \\
\text { (verifier) }\end{array}$ & \\
\hline & \multicolumn{6}{|c|}{ Reduced impact felling specified and implemented } \\
\hline C.2.6.1 & Trees marked for directional felling & IIA.2.1 & Operational low-impact felling & IIB. & Directional felling should be planned & AUSTRIAN TEST: $190 \mathrm{a} / 5 / \mathrm{C}$ \\
\hline
\end{tabular}




\begin{tabular}{|c|c|c|c|c|c|c|}
\hline & $\begin{array}{l}\text { and generally in a herringbone pattern } \\
\text { along pre-surveyed skid trail (verifier) }\end{array}$ & $\begin{array}{l}\text { [IIA.2] } \\
\text { IIA.4.4 }\end{array}$ & $\begin{array}{l}\text { techniques are available. } \\
\text { [Guidelines for logging have been } \\
\text { developed and are operational.] } \\
\text { Trees to be harvested are cleared of } \\
\text { climbers at least one year prior to } \\
\text { harvest. }\end{array}$ & \begin{tabular}{|l}
3.1 .9 \\
\\
IIB. \\
3.1 .7 \\
\\
IIB. \\
3.1 .8 \\
\\
\\
IIB. \\
3.2 .7
\end{tabular} & $\begin{array}{l}\text { and specified to reduce the damage to } \\
\text { potential crop trees and to favor } \\
\text { skidding. (verifier) } \\
\text { Pre-harvest vine cutting is prescribed } \\
\text { and specified when the forest structure } \\
\text { indicates high damage impact from } \\
\text { tree felling. (verifier) } \\
\text { When pre-harvest vine cutting is } \\
\text { prescribed it takes place at least } 12 \\
\text { months prior to actual tree felling and } \\
\text { only commercial harvest trees are } \\
\text { treated. (verifier) } \\
\text { Prescribed felling directions are } \\
\text { followed whenever possible and } \\
\text { proper felling techniques such as } \\
\text { proper undercuts, hinge height and } \\
\text { angle, wing cuts, and the use of } \\
\text { wedges are practiced. (verifier) }\end{array}$ & \\
\hline & \multicolumn{6}{|c|}{ Skidding damage to trees and soil minimised } \\
\hline $\begin{array}{l}\text { C. } 2.6 \\
\text { C. } 2.6 .3\end{array}$ & $\begin{array}{l}\text { Skidding damage to trees and soil } \\
\text { minimised } \\
\text { Less than } 10 \% \text { of marked residuals } \\
\text { damaged by tractor blade and rubbing } \\
\text { (verifier) }\end{array}$ & $\begin{array}{l}\text { [IIA. } \\
2.2 \text {. }\end{array}$ & $\begin{array}{l}\text { [Operational low-impact hauling } \\
\text { techniques are available] }\end{array}$ & $\begin{array}{l}\text { IIB. } \\
3.2 .3\end{array}$ & $\begin{array}{l}\text { No skidding or log transport takes } \\
\text { place when water logging or ruting } \\
\text { occurs. (verifier) } \\
\text { All mechanical skidders (wheel and } \\
\text { track) must be equipped with winches } \\
\text { and winching is used whenever impact } \\
\text { can be reduced (verifier) }\end{array}$ & AUSTRIAN TEST: $190 / / 5 / C, 190 / 5 / C$ \\
\hline
\end{tabular}


Annex 6: Analysis of Commonalities

\begin{tabular}{|c|c|c|c|c|c|c|}
\hline P.C.I.V & $\begin{array}{c}\text { 'Production' } \\
\text { Indonesia } \\
\end{array}$ & P.C.I.V & $\begin{array}{l}\text { 'Production' } \\
\text { Côte d'Ivoire }\end{array}$ & P.C.I.V & $\begin{array}{c}\text { 'Production' } \\
\text { Brazil }\end{array}$ & Remarks \\
\hline & & & & $\begin{array}{l}\text { IIB. } \\
3.2 .9 \\
\\
\text { IIB. } \\
3.2 .10\end{array}$ & $\begin{array}{l}\text { No evidence of skidders deviating } \\
\text { from pre-defined skid trails (verifier) } \\
\text { During mechanical skidding, the front } \\
\text { end of the log is raised off the ground } \\
\text { either by the use of a winch or grapple. } \\
\text { (verifier) }\end{array}$ & \\
\hline \multirow[b]{2}{*}{ C.3.8 } & \multicolumn{6}{|c|}{ AN EFFECTIVE MONITORING AND CONTROL SYSTEM AUDITS MANAGEMENT'S CONFORMITY WITH PLANNING } \\
\hline & Control maps updated at least annually & \begin{tabular}{|l} 
IIIB.3 \\
IIB .3 .1 \\
IIB.3.3 \\
IIB.3.4 \\
IIB .3 .5 \\
IIA.3.3 \\
IIA.4
\end{tabular} & $\begin{array}{l}\text { Monitoring [of NTFP] } \\
\text { Identification of indicator animals. } \\
\text { Capacity of use. } \\
\text { Identification of users. } \\
\text { Guidelines for monitoring, control and } \\
\text { supervision (periodical inventories and } \\
\text { surveys) } \\
\text { The working plan included in the } \\
\text { management plan is consistent with } \\
\text { assessed exploitable area, allowable cut } \\
\text { by group of species (whitewoods, } \\
\text { redwoods) and felling cycle. } \\
\text { Each harvest is subject to previous } \\
\text { validation and designation. Measures } \\
\text { are taken to best plan harvest and } \\
\text { reduce damage. }\end{array}$ & \begin{tabular}{|l} 
IIB.4. \\
IIB.4.2 \\
IIB.4.3.
\end{tabular} & $\begin{array}{l}\text { An effective monitoring and control } \\
\text { system audits management's } \\
\text { conformity with planning and } \\
\text { promotes improvement of operations } \\
\text { towards sustainability } \\
\text { Documentation of source and } \\
\text { destination for all forest products is } \\
\text { available at all intermediate log yards } \\
\text { and FMU field office locations. } \\
\quad \cdot \\
\text { The monitoring system covers the most } \\
\text { important features of forest } \\
\text { management, including environmental } \\
\text { and social impacts. It includes, } \\
\text { amongst others, the quality of water } \\
\text { resources, soil compaction, damage to } \\
\text { the residual stand, and regeneration of } \\
\text { desirable species. }\end{array}$ & AUSTRIAN TEST: $222 / 5 / \mathrm{C}$ \\
\hline \multirow[b]{2}{*}{ C.3.2 } & \multicolumn{6}{|c|}{ Continuous forest inventory (CFI) plots established \& measured regularly. } \\
\hline & $\begin{array}{l}\text { Continuous forest inventory (GFI) } \\
\text { plots established \& measured }\end{array}$ & IIA.1.2 & $\begin{array}{l}\text { Adequate effort is undertaken to } \\
\text { validate or adjust silvicultural and work } \\
\text { standards. }\end{array}$ & IIB.4.6. & $\begin{array}{l}\text { CFI plots are established and measured } \\
\text { in accordance with the forest }\end{array}$ & $\begin{array}{l}\text { AUSTRIAN TEST: } 221 / 8 / C \text { (broad } \\
\text { interpretation) }\end{array}$ \\
\hline
\end{tabular}




\begin{tabular}{|c|c|c|c|c|c|c|}
\hline P.C.I.V & $\begin{array}{l}\text { 'Production' } \\
\text { Indonesia }\end{array}$ & P.C.I.V & $\begin{array}{l}\text { 'Production' } \\
\text { Côte d'Ivoire }\end{array}$ & P.C.I.V & $\begin{array}{c}\text { 'Production' } \\
\text { Brazil }\end{array}$ & Remarks \\
\hline & regularly. & & $\begin{array}{l}\text { \{NOTE: According to Mengin- } \\
\text { Lecreulx this indicator includes the } \\
\text { substance of indicator IIA.1.1, and } \\
\text { verifier IIA.3.2.d both dealing with } \\
\text { CFI/PSP but deleted as being } \\
\text { redundant\} }\end{array}$ & & management plan & \\
\hline
\end{tabular}




\begin{tabular}{|c|c|c|c|c|c|c|}
\hline P.C.I.V & $\begin{array}{l}\text { 'Production' } \\
\text { Indonesia } \\
\end{array}$ & P.C.I.V & $\begin{array}{l}\text { 'Production' } \\
\text { Côte d'Ivoire }\end{array}$ & P.C.I.V & $\begin{array}{c}\text { 'Production' } \\
\text { Brazil } \\
\end{array}$ & Remarks \\
\hline & & & & 3.2 .14 & already been logged. (verifier) & \\
\hline \multirow{4}{*}{ C.2.6.2 } & \multicolumn{6}{|c|}{ Tree marking of seed stock and potential crop trees } \\
\hline & $\begin{array}{l}\text { Trees for retention (Pohon Inti) } \\
\text { marked with a yellow band } \\
\text { (verifier) } \\
\text { [TPTI Rules] }\end{array}$ & $\begin{array}{l}\text { [MA. } \\
4.5] \\
\\
\text { IIA.4.2 }\end{array}$ & $\begin{array}{l}\text { [Trees to be protected are plotted on a } \\
\text { map and conspicuously marked at } \\
\text { breast height prior to harvest.] } \\
\text { Trees to be felled are previously: } \\
\text { - plotted on a large-scale map (control } \\
\text { of compliance with silvicultural } \\
\text { standards, planning and control of } \\
\text { logging); } \\
\text { - marked at breast height and } \\
\text { ground level. }\end{array}$ & $\begin{array}{l}\text { IIB. } \\
3.1 .10 \\
\\
\text { IIB. } \\
3.2 .1\end{array}$ & $\begin{array}{l}\text { A harvesting map is produced, which } \\
\text { consolidates all information of forest } \\
\text { infrastructure, tree mapping, felling } \\
\text { direction, and skid trail layout at a } \\
\text { scale of } 1: 1000 \text {. (verifier) } \\
\text { Tree marking is carried out in } \\
\text { accordance with the pre-harvest } \\
\text { inventory: commercial harvest trees, } \\
\text { potential crop trees and protected trees } \\
\text { are clearly marked and distinguished, } \\
\text { for retention, protection or felling, in } \\
\text { which case, with felling direction } \\
\text { (verifier) }\end{array}$ & \\
\hline & \multicolumn{6}{|c|}{ Long term security of FMU: this was dealt with under 'policy' } \\
\hline & See Policy D.1.1, D.2.1 & & Policy 0.1 .2 & $\begin{array}{l}\text { IIB.1. } \\
\text { IIB.1.1 } \\
\text { IIB.1.2 }\end{array}$ & $\begin{array}{l}\text { The long term security of the forest } \\
\text { management unit is assured. } \\
\text { Land tenure of the forest management } \\
\text { unit is clear and legally secure. } \\
\text { The land is dedicated by the owners to } \\
\text { sustainable long term natural forest } \\
\text { management. }\end{array}$ & $\begin{array}{l}\text { II.B.1 -IIB.1.2(Brazil) to count as } \\
\text { 'common' }\end{array}$ \\
\hline & \multicolumn{6}{|c|}{ Training \& qualification of staff of FMU: this was dealt with under 'policy' } \\
\hline & STAFF - see Policy D.4.1 & II.2 & $\begin{array}{l}\text { Forest staff is adequate in numbers, } \\
\text { qualification and skill to develop and } \\
\text { manage the forest for all its components } \\
\text { (timber production, other forest }\end{array}$ & $\begin{array}{l}\text { IIB. } \\
2.1 .13\end{array}$ & $\begin{array}{l}\text { A sufficient number of qualified forest } \\
\text { staff are available to carry out the } \\
\text { necessary management activities } \\
\text { (verifier) }\end{array}$ & $\begin{array}{l}11.2 \text { (Côte d'Ivoire) to count as } \\
\text { 'common' }\end{array}$ \\
\hline
\end{tabular}




\begin{tabular}{|c|c|c|c|c|c|c|}
\hline & & & $\begin{array}{l}\text { products, ecology, farmer-forest } \\
\text { relationship). } \\
\text { Means of verification: }\end{array}$ & & & \\
\hline \multirow[b]{2}{*}{ C.3.11 } & \multicolumn{6}{|c|}{ Enrichment planting: this was dealt with under 'ecology' } \\
\hline & $\begin{array}{l}\text { Enrichment planting only where } \\
\text { seedlings and seed sources are lacking } \\
\text { and only with indigenous commercial } \\
\text { species. }\end{array}$ & & See Ecology III.9 & & See Ecology 1.2.3 & $\begin{array}{l}\text { C.3.11 (Indonesia) to count as } \\
\text { 'common' }\end{array}$ \\
\hline \multirow[b]{3}{*}{ C.3.7 } & \multicolumn{6}{|c|}{ Hydrology, protection of water courses: this was dealt with under 'ecology' } \\
\hline & See Ecology I.3.2, I.3.4 & $\begin{array}{l}\text { ПIA. } \\
11.4\end{array}$ & $\begin{array}{l}\text { Logging, and forest management in } \\
\text { general, do not disturb hydrological } \\
\text { network. If a watercourse is obstructed } \\
\text { for such reason, appropriate corrective } \\
\text { measures are taken within a very short } \\
\text { time (at most a few days). } \\
\text { Verification: }\end{array}$ & \begin{tabular}{|l} 
IIB. \\
3.2 .4 \\
\\
\\
\\
IIB. \\
3.2 .6 \\
\end{tabular} & $\begin{array}{l}\text { Erosion control practices are utilized } \\
\text { in the construction of all FMU } \\
\text { infrastructure to avoid: } \\
\text { - lateral erosion in cuts and on fills } \\
\text { - silting of stream crossings } \\
\text { - cutting of road side ditches on steep } \\
\text { grades } \\
\text { - formation of sand traps in low spots } \\
\text { (verifier) } \\
\text { Water bars are installed when roads } \\
\text { are abandoned (verifier) } \\
\end{array}$ & $\begin{array}{l}\text { II.A.11.4 (Corte d'ivoire) to count as } \\
\text { 'common' }\end{array}$ \\
\hline & $\begin{array}{l}\text { Residual stands satisfactory } \\
\text { regenerated }\end{array}$ & & See Ecology III.1 & $\begin{array}{l}\text { IIB. } \\
3.1 .11 \\
\end{array}$ & $\begin{array}{l}\text { Silvicultural treatments for the annual } \\
\text { coupe are well defined. }\end{array}$ & $\begin{array}{l}\text { C.3.7 (Indonesia) to count as } \\
\text { common' }\end{array}$ \\
\hline \multirow[b]{2}{*}{ C.3.12 } & \multicolumn{6}{|l|}{ Indonesia \& Côte d'lvoire } \\
\hline & $\begin{array}{l}\text { No net change in natural forest area as } \\
\text { a result of forest management }\end{array}$ & $\begin{array}{l}\text { I. } \\
1.2 \\
{[1.2 .2]}\end{array}$ & $\begin{array}{l}\text { Area of reserved forests and overall } \\
\text { area of forests are not declining } \\
\text { It is apparent that the reserved forest } \\
\text { and the forest area are not declining. } \\
\text { [No clearing of forest took place in the } \\
\text { last three years.] }\end{array}$ & & & \\
\hline
\end{tabular}




\begin{tabular}{|c|c|c|c|c|c|c|}
\hline C.1.6.1 & $\begin{array}{l}\text { Explicit reference to best management } \\
\text { practice made* } \\
\text { Reference to national \& other } \\
\text { guidelines, e.g. TPTI, FAO } \\
\text { Harvesting Practices (verifier) } \\
\end{array}$ & IIA.1.3 & $\begin{array}{l}\text { Silvicultural and work standards are in } \\
\text { compliance with FAO technical } \\
\text { standards. }\end{array}$ & & & \\
\hline C. 2.5 & $\begin{array}{l}\text { Harvesting limits on species, sizes and } \\
\text { total volume set to an appropriate level } \\
\text { and adhered to }\end{array}$ & IIA.1.5 & $\begin{array}{l}\text { In the field of harvesting, the standards } \\
\text { are explicit on: } \\
\text { - number of large trees (e.g. dbh } \geq 50 \\
\text { cm) to be maintained by ha and group } \\
\text { of commercial species (whitewoods, } \\
\text { redwoods), taking into account } \\
\text { richness of future crop stand for the } \\
\text { same species (e.g. dbh from } 5 \text { to } \\
50 \mathrm{~cm} \text { ); } \\
\text { - minimum number of large trees (dbh } \\
\geq 50 \mathrm{~cm} \text { ) to be maintained by ha and } \\
\text { species; } \\
\text { maximum number of trees to be } \\
\text { harvested per ha; } \\
\text { - minimum distance between two trees } \\
\text { to be felled, in order to avoid too } \\
\text { large gaps. } \\
\text { Verifications (based on SODEFOR } \\
\text { standards): }\end{array}$ & & & \\
\hline
\end{tabular}




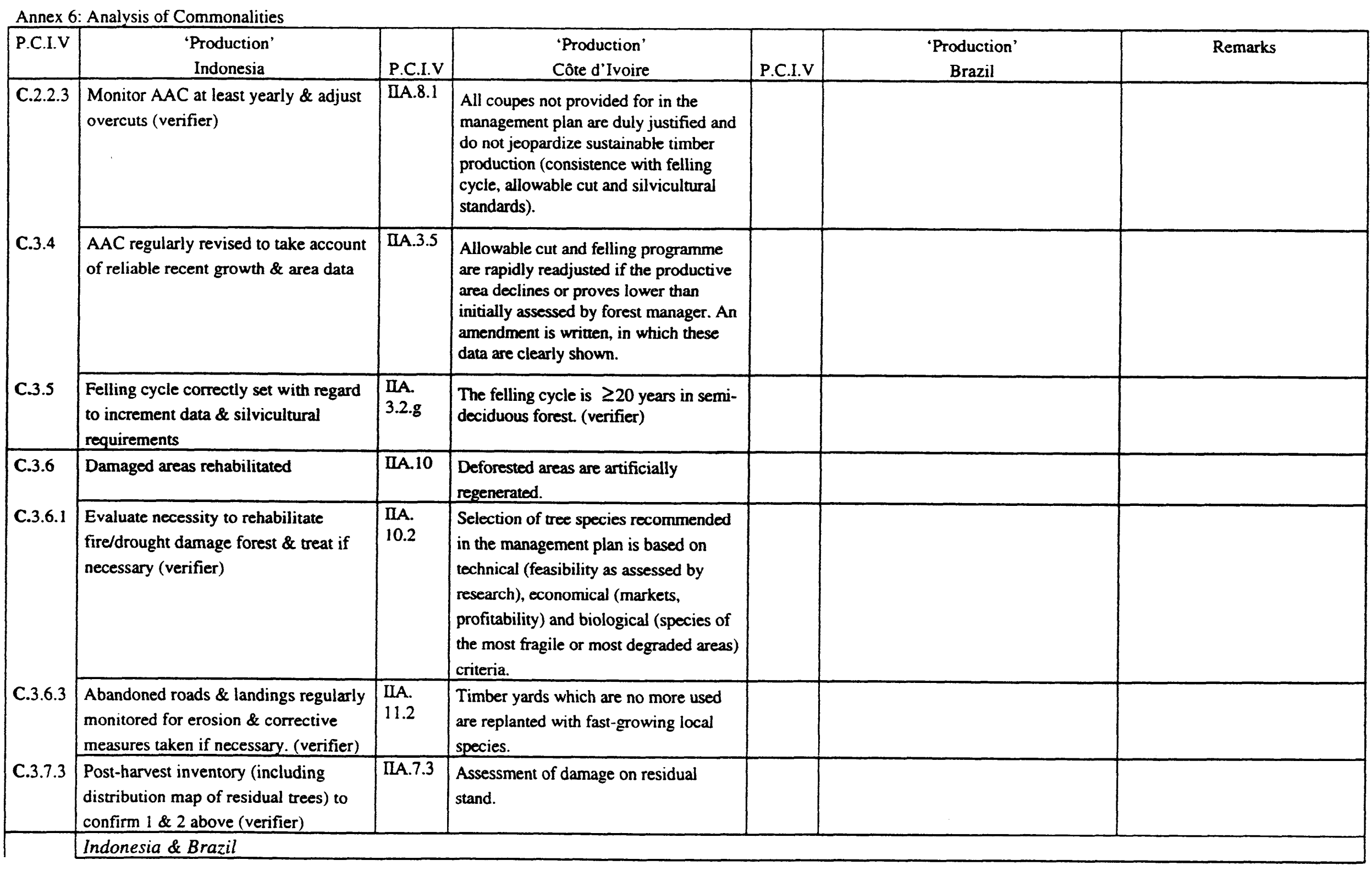




\begin{tabular}{|c|c|c|c|c|c|c|}
\hline C. 2.4 .3 & $\begin{array}{l}\text { Roads, where possible, located on } \\
\text { ridges and uphill skidding practiced } \\
\text { (verifier) }\end{array}$ & & & {$\left[\begin{array}{l}\text { [IIB. } \\
3.1 .4] \\
\\
{[\text { [IIB. }} \\
3.1 .5]\end{array}\right.$} & $\begin{array}{l}\text { The planning and layout of primary } \\
\text { and secondary skid trails is based on } \\
\text { the location of the commercial harvest } \\
\text { trees from the pre-harvest inventory } \\
\text { and topography. (verifier) } \\
\\
\text { Harvesting planning has to take into } \\
\text { account that skid trails are never } \\
\text { allowed to cross stream beds. (verifier) }\end{array}$ & \\
\hline \multirow{3}{*}{$\begin{array}{l}\text { C.3. } \\
\text { C.3.1 }\end{array}$} & Unique to one site only & & & & & \\
\hline & Continuity of resource flow is assured & & & & & \\
\hline & $\begin{array}{l}\text { Reliable growth data for commercial } \\
\text { species under appropriate stand } \\
\text { conditions available }\end{array}$ & & & & & \\
\hline \multirow{2}{*}{ C.3.3 } & & & & IIB.3.1 & $\begin{array}{l}\text { An annual operating plan is written to } \\
\text { guide all forest operations. }\end{array}$ & \\
\hline & & & & $\begin{array}{ll}\text { IIB. } \\
3.2 .11\end{array}$ & $\begin{array}{l}\text { In all phases of the harvesting } \\
\text { operations wood waste is minimized. } \\
\text { There is no evidence of high stumps, } \\
\text { excessive bucking losses. splitting and }\end{array}$ & \\
\hline
\end{tabular}




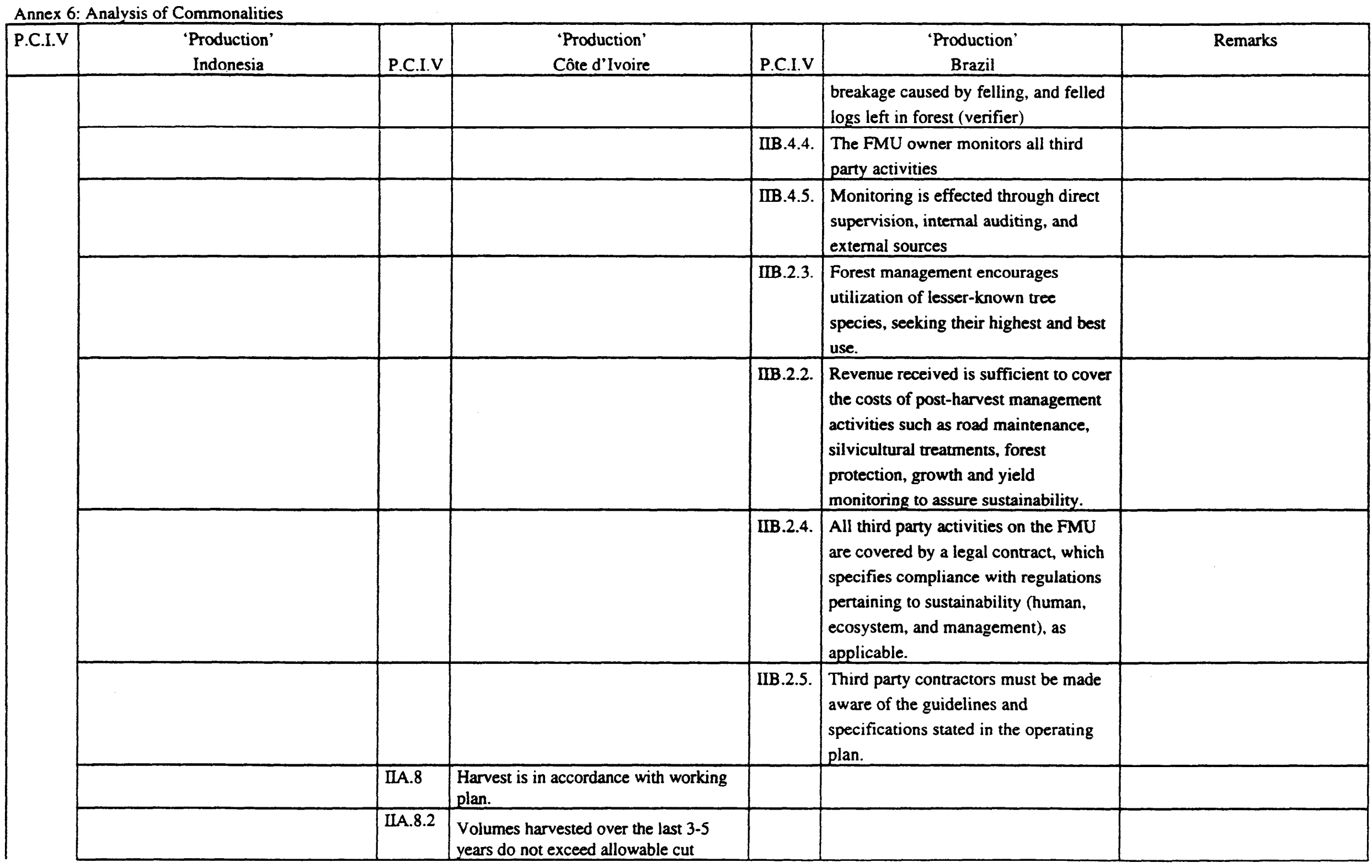




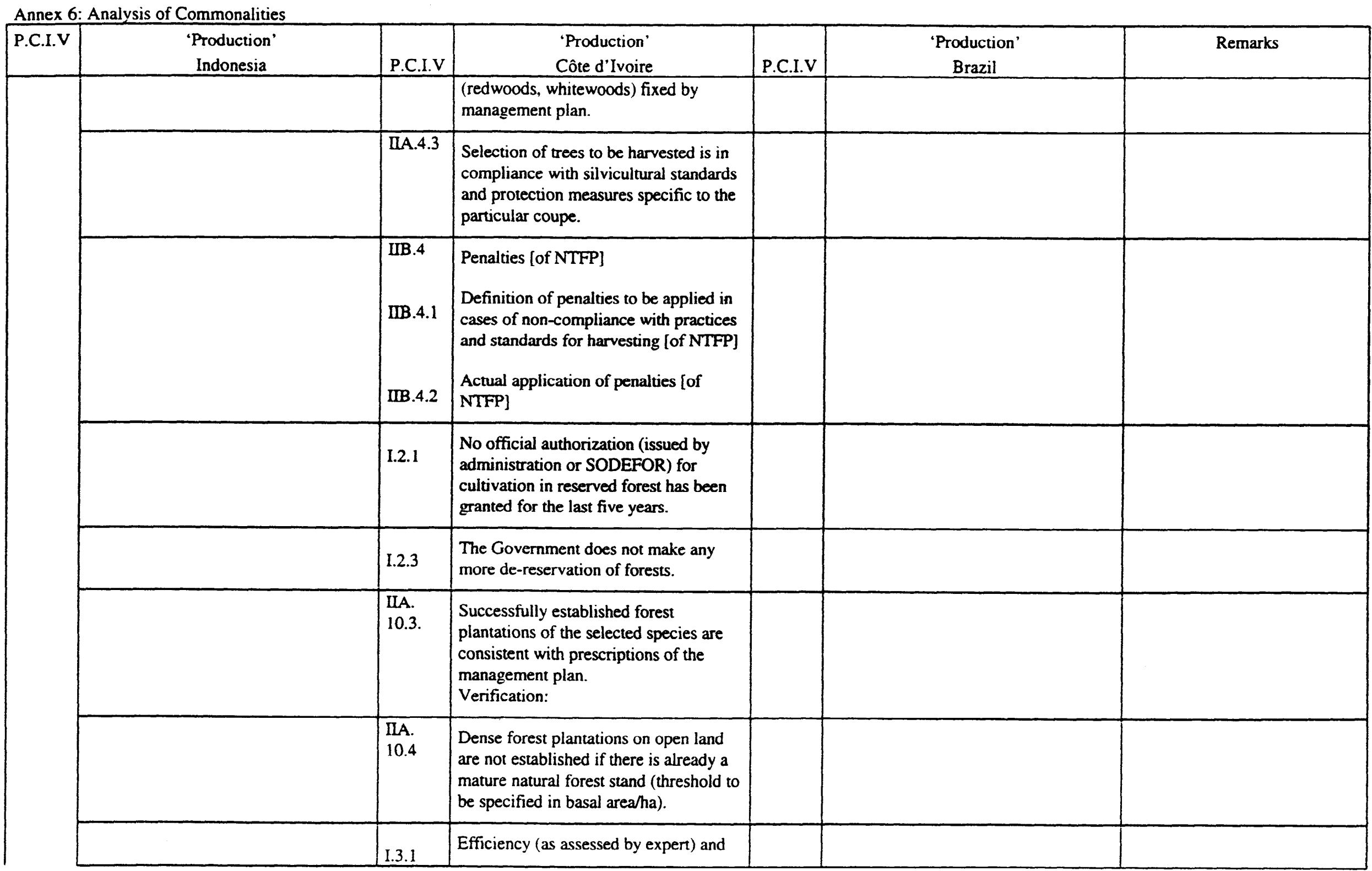


Annex 6: Analysis of Commonalities

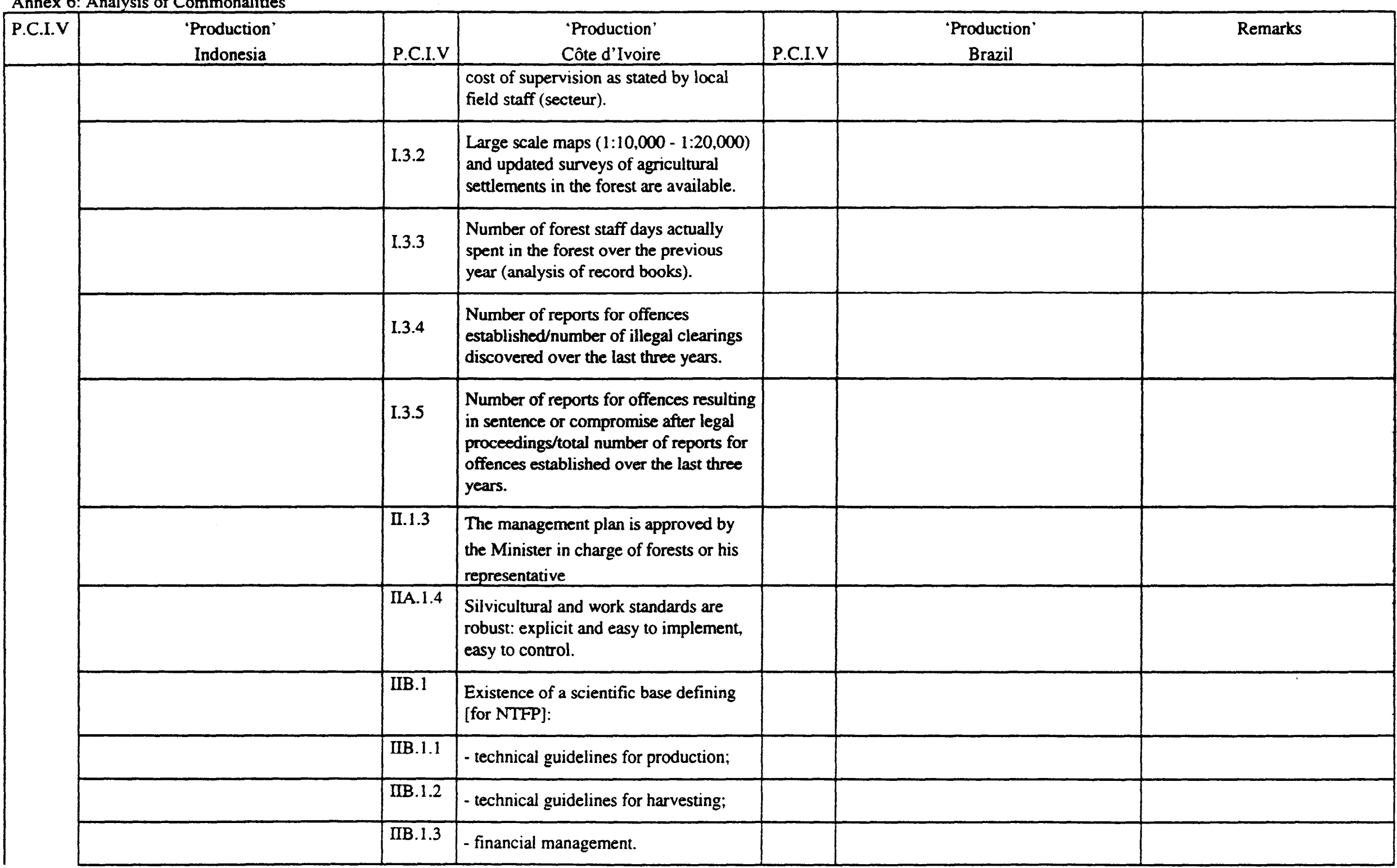


Annex 6: Analysis of Commonalities

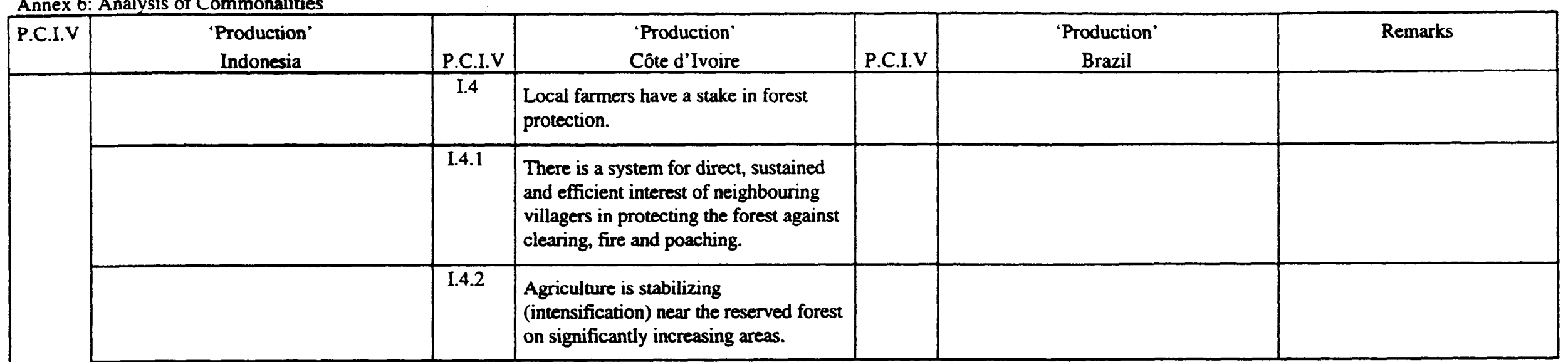




\section{ANNEX 7}

\section{A summary of Principles, Criteria, Indicators and Verifiers pertaining to People's Roles in Sustainable Forest Management}

\begin{tabular}{|c|c|c|c|c|}
\hline $\mathbf{P}$ & $\mathbf{C}$ & $\mathbf{I}$ & $\mathbf{V}$ & Principles, Criteria, Indicators, and Verifiers \\
\hline 1 & 1.3 & $\begin{array}{l}1.1 .1 \\
1.1 .2 \\
1.1 .3 \\
1.1 .4\end{array}$ & $\begin{array}{l} \\
1.2 .2 .1 \\
1.2 .2 .2 \\
1.2 .2 .3 \\
\\
1.2 .3 .1 \\
1.2 .3 .2 \\
1.2 .3 .3 \\
1.2 .4 .1 \\
1.2 .4 .2 \\
1.2 .4 .3 \\
\end{array}$ & 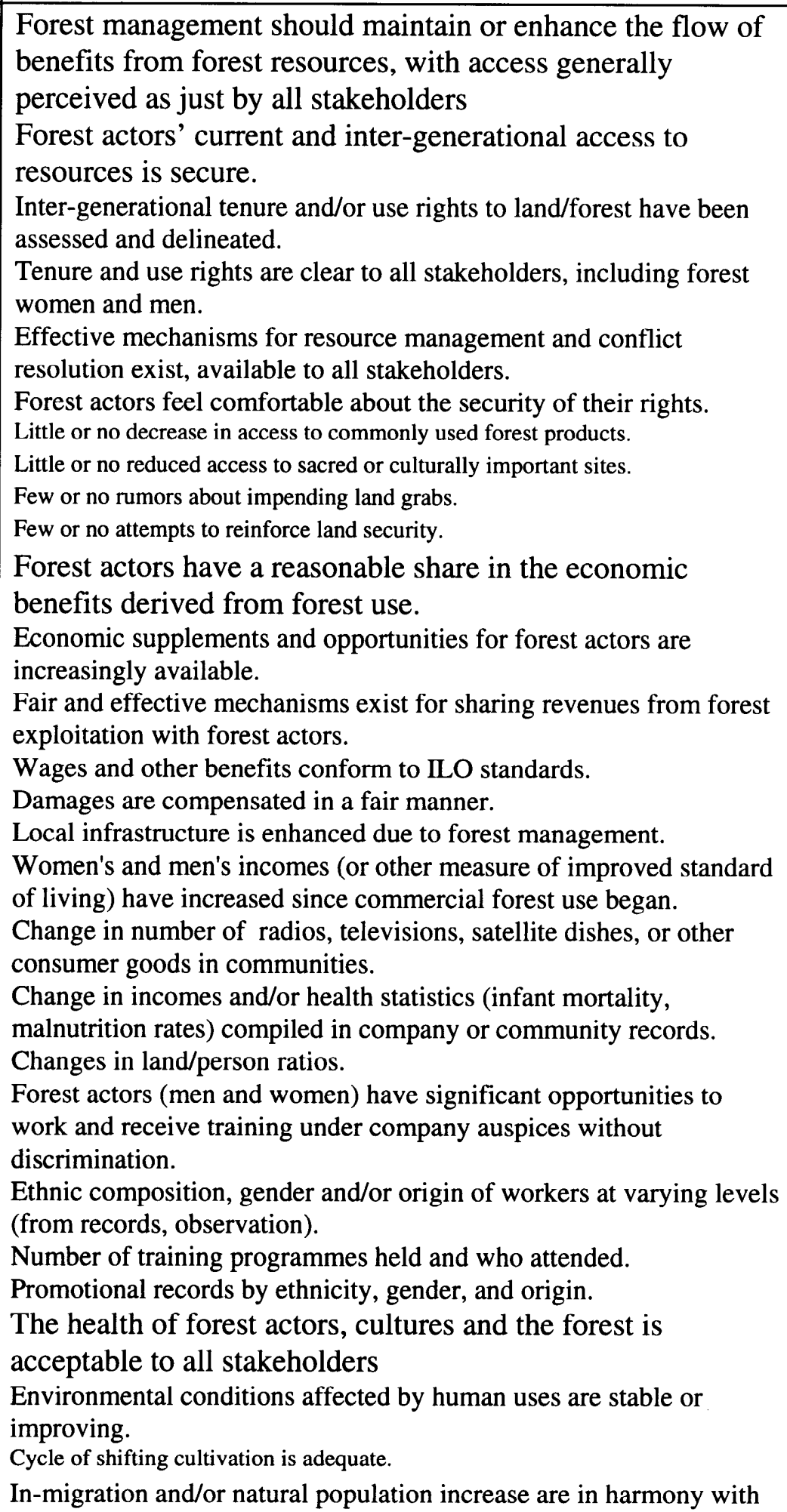 \\
\hline
\end{tabular}




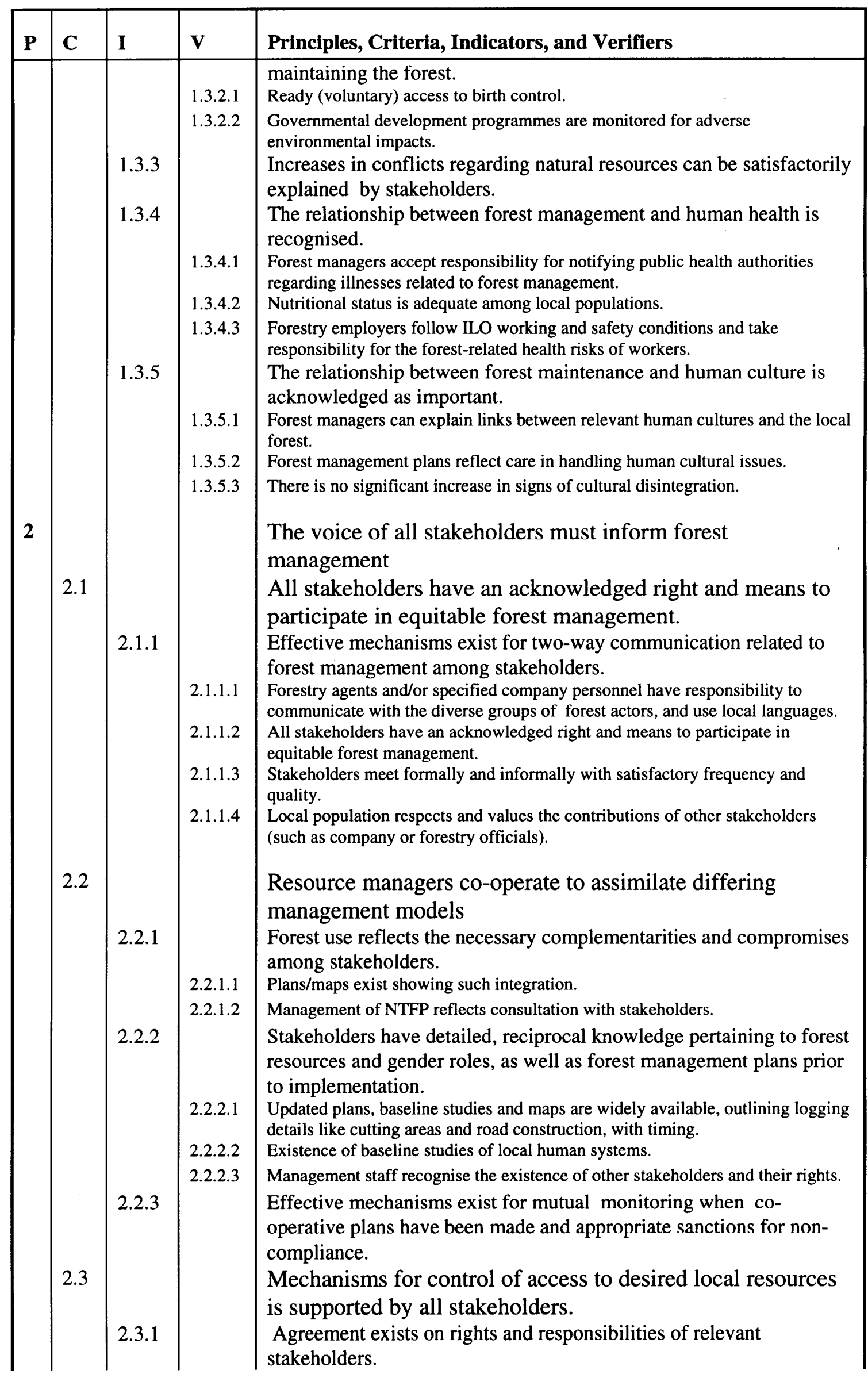




\begin{tabular}{|l|l|l|l|l|}
\hline $\mathbf{P}$ & $\mathbf{C}$ & $\mathbf{I}$ & $\mathbf{V}$ & Principles, Criteria, Indicators, and Verifiers \\
\hline & & 2.3 .2 & 2.3 .1 .1 & $\begin{array}{l}\text { Level of conflict is understood and acceptable to stakeholders. } \\
\text { Effective and acceptable local mechanisms exist to determine guilt } \\
\text { and punish offenders equitably when rules are transgressed. } \\
\text { Specific measures, used in times of conflict, are available to and can be } \\
\text { explained by all stakeholders. } \\
\text { Evidence exists for regular mutual monitoring. } \\
\text { Local NGO's are available and involved in activities to support forest actors. }\end{array}$ \\
\hline
\end{tabular}


ANNEX 8

\section{SETS OF PRINCIPLES, CRITERIA, INDICATORS AND VERIFIERS} RESULTING FROM TESTS

The following section is based on the C\&I reported in the final or draft final reports of the four tests. The order of presentation is:
1) Indonesia
2) Côte d'Ivoire (based on Mengin-Lecreulx's list of modified criteria amd indicators in Annex 20 of the Côte d'Ivoire final report)
3) Brazil
4) Austria 


\section{FINAL PROPOSALS OF EXPERT TEAM TO WORKSHOP - INDONESIAN TEST CRITERIA AND INDICATORS}

\begin{tabular}{|c|c|c|c|c|c|c|c|c|c|}
\hline $\mathrm{P}$ & $\mathrm{C}$ & I & $\mathrm{v}$ & Description & ITW & LEI & SW & SA & $\mathrm{D}$ \\
\hline $\mathbf{I}$ & & & & Ecosystem integrity is maintained & & & & & \\
\hline \multirow{5}{*}{\multicolumn{2}{|c|}{1}} & & & Resilience of forest ecosystem is maintained & & & & & \\
\hline & & 1 & & $\begin{array}{l}\text { Representative areas and especially sites of ecological and } \\
\text { environmental significance are identified and are set aside } \\
\text { and not logged. These should total not less than } 10 \% \text { of the } \\
\text { forest management unit. }\end{array}$ & $\begin{array}{l}\text { A2.2.1 } \\
\text { A2.2.3 } \\
\text { A 4.1 } \\
\text { B } 2.1 \\
\text { C } 1.5 \\
\end{array}$ & $\begin{array}{l}\mathrm{KE} 1.2 \\
\operatorname{var} 1\end{array}$ & $\begin{array}{l}5.5 \\
5.6\end{array}$ & $\begin{array}{l}5.102 \\
5.103 \\
5.305 \\
10.104 \\
5.108 \mathrm{~b} \\
\end{array}$ & $\begin{array}{l}3.6 \\
4.4 .1 \\
\text { An3.1a }\end{array}$ \\
\hline & & 2 & & $\begin{array}{l}\text { Potentially dominating secondary successional vegetation } \\
\text { is not abundant in logged-over stands }\end{array}$ & C5.5 & $\begin{array}{l}\text { KE } 9.1 \\
\operatorname{var} 2\end{array}$ & - & - & - \\
\hline & & & 1 & $\begin{array}{l}\text { SECONDARY SUCCESSION SPECIES (E.G. MACARANGA SPP., } \\
\text { ANTHOCEPHALUS SPP.) ACCOUNT FOR LESS THAN } 5 ? \% \text { OF THE } \\
\text { STEMS IN THE STAND (DBH>10 CM) }\end{array}$ & & & & & \\
\hline & & & 2 & $\begin{array}{l}\text { CREEPERS SUCH AS MERREMIA SPP. AND MESONEURON SPP. ARE } \\
\text { GENERALLY NOT PRESENT WITHIN STANDS. }\end{array}$ & & & & & \\
\hline \multirow{8}{*}{\multicolumn{2}{|c|}{2}} & & & $\begin{array}{l}\text { Structure \& diversity of forest ecosystem resembles } \\
\text { original forest }\end{array}$ & & & & & \\
\hline & & 1 & & $\begin{array}{l}\text { There are prescribed measures for the protection of key, } \\
\text { rare and endangered species, of both national and } \\
\text { international significance. }\end{array}$ & $\begin{array}{l}\text { A } 2.1 \\
\text { C } 1.7\end{array}$ & $\begin{array}{l}\text { KE } 9.1 \\
\operatorname{var} 2\end{array}$ & $\begin{array}{l}5.4 \\
5.3\end{array}$ & $\begin{array}{l}5.107 \\
5.106 \\
10.104 \\
\end{array}$ & $\begin{array}{l}4.3 .1 \\
\text { An3.1d }\end{array}$ \\
\hline & & 2 & & Overmature trees are maintained as habitat & - & - & 5.4 & $5.312 \mathrm{c}$ & \\
\hline & & 3 & & $\begin{array}{l}\text { Silvicultural treatments (including climber cutting) are } \\
\text { highly specific and selective and are confined to the barest } \\
\text { minimum. }\end{array}$ & $\begin{array}{l}\text { C } 1.7 \\
\text { A4.2.2.3.3 }\end{array}$ & & - & 5.310 & \\
\hline & & 4 & & $\begin{array}{l}\text { Residual living basal area after logging is not less than } 15 \\
\mathrm{~m} 2 / \mathrm{ha}\end{array}$ & $\begin{array}{l}\text { C } 5.5 \\
\text { C } 4.3 \\
\end{array}$ & - & - & - & \\
\hline & & 5 & & Canopy opening is minimised & C 5.5 & & - & $\begin{array}{l}5.308 \\
5.318 \mathrm{a}\end{array}$ & \\
\hline & & & 1 & $\begin{array}{l}\text { CANOPY OPENINGS (EXCLUDING PERMANENT ROADS) ARE LESS } \\
\text { THAN ?? M2 }\end{array}$ & & & & & \\
\hline & & 6 & & $\begin{array}{l}\text { Less than 35\% damaged trees in residual stand ( }>20 \mathrm{~cm} \\
\text { DBH) }\end{array}$ & C 5.5 & $\begin{array}{l}\mathrm{KE} 4.1 \\
\text { var 1 } \\
\mathrm{KE} 9.1 \\
\mathrm{var} 2 \\
\end{array}$ & - & - & \\
\hline \multirow{4}{*}{\multicolumn{2}{|c|}{3}} & & & Ecosystem function is maintained & & & & & \\
\hline & & 1 & & $\begin{array}{l}\text { Chemicals banned in Europe, America or target country } \\
\text { are not used. }\end{array}$ & C 3.3 & $\begin{array}{l}\text { KE } 9.1 \\
\text { var } 1\end{array}$ & $\begin{array}{l}5.8 \\
5.9\end{array}$ & 5.608 & \\
\hline & & 2 & & Appropriately sized stream/lake buffers not disturbed & C 5.2 & $\begin{array}{l}\mathrm{KE} 1.2 \\
\operatorname{var} 1\end{array}$ & 5.6 & 5.508 & \\
\hline & & 3 & & Soil erosion is minimised & C 5.2 & $\begin{array}{l}\text { KE } 9.1 \\
\text { var } 1\end{array}$ & 5.13 & $\begin{array}{l}5.315 \\
5.201 \\
\end{array}$ & \\
\hline
\end{tabular}


Indonesian Test

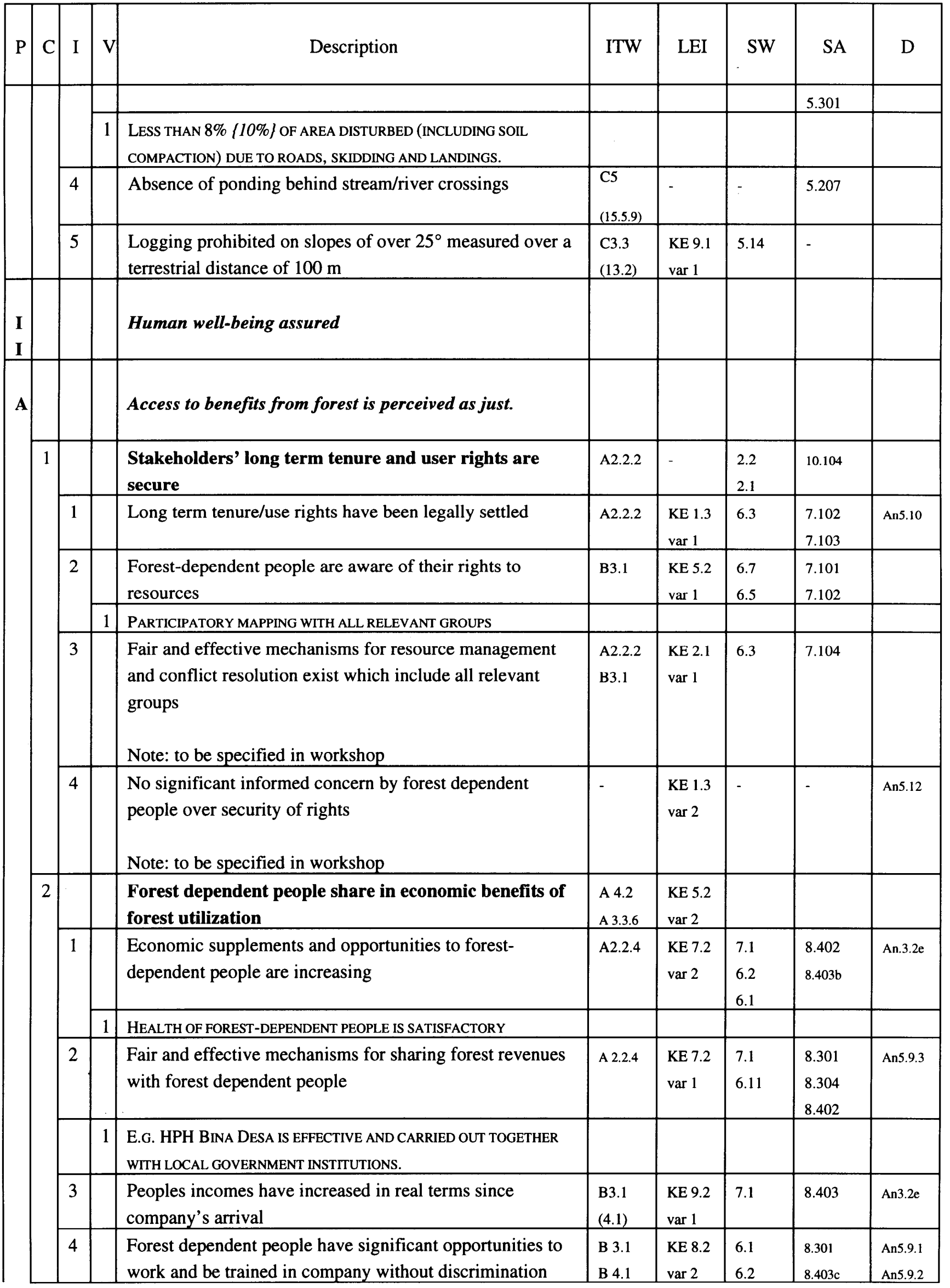


Indonesian Test

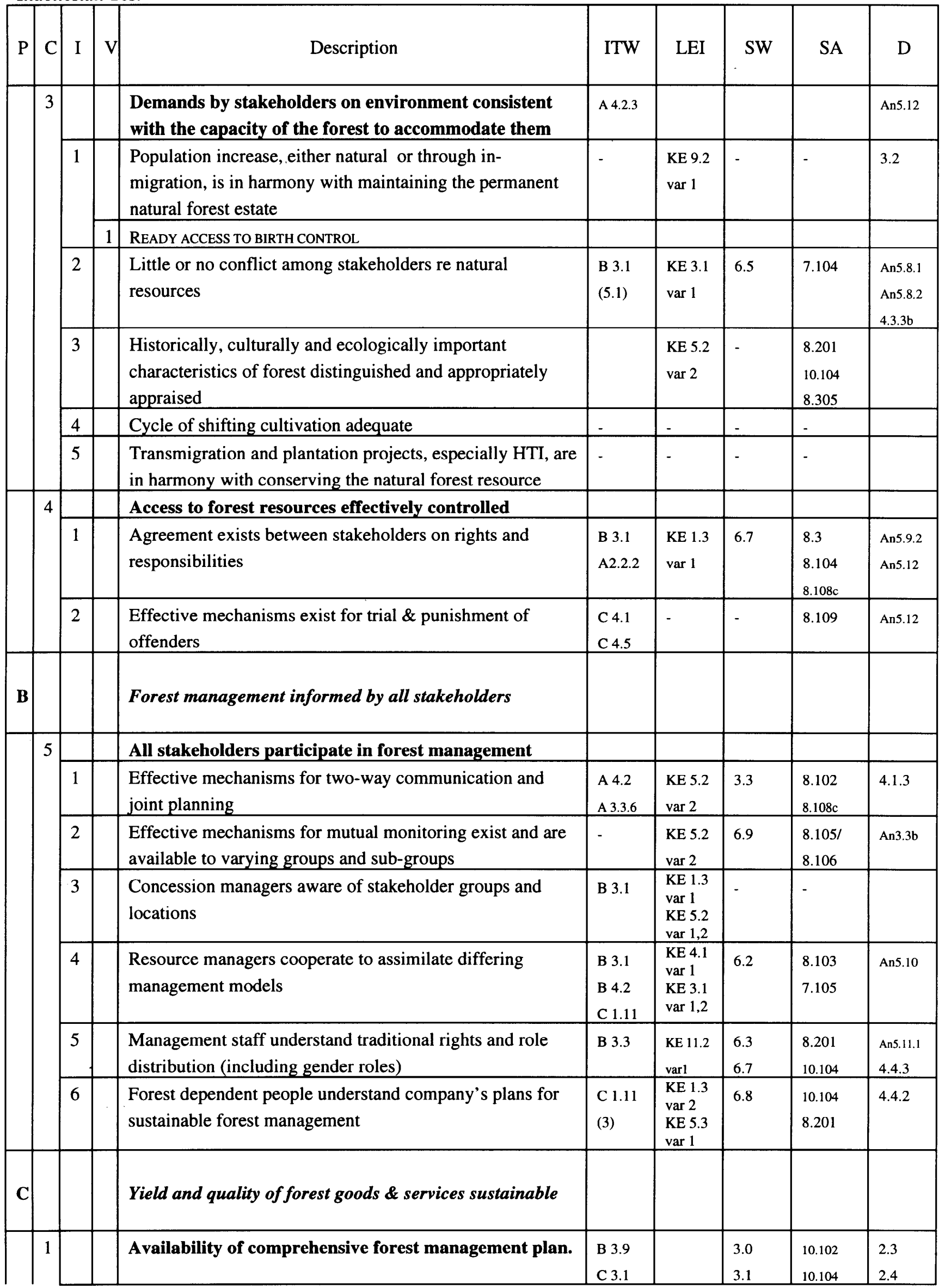


Indonesian Test

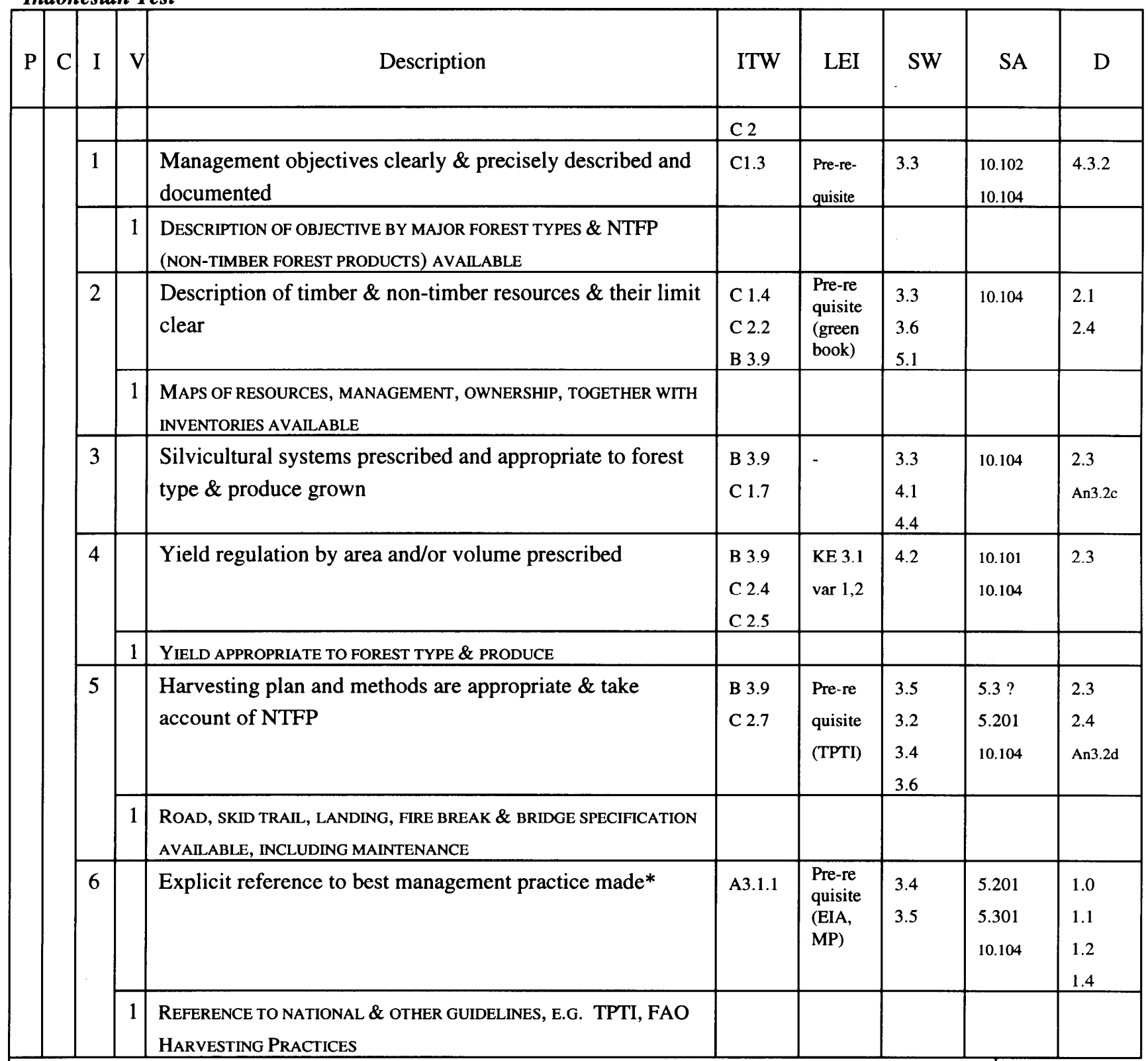

*NOTE: Management plan to contain prescriptions for environmental protection as detailed under Principle I, and for social aspects as detailed under principles IIA and IIB.

\begin{tabular}{|c|c|c|c|c|c|c|c|c|}
\hline 2 & & & $\begin{array}{l}\text { Implementation \& control of forest management plan } \\
\text { (as detailed above) is effective }\end{array}$ & $\begin{array}{l}\text { B } 3.10 \\
\text { B } 3.11 \\
\text { C 1 1,2.3.4 }\end{array}$ & $\begin{array}{l}\mathrm{KE} 3.1 \\
\text { var } 2 \\
\mathrm{KE} 4.1 \\
\text { var 1 } \\
\end{array}$ & 4.0 & $\begin{array}{l}5.1 \\
5.2 \\
5.3 \\
\end{array}$ & 2.3 \\
\hline & \multirow[t]{5}{*}{1} & & $\begin{array}{l}\text { Clear demarcation of forest management unit and coupe } \\
\text { boundaries carried out }\end{array}$ & $\begin{array}{l}\text { В } 3.9 \\
\text { в } 3.10 \\
\text { C } 5.1 \\
\end{array}$ & $\begin{array}{l}\mathrm{KE} 1.1 \\
\operatorname{var} 1\end{array}$ & 2.2 & 10.104 & $\begin{array}{l}1.1 \\
2.2\end{array}$ \\
\hline & & 1 & COUPES ALLOCATED SYSTEMATICALLY & & & & & \\
\hline & & 2 & $\begin{array}{l}\text { GOOD \& POOR FOREST ALLOCATED IN THE SAME PROPORTION AS } \\
\text { THAT IN WHICH IT OCCURS }\end{array}$ & & & & & \\
\hline & & 3 & $\begin{array}{l}\text { COUPE BOUNDARIES CORRECTLY DEMARCATED AS ON GROUND \& } \\
\text { CHECKED (E.G. BY GPS) }\end{array}$ & & & & & \\
\hline & & 4 & PROTECTION AND MANAGEMENT REGIMES RECORDED & & & & & \\
\hline & 2 & & Annual Allowable Cut regulated \& controlled by area $\& / o r$ & $\mathrm{C} 4$ & KE 3.1 & 4.3 & 6.102 & 2.3 \\
\hline
\end{tabular}


Indonesian Test

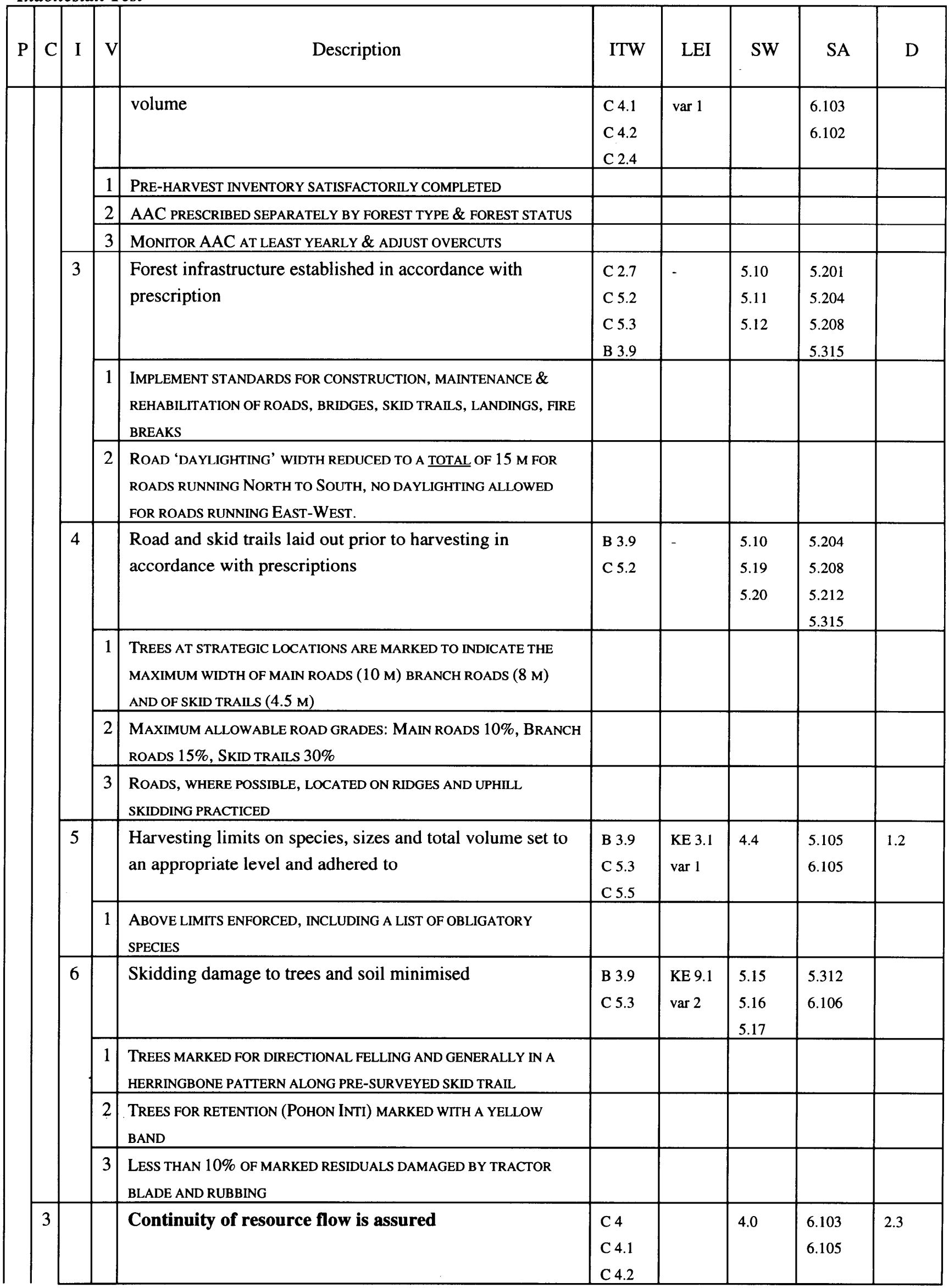


Indonesian Test

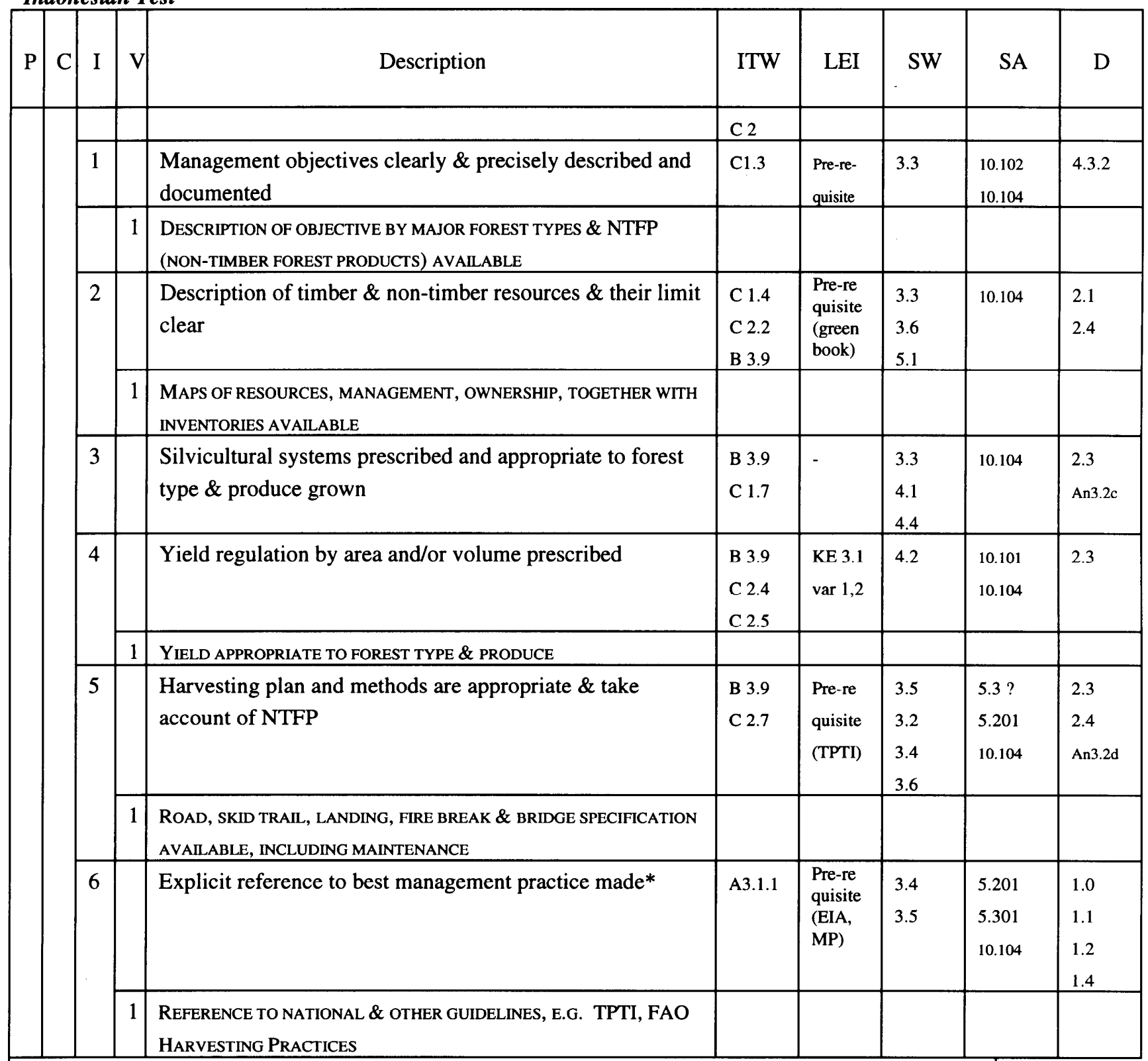

*NOTE: Management plan to contain prescriptions for environmental protection as detailed under Principle I, and for social aspects as detailed under principles IIA and IIB.

\begin{tabular}{|c|c|c|c|c|c|c|c|c|}
\hline 2 & & & $\begin{array}{l}\text { Implementation \& control of forest management plan } \\
\text { (as detailed above) is effective }\end{array}$ & $\begin{array}{l}\text { B } 3.10 \\
\text { B } 3.11 \\
\text { C 1 1,2.3.4 }\end{array}$ & $\begin{array}{l}\mathrm{KE} 3.1 \\
\text { var } 2 \\
\mathrm{KE} 4.1 \\
\text { var 1 } \\
\end{array}$ & 4.0 & $\begin{array}{l}5.1 \\
5.2 \\
5.3 \\
\end{array}$ & 2.3 \\
\hline & \multirow[t]{5}{*}{1} & & $\begin{array}{l}\text { Clear demarcation of forest management unit and coupe } \\
\text { boundaries carried out }\end{array}$ & $\begin{array}{l}\text { В } 3.9 \\
\text { в } 3.10 \\
\text { C } 5.1 \\
\end{array}$ & $\begin{array}{l}\mathrm{KE} 1.1 \\
\operatorname{var} 1\end{array}$ & 2.2 & 10.104 & $\begin{array}{l}1.1 \\
2.2\end{array}$ \\
\hline & & 1 & COUPES ALLOCATED SYSTEMATICALLY & & & & & \\
\hline & & 2 & $\begin{array}{l}\text { GOOD \& POOR FOREST ALLOCATED IN THE SAME PROPORTION AS } \\
\text { THAT IN WHICH IT OCCURS }\end{array}$ & & & & & \\
\hline & & 3 & $\begin{array}{l}\text { COUPE BOUNDARIES CORRECTLY DEMARCATED AS ON GROUND \& } \\
\text { CHECKED (E.G. BY GPS) }\end{array}$ & & & & & \\
\hline & & 4 & PROTECTION AND MANAGEMENT REGIMES RECORDED & & & & & \\
\hline & 2 & & Annual Allowable Cut regulated \& controlled by area $\& / o r$ & $\mathrm{C} 4$ & KE 3.1 & 4.3 & 6.102 & 2.3 \\
\hline
\end{tabular}


Indonesian Test

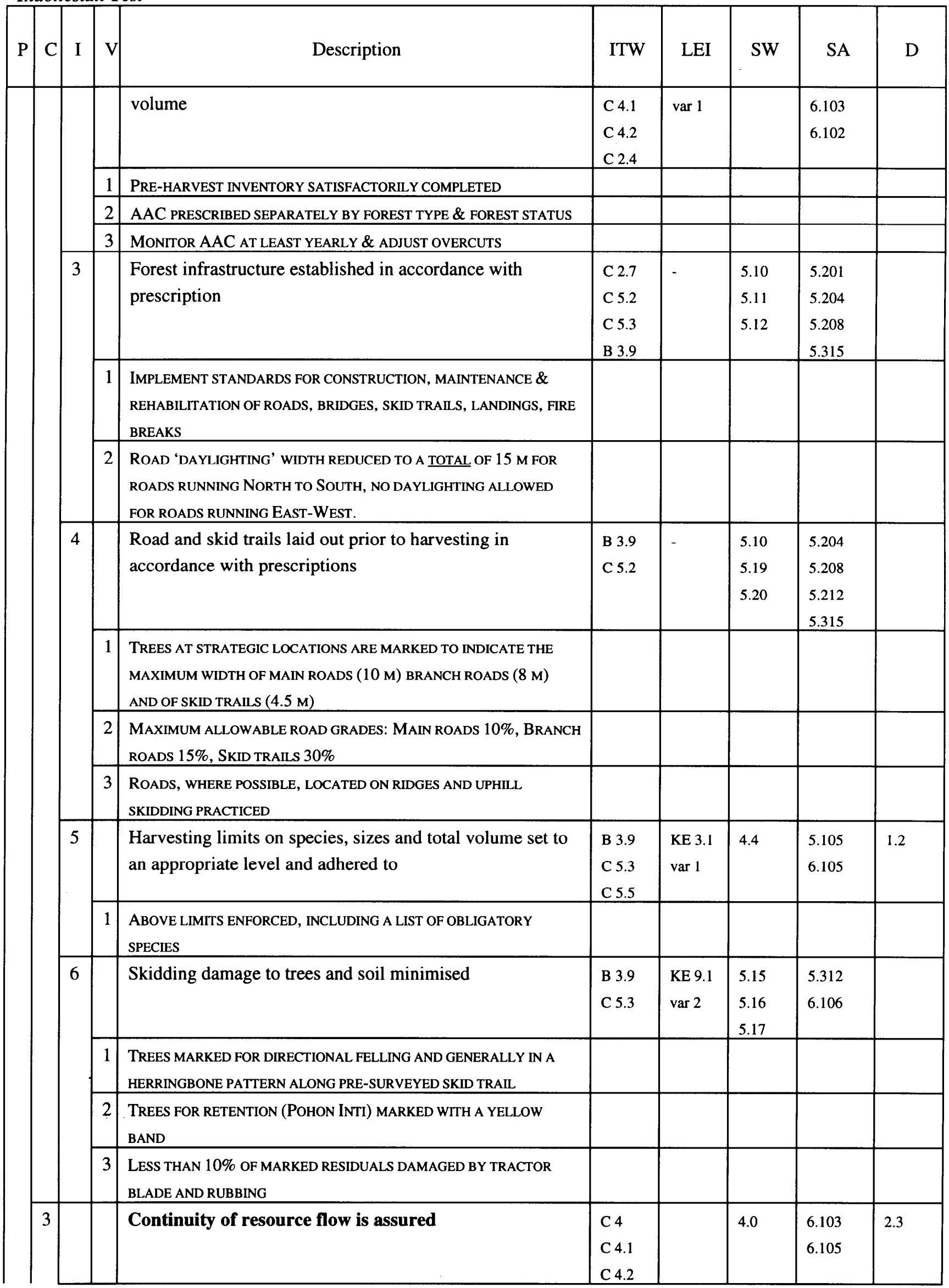


Indonesian Test

\begin{tabular}{|c|c|c|c|c|c|c|c|c|}
\hline $\mathrm{P}$ & C & $\mathrm{v}$ & Description & ITW & LEI & SW & SA & $\mathrm{D}$ \\
\hline & & & & $\begin{array}{l}\text { C } 4.7 \\
\text { C } 5.5\end{array}$ & & & & \\
\hline & 1 & & $\begin{array}{l}\text { Reliable growth data for commercial species under } \\
\text { appropriate stand conditions available }\end{array}$ & $\mathrm{C} 2.3$ & $\begin{array}{l}\mathrm{KE} 3.1 \\
\mathrm{var} 1\end{array}$ & 4.2 & 10.104 & 2.1 \\
\hline & 2 & & $\begin{array}{l}\text { Continuous forest inventory (CFI) plots established \& } \\
\text { measured regularly. }\end{array}$ & $\mathrm{C} 2.2$ & $\begin{array}{l}\text { KE } 3.1 \\
\operatorname{var} 1\end{array}$ & $\begin{array}{l}4.2 \\
4.5 \\
\end{array}$ & 10.104 & 1.1 \\
\hline & 3 & & $\begin{array}{l}\text { Net productive area of permanent forest accurately } \\
\text { determined \& updated at least every five years }\end{array}$ & $\mathrm{C} 2.2$ & $\begin{array}{l}\mathrm{KE} 1.1 \\
\mathrm{var} 1\end{array}$ & 4.2 & 6.103 & 1.1 \\
\hline & 4 & & $\begin{array}{l}\text { AAC regularly revised to take account of reliable recent } \\
\text { growth \& area data }\end{array}$ & $\begin{array}{l}\text { C } 4.2 \\
\text { C } 2.3 \\
\text { C } 1.9 \\
\text { C } 1.7\end{array}$ & $\begin{array}{l}\mathrm{KE} 3.1 \\
\text { var } 2 \\
\mathrm{KE} 4.1 \\
\mathrm{var} 1\end{array}$ & 4.2 & 6.103 & \\
\hline & 5 & & $\begin{array}{l}\text { Felling cycle correctly set with regard to increment data \& } \\
\text { silvicultural requirements }\end{array}$ & $\mathrm{C} 2.6$ & $\begin{array}{l}\text { KE } 3.1 \\
\operatorname{var} 1,2\end{array}$ & & 6.103 & \\
\hline & \multirow[t]{5}{*}{6} & & Damaged areas rehabilitated & $\begin{array}{l}\text { B } 3.9 \\
\text { C } 5.5 \\
\text { A4.2.2.3. } \\
\end{array}$ & $\begin{array}{l}\text { KE } 4.1 \\
\operatorname{var} 1\end{array}$ & & $\begin{array}{l}5.315 \\
5.511 \\
5.512 \\
\end{array}$ & 1.2 \\
\hline & & 1 & $\begin{array}{l}\text { EVALUATE NECESSITY TO REHABILITATE FIRE/DROUGHT DAMAGE } \\
\text { FOREST \& TREAT IF NECESSARY }\end{array}$ & & & & & \\
\hline & & 2 & $\begin{array}{l}\text { EVALUATE ECONOMIC \& ECOLOGICAL DESIRABLILTY OF PLANTING } \\
\text { LANDING \& ROAD SIDE }\end{array}$ & & & & & \\
\hline & & 3 & $\begin{array}{l}\text { ABANDONED ROADS \& LANDINGS REGULARLY MONITORED FOR } \\
\text { EROSION \& CORRECTIVE MEASURES TAKEN IF NECESSARY. }\end{array}$ & & & & & \\
\hline & & 4 & $\begin{array}{l}\text { IF PLANTING REQUIRED, PREFER INDIGENOUS SPECIES APPROPRIATE } \\
\text { TO THE AREA }\end{array}$ & & & & & \\
\hline & \multirow[t]{5}{*}{7} & & Residual stands satisfactory regenerated & $\begin{array}{l}\text { B } 3.9 \\
\text { C } 5.5\end{array}$ & $\begin{array}{l}\text { KE } 4.1 \\
\text { var } 1\end{array}$ & 4.6 & $\begin{array}{l}10.206 \\
6.107 \\
5.312 \\
\end{array}$ & 1.2 \\
\hline & & 1 & $\begin{array}{l}\text { RESIDUALS ADEQUATE IN NUMBER UNDAMAGED, HEALTHY \& GOOD } \\
\text { FORM OF COMMERCIAL SPECIES }\end{array}$ & & & & & \\
\hline & & 2 & $\begin{array}{l}\text { REGENERATION OF COMMERCIAL SPECIES FROM SEEDLING SIZE UP } \\
\text { ADEQUATE }\end{array}$ & & & & & \\
\hline & & 3 & $\begin{array}{l}\text { POST-HARVEST INVENTORY (INCLUDING DISTRIBUTION MAP OF } \\
\text { RESIDUAL TREES) TO CONFIRM } 1 \& 2 \text { ABOVE }\end{array}$ & & & & & \\
\hline & & 4 & FUTURE CROP TREES RELEASED IF NECESSARY & & & & & \\
\hline & 8 & & Control maps updated at least annually & $\begin{array}{l}\text { C } 4.7 \\
\text { C } 1.6 \\
\text { C } 1.10\end{array}$ & & 3.4 & $\begin{array}{l}10.204 \\
10.205\end{array}$ & An $3.2 \mathrm{~b}$ \\
\hline & 9 & & $\begin{array}{l}\text { Records of outturn \& forest operations updated annually } \\
\text { and available }\end{array}$ & C 4.7 & $\begin{array}{l}\text { KE11.1 } \\
\operatorname{var} 1\end{array}$ & 10.1 & & \\
\hline & $\begin{array}{l}1 \\
0\end{array}$ & & $\begin{array}{l}\text { Worked coupes protected from encroachment } \& \text { from pre- } \\
\text { mature re-entry }\end{array}$ & C 5.1 & $\begin{array}{l}\mathrm{KE} 1.1 \\
\text { var } 1 \\
\mathrm{KE} 1.3 \\
\operatorname{var} 2 \\
\mathrm{KE} 2.1 \\
\operatorname{var} 1\end{array}$ & 5.21 & 10.104 & \\
\hline & $\begin{array}{l}1 \\
1\end{array}$ & & $\begin{array}{l}\text { Enrichment planting only where seedlings and seed } \\
\text { sources are lacking and only with indigenous commercial } \\
\text { species. }\end{array}$ & C5.5 & - & 4.6 & $\begin{array}{l}5.511 \\
5.503\end{array}$ & \\
\hline
\end{tabular}


Indonesian Test

\begin{tabular}{|c|c|c|c|c|c|c|c|c|c|}
\hline$P$ & $\mathrm{C}$ & I & $\mathrm{V}$ & Description & ITW & LEI & SW & SA & $\mathrm{D}$ \\
\hline & & $\begin{array}{l}1 \\
2 \\
\end{array}$ & & $\begin{array}{l}\text { No net change in natural forest area as a result of forest } \\
\text { management }\end{array}$ & - & $\begin{array}{l}\text { KE1.1 } \\
\operatorname{var} 1\end{array}$ & - & 7.106 & \\
\hline $\mathbf{D}$ & & & & $\begin{array}{l}\text { Policy, planning \& institutional framework effective and } \\
\text { committed to sustainability } \\
\text { NOTE: These are national level criteria and indicators }\end{array}$ & & & & & \\
\hline & 1 & & & $\begin{array}{l}\text { Legal \& policy framework recognize the benefits } \\
\text { occurring from forests \& seeks to optimize \& maintain } \\
\text { them. }\end{array}$ & & & & & \\
\hline & & 1 & & $\begin{array}{l}\text { A permanent forest estate (PFE) comprising both } \\
\text { protection and production forest has been constituted, after } \\
\text { due \& diligent enquiry in each forest \& promulgated by } \\
\text { decree. }\end{array}$ & $\begin{array}{l}\text { A } 2.12 \\
\text { A } 3.1 .1 \\
\text { A } 4.1\end{array}$ & $\begin{array}{l}\mathrm{KE} 1.1 \\
\operatorname{var} 1\end{array}$ & 2.2 & - & 3.5 \\
\hline & & 2 & & $\begin{array}{l}\text { The PFE reflects the existing diversity of forest types, their } \\
\text { conservation, environmental, economic \& cultural values } \\
\text { in terms of quantity and quality. }\end{array}$ & B 2 & $\begin{array}{l}\mathrm{KE} 1.2 \\
\operatorname{var} 1\end{array}$ & $3.3(\mathrm{vi})$ & 5.103 & $\begin{array}{l}3.6 \\
4.2\end{array}$ \\
\hline & & 3 & & $\begin{array}{l}\text { A clearly understood \& effective system of incentives and } \\
\text { deterrents exists to promote best forest management } \\
\text { practices. }\end{array}$ & C 4.4 & $\begin{array}{l}\mathrm{KE} 4.1 \\
\operatorname{var} 1\end{array}$ & 4.1 & - & An $3.2 \mathrm{c}$ \\
\hline & & 4 & & $\begin{array}{l}\text { Policy and legal frameworks encourage the reduction of } \\
\text { waste in production processes. }\end{array}$ & A4.2.3.4 & - & 5.22 & 9.103 & \\
\hline & & 5 & & $\begin{array}{l}\text { An adequate percentage of the total revenue from forest is } \\
\text { re-invested in maintaining the PFE. }\end{array}$ & - & $\begin{array}{l}\text { KE } 6.1 \\
\operatorname{var} 1 \\
\text { KE } 7.1 \\
\operatorname{var} 1 \\
\end{array}$ & 8.3 & 8.401 & An2.2 \\
\hline & & 6 & & $\begin{array}{l}\text { International conventions on the protection of the } \\
\text { environment \& the basic rights of people have been } \\
\text { ratified and are followed }\end{array}$ & A2.1.1 & $\begin{array}{l}\mathrm{KE} 1.3 \\
\operatorname{var} 1,2\end{array}$ & $\begin{array}{l}5.3 \\
5.4 \\
6.3 \\
6.7\end{array}$ & - & 4.1 .1 \\
\hline & & 7 & & $\begin{array}{l}\text { A clear \& well understood policy on harvesting \& utilizing } \\
\text { of forest products exists; licensing of harvesting \& of } \\
\text { manufacture of major forest products lies within a single } \\
\text { government department }\end{array}$ & A 3.2 & $\begin{array}{l}\text { Pre-re } \\
\text { quisite } \\
\text { (FA) } \\
\text { KE } 3.1 \\
\text { var } 1,2 \\
\end{array}$ & - & - & \\
\hline & & 8 & & $\begin{array}{l}\text { Policy \& legal frameworks enable forest management to be } \\
\text { a transparent } \& \text { planned process. }\end{array}$ & - & - & - & 10.101 & \\
\hline & & 9 & & $\begin{array}{l}\text { Utilization licenses, issued through a prescribed \& } \\
\text { transparent procedure include at least the minimum terms } \\
\text { recommended by FAO \& are valid, subject to satisfactory } \\
\text { performance, for a period at least as long as the felling } \\
\text { cycle. }\end{array}$ & C 1.2 & FA & - & - & \\
\hline & $\begin{array}{l}1 \\
0\end{array}$ & & $\begin{array}{l}\text { Maintenance of opportunities for the production of a } \\
\text { diversity of goods \& services is the stated aim of policy }\end{array}$ & - & - & - & - & \\
\hline & & & 1 & ACCURATE, UPTO DATE AND AGREED MAPS EXIST & & & & & \\
\hline & 2 & & & $\begin{array}{l}\text { Policy and legal frameworks recognize that } \\
\text { distribution \& access to forest goods \& services must }\end{array}$ & & & & & \\
\hline
\end{tabular}


Indonesian Test

\begin{tabular}{|c|c|c|c|c|c|c|c|c|c|}
\hline $\mathrm{P}$ & $\mathrm{C}$ & I & $\mathrm{v}$ & Description & ITW & LEI & SW & SA & $\mathrm{D}$ \\
\hline & & & & be equitable. & & & & & \\
\hline & & 1 & & $\begin{array}{l}\text { Policy and legal frameworks provide the security for } \\
\text { tenure, usufruct \& ownership rights to forest lands } \\
\text { especially for the traditionally forest dependent people. }\end{array}$ & & $\begin{array}{l}\text { KE1.3 } \\
\text { var } 1\end{array}$ & - & - & 4.1 .3 \\
\hline & & 2 & & $\begin{array}{l}\text { Mechanisms exist to ensure that conflicts are resolved in } \\
\text { transparent, participatory \& fair manner with access to } \\
\text { information for all parties concerned. }\end{array}$ & B 3.1 & $\begin{array}{l}\text { KE } 2.1 \\
\text { var } 1\end{array}$ & - & 7.104 & \\
\hline \multirow{4}{*}{\multicolumn{2}{|c|}{3}} & & & $\begin{array}{l}\text { The legal \& policy making processes are recognized as } \\
\text { informed, transparent } \& \text { iterative processes, open to } \\
\text { reform }\end{array}$ & C 1.8 & & & & \\
\hline & & 1 & & $\begin{array}{l}\text { Policy and planning is based on recent } \& \text { accurate } \\
\text { information }\end{array}$ & A 1.1 & $\begin{array}{l}\text { Pre-re } \\
\text { quisite }\end{array}$ & 3.3 & 10.102 & \\
\hline & & 2 & & $\begin{array}{l}\text { Effective instruments for inter-sectoral co-ordination on } \\
\text { land use \& land management exist. }\end{array}$ & - & 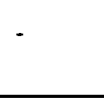 & - & - & \\
\hline & & 3 & & $\begin{array}{l}\text { Mechanism exist for planning processes to be initiated } \\
\text { from below as well as from above. }\end{array}$ & & - & . & $\begin{array}{l}10.104 \\
(\mathrm{~d} x, \mathrm{x} \text { i) }\end{array}$ & \\
\hline & 4 & & & $\begin{array}{l}\text { The execution of policy is facilitated by effective } \\
\text { institutions }\end{array}$ & & & & & \\
\hline & & 1 & & $\begin{array}{l}\text { Institutions responsible for forest management } \& \text { research } \\
\text { are adequately funded \& staffed. }\end{array}$ & $\begin{array}{l}\text { A } 3.2 \\
\text { B } 3.3 \\
\text { A4.2.1 }\end{array}$ & . & 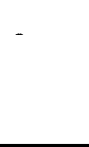 & . & \\
\hline & & 2 & & $\begin{array}{l}\text { Power is distributed effectively between the various levels } \\
\text { in the hierarchy \& decentralization is encouraged }\end{array}$ & A 3.2 & - & - & - & \\
\hline & & 3 & & $\begin{array}{l}\text { Capacity building is practised where appropriate to } \\
\text { strengthen institution at all levels }\end{array}$ & . & - & - & - & \\
\hline & & 4 & & $\begin{array}{l}\text { Institutions for arbitration } \& \text { conflict resolution exist } \& \text { are } \\
\text { effective. }\end{array}$ & - & & & - & \\
\hline
\end{tabular}




\section{Indonesian Test}

Notes:

$\begin{array}{llll}\mathrm{P} & =\text { Principle } & \text { ITW } & : \text { Initiative Tropenwald } \\ \mathrm{C} & =\text { Criterion } & \text { SW } & : \text { Smart Wood (Rainforest Alliance) } \\ \mathrm{I} & =\text { Indicator } & \text { SA } & : \text { Soil Association (Woodmark) } \\ \mathrm{V} & =\text { Verifier } & \text { LEI } & \text { : Lembaga Ekolabel Indonesia } \\ \text { ICE } & : \text { Key Element \# in LEI } & \text { D } & : \text { Dutch (DBB) standard } \\ \text { Var } & =\text { variable \# in LEI } & \\ & & \\ \text { EIA } & =\text { Environmental Impact Assessment } & \\ \text { MP } & =\text { Management Plan } & \\ \text { FA } & =\text { Forestry Agreement }\end{array}$




\section{Côte d'Ivoire Test}

\section{LIST OF MODIFIED CRITERIA AND INDICATORS}

Note: References to the base sets of C\&I are to be found in the original lists of C\&I in Mengin-Lecreulx et al. (1995). 


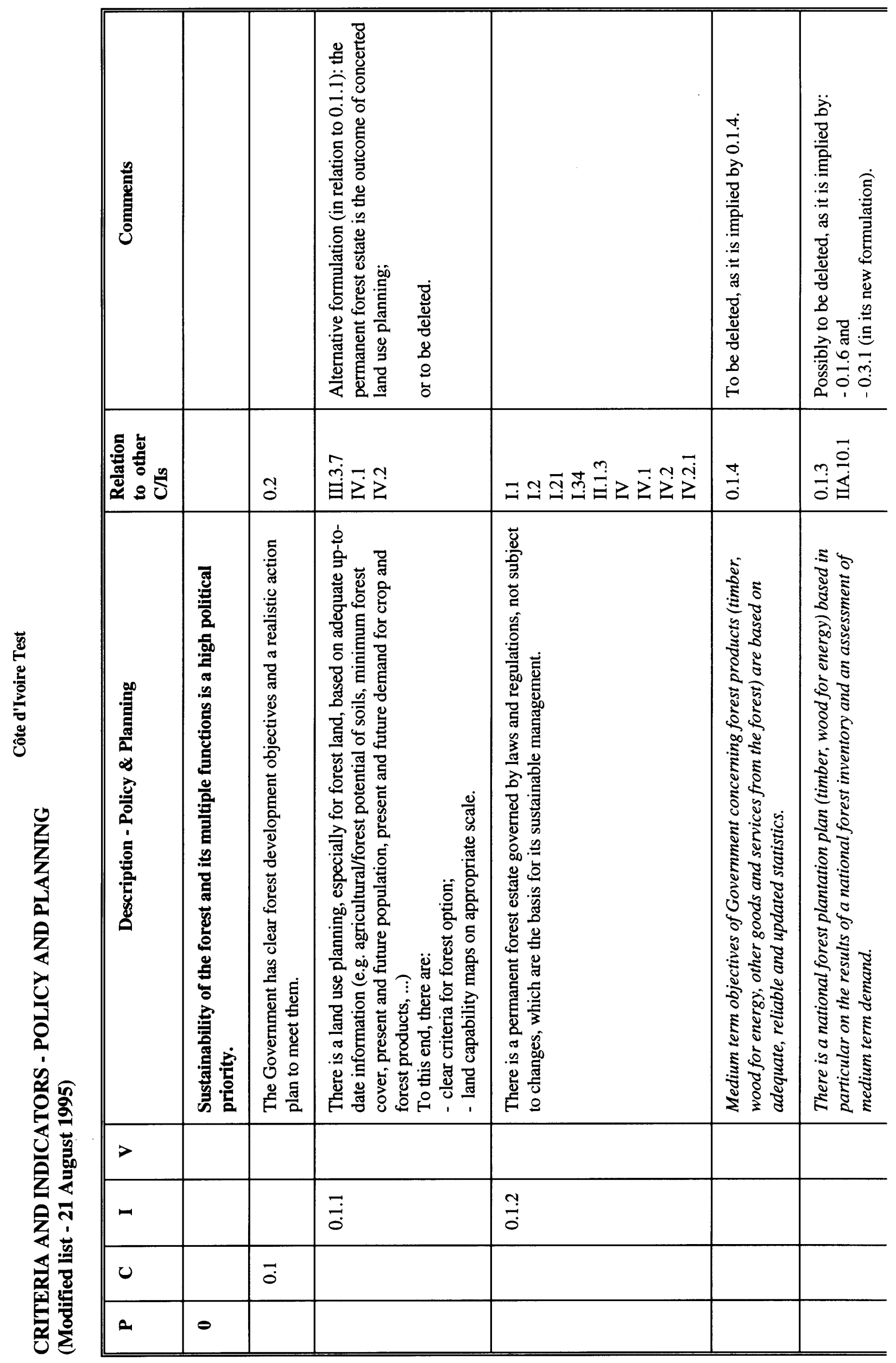




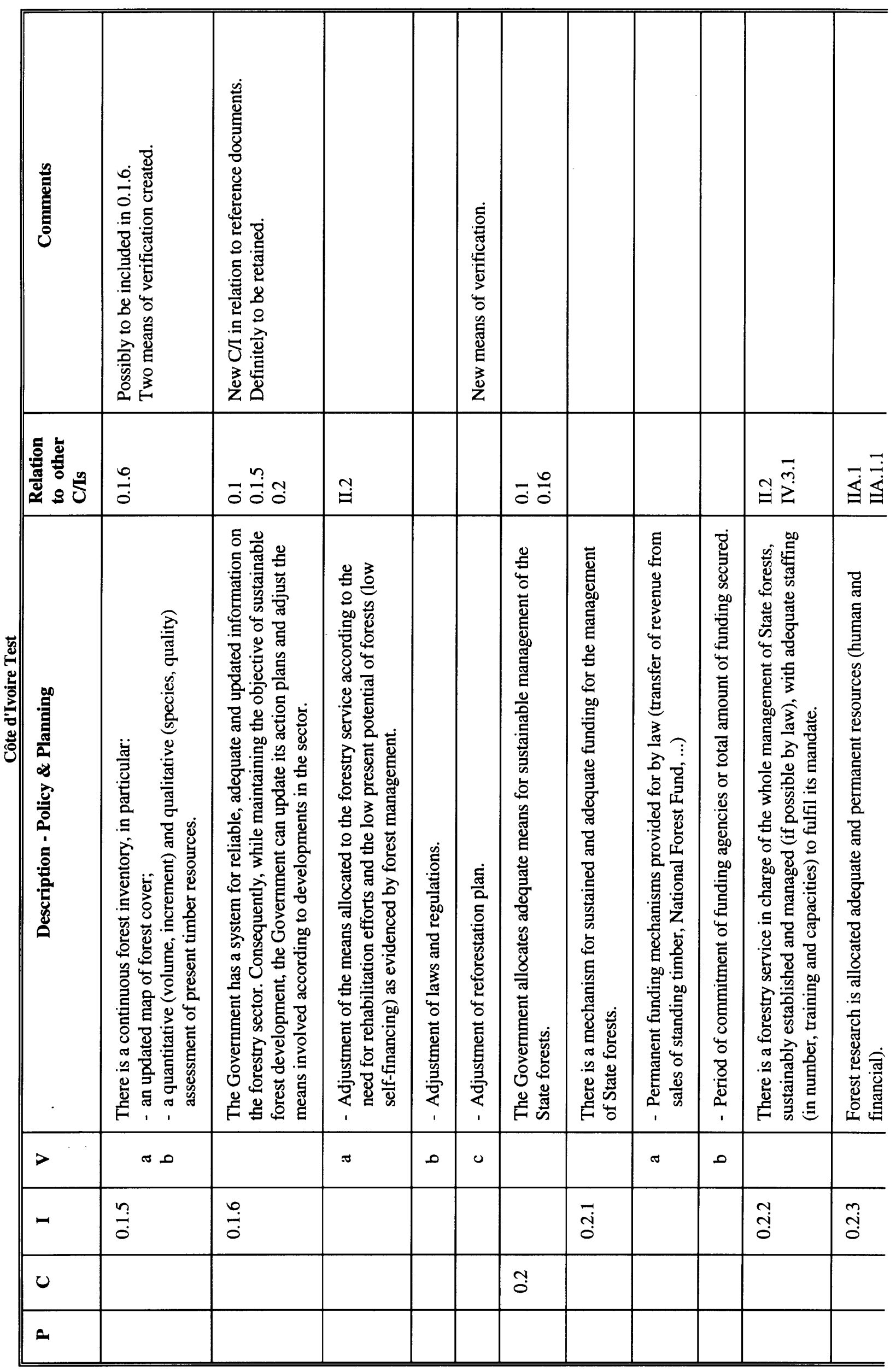




\begin{tabular}{|c|c|c|c|c|c|c|c|c|c|}
\hline 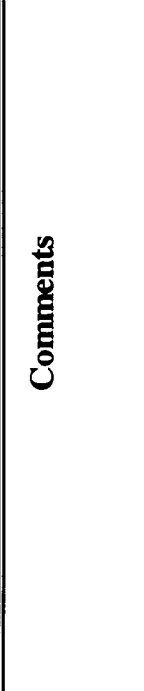 & & & & & & 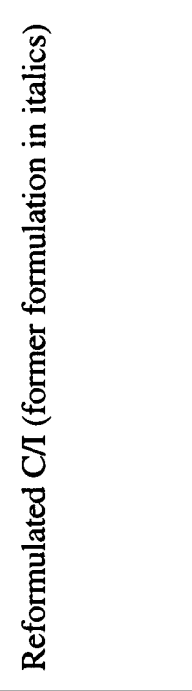 & & & 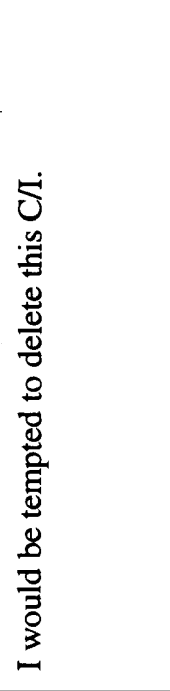 \\
\hline 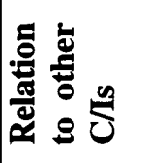 & 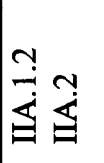 & & & & & $\begin{array}{l}\stackrel{m}{0} \\
\dot{\Xi}\end{array}$ & $\underset{\stackrel{\sim}{+}}{\stackrel{\sim}{+}}$ & & \\
\hline 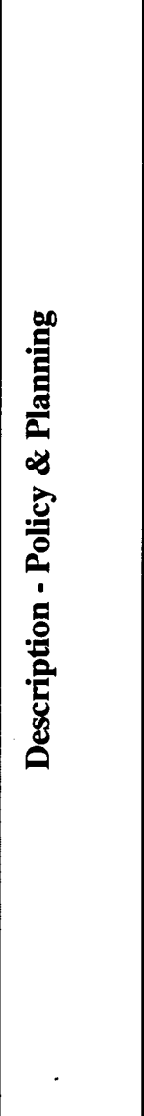 & 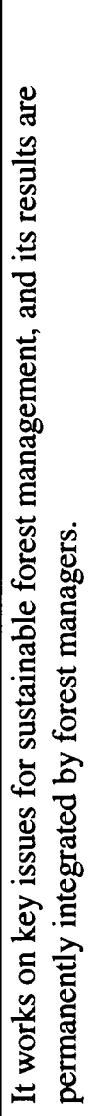 & 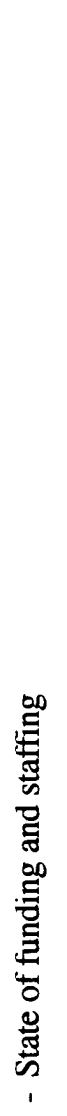 & 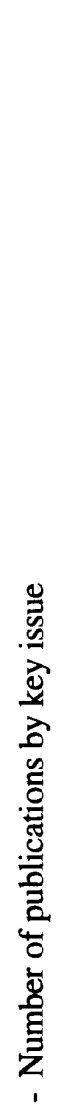 & 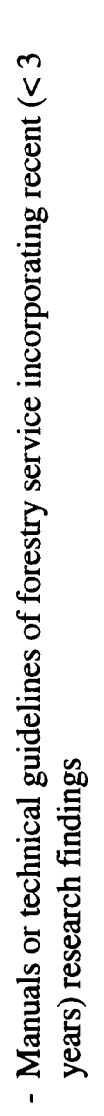 & 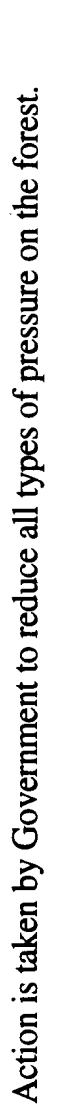 & 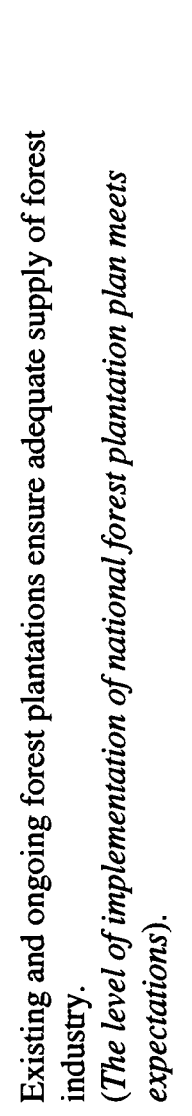 & 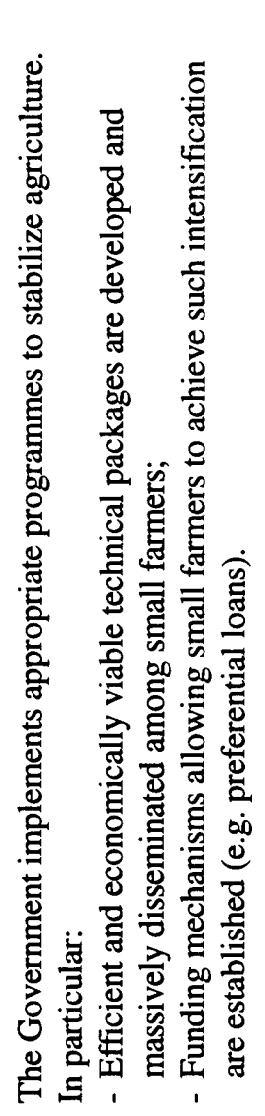 & 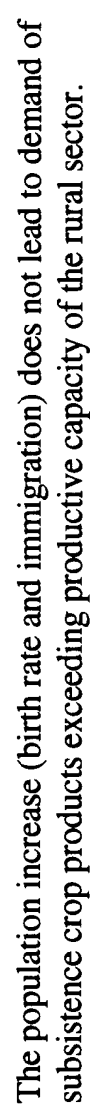 & 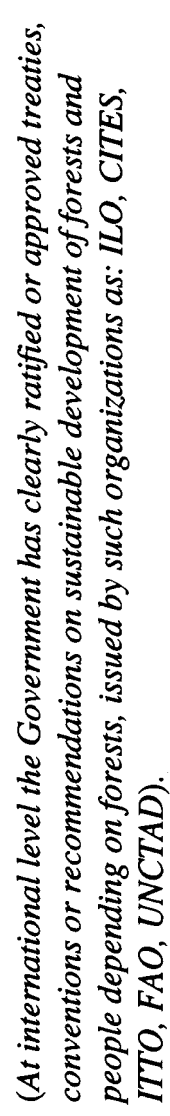 \\
\hline$>$ & & $\sigma$ & مـ & 0 & & & & & \\
\hline$\tau$ & & & & & & $\overrightarrow{\dot{o}}$ & $\stackrel{n}{n}$ & $\stackrel{m}{m}$ & \\
\hline u & & & & & 0 & & & & \\
\hline 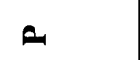 & & & & & & & & & \\
\hline
\end{tabular}




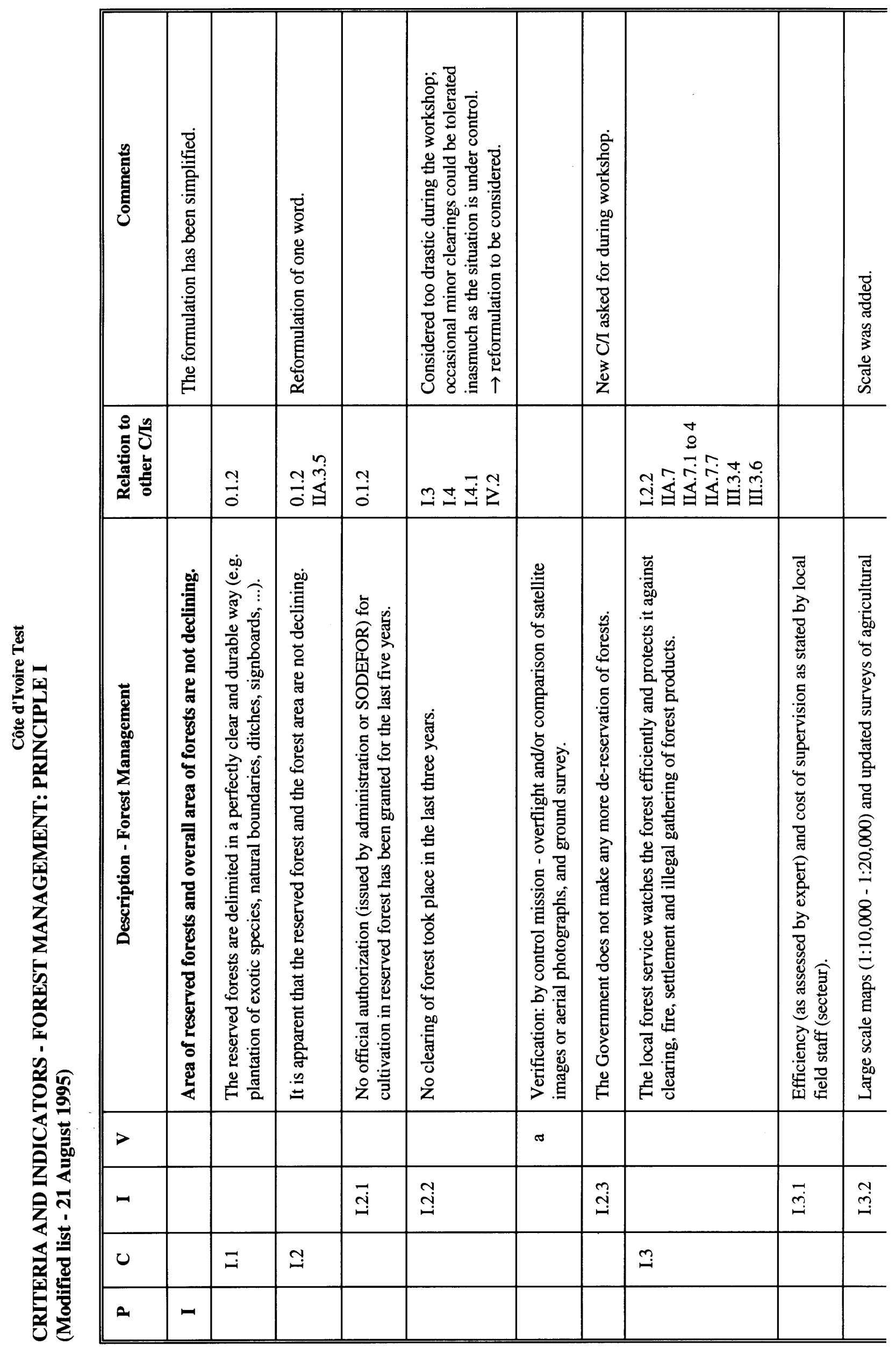




\begin{tabular}{|c|c|c|c|c|c|c|c|c|}
\hline 章 & & 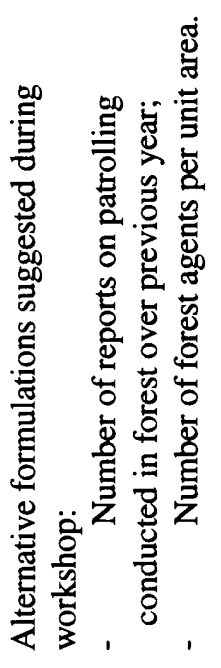 & 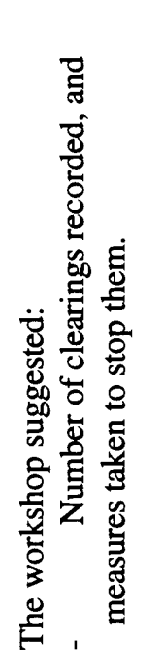 & & $\begin{array}{l}\frac{\vec{d}}{0} \\
\frac{0}{0} \\
\frac{0}{0} \\
0 \\
0 \\
0\end{array}$ & & & 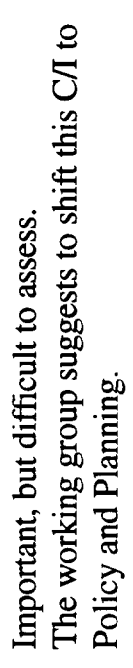 \\
\hline 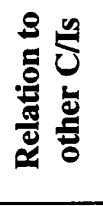 & & & 䓹 & & & 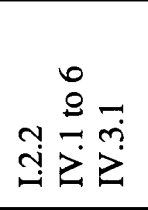 & $\stackrel{\sim}{\sim} \underset{\sim}{\stackrel{m}{m}}$ & 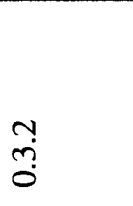 \\
\hline 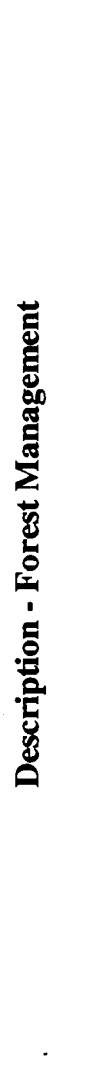 & 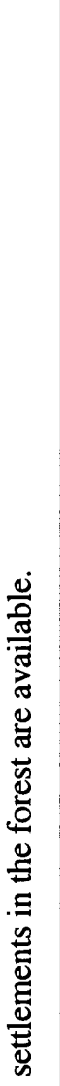 & 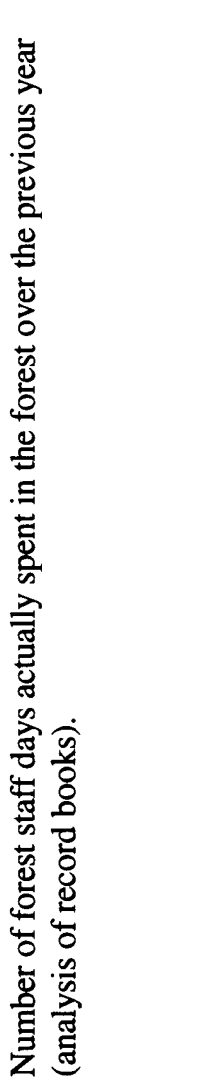 & 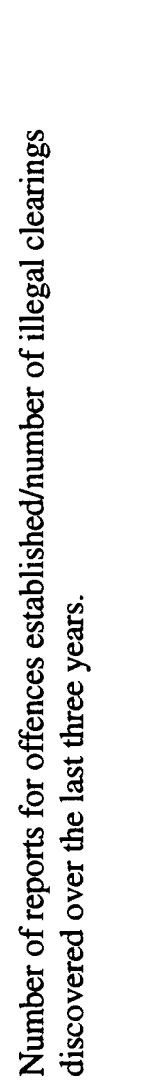 & 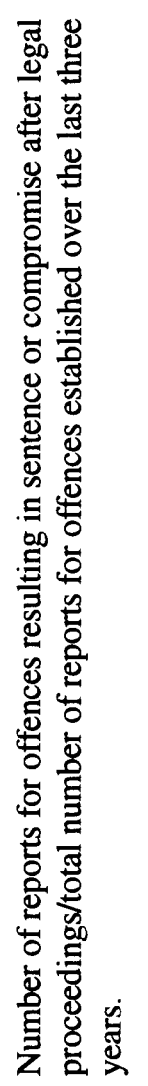 & 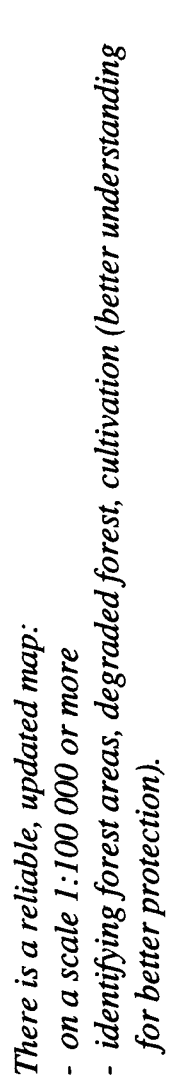 & 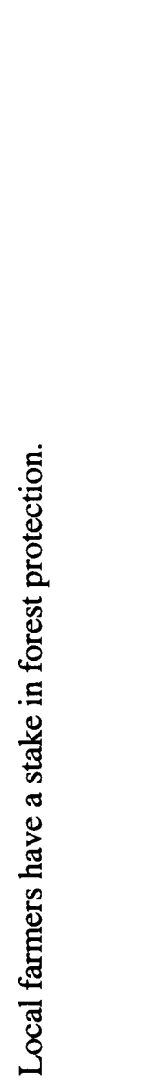 & 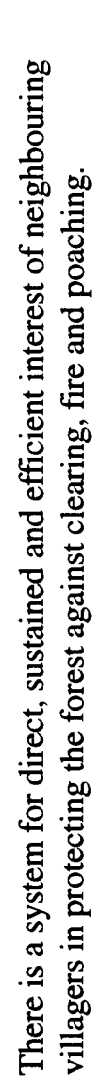 & 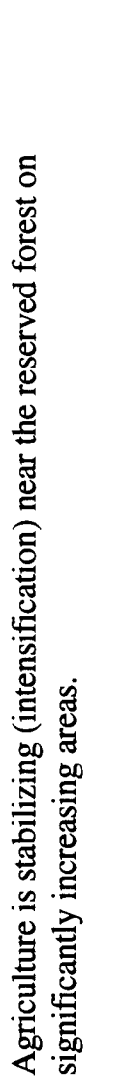 \\
\hline \multicolumn{9}{|l|}{$>$} \\
\hline- & & $\stackrel{m}{M}$ & $\stackrel{+}{\stackrel{\oplus}{\hookrightarrow}}$ & $\stackrel{n}{m}$ & 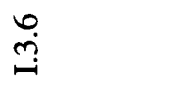 & & 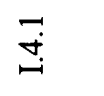 & $\stackrel{\stackrel{\sim}{\sharp}}{\sim}$ \\
\hline$u$ & & & & & & $\underset{\sim}{ \pm}$ & & \\
\hline $\boldsymbol{H}$ & & & & & & & & \\
\hline
\end{tabular}




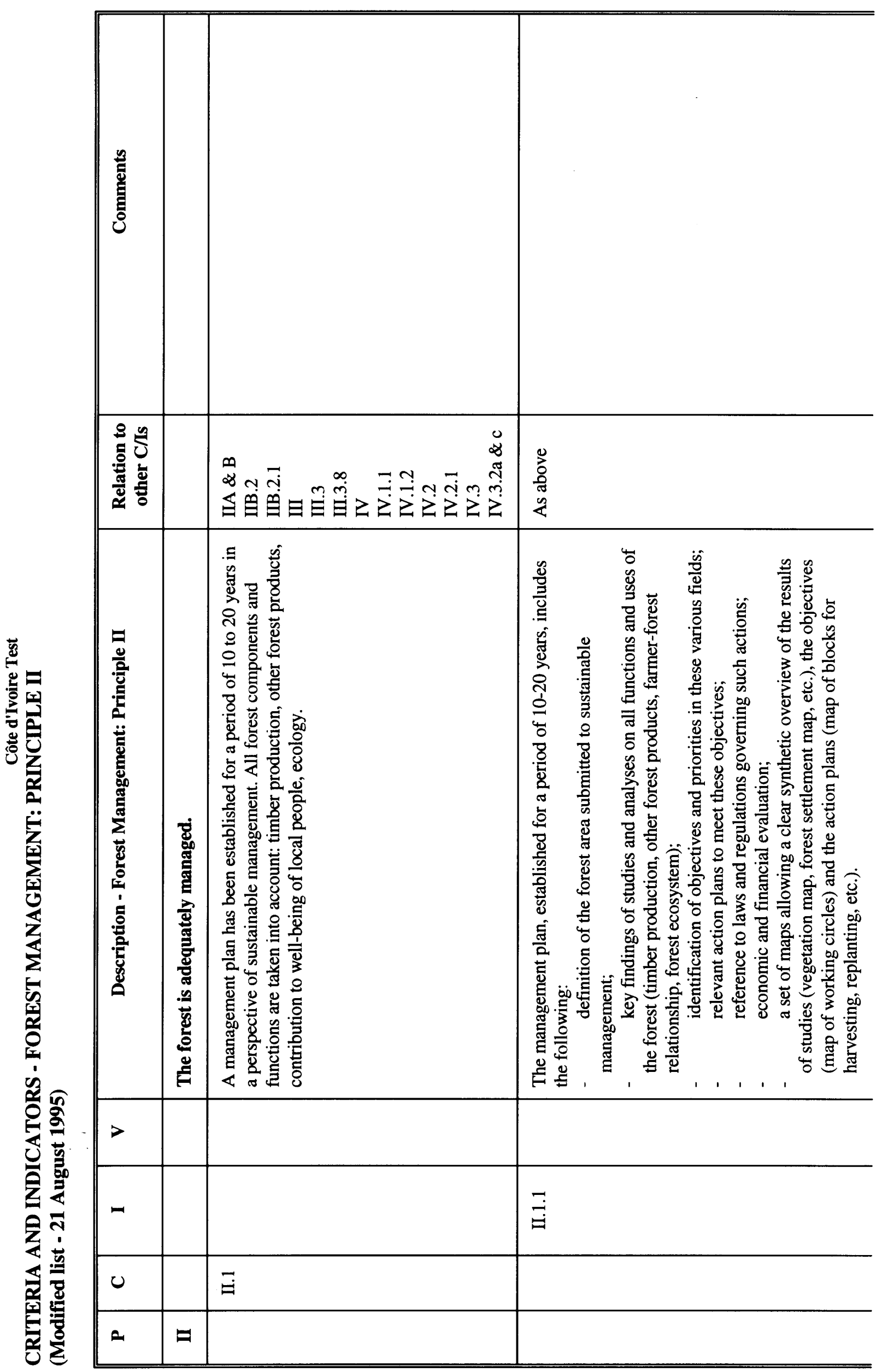




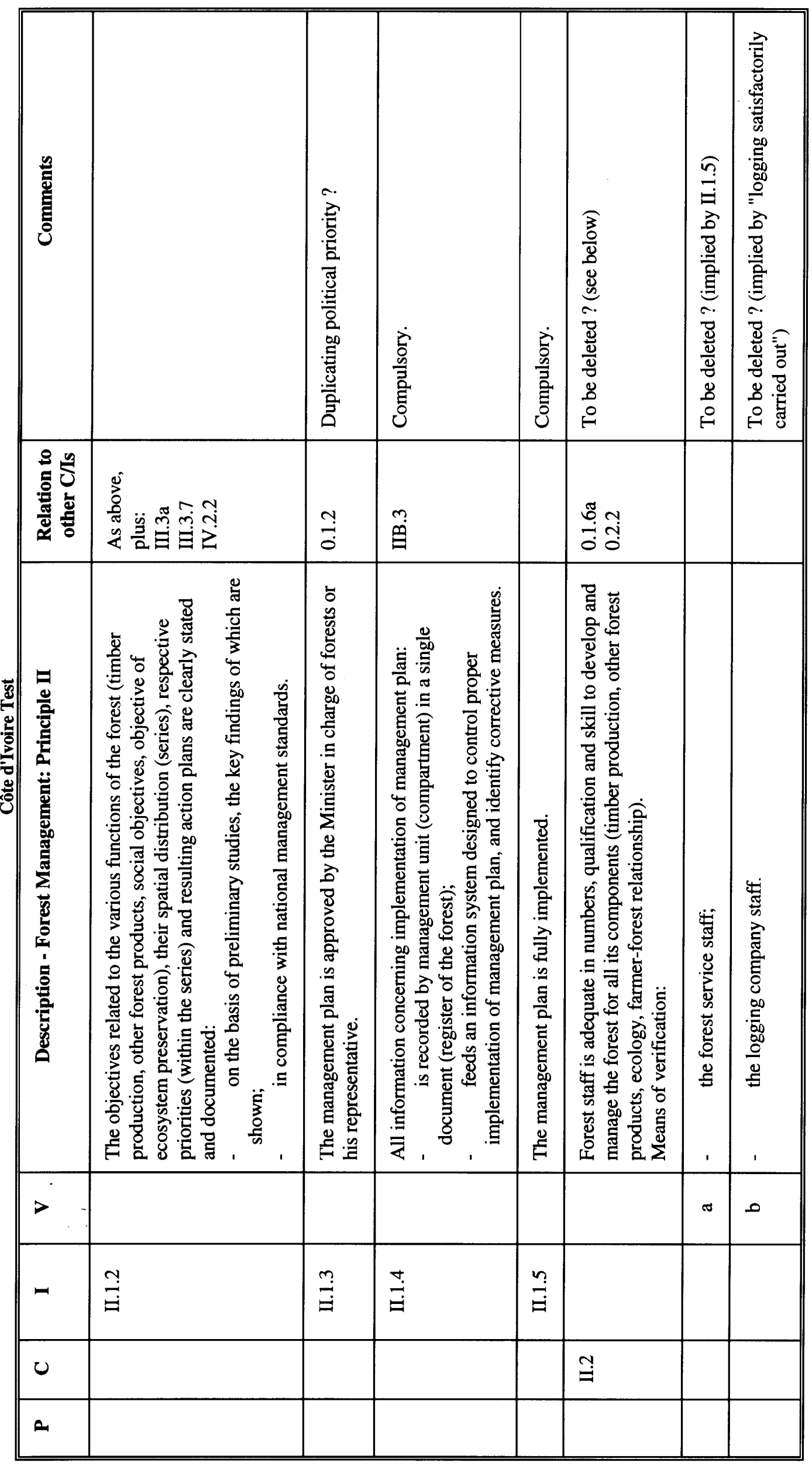




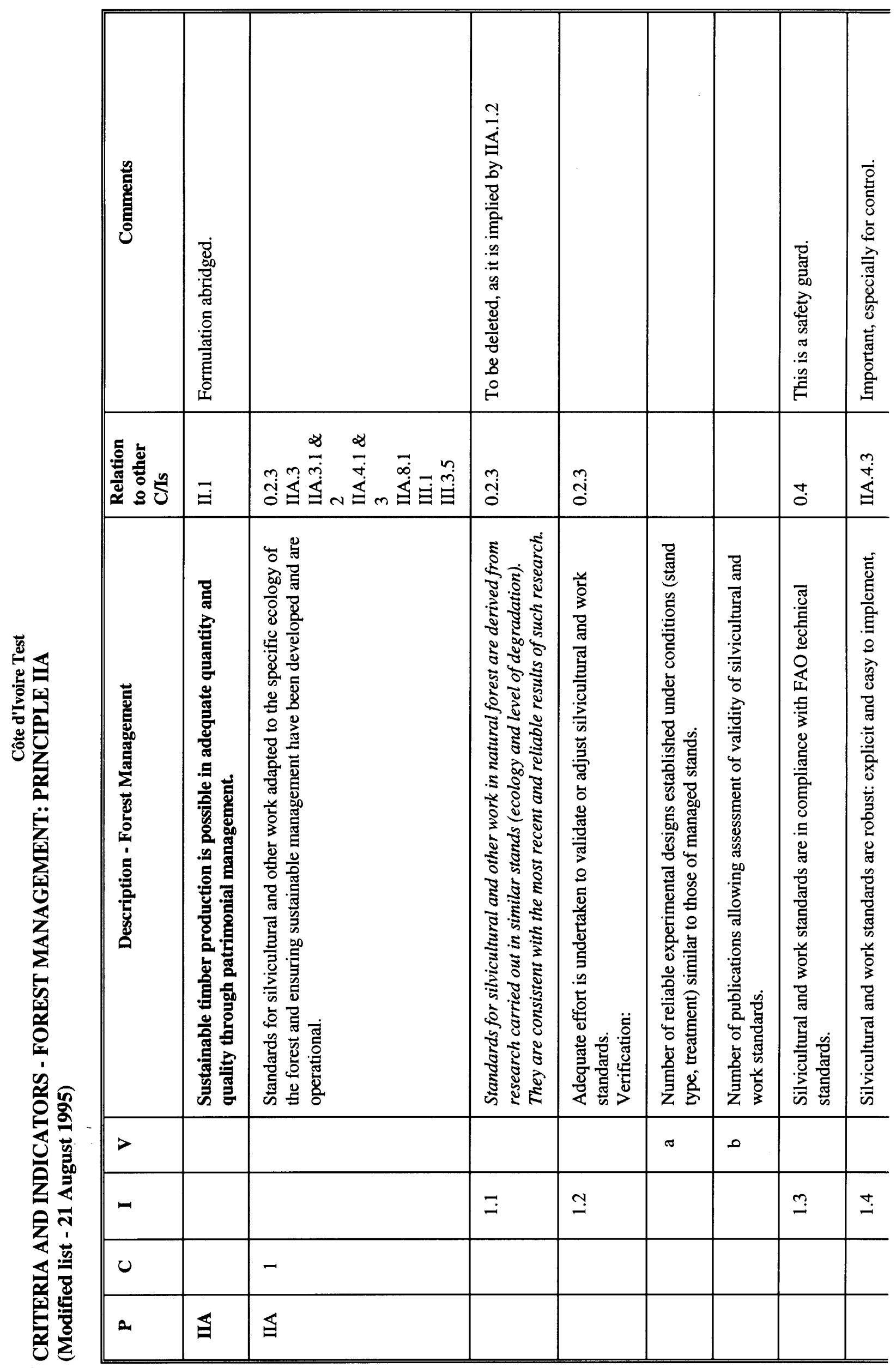




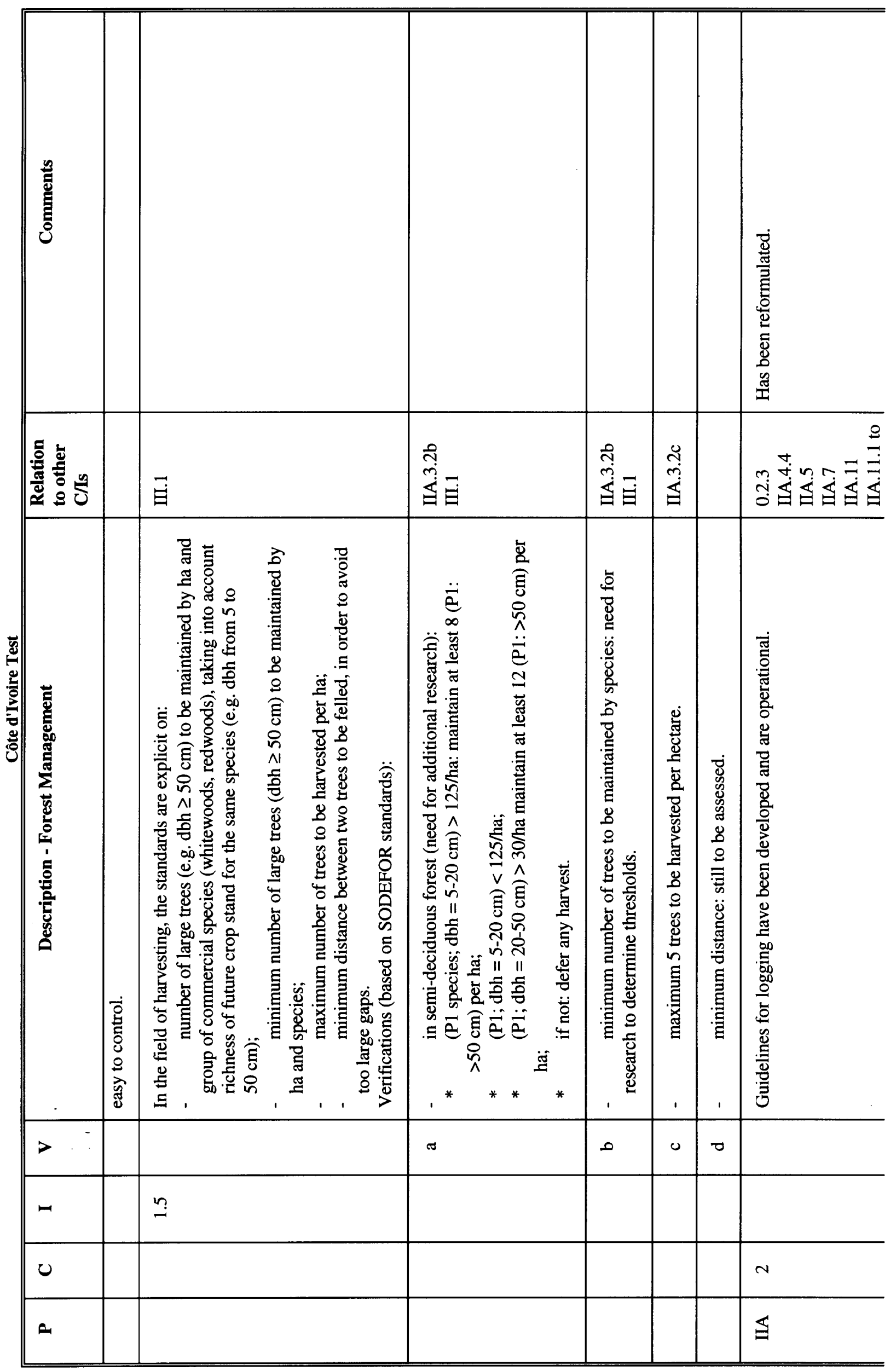




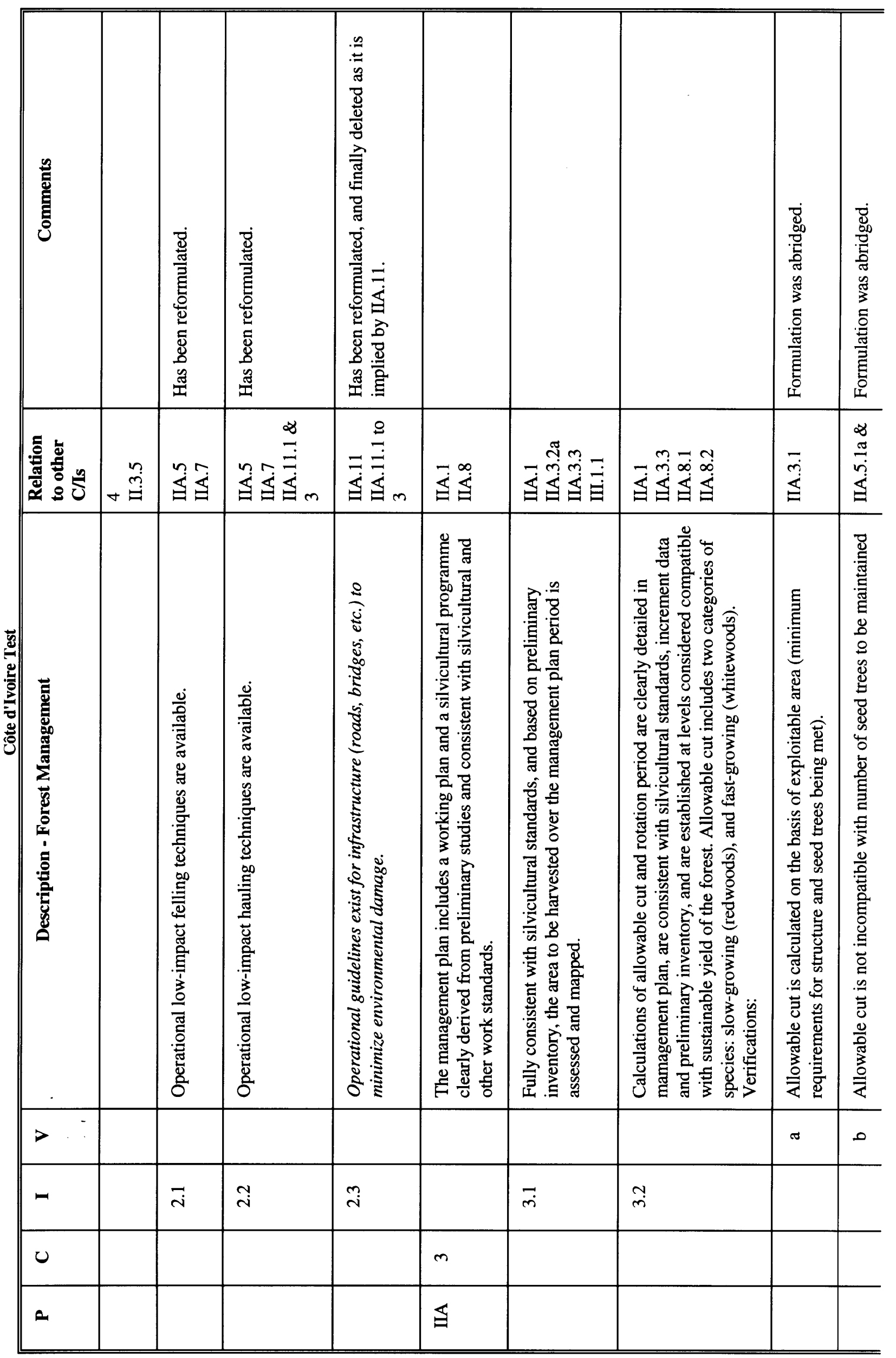




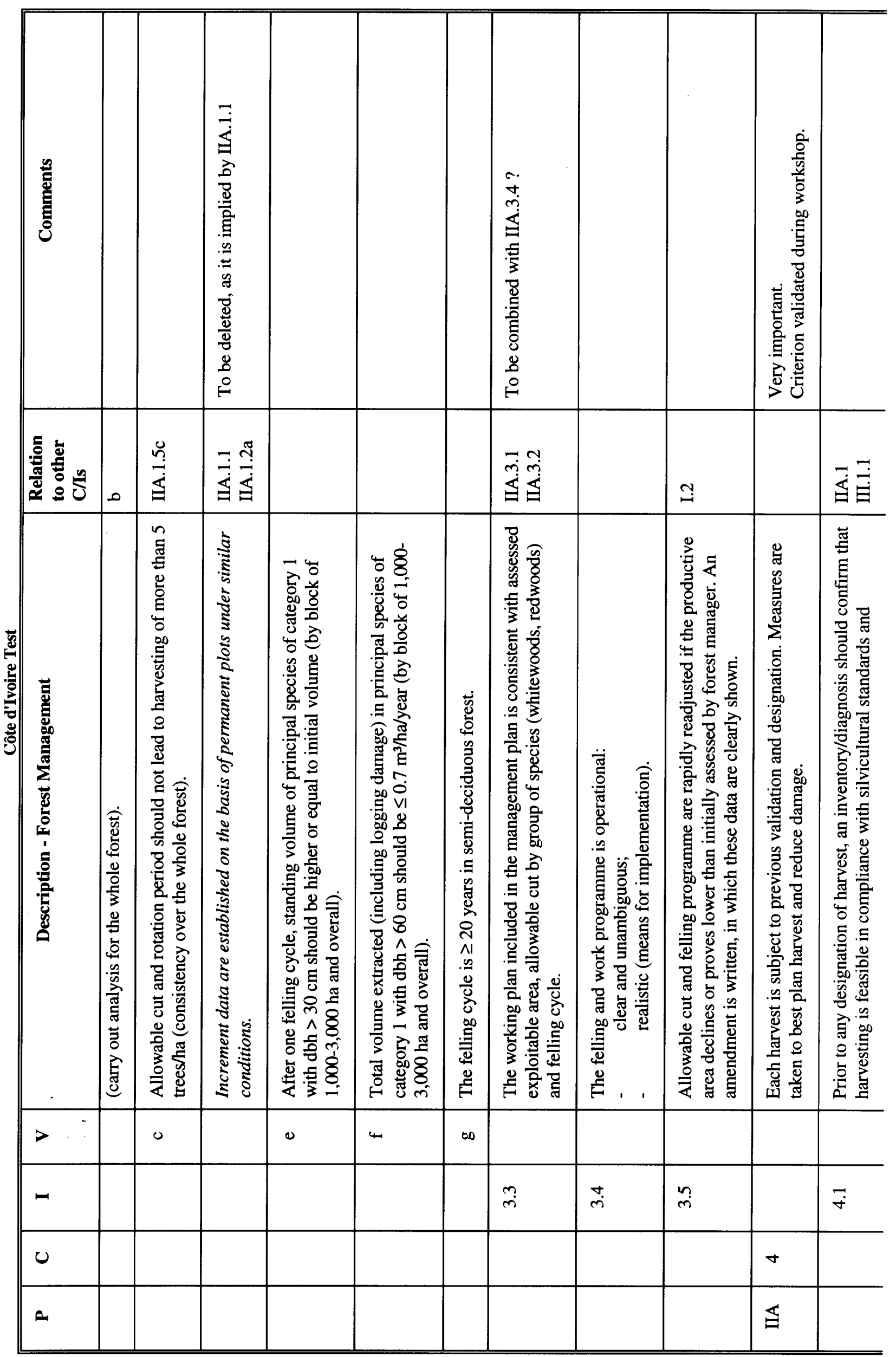




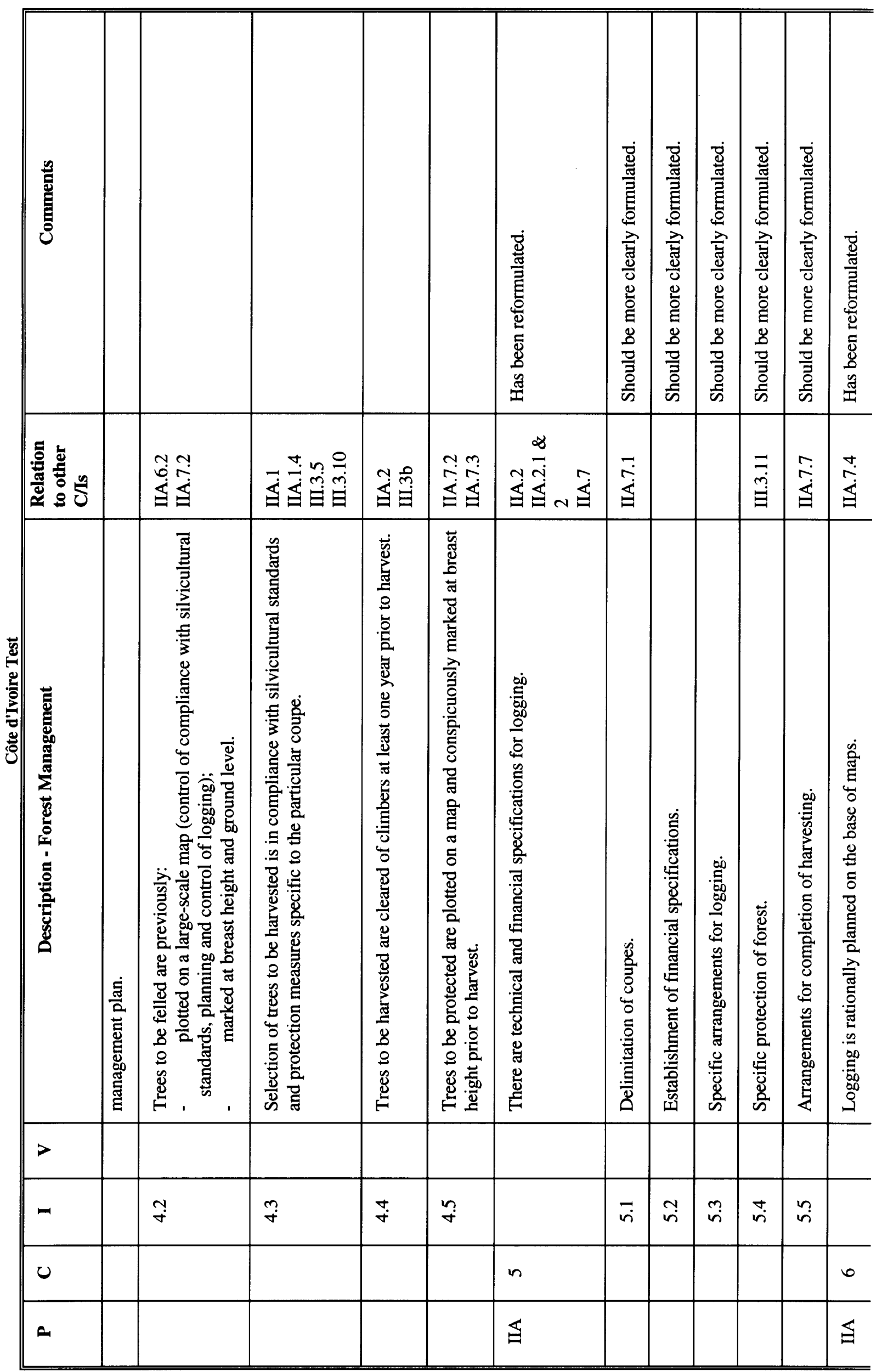




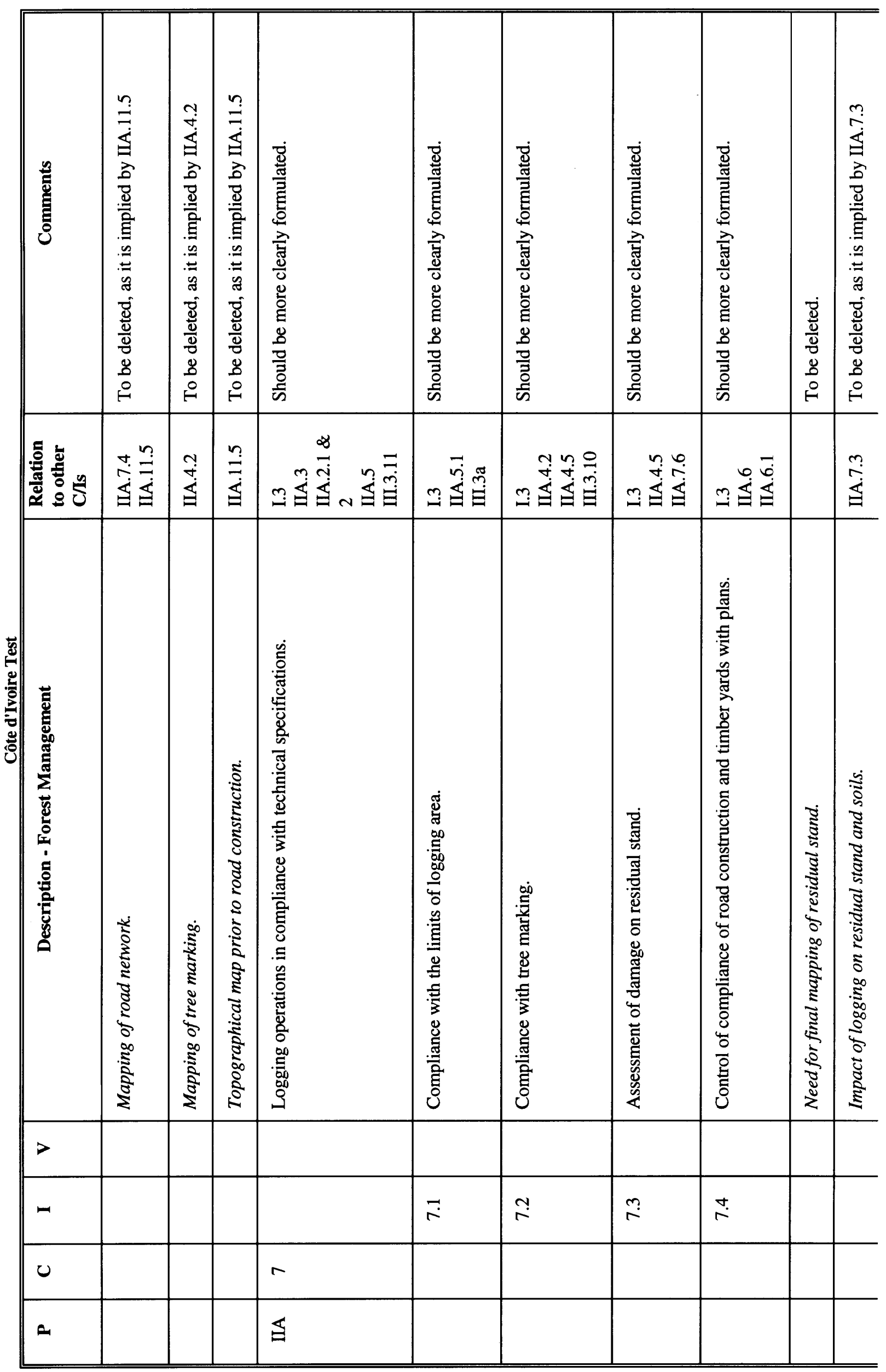




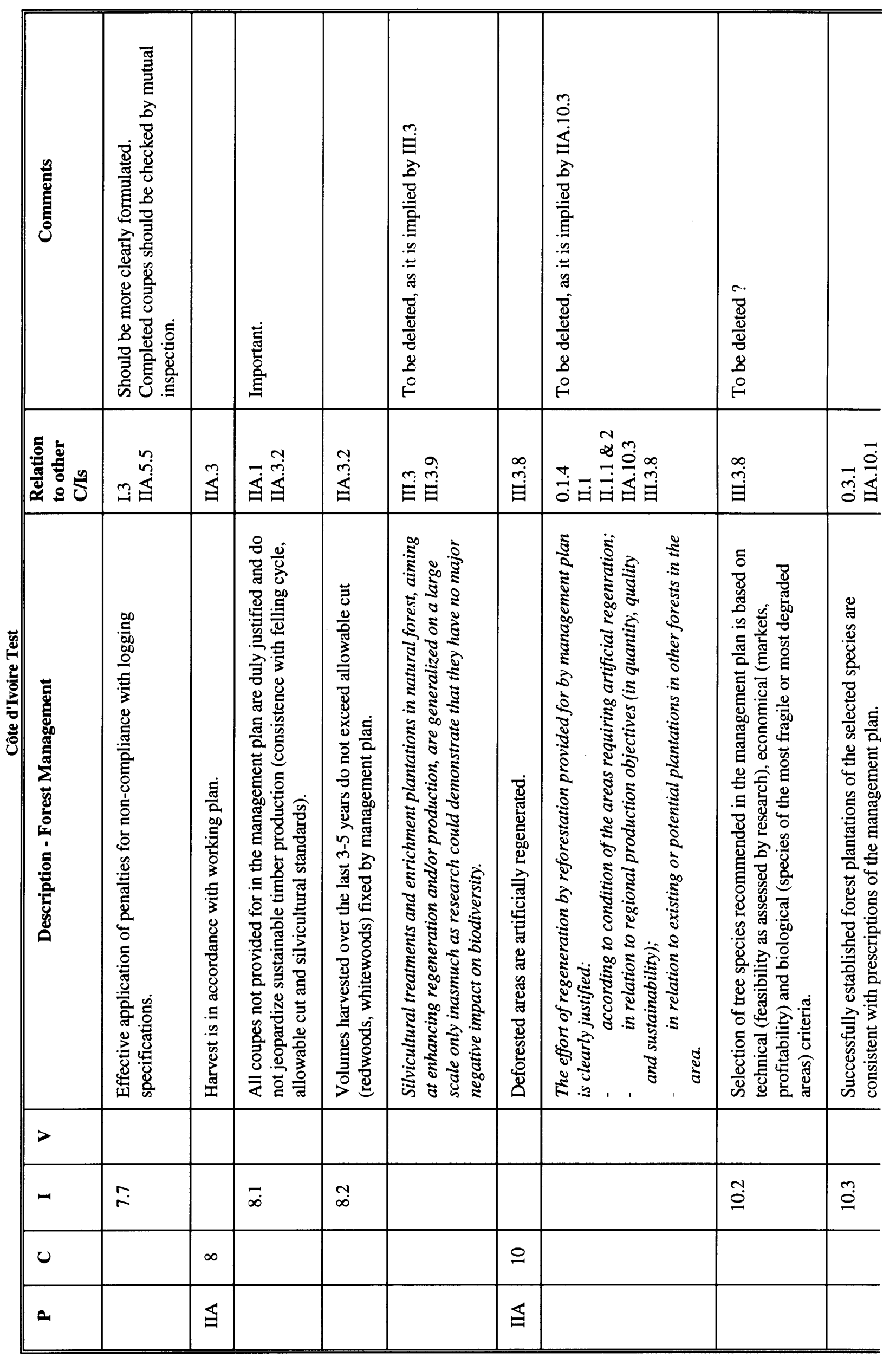




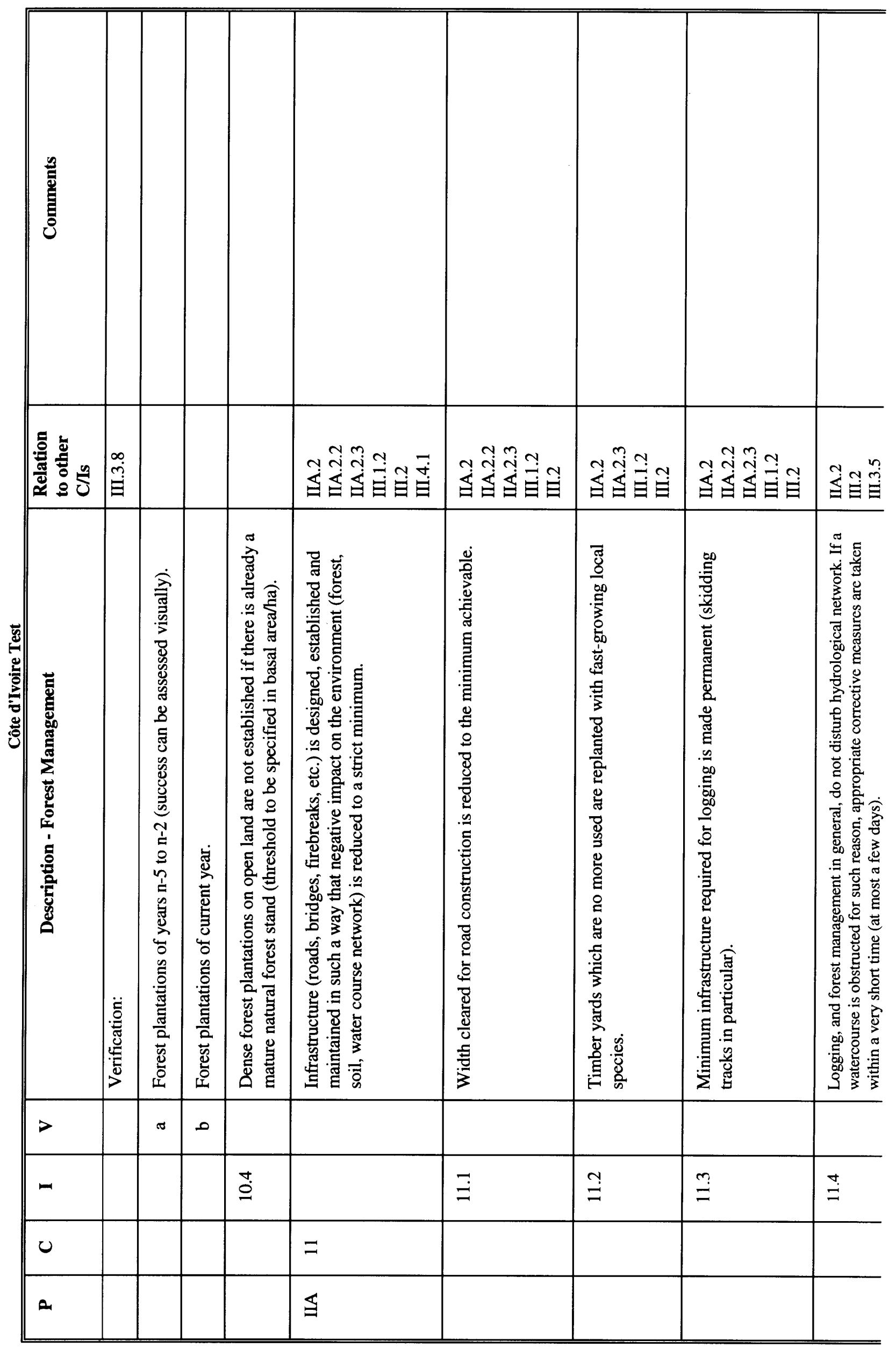




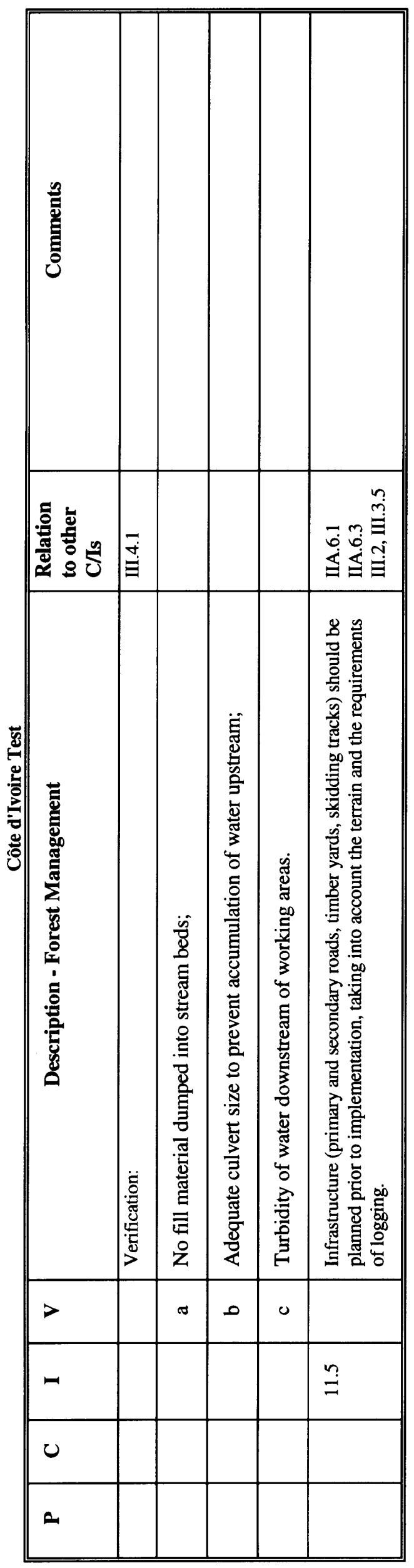




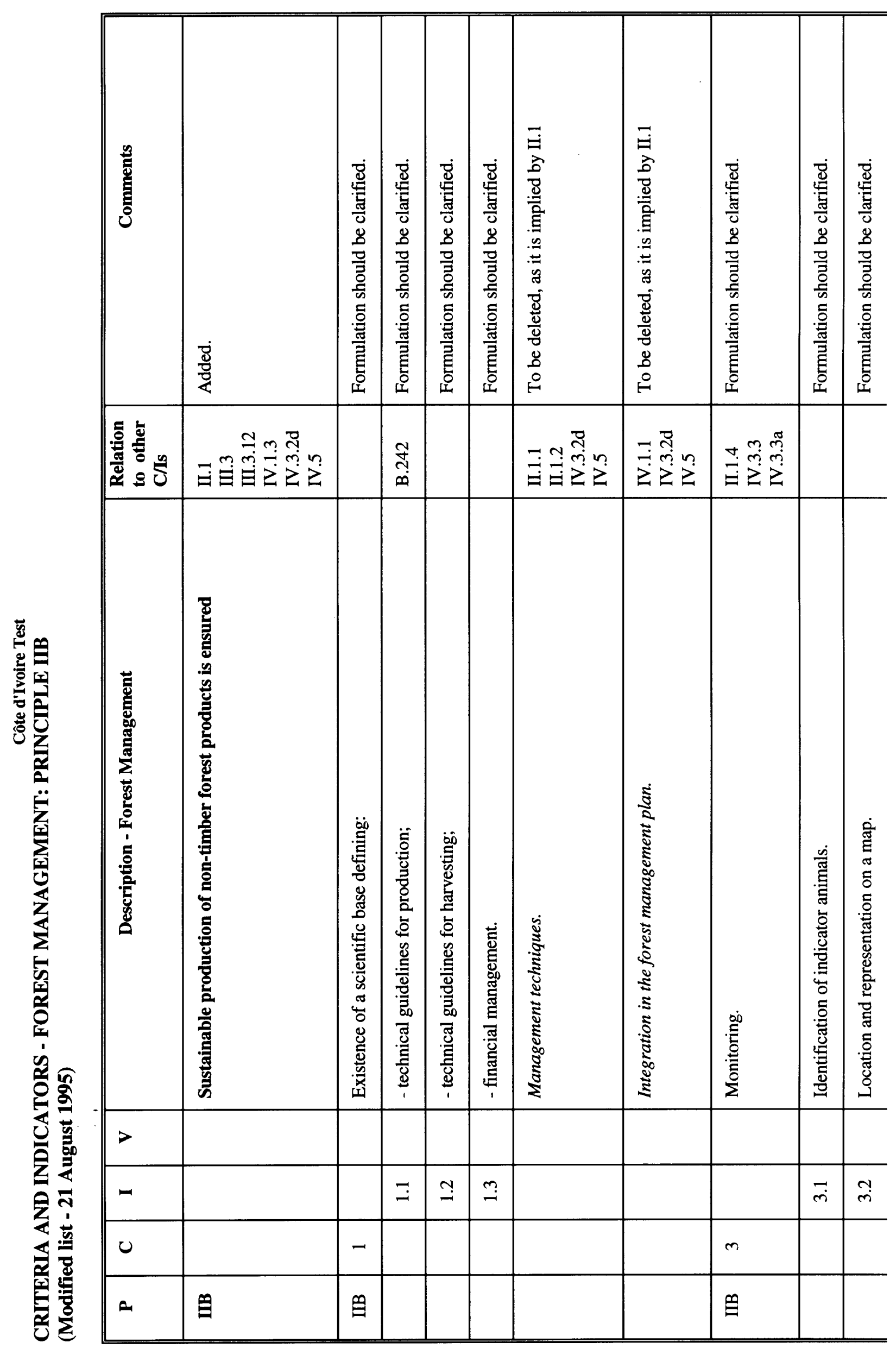




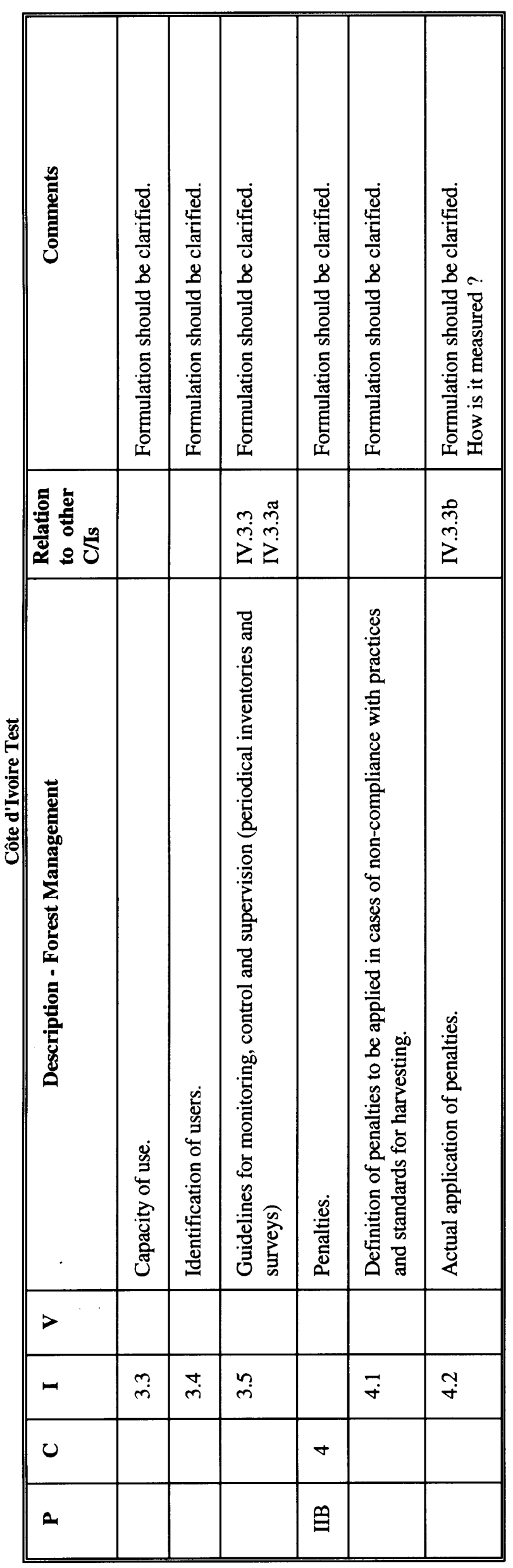




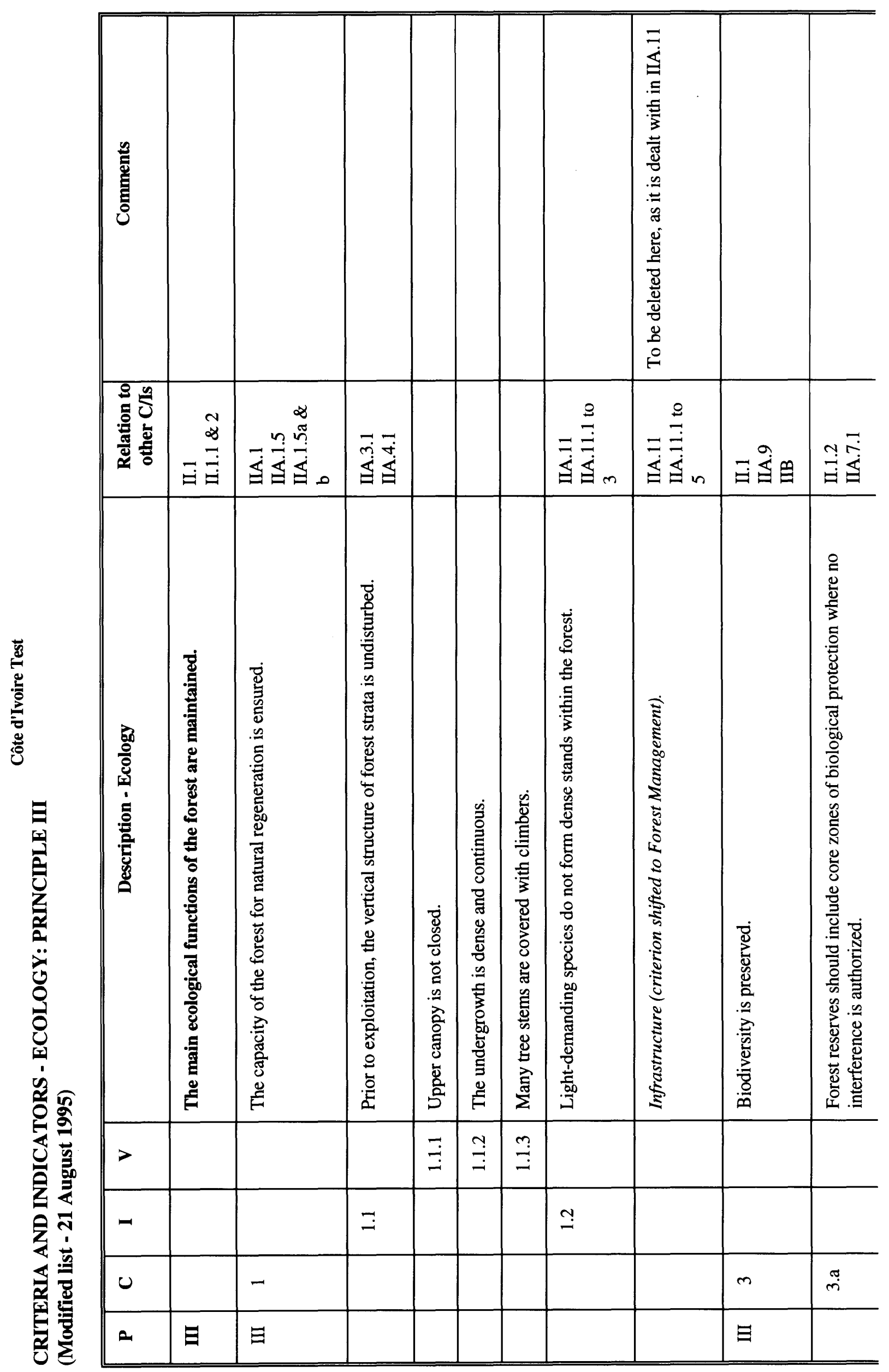




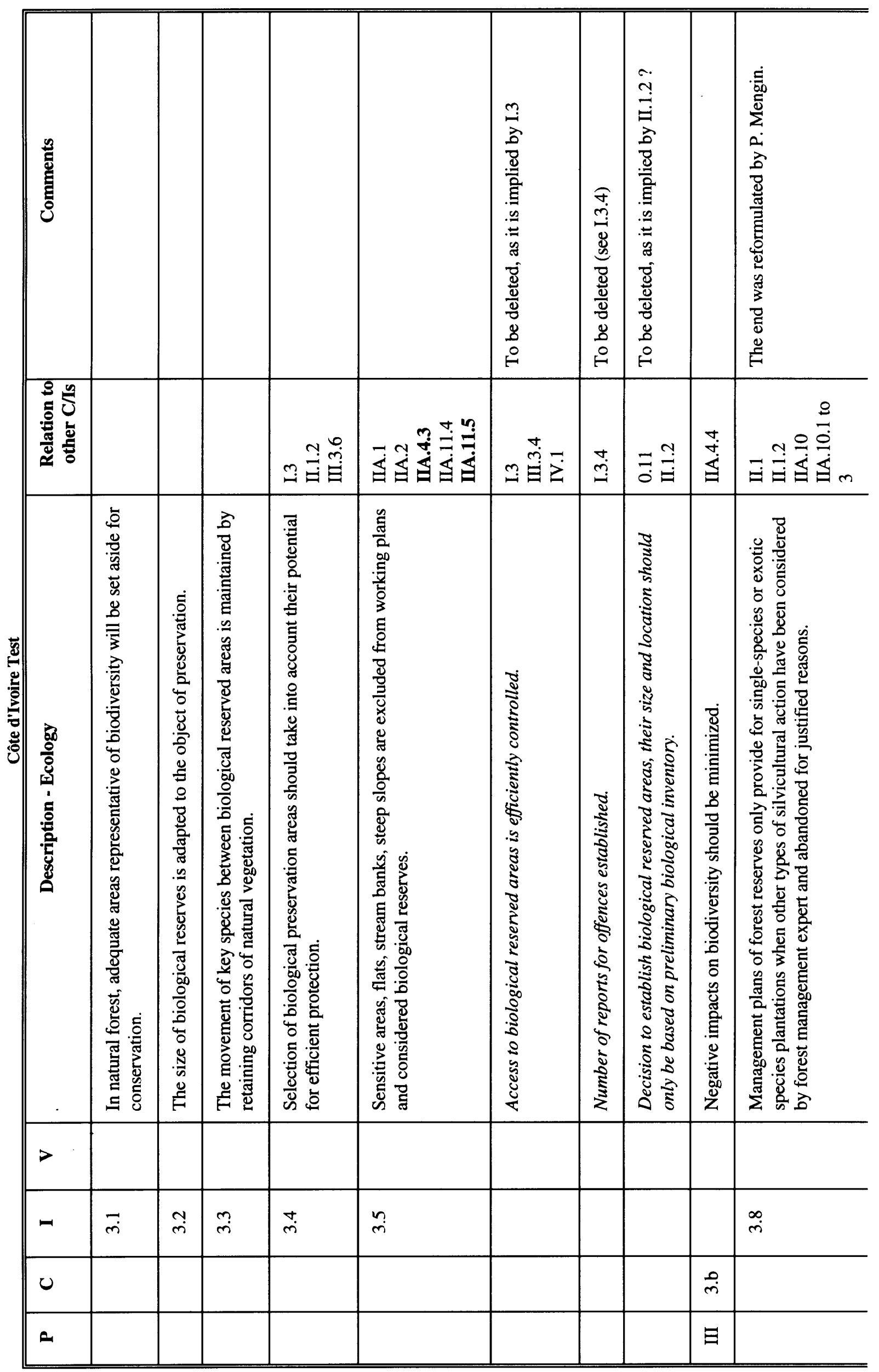




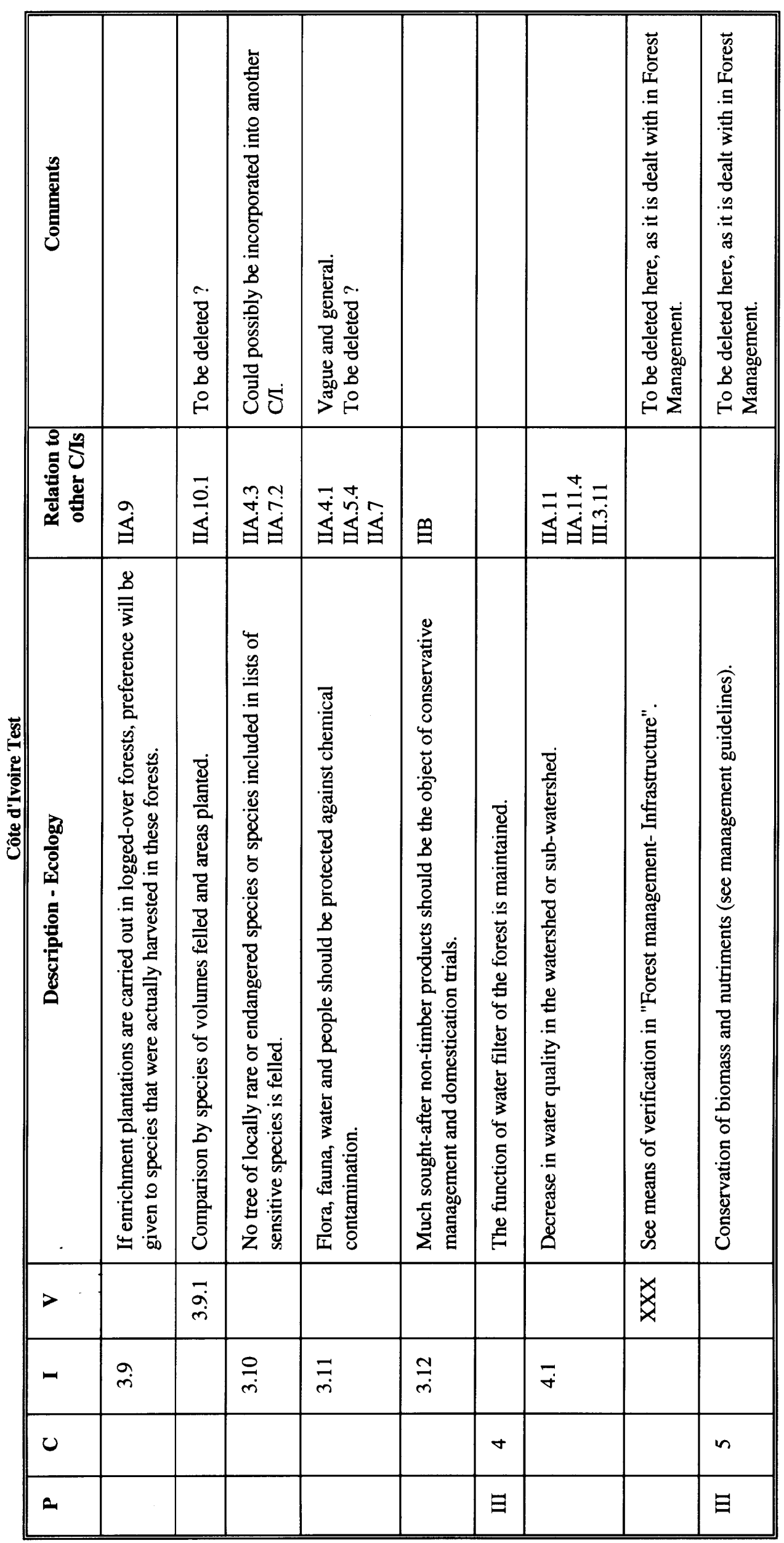




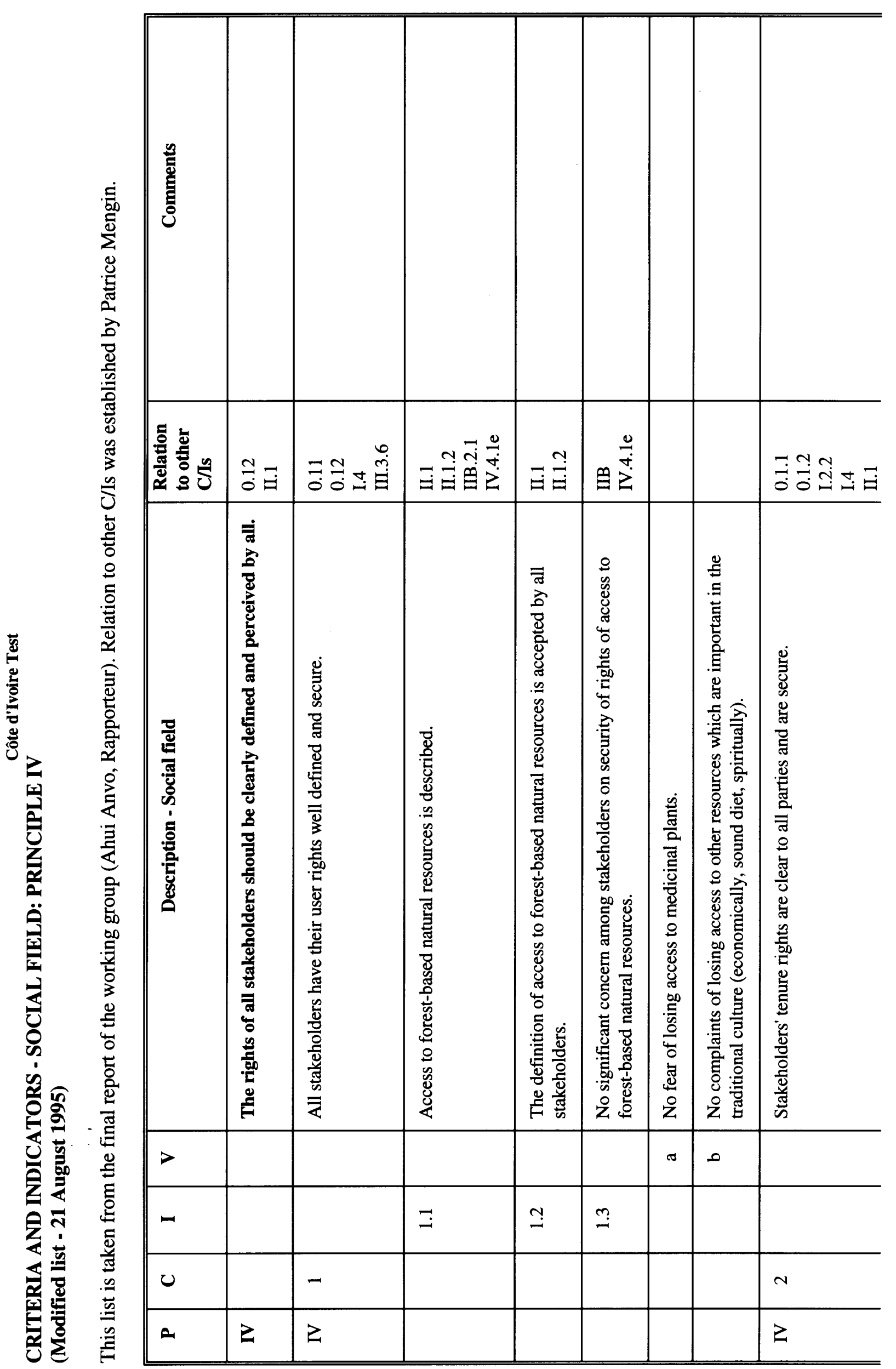




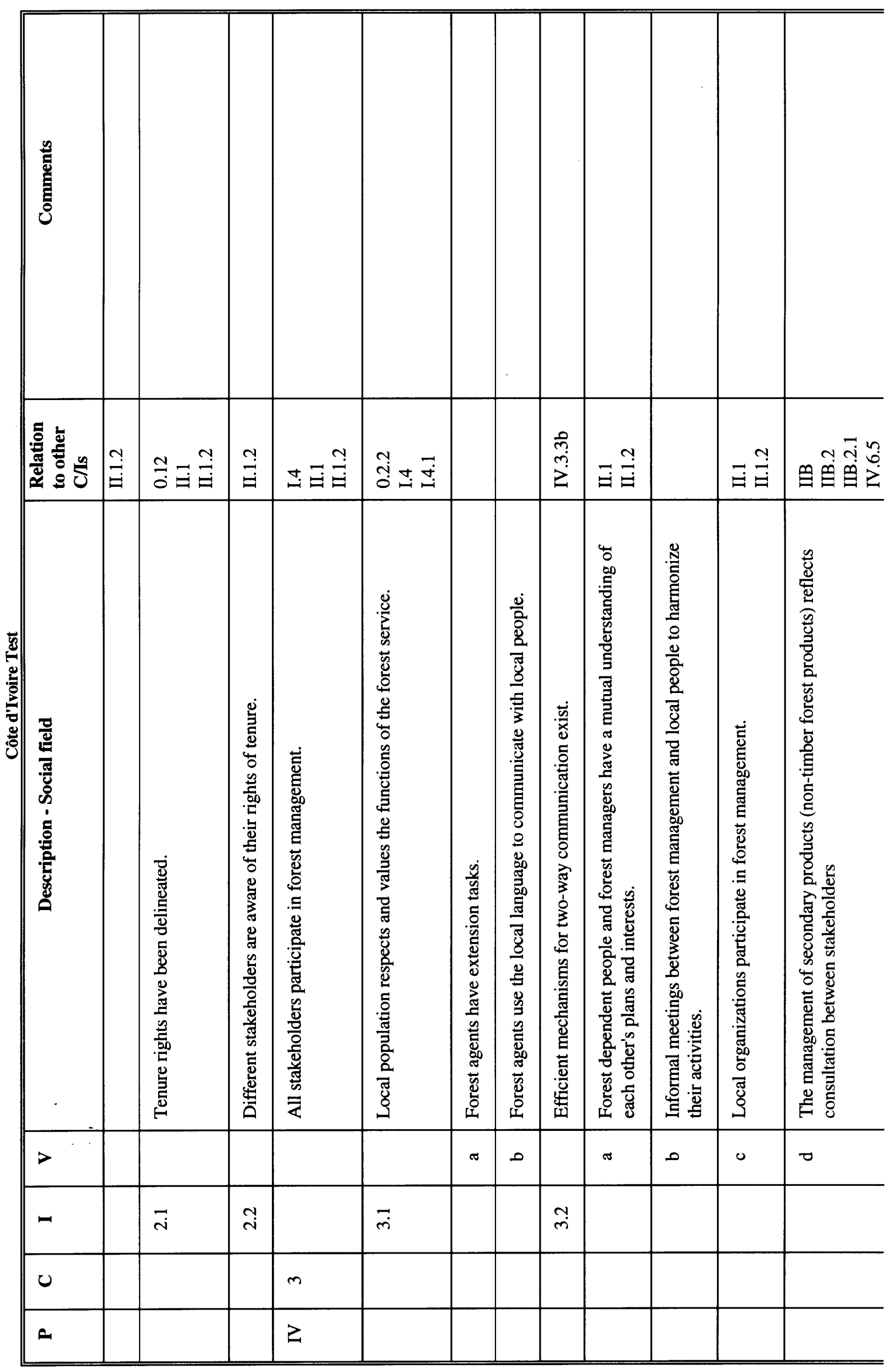




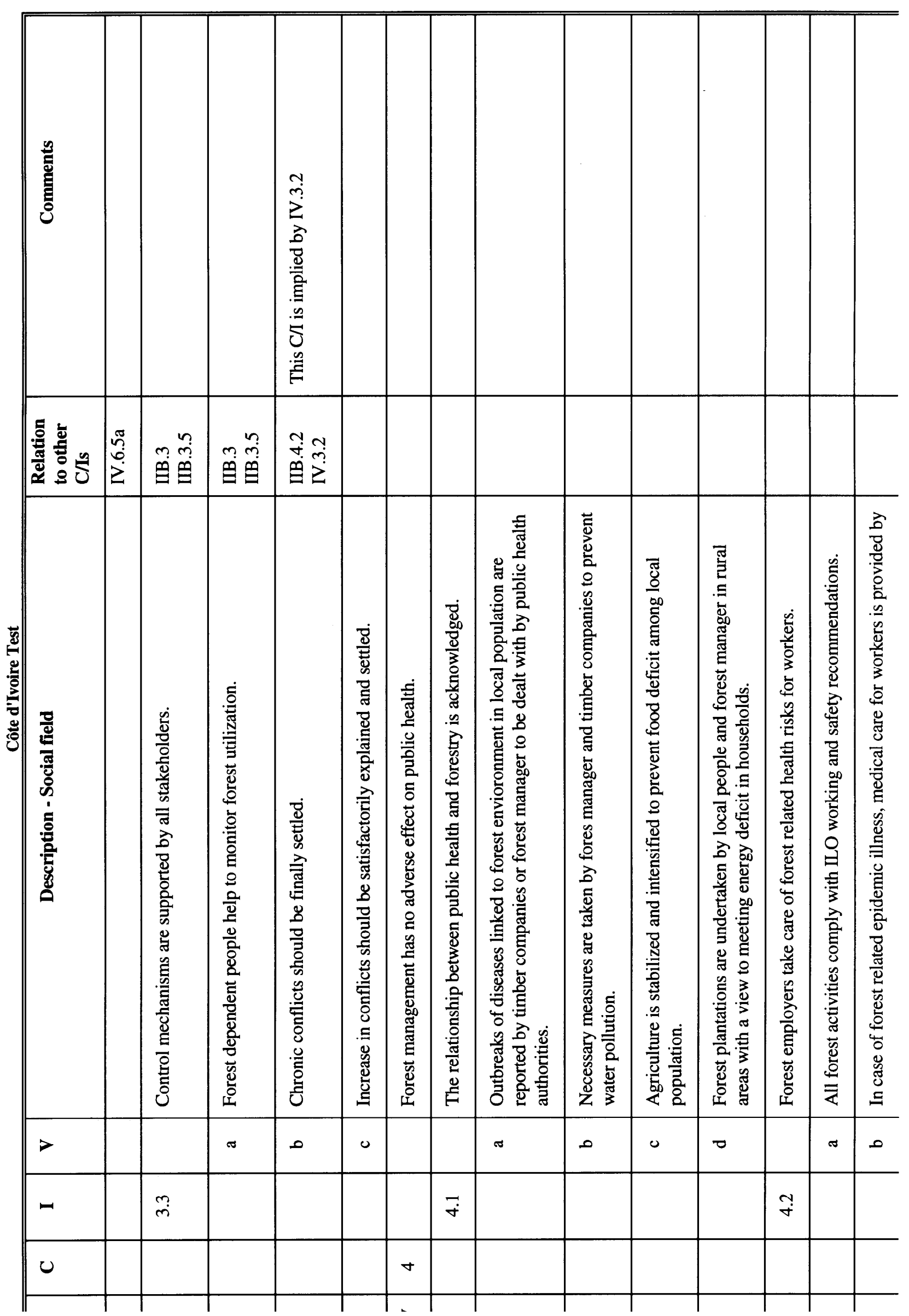




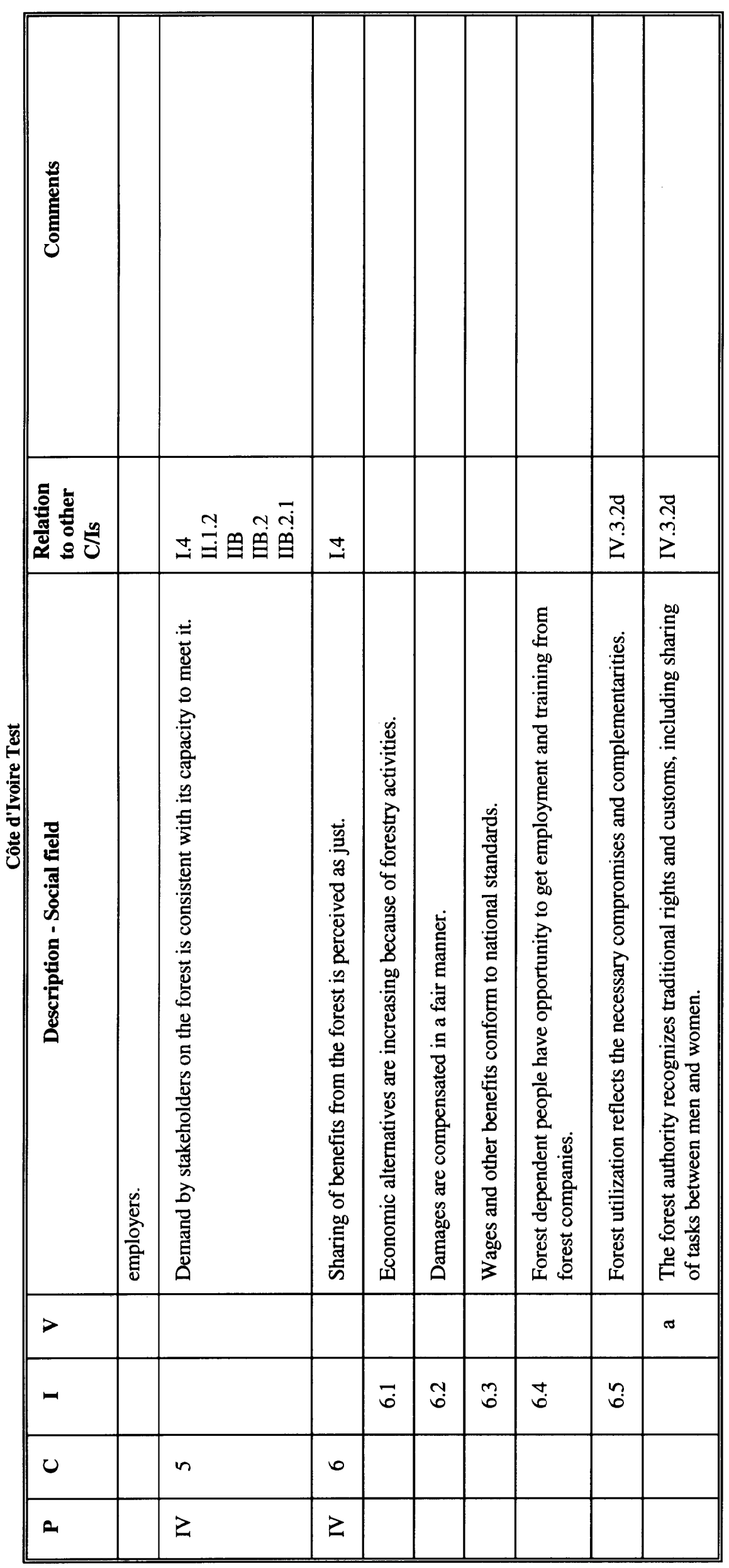




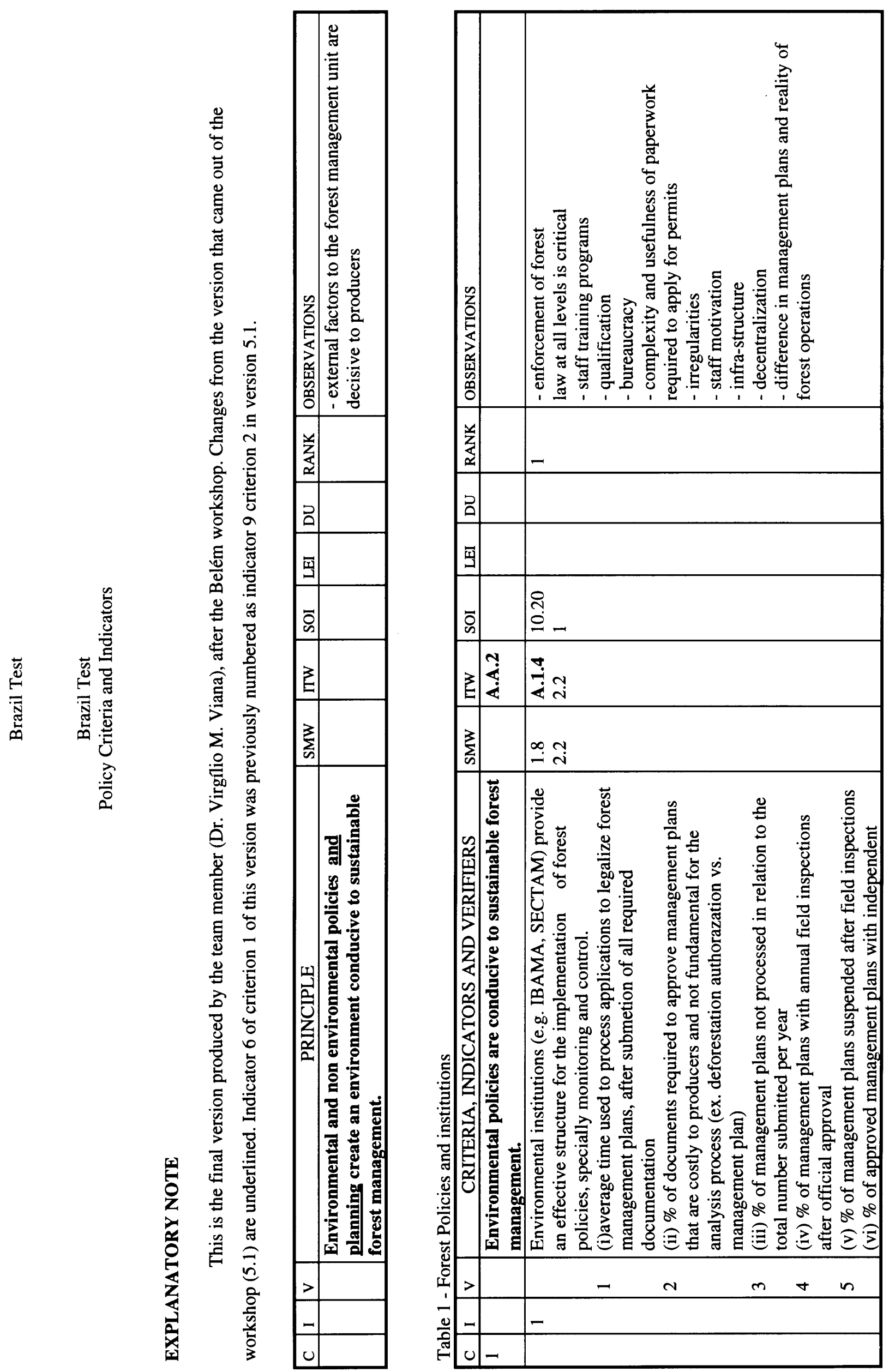




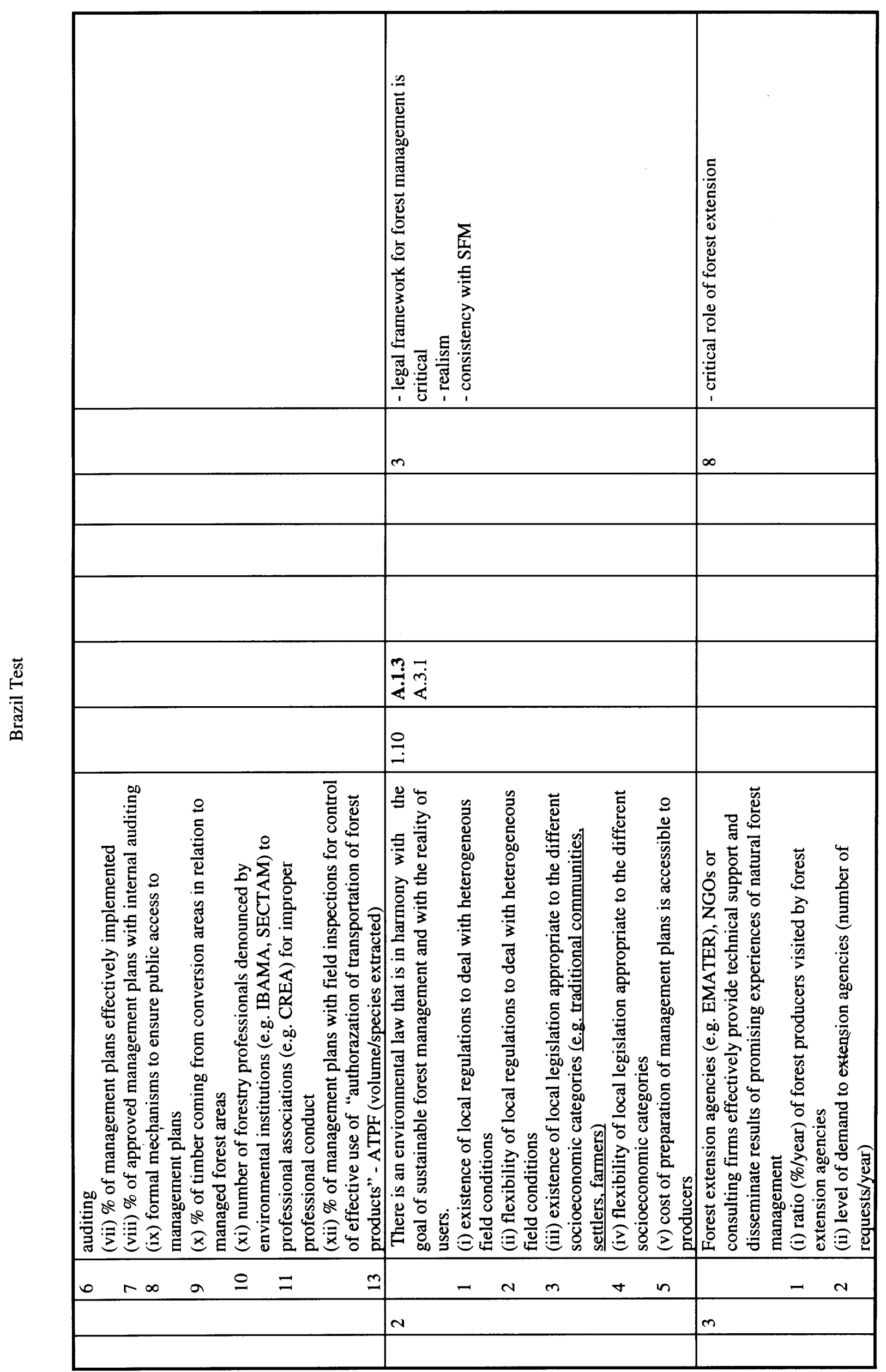




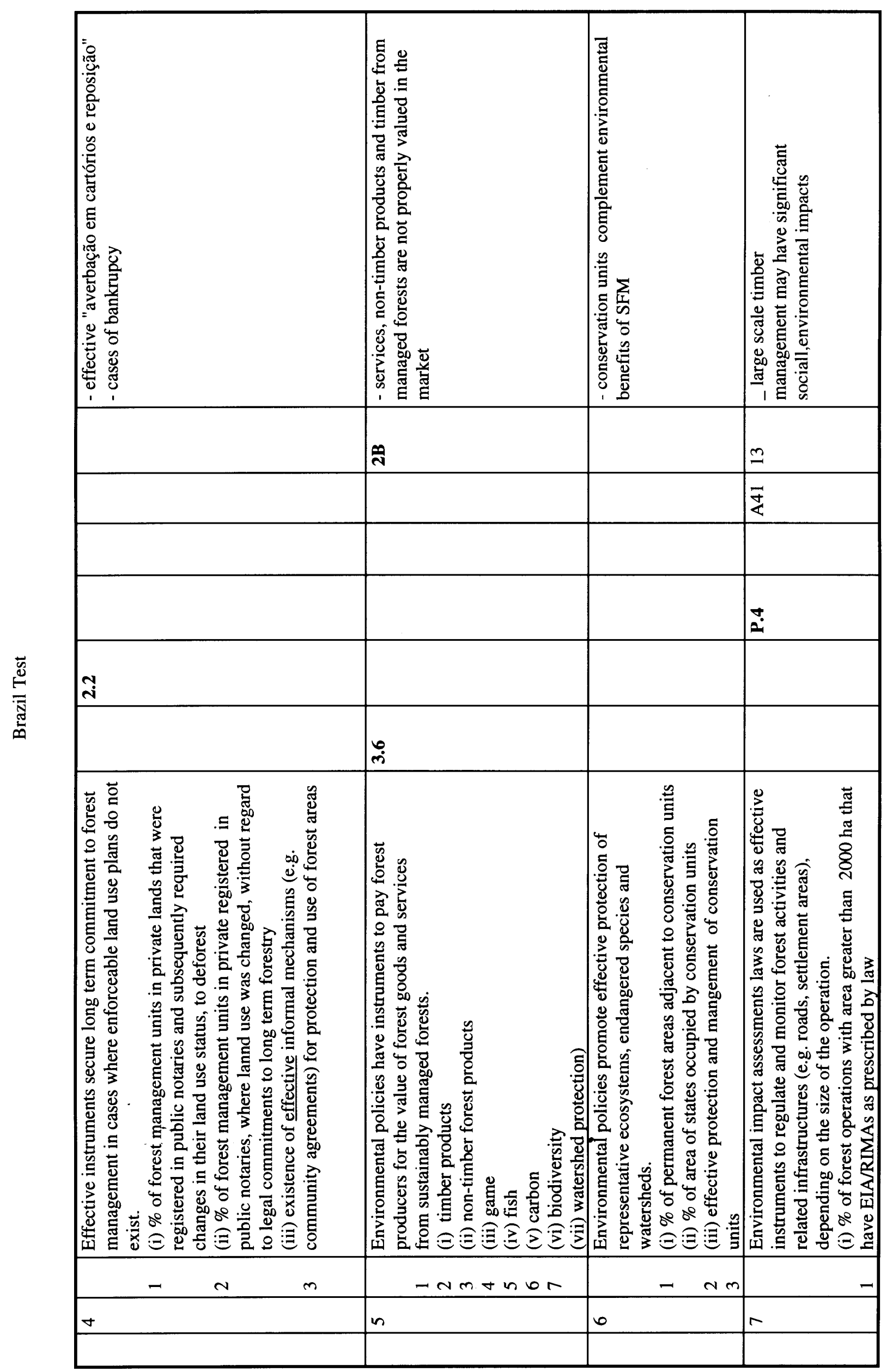




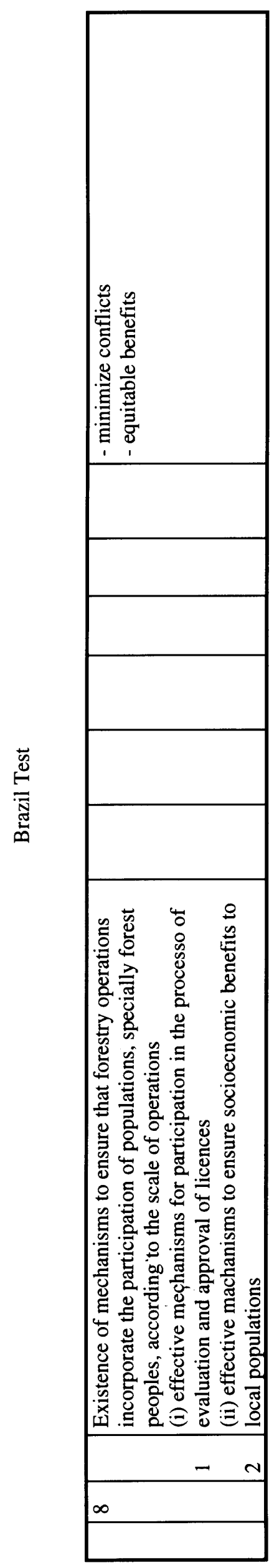




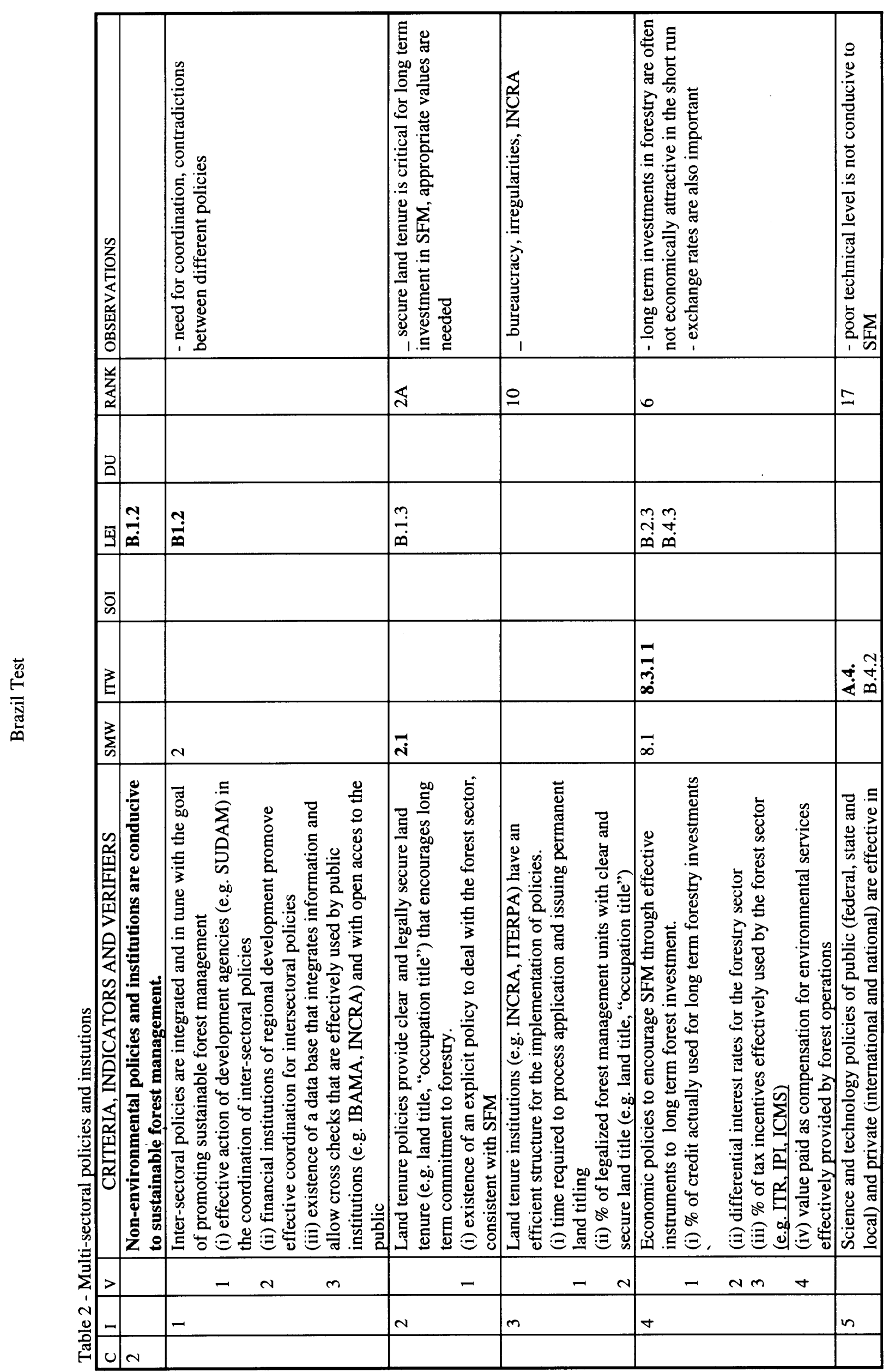




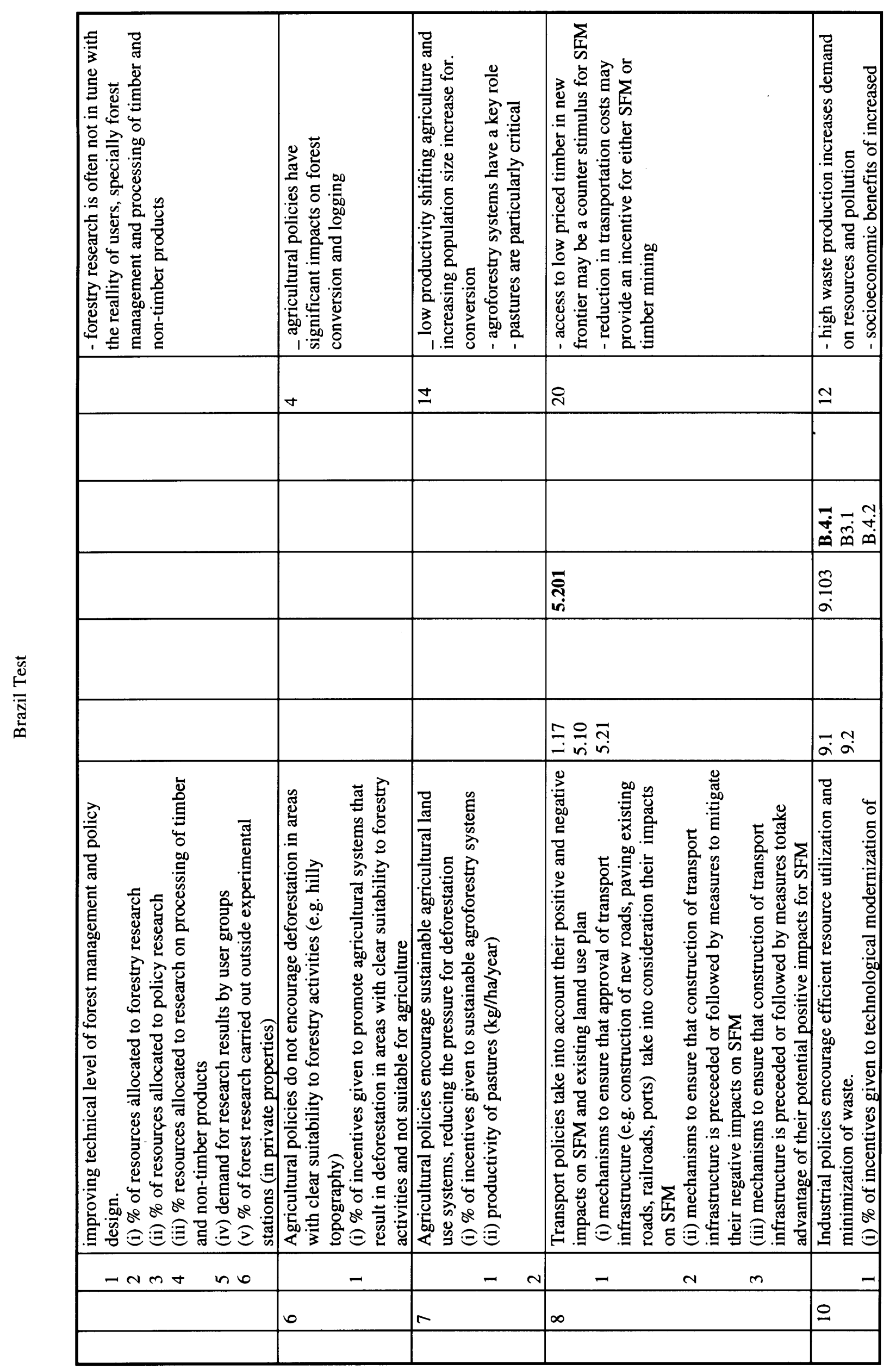




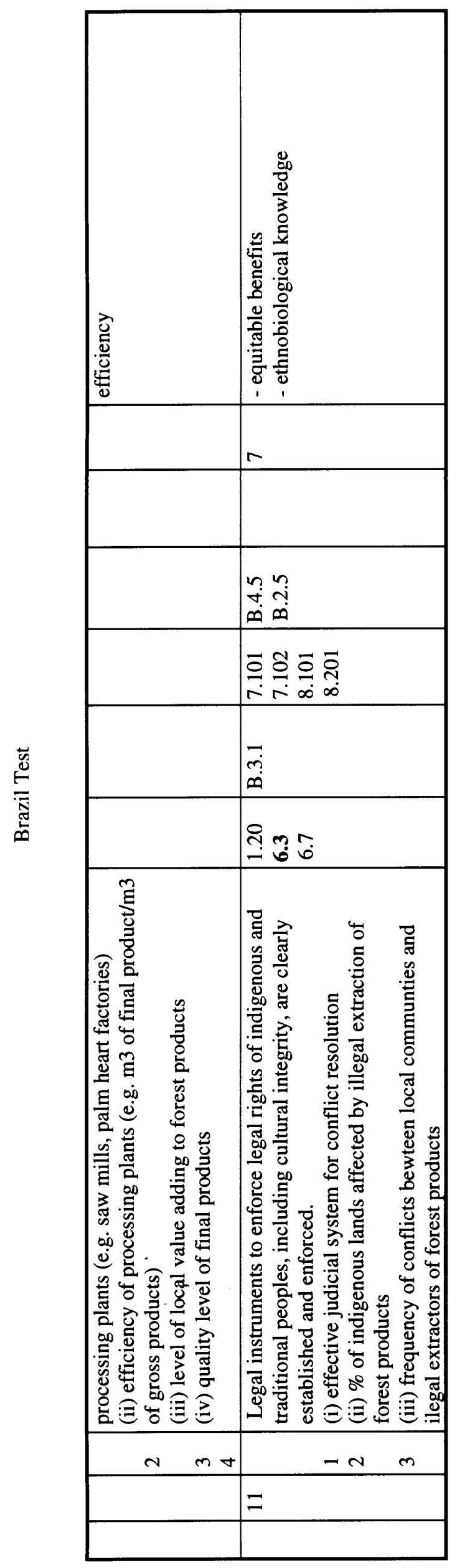




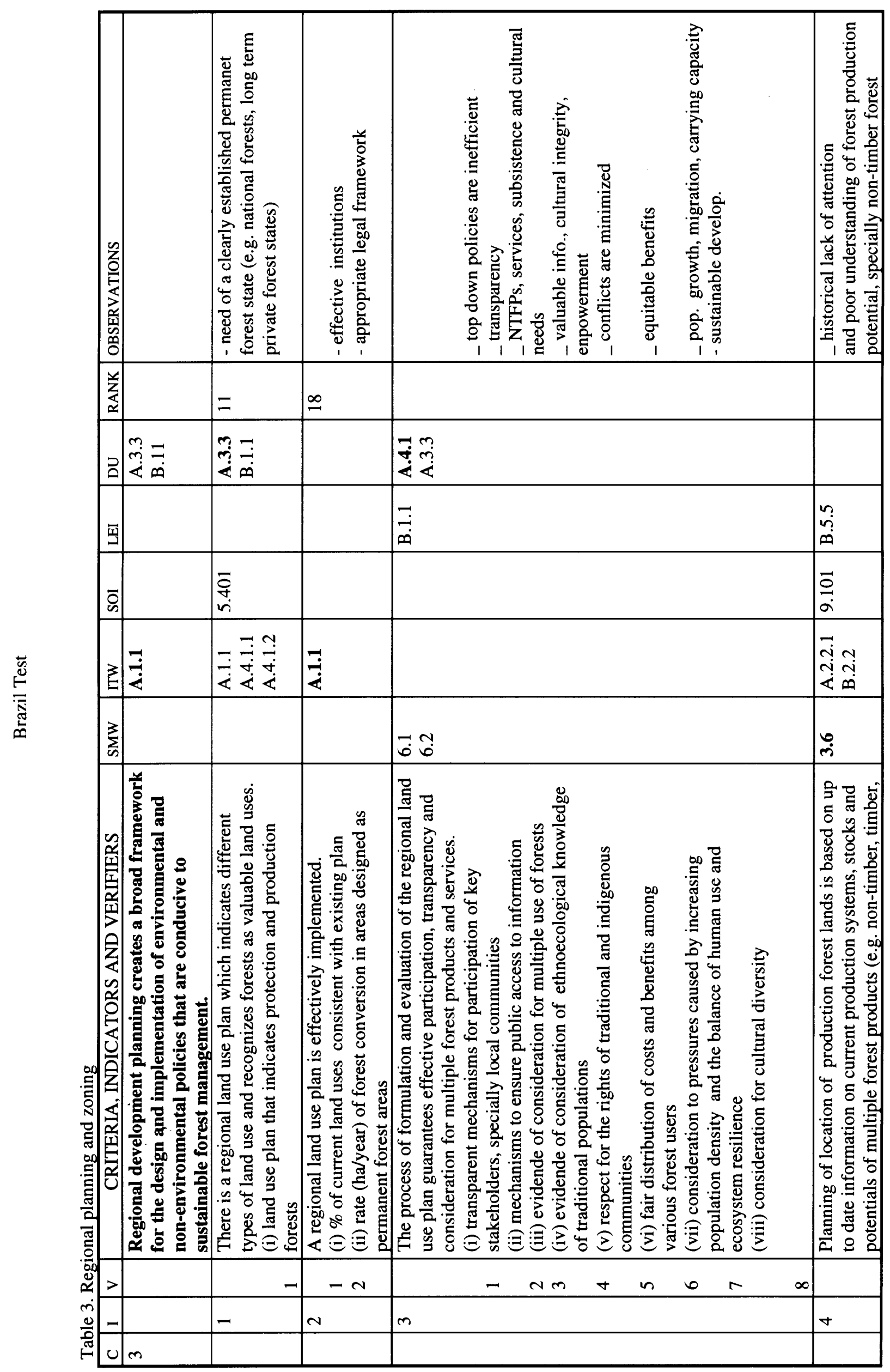


181

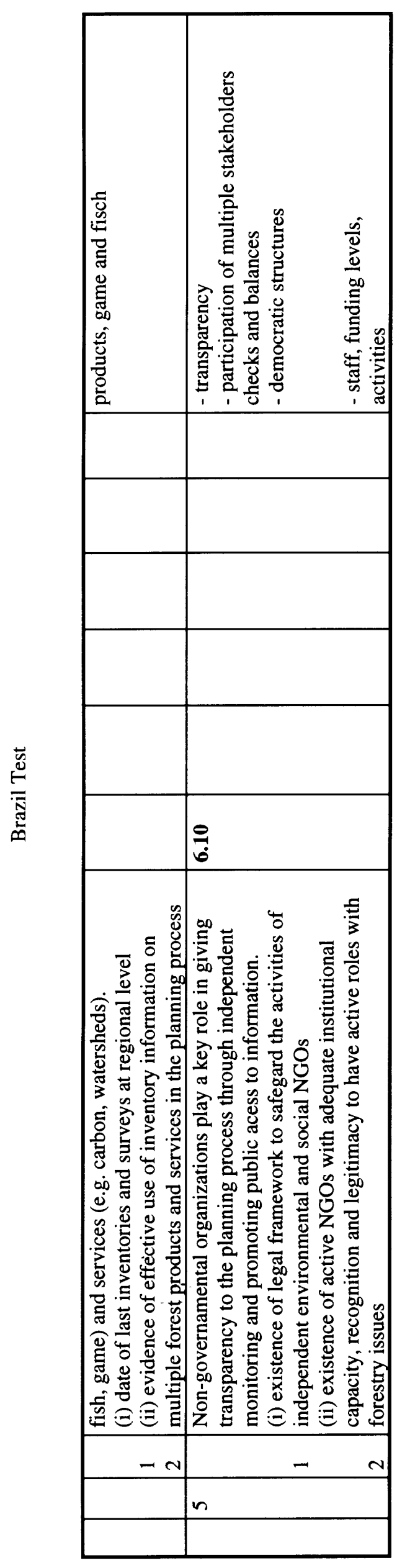




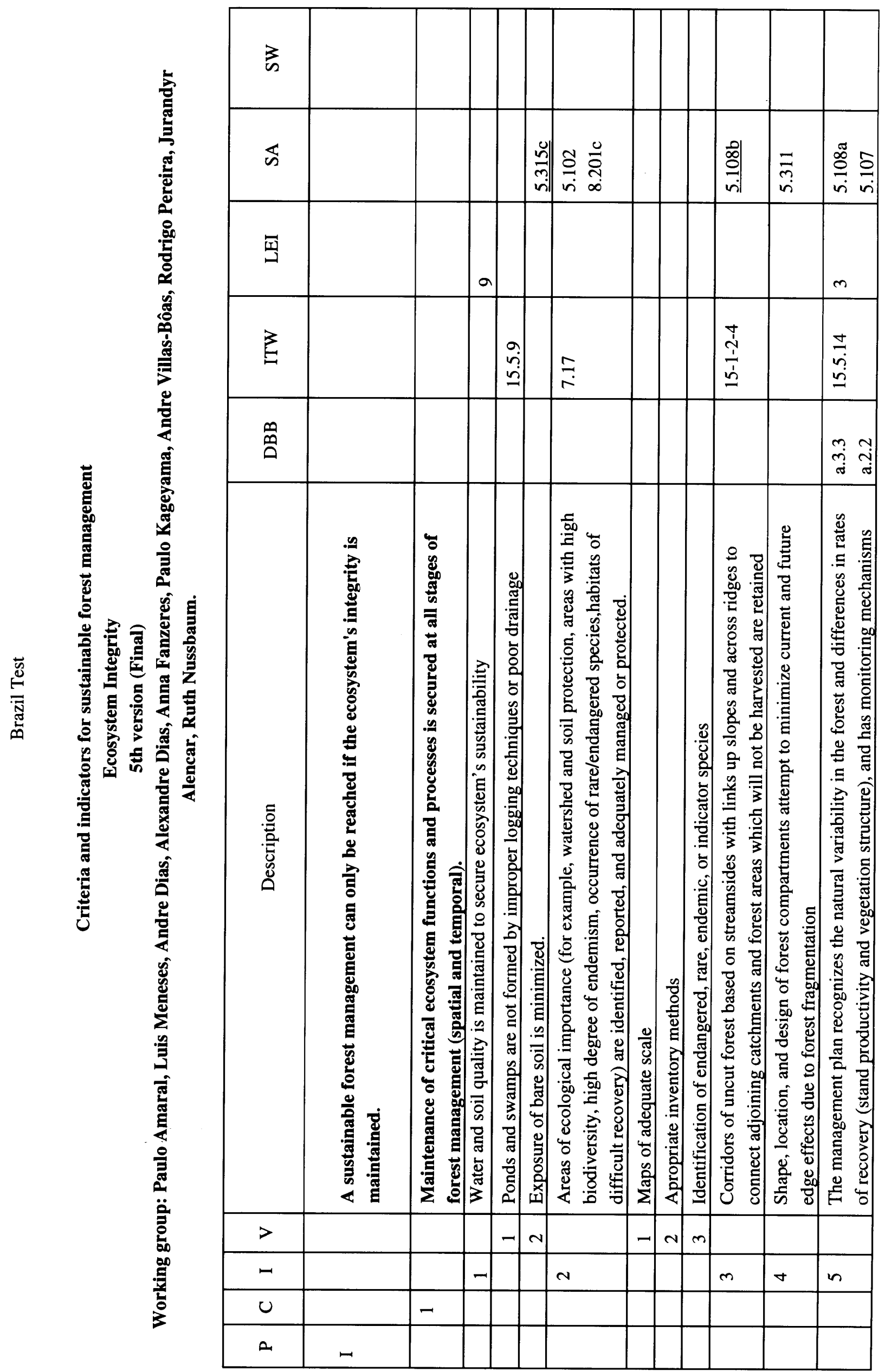




\begin{tabular}{|c|c|c|c|c|c|c|c|c|c|c|c|c|c|c|}
\hline 总 & & & & $\frac{m}{n}$ & & & $\bar{i}$ & & & & & & & \\
\hline ஷ্ & & & है & $\frac{\hat{m}}{n}$ & & $\frac{\varnothing}{i}$ & & $\begin{array}{l}\frac{\pi}{N} \\
\frac{N}{n} \\
n \\
n\end{array}$ & $\frac{\stackrel{0}{0}}{6}$ & & & & $\frac{n}{n}$ & $\frac{n}{n}$ \\
\hline 国 & & & & & $r$ & & & & & & & & & \\
\hline 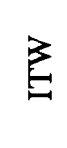 & & & & $\begin{array}{l}\stackrel{\sim}{n} \\
\ddot{n} \\
\ddot{n}\end{array}$ & & 水 & & $\left|\begin{array}{c}c \\
\dot{p} \\
\dot{v} \\
\underline{n}\end{array}\right|$ & & $\begin{array}{l}\vec{n} \\
\ddot{n} \\
\ddot{n}\end{array}$ & & $\begin{array}{l}\bar{a} \\
\tilde{m} \\
\ddot{n}\end{array}$ & & 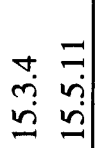 \\
\hline 畐 & & & & & & & & & & & & & & \\
\hline 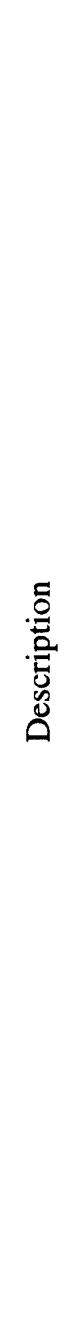 & 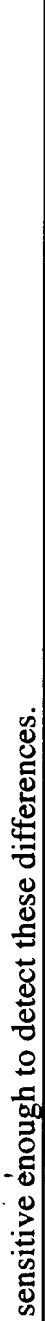 & 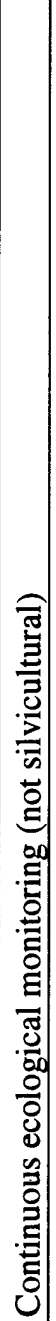 & 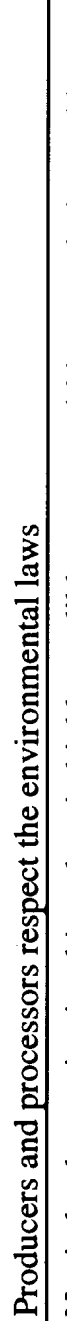 & 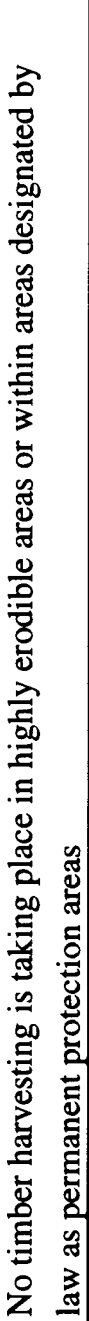 & 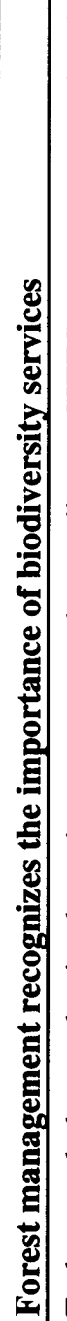 & 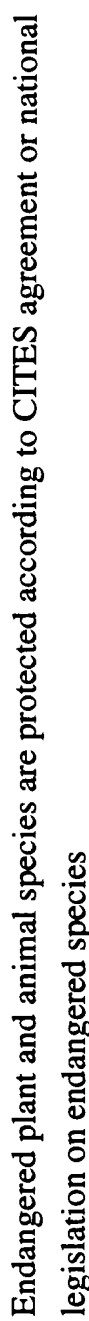 & 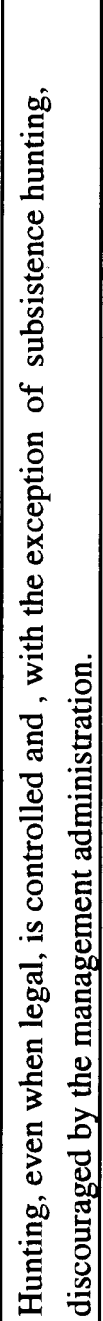 & 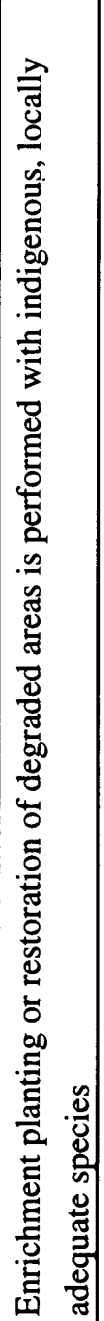 & 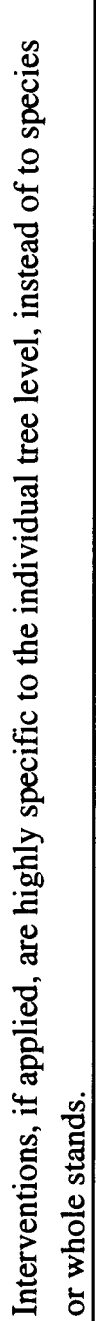 & 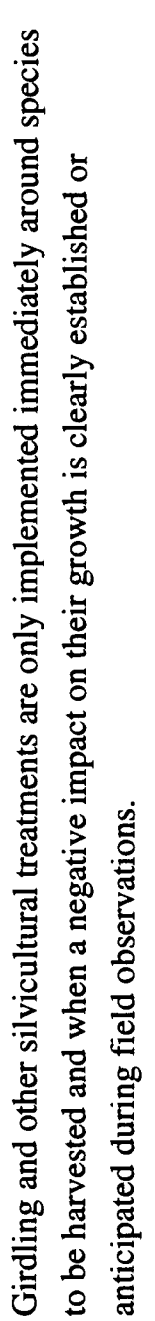 & 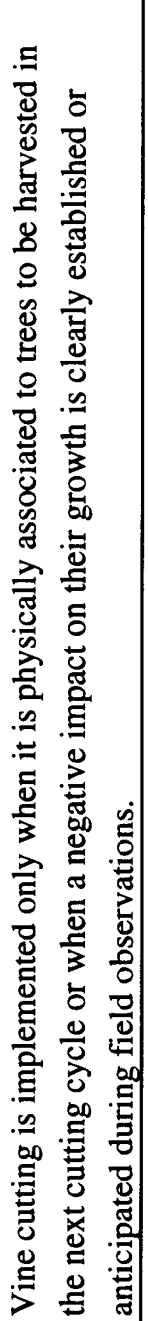 & 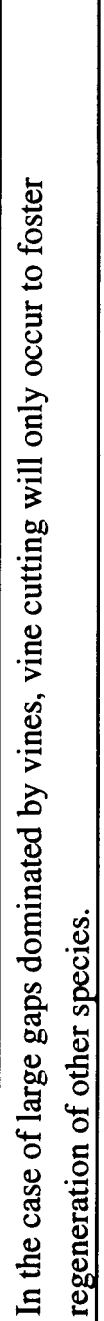 & 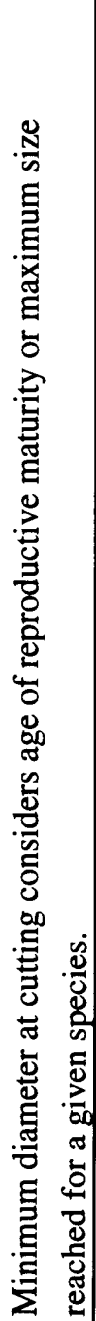 & 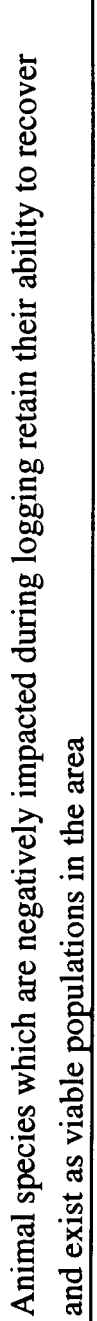 \\
\hline$>$ & & -1 & & - & & & & & & - & N & $m$ & & \\
\hline- & & & 0 & & & - & $N$ & $m$ & $\forall$ & & & & $n$ & 0 \\
\hline$u$ & & & & & $N$ & & & & & & & & & \\
\hline 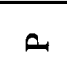 & & & & & & & & & & & & & & \\
\hline
\end{tabular}




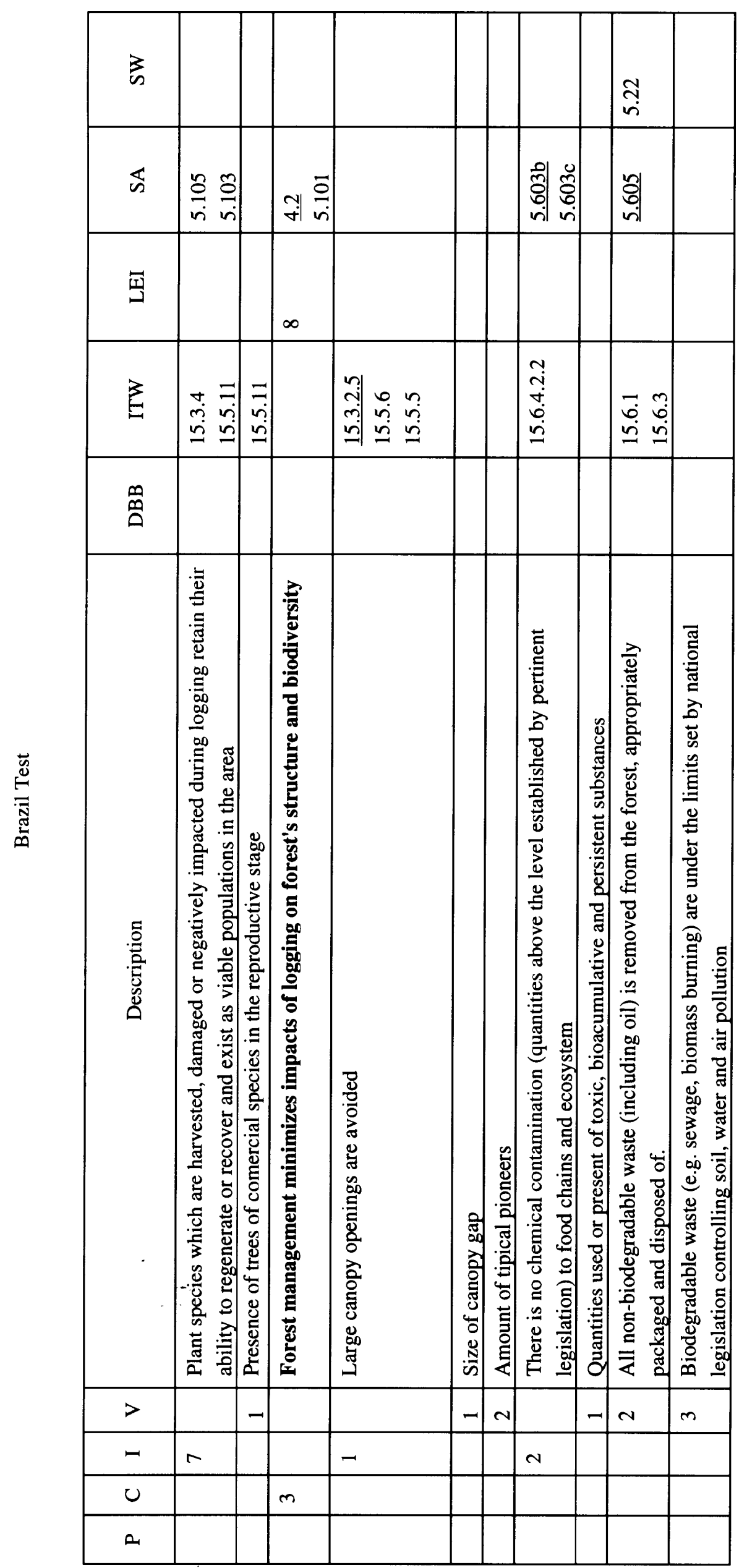


苞

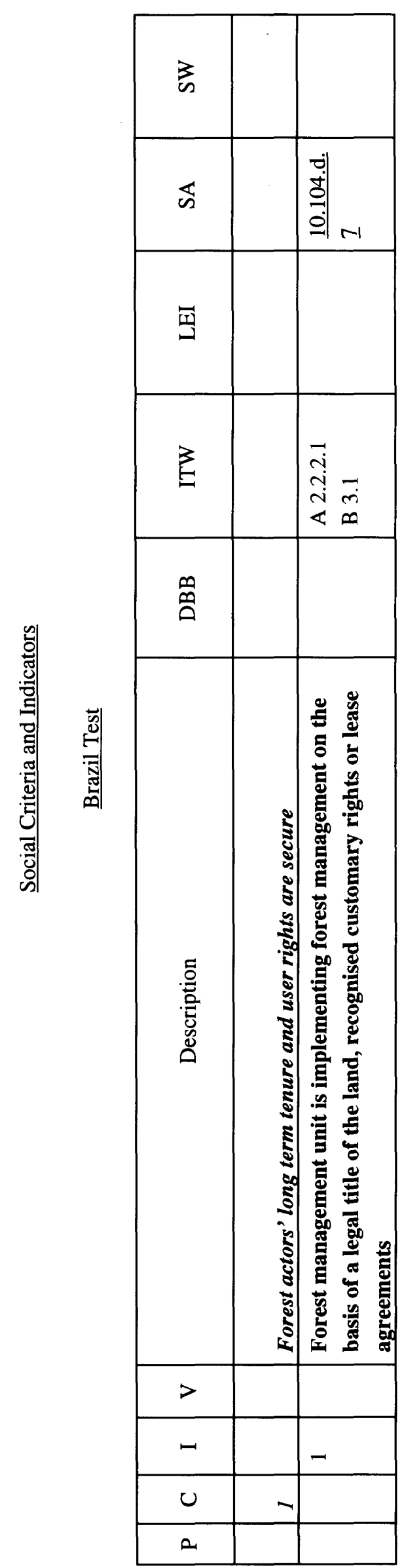




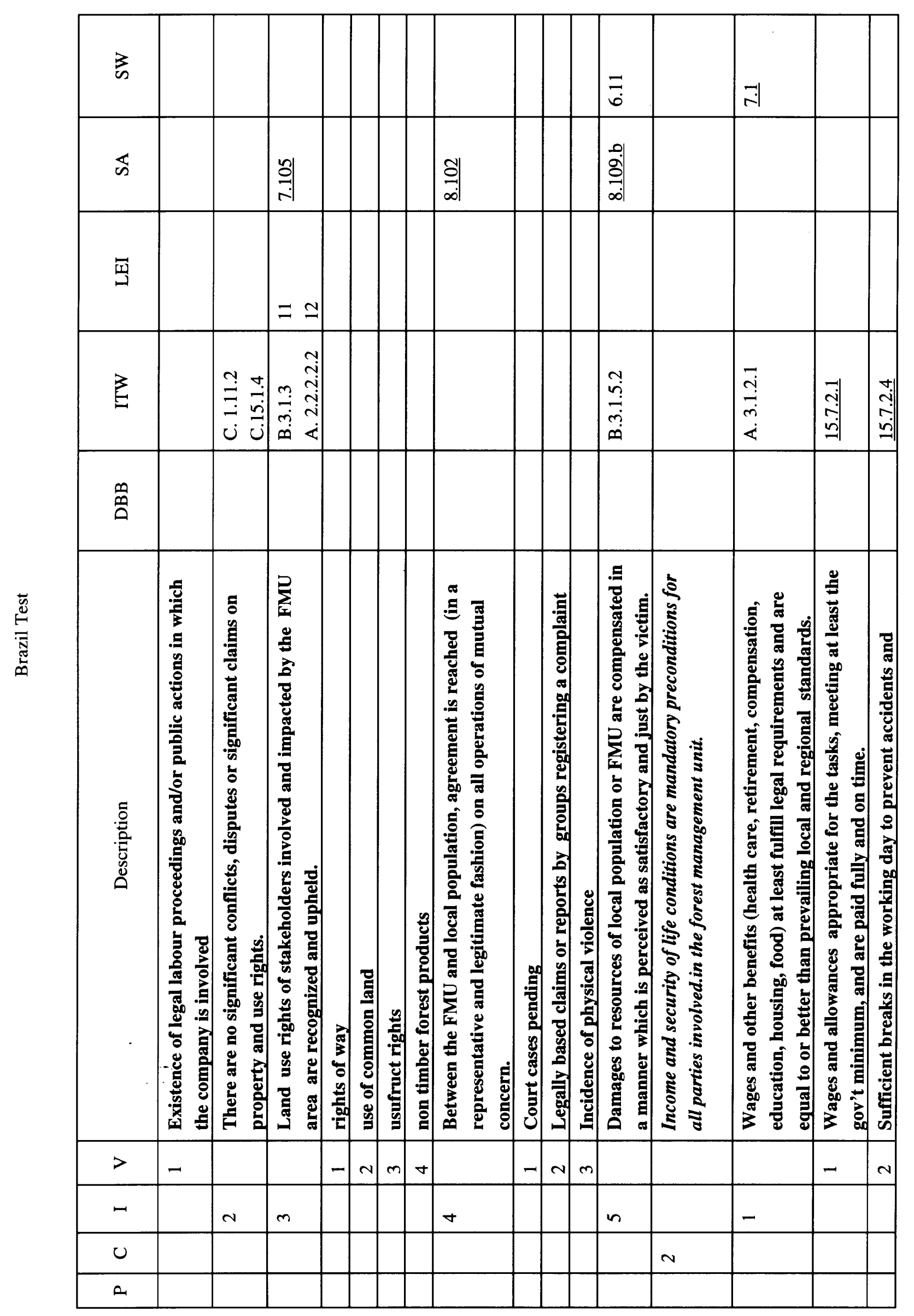




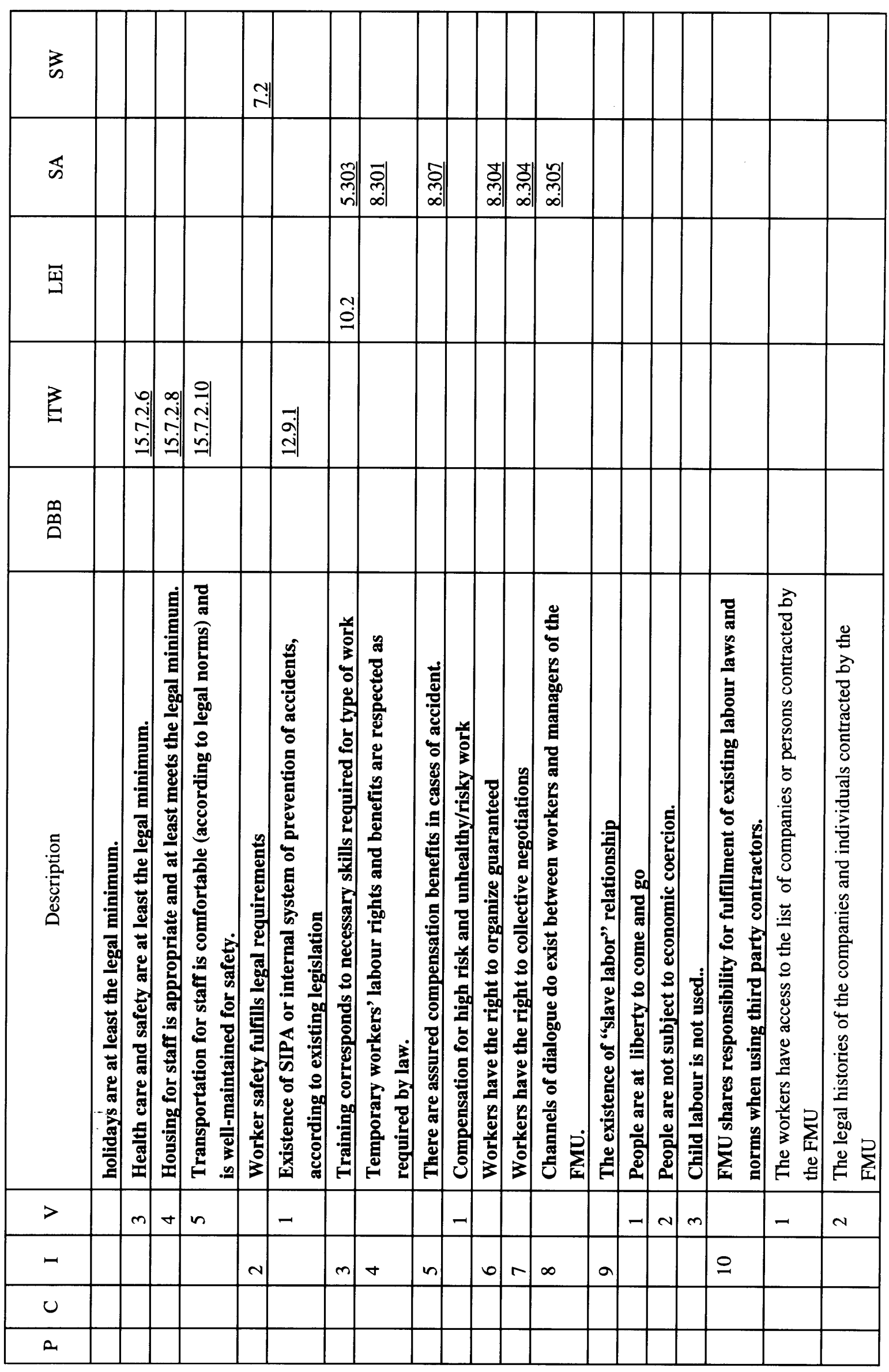



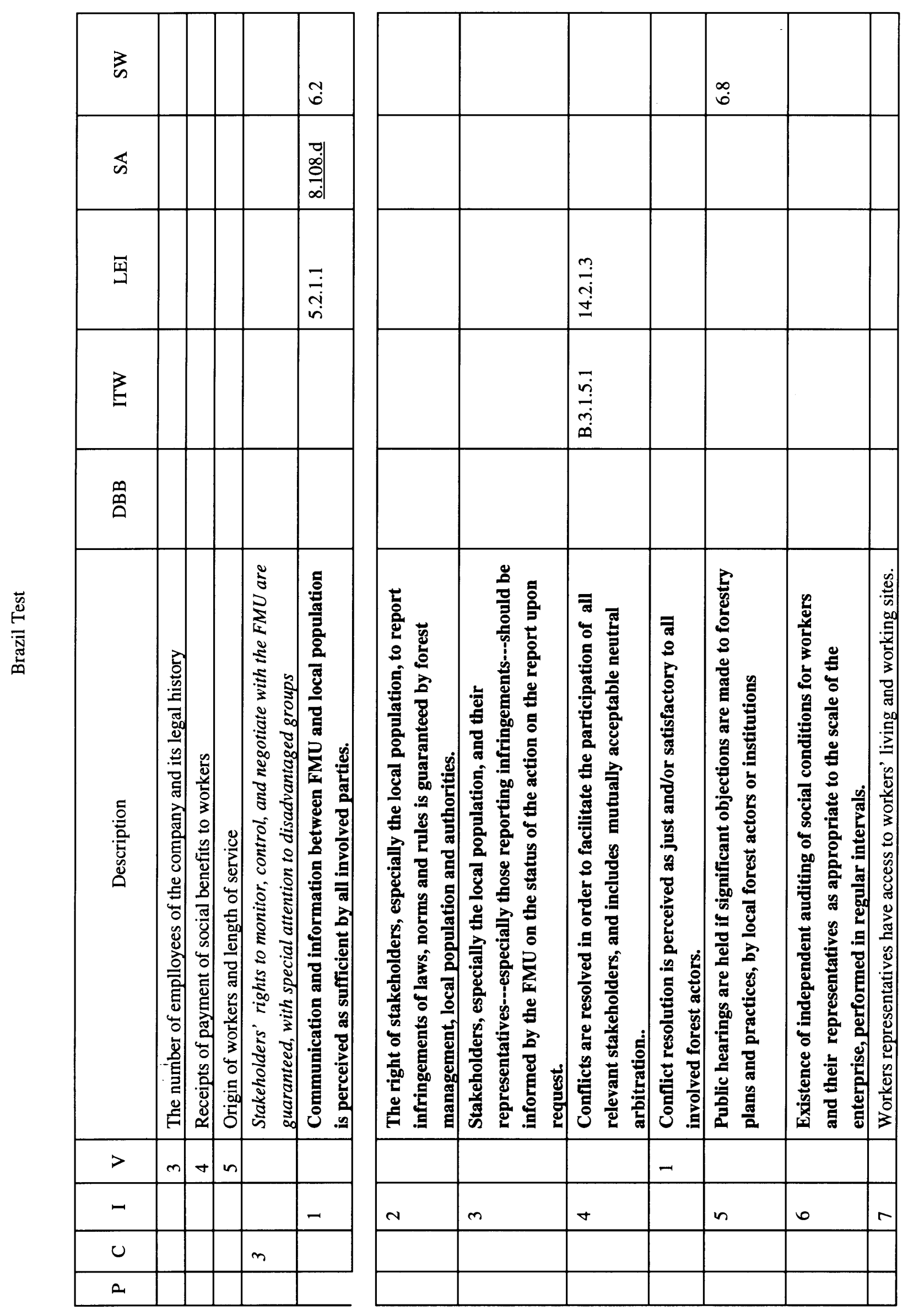


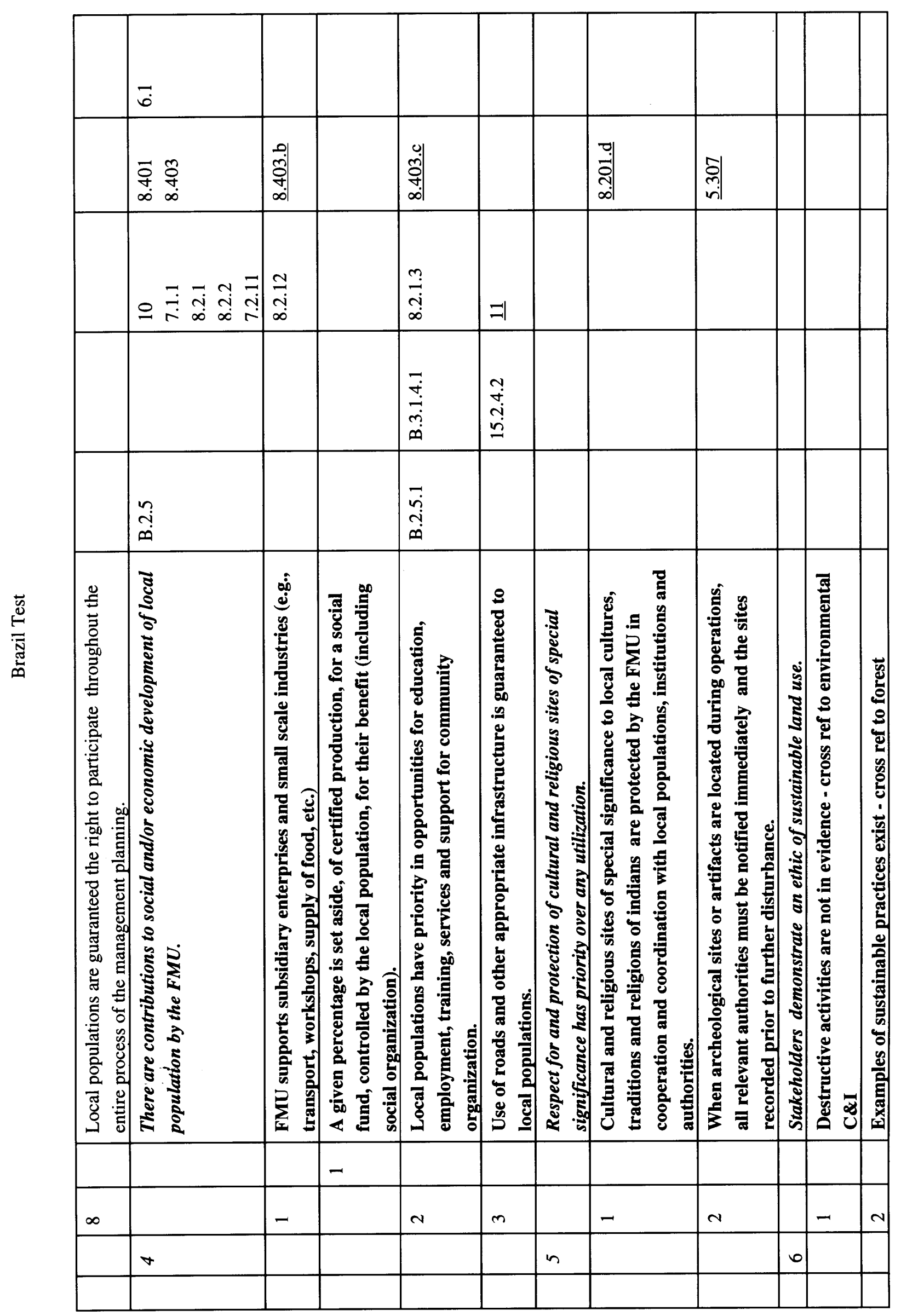




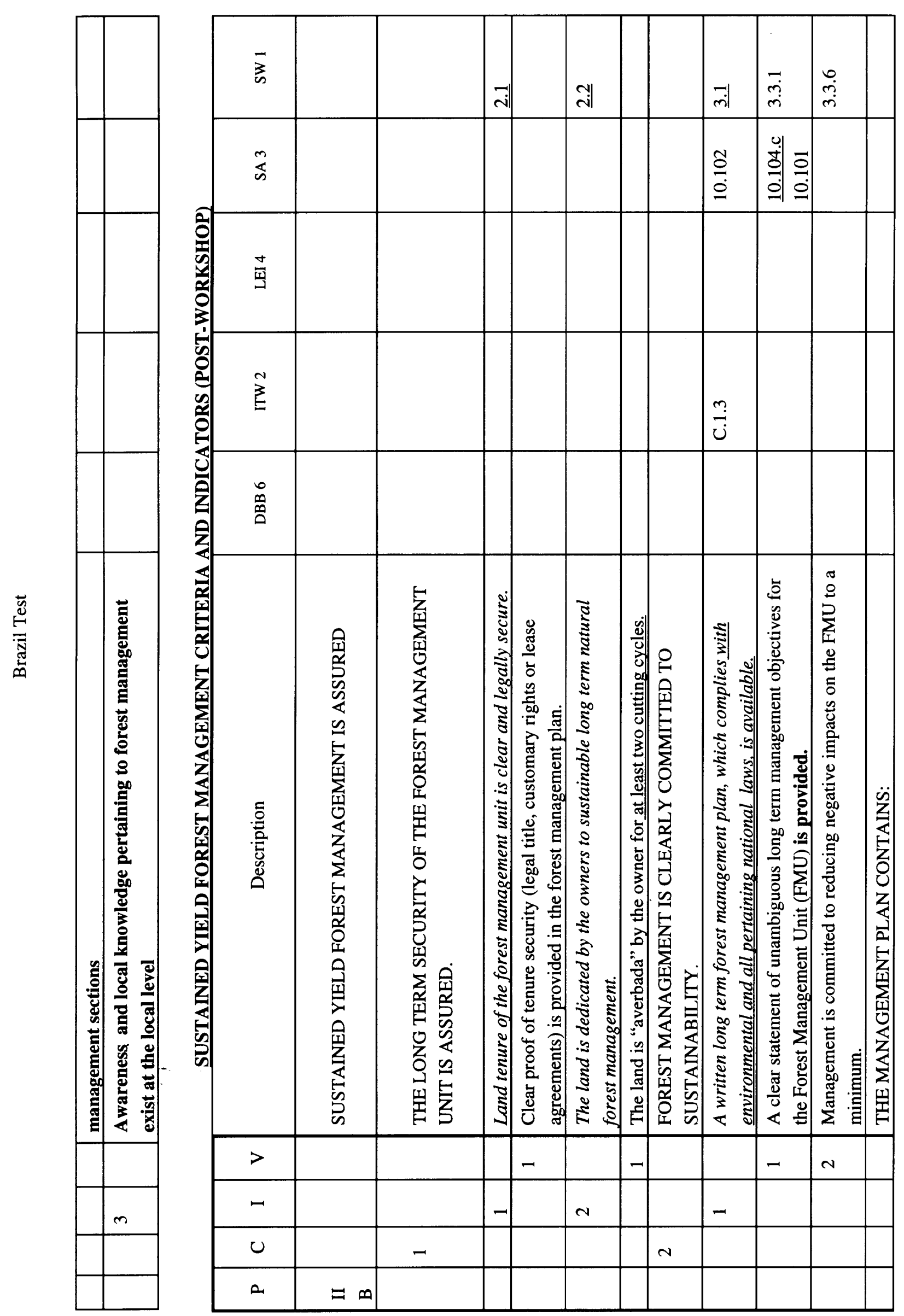




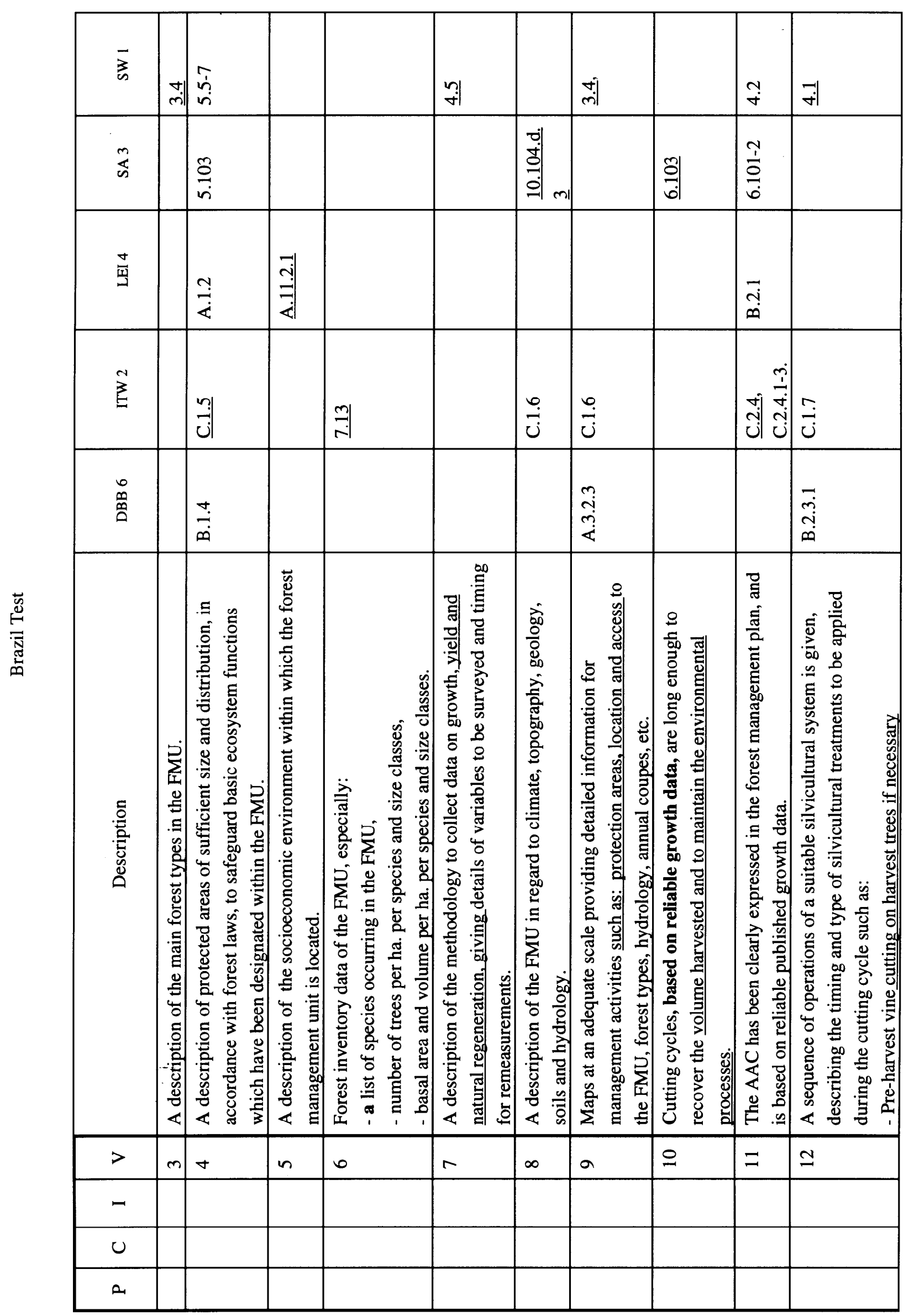




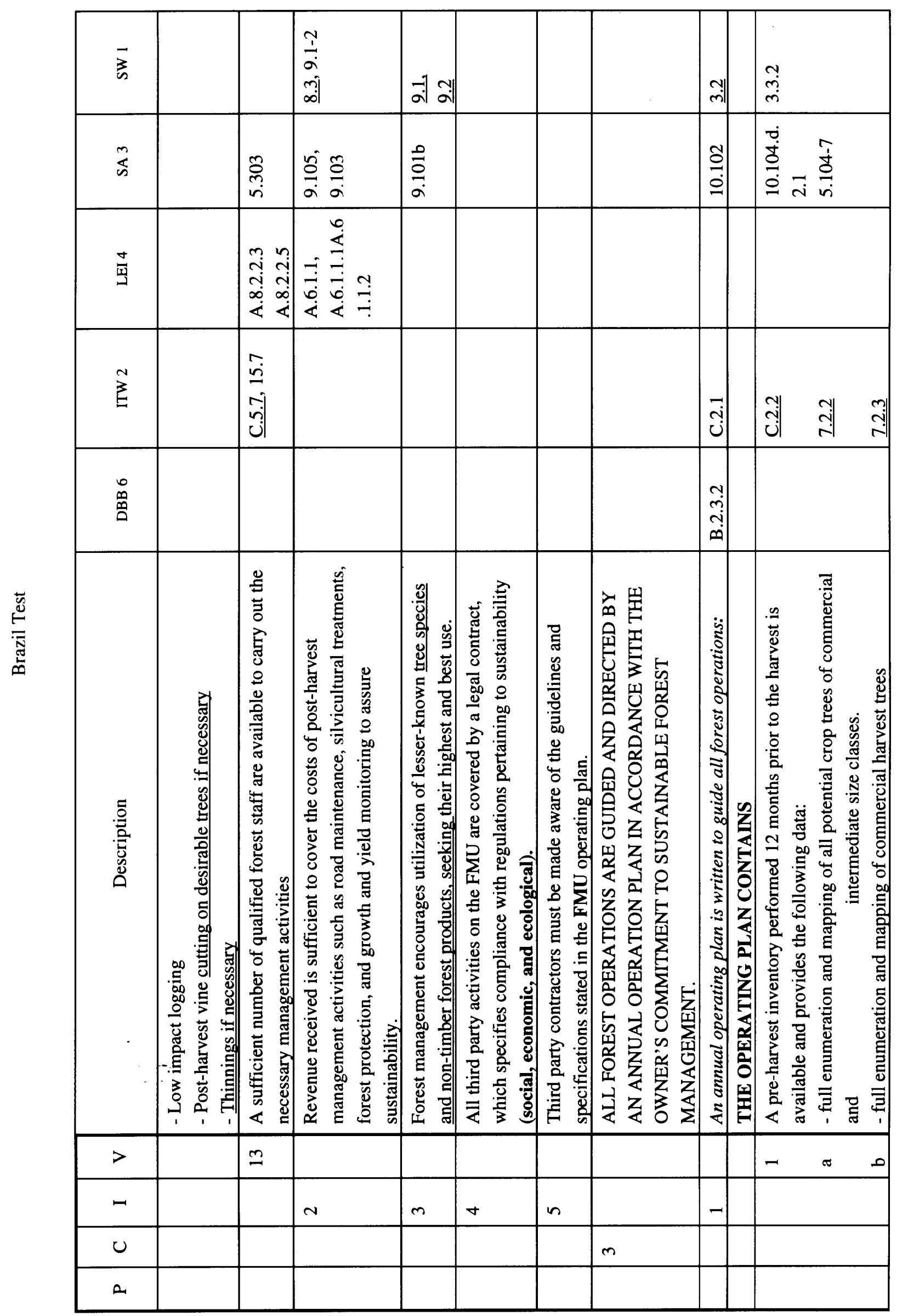




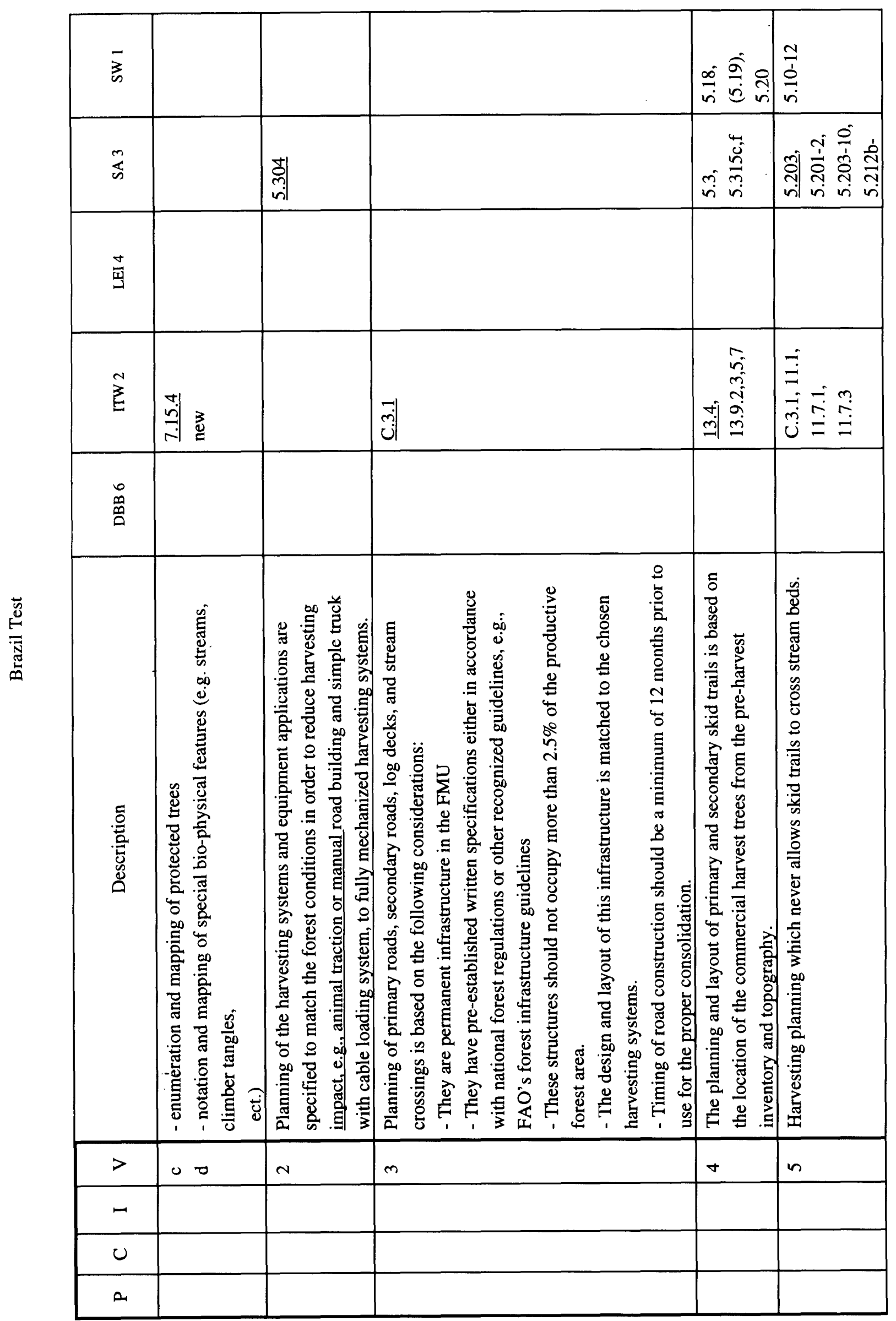




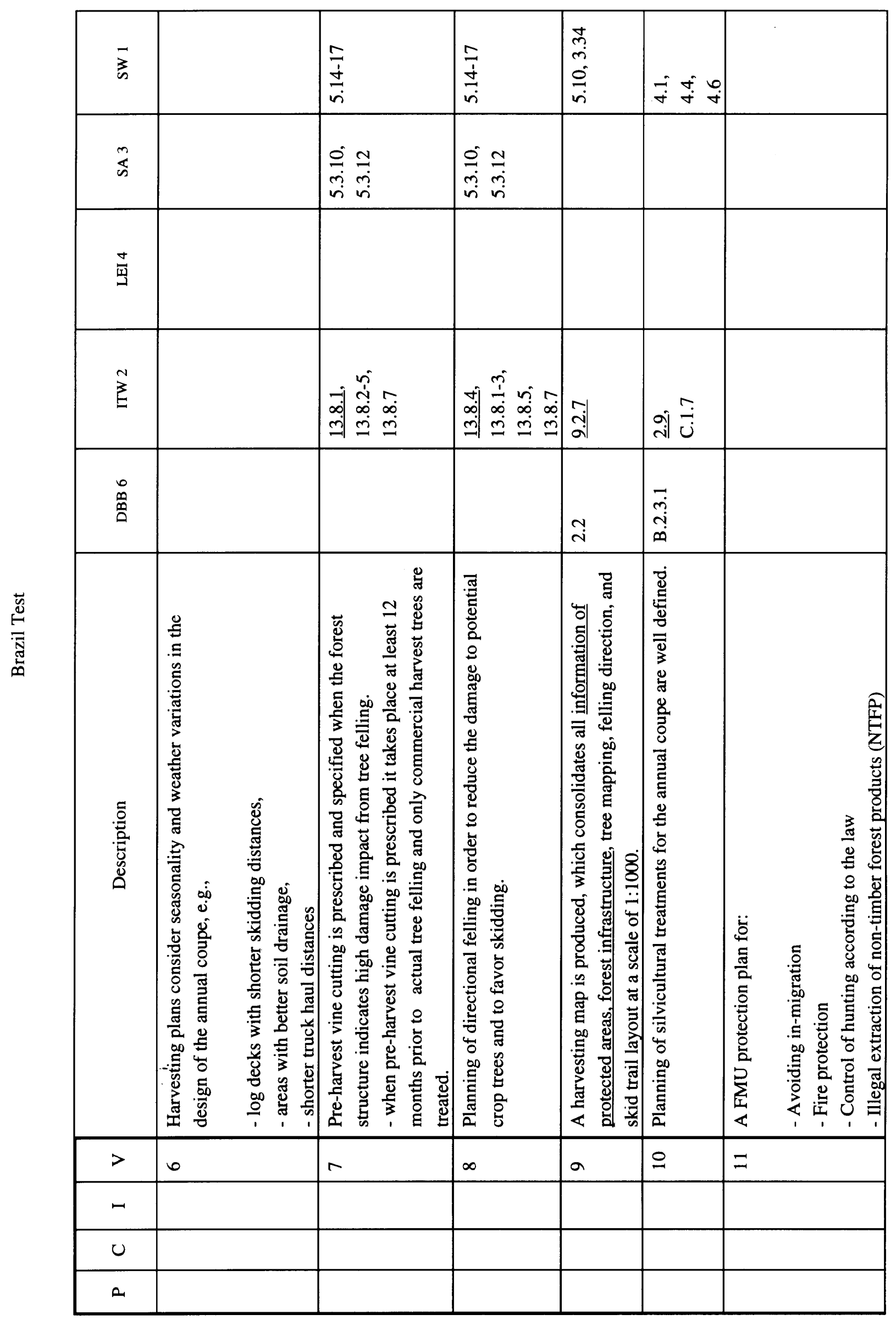




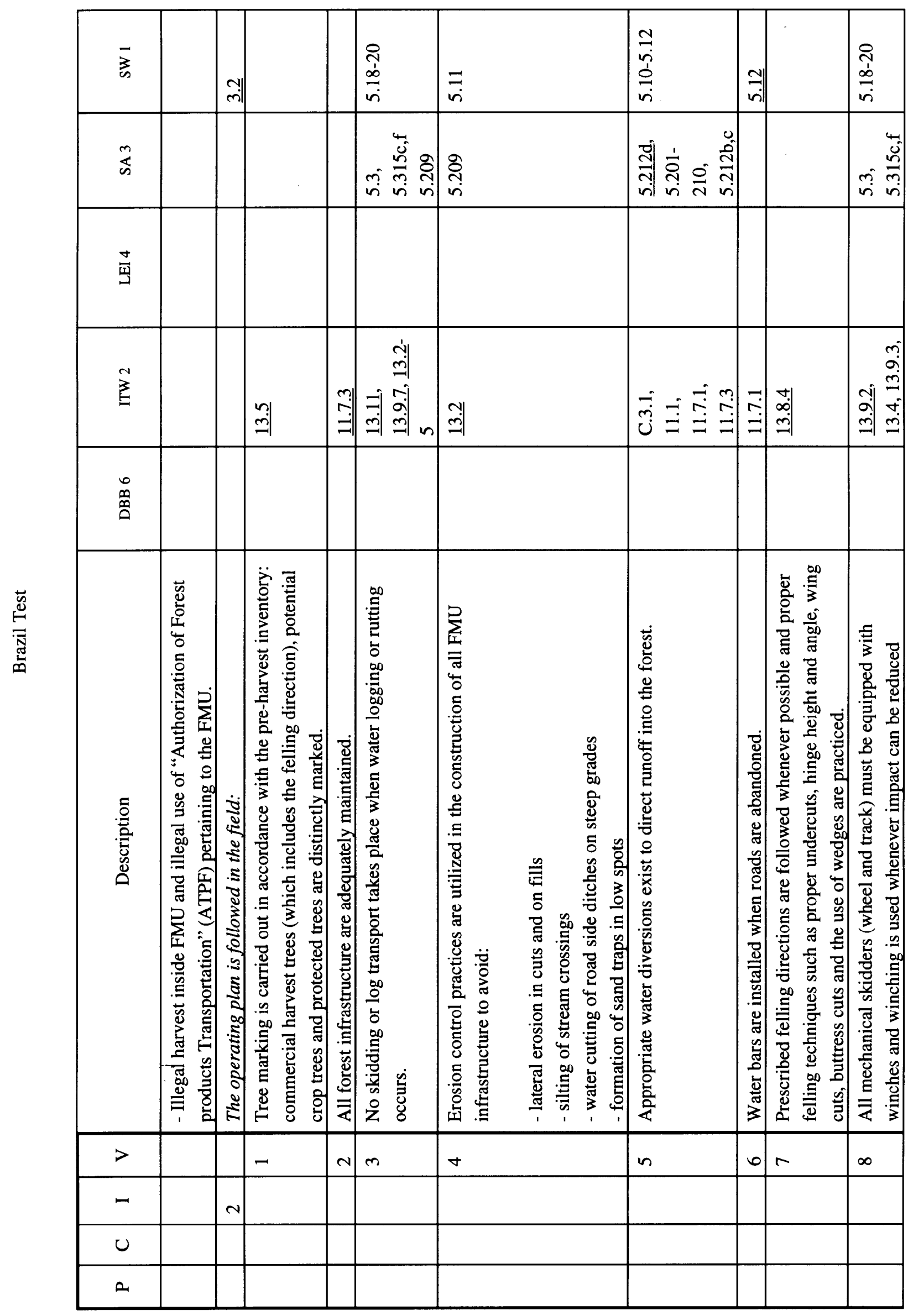




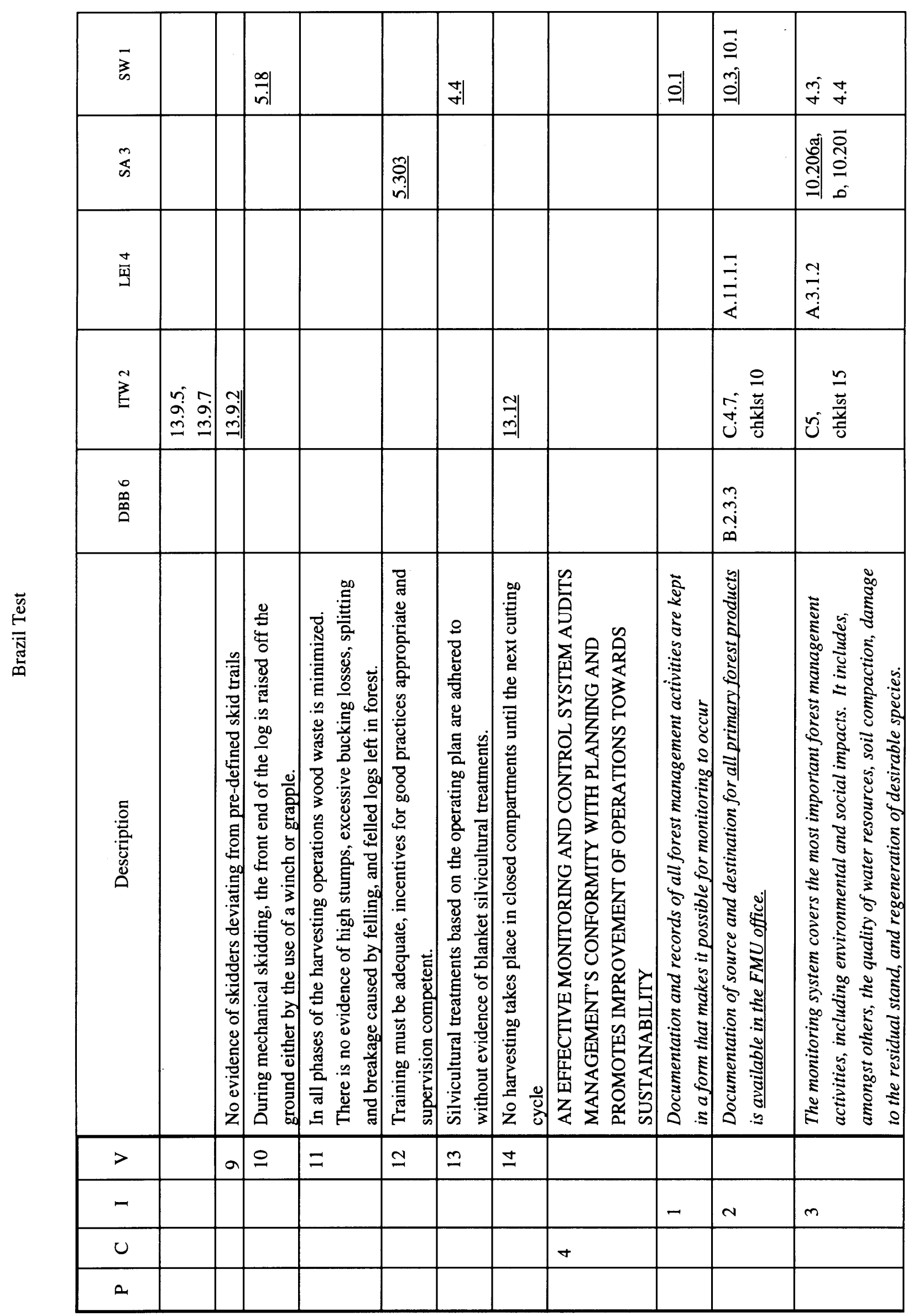




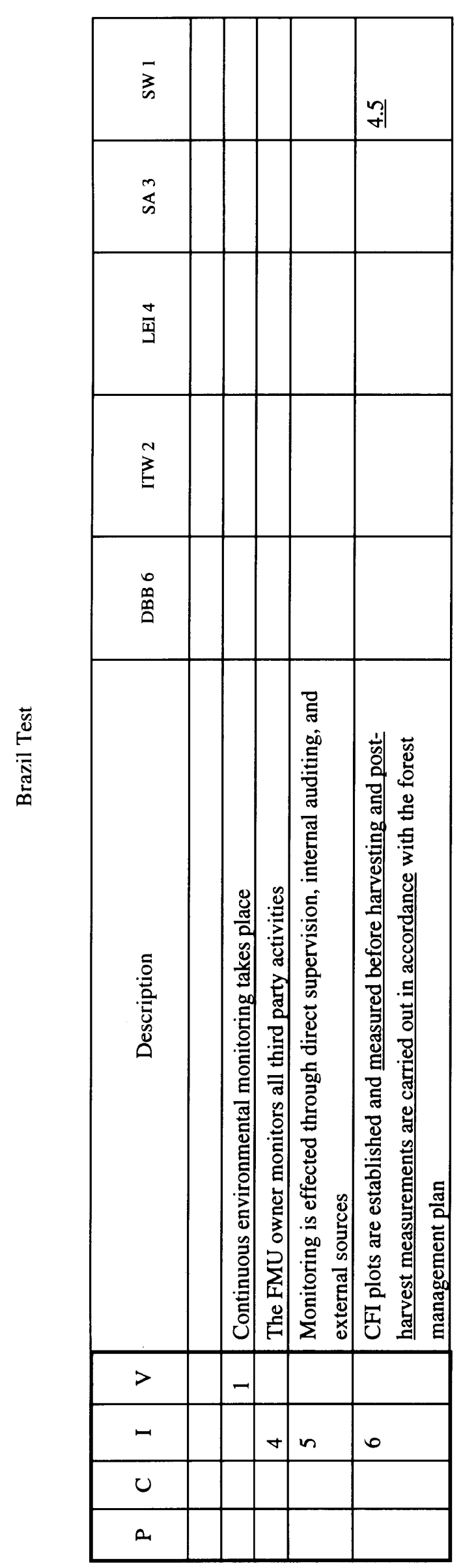




\section{TEST OF C\&I IN AUSTRIA: SET OF PRINCIPLES, CRITERIA AND INDICATORS}

\section{Explanation}

- In the present set the comments made in the course of the workshop discussions (November 2-3, 1995) are included.

- Description of the numbering:

The numbering of the new set is based on the original set according to which the testing was carried out. The latter shows a numbering from 1 to 278 and is divided in the following sections: General and Organizational Requirements (1-42), Ecological Principles (43-165, plus 277/278 concerning plantations), Economic Principles (166-233), and Socio-economic Principles (234-276). Although most of the used points had to be rephrased, the original numbering was retained. But since the new set has been enlarged to include aspects which had not been considered in the original set, the existing numbering had to be modified accordingly:

- Ecological Sector: For new points numbers $>300$ (and $>400$ ) were used

Economic Sector: For new points numbers $>400$ (and $>500$ ) were unsed

Socio-economic Sector: For new points numbers $>500$ were used.

The original set consists of principles, criteria and indicators which were compiled from different national and international set of criteria. The origins of the criteria or indicators are given by means of the number after the slash (compare introduction to the original set). As far as the economic and the socio-economic sector as included in the new set are concerned, number and source of the criterion/indicator may be followed by a C, E, or F. These letters refer to the group or the member of the team responsible for the rephrasing of a point,

C standing for working group on economic aspects (Dr. E. Senitza, DI S. Terzer)

E for Dr. F. Rest and

F for Mrs F. Grünberg

For example:

Indicator 246/8/F means: the indicator in question is based on indicator $246 / 8$ of the original set of criteria and indicators as it was presented at the beginning of the testing procedure and was only slightly modified. The extension "F" refers to the test team member (coder F) responsible for rephrasing the indicator. This should allow to recontact the person in charge to answer future questions e.g. as to how the decision came about. It furthermore makes the modification more transparent. In the chapter "internal aspects" rephrased indicators were numbered from 501, the chapter on the design of the external relations starts with number 601.

Definitions of special terms of the ecological sector can be found at the end of the respective chapter.

- Those indicators which the test team members considered to be the most important ones are given in boxes.

Box: Indicates the most important indicators

- In the case of principles $(\mathrm{P})$, guidlines $(\mathrm{G})$, and indicators $(\mathrm{I})$, the , $\mathrm{C}^{\text {“ }}$ for criterion was put before the headline or the text.

The object of the certification is the forest management in the stricter sense of the term and not the enterprise in itself!

Guidline for certifyers: External impacts which cannot be influenced by the enterprise (e.g. ambient air pollution, etc.) are taken into consideration when evaluating those indicators which are clearly effected by these impacts.

\subsection{GENERAL AND ORGANIZATIONAL REQUIREMENTS}

\section{PREAMBLE}

The principles listed below are designed to be a globally valid set. For their implementation on the regional level, however, adaptions may be uselful. All organizational questions have to be resolved beforehand. 


\subsubsection{Meeting of General and Legal Requirements}

\subsection{1 General Information/Identification}

\subsection{Identification of the areas subject to management}

1/14 The area on which sustainable forest management is carried out has to be determined by clearly defined area units. The description comprises: name, geographic location with details on the course of the borderlines, size.

\subsection{Management}

2/14 Name and address of the landowner or the concessionary

3/14 Name and address of the responsible manager

\subsection{Product Identification}

4/14 Products from certified enterprises or areas shall be made clearly identifiable by special marks or separate storage.

\subsubsection{Compliance with Legal Standards}

5/14 Within the framework of forest management the landowner or concessionary engages to fulfill the respective laws in force and to comply with the principles of the following international obligations (framework conditions): ILO, ITTA CITES, Convention on Biodiversity.

6/14 Should the requirements laid down in the set go beyond the regional standards, the applicant has to commit himself to fulfilling these requirements.

7/14 On the national level the following rules and regulations have to be observed:
a) Forestry law
b) Land use planning
c) Property rights
d) Other ecological rules and regulations
e) Other economic obligations
f) Social rules and regulations

\subsubsection{Basic Data on Means of Production and Framework Conditions}

In order to guarantee transparentness of the sustainability of forest management information on the means of production as well as the general management conditions, including information on how these data are compiled, are necessary.

The expenditure of data gathering is adapted to the size of the management unit as well as to the intensity of management [check list].

\subsubsection{Necessary ecological data}

\subsection{General description of the area}

8/14 Climate, topography, geology, soil, anthropogenic influences [orders of magnitude: see criteria and indicators], water cycle, regional land use planning (conurbations, percentage of forested area, agricultural use ....)

\subsection{Biodiversitv}

9/14 Area data on natural forest communities and current growing stock

10/14 Area data on forest structure

11/14 Description of ecosystem types and their successions

12/14 Abundance and distribution of animal and plant key species, e.g. rare and endangered species, species which are important for the local economy or for the functioning of the forest ecosystem. 
Test Austria

\subsection{Protection areas and areas designated for specific forms of use}

13/14 Legal status, size of the area and subject of protection:

- protection areas for ecosystems/habitats

- areas with a high diversity/endemism

- water catchment areas

- erosion protection areas

- wetland biotopes

- others

\subsubsection{Necessary economic and production data}

\subsection{Product diversity}

14/14 Information on the kind and extent of the use of the forest products (timber and non-timber) as well as on hunting and other services rendered (this includes traditionally used plants and animals and the exploitation of secondary tree species).

\subsection{Forest}

15/14 Area data: Total area; production and non-production areas, age/diameter structure, forest maps giving details on forest functions

16/14 Timber supply with regard to assortment and diameter classes

17/14 Available information on regeneration and increment

18/4 Information on logging and log transport

\subsection{Personnel, logistics, etc.}

19/4 Information on development, logging and log transport

20/14 Information on employees and jobs

21/14 Information on phytopharmaceuticals and wood preserves used

22/14 [Information on wages and salaries, unless there are collective agreements.]

\subsubsection{Other data}

23/14 Information on chartered and non-chartered forest exploitation rights

24/14 Information on forest sites of archeologic, historical, religious or cultural significance.

\subsubsection{Management concept}

\subsubsection{General requirements}

25/14 In order to guarantee the sustainability of forest management systems over the long term, an appropriate management concept adapted to the size of the enterprise has to be provided. In this connection, management measures traditionally carried out in coppices, which are often not recorded in writing, are being taken into consideration.

$26 / 14$ a) The legal rules and regulations on which the management concept is based have to be cited.

\subsubsection{Description of management objectives}

27/14 Objectives have to be defined on the basis of the general data requirements listed in chapter B concerning means of production and framework conditions.

28/14 In choosing forest management systems appropriate consideration should be given to ecological, economic and social aspects. Especially possible negative impacts and measures to minimise them should be specified. 
Test Austria

\subsubsection{Ecological aspects}

29/14 Measures for the protection of biological diversity (including rare and endangered species), of soil and water bodies have to be specified.

\subsubsection{Economic aspects}

30/14 Management of growing stock

31/14 Afforestation and silvicultural measures

32/14 Logging operations and log transport

33/14 Road construction

34/14 Forest protection measures

\subsubsection{Social measures}

35/14 Rights and obligations towards the population, especially indigenous peoples, with regard to forest exploitation.

36/14 Payment schemes

37/14 Training and job organization

$38 / 14$ Safety in the workplace

\subsubsection{Documentation and Monitoring}

\subsubsection{Documentation}

39/14 The forest owner/concessionary engages to keep all information necessary for obtaining the certificate.

\subsubsection{Monitoring}

40/14 The organizational framework conditions have to guarantee that improper use of the quality mark is prevented by appropriate monitoring.

41/14 For renewed qualification for the quality mark an updated setof data has to be provided.

42/14 The data have to comprise the aspects cited in the above mentioned chapters

\subsection{ECOLOGICAL ASPECTS}

Subject of certification is the forest(ed) area of an enterprise. Non-forest areas (including plantations) as well as their location with regard to the forested areas are not taken into account (this applies to Austria). The latter shall be assessed on a national level with a view to landscape ecology (landscape planning). (For an exact definition of terms see Annex)

The indicators that are the most important are framed.

\subsubsection{Quantity and Quality of Ecosystem Components}

P: The abiotic and biotic elements of forest ecosystems have to be preserved and negative impacts from forest management measures have to be kept to a minimum, especially with regard to soil, water and biodiversity.

\subsubsection{Soil}

$\mathrm{P}(64 / 14$.): Forest management has to be carried out in a way so as guarantee that local (natural)soil conditions (quantity, quality) will not be adversely affected, not even in the long run.

63/7...1: The location of sensitive soils, and the measures required to ensure that the physical, chemical and biological conditions essential for maintaining the long-term productivity of those soils are protected, maintained or enhanced, are documented in appropriate plans and descriptions (FPC). 
Test Austria

\subsection{C: Forest Area, Forest Fertilization, Soil Tillage}

54/13...1: The forest area is not diminished in size. Forest losses through authorized deforestations by the enterprises have to be compensated by afforestation of adequate areas.

69/14...1: No fertilization measures aiming exclusively at an increase of increment. However, initial fertilizations for young crops are carried out as well as fertilization aiming for forest soil rehabilitation in order to stabilize the ecosystem (ÖFA).

302/new...I: In areas exceeding $100 \mathrm{~m}^{2}$ no soil tillage deeper than $20 \mathrm{~cm}$. (Exception: Justified stand conversions and rehabilitation measures.

\subsection{C: Growing stock, size of cuttings, logging and log transport}

303/new...G: The impact of logging operation on soils must be minimized especially with regard to clearcuttings, earth moving for road construction (82/3), bare soil exposure (86/3) (SA)

68/14...G: Minimization of the input of pollutants (e.g. chemical substances, oils) by the enterprise and of the removal of nutrients (e.g. foliage, branches, roots).

301/new...I: After timber harvesting roots and branches (of less than $3 \mathrm{~cm}$ diameter) are left on the logging site.

66/14...G: Maintaining a degree of stocking which potects the soil against extensive erosion. (ÖFA)

67/14...1: No complete or extensive tree felling (canopy cover less than 40\%) exceeding an area of 0.5 ha, which would leave top soil bare and sensitive to erosion, i.e. widths of felling areas shall not exceed 15 meters, the height of half of the adjacent dominant trees exceeding $20 \mathrm{~m}$ on both longitudinal sides of the logging gap). Exception is made with incidental fellings; subsequent cuttings or removal cuttings may be carried out only after at least 2000 trees per ha have attained a height of $>1 \mathrm{~m}$ or at least $70 \%$ of the area are covered with trees bigger than $0.5 \mathrm{~m}$ height above ground. (Exceptions may be made in the case of justified reasons).

77/8...1: No complete or extensive timber harvesting (canopy cover less than 40\%) exceeding an area of 0.2 ha on slopes exceeding 35 degrees measured over 100 meters, which would leave top soil bare and sensitive to erosion (width of felling areas shall not exceed 15 meters). Exception: incidental fellings; subsequent cuttings or removal/cutting may be carried out only after at least 2000 trees per ha have reached a height $>2$ meters. (Exceptions may be made in the case of justified reasons).

304/new...I: There are sufficient and intact drainage facilities on all roads to prevent soil erosion.

102/2...1: There are engineering standards for the planning, design and use of roads as well as for the making of skid trails - alignment, slope width, total surface area, stream crossings, culverts, drainage lines and water bars, use in bad weather, treatment after logging activities. These standards are adequate and appropriate for local conditions. These standards are observed.

199/1 ...I. There are guidelines concerning the equipment and use of harvesting machinery with a view to minimising possible damages from logging and log transport activities, e.g. skidding vehicles, cable yarding equipment. These guidelines are observed.

78/10...G: Minimising soil damage i.e. soil compaction through the use of tyred vehicles and skidding. (WÖPS)

305/new...I: Distance between skidding tracks no smaller than two tree lengths (tree length relative to the height of the adjacent stand). No perceivable soil damage due to driving off roads and skid trails.

88/3...1: Skid trail gradients must not exceed 25\% (R.ALL), unless there are special local regulations.

\section{2.i .2 Water}

P: Forest management shall not impair water quality nor have negative impacts on the hydrologic cycle.

\subsection{C: Drainage facilities, shoreline design}

106/14...1: No introduction of new drainage facilities in the forest off roads and tracks, existing drainage facilities are not technically improved (ÖFA).

Exception: Prevention of landslides. 


\section{Test Austria}

111/2...1: There are regualtions for the protection of riparian reserves along streams, water courses and stream heads, along shorelines, and around lakes. These regulations are observed (Ind.).

\subsection{C: Logging and $\log$ transport}

112/3...G: H arvesting machinery must not enter streamsides except at designated and designed stream crossings. The number of such crossings must be minimised (SA).

114/3...G: Lop and top are not being pushed into streamsides (SA).

\subsection{C: Road Construction}

P: The impact of road construction on water quantity and quality must be minimised.

115/3...G: Minimising the number of stream crossings (SA).

116/3...G: Keeping valley bottom roads and tracks as far as possible away from streams (SA). (Limit values according to local regulations).

119/8...G: No road filling materials are introduced into stream courses (R.All).

\subsection{C: Forest Protection}

P: Forest management must prevent contamination of water by herbicides and pesticides by, inter alia, the following measures (KSZE):

306/new...I: There are regulations concerning planning, implementation, control and documentation of the use of chemicals in order to prevent water contamination: these regulations are observed.

120/3...G: No application of chemicals within $10 \mathrm{~m}$ of watercourses and $30 \mathrm{~m}$ around reservoirs and lakes (SA).

121/3...G: No application when heavy rain in expected, during wet weather, on frozen, snow-covered ground or soil which has been baked dry during a drought (SA).

122/3...G: No burying or disposal of chemicals in watercourses or lakes, no washing of equipment in watercourses (SA).

123/3...G: No soaking of seedlings treated with chemicals in drains or watercourses prior to planting (SA). 124/3...G: Locating fuel tanks and storage sites so that spillages from damage, defects or refuelling will not enter watercourses (SA).

\subsubsection{Biodiversity}

\subsection{Structural and Age-class Diversity}

P (58/14): Forest management shall guarantee a diversity of various types of ecosystems, stages of succession and structures in accordance with the local conditions.

46/2...1: Standing dead trees and woodpecker's trees should be left unless they are a considerable security risk. On an area of 10 ha at least 10 old trees of the upperstory (e.g. woodpecker's trees and eyrie trees) are left without being exploited until their natural decay after their death (with management units smaller than 10 ha at least 1 ancient tree per ha, no requirements for units of less than 1 ha). These trees are identified and recorded (especially with regard to third party damage claims).

\subsection{Genetic Diversity}

P (59/14): Forest management activities must be geared to guarantee the conservation of local, native plant and animal species (regeneration, migration) in the long run.

307/new...I: All tree species of the potential natural forest communities which comprise at least 50 ha shall be represented.

308/new...I: The ecologically most important characteristic tree species of the potential natural forest community are - either by individual trees or by clumps - sufficiently (on average at least 100 potential crop trees per ha) represented in the respective regeneration areas, representing at least $30 \%$ in old growth stands. If there is more than one characteristic tree species each of them shall be proportionally represented (e.g. three character tree species shall be represented by $10 \%$ each). 
Test Austria

49/4..1: There are regulations controlling inappropriate, i.e. threatening the existence of the respective animal or plant population, hunting, fishing, trapping and collecting. These regulations are observed (FSC).

P (60/14): Forest management maintains the genetic variability within all species and allows the exchange of genetic material species.

309/new...I: With seeding and (re)afforestation the genetic provenances of seeds and planting stock have to be suitable for the local conditions. There has to be documentary evidence of the respective genetic provenances.

62/14...G: The growing of species and genetic provenances outside their potential natural distribution area is carried out only after careful assessment of all positive and negative aspects. Negative ecological impacts have to be avoided.

3 10/new...I: Introduced tree species (tree species outside their natural distribution area) account for maximum $40 \%$ of the whole forested area and do not exceed $20 \%$ of the total regeneration area.

311/new...G: No game species must be released outside their natural distribution area.

61/4...G: In general no genetically modified organisms must be released in forests.

\subsection{Protection Areas:}

44/14...1: It is guaranteed that concessionaries when harvesting do not do any damages to legally stipulated protection areas, which had been agreed upon with the owner.

50/5...1: With forestry enterprises of more than 200 ha at least 5\% of the total wooded area are entirely dedicated to protection measures in order to promote rare and endangered animal and plant species and their habitats (e.g. breeding and feeding sites, forest communities). These may be total protection areas or protection areas in which special measures are carried out. If in the forested area in question no such area can be designated in cooperation with nature conservation or forestry authorities, adequate measures have to be taken on 5\% of the total forested area. For example: deliberate increase of the percentage of standing dead trees and fallen logs (only one selective cutting for timber extraction within a decade during which no more than $10 \%$ of the timber volume may be harvested); increase of the rotation length by at least 30 years with regard to the surrounding stands, identification of areas with light demanding trees and pioneer species, of small wood on forest edges (forest edge tending), coppice with standards systems or forest pastures with controlled grazing on areas which are nowadays or have formerly been used as such (rare, old forest management systems). These measures and the respective areas are recorded.

\subsubsection{Vitality, Health, Productivity}

\subsubsection{C Stability, Resilience, Natural Regulating Mechanisms:}

P: In forest management the maintenance and improvement of the functional capacity of ecosystems, their dynamics as well as their vitality and stability have to be guaranteed.

- Maintaining the capacity of ecosystems to react upon external impacts and processes.

- Especially forest stands adapted to the local conditions must be maintained and supported in order to profit to a maximum from natural control mechanisms.

135/14...G: Exploited forest areas are regenerated within ecologically appropriate periods by means of tree species and planting stock of provenances which are suitable for local conditions making maximum use of the natural regeneration potential.

312/new...I: At least $20 \%$ of the regeneration area are regenerated by natural regeneration (without afforestation). This does not apply to enterprises of less than 50 ha forested area and to enterprises in which there are no seed trees suitable for local conditions.

\subsubsection{C Forest Protection and Preventive Measures:}

313/new...G: Preventive pest control measures are preferable to therapeutic measures, and adequate biological measures are preferable to chemical measures.

136/5...1: There are regulations relative to pest and pathogen control and these are adhered to (e.g. consideration/incorporation of inevitable epidemics in pest control measures and their documentation, financial provisions and future protection measures; SCS). 


\section{Test Austria}

153/3...I: Contingency plans detailing action to be taken in the event of pollution by chemical substances or natural disasters like forest fires (SA). These regulations are observed.

152/3...G: All equipment for the transport, storage and application of chemicals are maintained in a safe and leakproof condition (SA).

\subsubsection{C Stress Factors and Risk Assessment:}

146/9...C: Stress factors: Insects/disease/weather, air quality, fire, climate, competition, topography, utilization (KSZE)

148/6...I: Documentation of serious damage done by biotic and abiotic agents (Sustainability Monitoring):

- serious damage caused by insects and diseases with an assessment of the seriousness of the damage as a function of (mortality or) loss of forest (Hels.)

- annual area of forest destroyed by forest fires, landslides, etc. (Hels.)

- annual area affected by storm damage and volume harvested from these areas (Hels.)

- proportion of regeneration area seriously damaged by game, other animals or by grazing (Hels.).

149/5...I: Documentation of the frequency and effectiveness of pesticide use: stated reasons for their use (SCS), locational accuracy of application, appropriate timing, efficacy chemical measures by vegetative results (SCS), use of targeted and/or broadcast aerial insecticide spraying.

159/9...I: The impact of big herbivores (hoofed animals, etc.) on forest vegetation does not reduce tree species diversity (comparison of reference plots - see method of assessment); exception: reserves for big herbivores. Method of assessment: comparison of nature and abundance of regeneration in controlled areas, some of which are easily accessible for herbivores, others fenced in (KSZE). Minimum size of reference plots: $5 \times 5 \mathrm{~m}$; there is at least one pair of reference plots per 50 ha of forested area with a distribution corresponding to existing potential natural forest communities. There is at least one pair of refernce plots in enterprises smaller than 50 ha. (Guidelines for the establishment and control of reference plots have to be defined on a regional/national level.

Exemption: As far as guidelines (G) and indicators (I) are concerned, exceptions to the regulations may be made for individual enterprises provided that only a single guideline or indicator is concernced and the enterprise provides sound reasons guaranteeing that an exception in this particular case does not jeopardize the maintenance of sustainable forest management.

\section{$\underline{\text { APPENDIX }}$}

\section{Definition of Terms}

Potential Natural Forest Community according to WÖPS FRANK-HINTERLEITNER. (Oktober 1994): Assumed vegetation of a specific site which after the cease of human impact would correspond to the actual site potential. This concept serves to represent the natural potential of a specific site or a landscape in the sense of "potential natural forest communities as they exist nowadays". The tree species forming such a potential natural forest community have to be defined. This does not include introduced tree species (i.e. tree species outside their natural distribution area). Practicable guidelines for the assessment of potential natural forest cumminities have to be established.

Characteristic Tree Species: Tree species characterising a specific potential natural forest community, and which are inevitable for maintaining forest community-specific processes and ecological functions. In a spruce-fir-beech wood, for example, the characteristic tree species would be spruce, silver fur, and red beech. The characteristic tree species of a given potential natural forest community have to be defined.

Forest Regeneration Area: Forested area (clearcut areas and sheltered areas) which at the time of assessment are subject to either natural (seed trees) or artificial (reafforestation, seeding) regeneration, up to a young forest stand height of $2 \mathrm{~m}$. In the case of a waiting period before qualifying for the quality mark (e.g. a "probation period" of 5 years) the regeneration area emerged during this period will be considered. 
Test Austria

Plantations: According to FAO, an artificially created forest, either on formerly non-forested areas or by substituting existing forests by new and essentially different species or species compositions. Plantations are characterized by management measures similar to those used in agriculture, such as extensive soil cultivation, mechanical tending, monocultures, fertilization, chemical plant protection and/or mechanical total harvesting as well as short rotation periods. For Austria: only those areas stocked with trees in the a.m. sense shall be regarded as plantations which are not considered as forest under the Austrian Forestry Law.

G uideline $(\mathrm{G})$ : Basic requirements, however less operable than indicators and thus can only partly be controlled.

\subsection{ECONOMIC ASPECTS}

\subsubsection{Forest Products and Forest Functions}

P: The various forest products - wood and others - shall be exploited in the best possible and most efficient way. One specific form of use must not impair another's potential in the long run.

P: Forest management shall guarantee a sustainable and diversified supply of timber and other forest products

\subsection{1 .1 Spatial Distribution and Extent}

174/2/C C: Spatial distribution of forest products and functions: e.g. timber production, (protection)/closed forest, amenity and recreation (e.g. bridle paths, cycle tracks, keep-fit trails, nature trails, etc.), water (springs and water protection and conservation areas), hunting (including hunting reserves) and fishing, pasture, secondary benefits such as resin, dwarf pines, Christmas trees, etc.), other secondary estate uses in forests.

401/C I: General identification maps are available: for instance FDP (general forest development plan), specific forest development plans with operational details for the enterprises, maps identifying areas allocated to specific forms of use and which are thus subject to special conservation measures, identification of danger areas, areas for which specific management goals have been set, forest function planning, game ecological land use planning, regional land use planning.

402/C I: There are quantified data concerning the use of the forest services provided: e.g. harvest levels (yield/ha), cutting size, population statistics of protected settlement areas, number of visitors/turnover, spring runoff/profits, hunting bag statistics/payment for hunting ground, large animal units relative to forest pasture area, profits from secondary uses.

403/C I: There are adequate procedures to settle conflicts in the case of conflicting interests regarding the use of forest products and services. These procedures are applied and recorded and negative impacts of the different forest functions on each other are identified and recorded.

404/C I: No obvious negative impacts definitely caused by forest management on adjacent areas and regions. (Forest and non-forest areas).

421/C G: Satisfactory use has to be made of existing procedures giving interested parties or individuals a

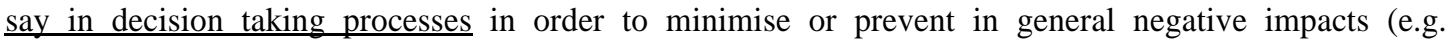
possibility of interested parties to officially voice their opinion, hunting societies, etc.).

\subsubsection{Profitability}

P: Forest management has to be carried out in a way so as to preserve forests in at least the same condition for economic exploitation by future generations.

P. Prices for timber and other forest products have to be determined with a view to beeing an incentive for long-term forest management, taking into consideration the ecological, social and operational production costs.

\subsubsection{Financial Productivity}

180/5/C C: Financial efficiency allowing the operational survival of an enterprise and guaranteeing a minimum of silvicultural tending measures and the maintenance of a minimum of infrastructure.

412/CI: An on average at least balanced income - expenditure ratio over a period of at least 10 years. In this connection income comprises all money returns from wood sale and profits from non-timber forest 
functions (cf. chapter 3.4) including compensation payments and financial grants. Expenses cover silvicultural, tending, harvesting, material and administrative costs.

Exception: Start-up enterprises where high investment (including own capital funds) coincides with negative operating results.

Remarks: arithmetic approaches for not financially compensated non-timber forest services may be taken into account if beneficiary and forest owner are identical or closely related to each other (e.g. community forests in mountainous areas). There are problems in the case of high amount of positive external effects which are neither paid-off nor compensated by means of grants.

\subsubsection{Investment of Capital and Personnel}

426/C C: appropriate and sufficient investment in stand improvement measures and/or improved (here: more efficient) logging and log transport techniques and/or in personnel training.

203/5/C I: There is a minimum of investment in or commitment to further professional training for managerial and non-managerial staff (e.g 1 day/year) (cf. 505-507).

204/5/C I: Investment rate or annual expenditure in improved harvesting and log transport techniques (relative to e.g. a five year-period). This includes the application of special harvesting and $\log$ transport techniques by the enterprise.

205/5/C I: Investment rate or annual expenditure in re-afforestation, forest tending measures aiming at an increase in value or quality (e.g. pruning), vegetation control, stand improvement programmes, monitoring, resource protection programmes (including all investment in resource maintenance, e.g. garages for maintaining machinery,...) or others. This also includes corresponding investment of own capital funds.

\subsubsection{Utilizations / management contract}

189A/I/C C: Long-term determination of management measures if forest owner and management company are not identical or closely related to each other.

189/1/C I: The owner of the forest and the management company or the concessionary, respectively, have signed a utilization / management contract stipulating the legally binding rights and obligations of the contracting parties. This contract furthermore includes the framework conditions for long-term management (exceeding one forest or tree generation) of the forest (ITW). This must include an appropriate stand regeneration rate and a sufficient amount of tending activities.

\subsubsection{Silviculture and Forest Protection}

\subsection{Silvicultural Systems}

413/C C: economically efficient silvicultural systems and regeneration measures in accordance with the dominant forest services and functions.

414/C I: Expense ratio between the expenses for artificial formation of stands, protection and tending measures and the total expenses of the forest enterprise (harvesting and skidding costs, administrative costs) depending on the dominant natural forest community and the respective region. Limit value: e.g. on average $<15 \%$ over the last five years (could be also assessed on account of the growth area on the basis of the operational test net. Exception: after natural disasters, companies which are being restructured or converted and (run-down) start-up enterprises needing heavy investment (comp. 412/C)

\subsection{Regeneration and Tending Measures}

172/5/C C: Extent and efficiency of stand formation measures, young growth tending and stand release treatments in order to guarantee at least the dominant required forest services.

170/5/C I: New stands are established on areas which are suitable for or in need of regeneration without leaving gaps $>400 \mathrm{~m}^{2}$. In doing so all possible advantages of the local site conditions are being made use of and there are sufficient young stand treatment measures including regulation of species mixture to achieve the growing-stock objective (according to natural forest communities and the silvicultural objective as laid down in the forest management plan. 


\section{Test Austria}

407/C I: The degree of thinning does not lower stocking density under the critical level, i.e. until an obvious decrease in increment can be observed, nor to a level at which the functional stability would be impaired. With thinning measures crown-density must not be reduced under 0.6. Exception: stand conversions.

\subsection{Seed trees}

410/C G: In the future a diversified tree species mixture shall be maintained, or achieved, respectively, in order to obtain a range of products as diversified as possible to meet non-predictable market demands as well as with regard to other possible future products (e.g. genetics, pharmaceutical industry, etc...)

175/3/C I: In the case of natural regeneration a sufficient amount of seed trees of a sufficiently diversified species mixture has to be maintained to guarantee regeneration of the tree species in question depending of the specific potential natural forest community and the abundance of the individual tree species (compare chapter Ecology).

411/C G: Seed trees of rare native species should in any case be maintained as long as possible, in order to guarantee/allow the maintenance and regeneration of these tree species in the long run.

\subsection{Forest Protection and Forest Hygiene}

417/C G: In order to prevent forest damages which might threaten the existance of a whole stand, trees infested with potential primary pests have to be removed immediately and on a regular basis. For forest protection reasons, however, inconspicuous dead trees, should be left to an extent as mentioned in para 46/2. (see para 4/2).

418/C G: With forest protection nature and abundance of the methods applied have to be chosen with regard to an economically efficient cost-benefit ratio over the middle term (e.g. putting up of fences <-> single tree protection; protection against barking damage <-> killing, game enclosures, feeding; use of herbizides $<->$ soil utilization).

Preventive measures with regard to rare calamities (such as forest fires, pest infestations, storm damages) have to be taken in an economically sound way carefully assessing possible area and yield losses (e.g. decoy trees, firebreaks, etc.). Furthermore the risk frequency evaluated on the basis of long-term statistics or risk assessment models has to be taken into consideration.

419/C I: Not more than 10\% of the thicket and pole stems are affected by barking damage (total of old and new damages).

\subsubsection{Harvesting and Skidding}

\subsection{Harvesting Priorities}

169/5/C C: Harvesting priorities on the single tree and the stand levels taking into account the specific quality and increment situation and assortment distribution. Another reason for the setting of harvesting priorities is the improvement and maintenance of the functional stability.

406/C I: Harvesting activities are to a large extent limited to small areas and are carried out in accordance with the maturity of the individual stands and merchantability of the growing stock. Furthermore attention is paid to the state of the forest with regard to the predominant forest function. Exception: Forest conversions and incidental fellings (compare 171/5)

\subsection{Damages from Harvesting and Skidding}

\section{0/5/C: Use of soil and stand conserving harvesting and skidding methods.}

190 a/ $5 / \mathrm{C}$ I: A maximum of $10 \%$ of the upperstory stems, i.e. the future crop trees of the residual stand are affected by harvesting and skidding damages from stand thinning measures or the removal of individual $\underline{\text { trees. }}$.

An adequate growing stock is maintained in the lower story, especially in the case of natural regeneration. This is the case when the destruction of site-appropriate natural regeneration is limited to a maximum of $20 \%$ of the regeneration area. 
Test Austria

\subsection{Product Wastage}

191/5/C C: Wastage of Products and Resources

420/C G: There are no excessive losses through harvesting and skidding activities, which could have been avoided.

422/C I: The existing infrastructure (e.g. roads, equipment) is kept in good condition and properly maintained, thus guaranteeing the best possible long-term use of these resources.

423/C: G: Operating methods are chosen on account of their economical and efficient use of energy. This applies especially to the use of fossil energy.

424/C I: There are no unproportional losses or lasting damages done to production areas, products or other resources by forest management, e.g. damages on account of building activities in stands situated in lower-lying areas, destruction of springs or biotopes.

\subsubsection{Transport: Road and Skidding Track Network}

195/5/C C: An economically sound (density and construction according to local site conditions) network of roads and skidding tracks which are in line with the general requirements of the enterprise's forest development and logging plan considering the logging systems to be applied.

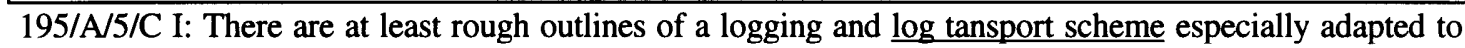
the enterprise's needs, citing the most appropriate (according to the state of the art) logging techniques for the individual stand sites.

196/5/C I: Average density of road and skidding track networks corresponding to the logging systems applied in the various management units. Limit values: forest roads $20-25 \mathrm{~m} / \mathrm{ha}$, skidding tracks $0-60 \mathrm{~m} / \mathrm{ha}$. 198/5/C I: There are no indications that management goals as laid down in the respective forest management plans are not reached because of limited accessibility, especially in the case of overexploitation of easily accessible areas at the same time.

197/5/C G: The construction of new roads is in an ecologically and economically sound ratio to the newly developed forest area.

425/C I: Road/skidding track construction costs can be covered within a period of 10 years by the timber of the pilot tracks and improvement of the contribution margins or a mathematical approach considering improved forest functions or services including grants.

\subsubsection{Timber Production}

206/5/C P: Management of the current (merchantable) growing stock in the aim of maintaining a diversified, assortment and varieties rich set of tree species of the best possible quality of even structure and composition.

\subsubsection{Stand Regeneration}

207/5/C C: Comparison of regeneration rates and stand development data with the volume of timber and the area of timber harvested, respectively.

415/C I: Regionally applied and recognized minimum standards concerning stand-conserving regeneration intervals (especially with regard to browsing damage, but also to weeds) are being adhered to. In the absence of such standards, the following requirements should be met:

a) In the case of natural regeneration at least 2000 plants growing on clearcut areas must have obtained a height of more than $1 \mathrm{~m}$ over a period of time corresponding to the natural regeneration of the natural forest community.

b) In the case of reafforestations at least 2000 plants must have obtained a height of more than $1 \mathrm{~m}$ within a maximum period of 15 years. Above $1500 \mathrm{~m}$ altitude this may take up to 20 years, above $2000 \mathrm{~m}$ up to 40 years.

218/1/C I: Stands are only exploited if a regeneration (reafforestation or natural regeneration) can be expected within reasonable and - depending on the site - economically sound regeneration intervals or over a period of 5 years.

$416 / C$ I: With natural regeneration measures in the case of doubt in areas where hunting has no predominant economic importance, enterprises may be required to proove that regeneration intervals inside and outside of game-control fences do not differ by more than 5 years. (see 314/A new) 
Test Austria

\subsubsection{Rotation Period}

208/5C I: Rotation lengths are determined in relation to the age of the stand with the maximum mean annual increment (increase in value, in the stricter sense of the term).

429/C I: Comparison of planned and actual rotation lengths by means of recognized growth charts (in Austria: yield tables) for the main tree species.

430/C G: In the case of continuous forest management systems appropriate production periods or targetted growing stock volumes according to appropriate framework value, defined and observed.

\subsubsection{Species Diversity}

210/5/C: C: Comparison of species and assortment composition by annual volume of timber harvested and annual exploitation area, respectively, with the logging objective (i.e. the calculated logging volume); exception: incidental fellings.

447/C I: Volume and assortment yield and the annual harvested area, respectively, quantified by a special control system correspond to the planned logging volumes.

\subsubsection{Planning and Control Mechanisms}

222/5/C I: Setting up and implementation of an appropriate planning and control system for silvicultural measures and timber harvesting

219/8/C I: There is a planning and control mechanism for the establishment of stands, tending and harvesting measures in which the reasons for the planned activities are given. Implemented measures are continuously recorded and controlled and their impact on the development of the stand and regeneration is assessed.

This planning and control mechanism has to be adapted to the size of the individual enterprise. A corresponding form has to be set up for small (private) forest estates.

223/5/C I: No unfounded deviations of more than an average of $+/-10 \%$ between annual harvest level and yield and the planned volumes over a period of more than 5 years nor exceeding or falling short of production periods by more than 20 years.

$229 / 1$

221/8/C I: Increment, growing stock and stand regeneration are continuously monitored by means of a forest inventory and control system (adapted to size and management intensity of the enterprise).

\subsubsection{Non-timber Forest Functions/Services}

\section{1/C C: Safeguarding of non-timber forest functions}

432/C G: If the vegetation makes hunting difficult forest management measures should allow for an improvement of the preconditions for sound hunting and for game population control measures (e.g. firing aisles, trees for raised hides, an appropriate road network).

433/C G: Forest management shows consideration for sustainable hunting practices, especially with regard to hunting facilities and places of special game ecological importance (feeding sites, winter shelters, eyrie trees, capercaillie biotopes).

435/C G: If hunting practices can be regulated on the company level management measures have to be taken guaranteeing that in the long run profits from hunting remain at a reasonable ratio towards forest protection expenses and silent losses (e.g. losses of tree species) and that they do not at the same time jeopardize other required forest functions.

$434 / \mathrm{C}^{--} \mathrm{I}$ : Forest areas with specific protective functions for human habitation and settlement areas including infrastructural facilities are identified and documented. The beneficiaries are identified and appropriate compensation for additional expenditures in forest management is laid down in public or private law.

436/C I: There are guidelines for the management of forest areas with a specific protective function against the wearing-away powers of wind, water and erosion. Silvicultural measures aim primarily at maintaining and improving stability with regard to the specific protective functions.

437/C I: If the supply of water and especially drinking water is of special regional or local importance forest management ensures best possible drinking water protection taking into consideration the long-term 


\section{Test Austria}

availability of drinking water in the best possible quality and quantity. There are guidelines for the silvicultural treatment of water protection areas. Compensation for services furnished by forest management is laid down in public or private law.

440/C I: There are guidelines for the management of important recreation and amenitv forests paying special attention to these functions (wayside design, viewpoints,...).

441/C I: R ecreational facilities are provided in important recreation forest areas. These services are appropriately compensated or compensation for additional expenditures in forest management is laid down in public or private law. At least the establishment of recreational facilities is made possible after fixing appropriate compensation.

442/C I: Forest areas with special noise abatement and/or ambient air pollution abatement functions are identified and recorded. If polluters and beneficiaries are identified compensation of additional expenditures in forest management is either laid down in public law or regulated by private-law agreements.

443/C I: There are guidelines for the treatment of these forest areas to ensure or enhance their noise abatement and/or ambient air pollution abatement-functions.

445/C G: Forest management considers the forests' landscape protection function by conserving or improving characteristic landscape elements (e.g. forest edges, tree monuments).

446/C I: In the case of specific local or regional needs regarding forest areas which have predominantly nature protection functions (e.g. old trees, biotopes) forest management is geared to conserving these areas and their protective functions after prior settlement of compensation issues with public or private institutions (non governmental organisations, associations). The establishment of information, monitoring and infrastructure facilities is made possible. 


\subsection{SOCIO-ECONOMIC ASPECTS}

\section{Comments and $D$ efinitions}

Formal rights are rights based on international and national laws and agreements recorded in writing.

Customary rights are rights of individuals or groups founded upon customary, long continued (e.g. 30 years in Austria; 20 years in Paraguay) practices and usage.

Traditional rights are rights of indigenous and traditional peoples which (up to now) have not been considered in the national and international context or have not (yet) been recorded, and which are based on the legal system of the individual cultures.

Local population: the current population of a specified geographic area, including indigenous and traditional population groups as well as population from colonizations and spontaneous settlements.

Traditional population: ethnic peoples and population groups within a nation whose traditional legal system is not the basis of national law or their language (except ethnic and linguistic minorities) is not the official language of the state. They may even be the majority population of the specific nation. Culture and especially the territories, rights and economic systems of traditional populations have to be especially respected.

Indigenous population: ethnic peoples or population groups who are the autochthonous population of a geographic area, or a nation-state respectively, and, who, in a historical process, were in the course of colonization or similar processes directly or indirectly (also because of the growing population pressure from neighbouring traditional and indigenous peoples) expelled or reduced in number. In most cases they are minorities or small (i.e. small in number) people. Culture and especially the territories, rights and economic systems of indigenous peoples have to be especially protected.

Both population types can in the broader sense be considered as indigenous. But on account of historical, political and other differences in their specific living conditions within the nation-states in which they are currently living, a differentiation between "traditional" and "indigenous" in the stricter sense of the term does make sense. Whether a population is considered as indigenous or traditional has in the last instance to be decided by the population group concerned.

Leading Forest Authority: person charged with overall planning and control of forest management.

Very small forest: Enterprises (management units) with a forested area of less than 50 ha.

S mall forest: Enterprises (management units) with a forested area of less than 200 ha.

\subsubsection{Design of external relations}

P: Sustainable management has to guarantee constructive and consistent socio-economic relations within its external sphere of influence.

\subsection{1 .1 Rights and Participation of the local/traditional/indigenous population}

P: Clarification of existing rights and obligations towards the population, especially towards indigenous peoples.

P: As a precondition to forest management land rights and usufructs of the (indigenous and the traditional/local) population of the area have to be fully registered, exactly defined and ensured and physical boundaries have to be established. This has to be done in a for the concerned communities acceptable way. This applies especially to indigenous peoples.

234/13/F P: As a precondition to forest management the formal, traditional, and customary land and usufruct rights of the local, traditional and especially indigenous population of the area and neighbouring regions have to be fully registered, defined and legally stipulated. Furthermore the boundaries of the estate (management unit) in question have to be physically demarcated. This has to be done in a way consistent with the culture of the concerned populations.

Rights of use include especially: land; water; game; fisheries; pastures; wild plants and fruit, medicinal plants, foods and luxury foods (e.g. honey); natural materials (e.g. firewood, materials for the construction of housings, means of transport, tools, clothing, etc.) and the like, as well as the right of access to these resources. 
Test Austria

246/8/F I: There are:

- legally binding surveyed maps indicating the areas the individual population groups of the region claim land titles and rights of usufruct to;

- valid property rights to the individual property areas (in copy);

- lists giving detailed information on geographical extension, contents and amount of the specified rights of use. These rights are acknowledged by all contracting parties.

- Specific measures for the protection of resources which are important for the local, traditional, and indigenous population

- established procedures for the settlement of conflicts over possessory titles and rights of usufruct. These procedures are recognized by all contracting parties.

601: I: Contracts concluded with the indigenous population are controlled and countersigned by a third person who enjoys the confidence of the indigenous population.

602: I: All data are drawn up in the languages of the local, traditional and indigenous population or at least in the respective lingua franca; for illiterate communities tape recordings are provided.

260/2/F I: Regular meetings are planned between the representatives of the contracting parties; these meetings are held and recorded.

603 I: The implementation of the agreements made can be easily verified.

241/12/F I: All agreements and especially those with regard to land titles and rights of use as well as conservation regulations are clearly laid down in the respective forest management plans and they are recognized.

604: I: The clearly marked boundaries of the individual estates are and remain visible (from 50 ha onwards).

235/14/b/F P: In general, unresolved conflicts over land titles preclude certification. Should in this connection a lawsuit be filed after certification, certification will be suspended until the situation is entirely clarified. (from 200 ha onwards).

$605 \mathrm{I}$ : There are clear statements of the within the national context competent state authorities, of the representatives of the local, traditional and indigenous population, as well as a written expert statement of a spokesperson of the indigenous population.

235a/14/F P: Local, traditional, and especially indigenous populations holding formal, traditional and customary rights of possession or usufruct maintain full control over forest management measures unless they delegate this control, or parts of it, voluntarily and deliberately to other organisations. In the case of traditional, but especially indigenous, populations, this delegation of control has to be carried out considering the respective cultural norms, conventions and socio-cultural control mechanisms. Contracts with indigenous groups are liable to formal renewal every two years.

238/3/F I: Detailed contracts relative to these agreements are drawn up in a way so that they are understandable for all contracting parties. With indigenous populations contracts are controlled and countersigned by a third, competent person who enjoys the confidence of the indigenous population.

606 I: Regular meetings with the representatives of all parties involved in order to discuss open questions, decide upon new measures to be taken and clarify situations are provided for. These meetings are adapted to the socio-cultural norms/ conventions of the traditional and indigenous population. These meetings are recorded; upon request tape recordings are made.

240/1/F I: There is detailed information on regulations for areas with conflicting forms of use. The implementation of these regulations can be verified. In case of doubt decisions have been taken in favour of the local, traditional and indigenous populations.

$607 \mathrm{I}$ : All agreements are concluded in a way allowing verification of their proper implementation.

P236/14/F G: Especially in the socio-economic and ecologic context, the intellectual property of traditional and indigenous peoples is formally accepted and appropriately compensated. The same applies to commercializations which are directly or indirectly linked to their ethnicity and indigenity.

608 I: There are corresponding legally binding contracts, the implementation of which can be verified. Contracts concluded with indigenous communities are controlled and countersigned by a competent third person who enjoys the confidence of the indigenous population. If neither the intellectual property nor the image of the traditional and indigenous population is exploited, there is a corresponding statement from representatives of the population as well as from competent third parties. 
Test Austria

\subsubsection{Cultural Heritage}

609 P: Sites of special cultural, historic or religious significance for the local, traditional and indigenous population are clearly identified, recognized and protected.

249/1/F I: Sites of special cultural, historic, and religious significance are identified, recorded und placed under efficient protection. These protection measures are worked out in accordance with the population concerned and their proper implementation can be verified.

610 I: There are protection measures which have been worked out in co-operation with the population concerned and potential competent state authorities.

\subsubsection{Jobs and integration of the local/traditional/indigenous population}

252/5 G: Jobs are in the first place offered to the local population. There are training opportunities enabling those interested to acquire the necessary skills/qualification.

254/2 I: Qualitative and quantitative share of the local population in the workforce (in \%?)

611 I: List of planned and implemented measures allowing the best possible integration of the local workforce. (Implemented measures for the best possible integration of the local workforce are recorded).

\subsubsection{Consultation of the local/traditional/indigenous population}

263/3/F C: The primary representative unit of the local, traditional and indigenous population is the selforganized community. The communities may designate representatives for conducting negotiations, consultations and controls.

612 I: The representative communities of the local, traditional and indigenous population are identified.

$613 \mathrm{I}$ : The representatives of the communities equally represent the concurrent interests of men, women, and of any fringe groups or minorities.

614 I: Regular meetings are agreed upon and being recorded. The implementation of agreements and measures can be monitored.

262/8/F I: Thematically qualified organisations, e.g. NGOs, the local, traditional or indigenous population wishes to consult are involved in the establishment and monitoring of contracts and their implementation. Furthermore they provide information and training programmes.

\subsubsection{Effects of local timber processing on the regional economy}

Further discussion of a possible inclusion of aspects of regional economy in a catalogue of criteria and indicators for sustainable forest management seems indispensable, especially with regard to the supraregional concessions which are granted to so-called Third World countries.

\subsubsection{Internal Aspects}

P: Sustainable (forest) management has to guarantee constructive and stable socio-economic relations within the enterprise.

P269/14 Management measures should be in line with all applicable rules and regulations concerning health and safety of the employees and their families. This includes

- adequate safety measures

- appropriate safety equipment

- health and accident insurance (including security of existance)

- sufficient education and training facilities and correct use of the working material

\subsubsection{Working conditions, safety provisions and health insurance}

P: Ensuarance of fair and adequate payment to motivate employees and to guarantee a sound use of forest resources.

255/3 C: Employment conditions (payment, equipment and working hours) are the same for local and non-local employees doing the same job.

501 I: Adequate minimum pay standards are defined and adhered to by the forest owner/concessionary. 


\section{Test Austria}

502 I: The applied (flexible ) payment schemes are recorded. They give due consideration to safety techniques and qualified work. They do not prevent sound forest management (intensity, quality, safety provisions).

P/G: Ensurance of fair working conditions in order to guarantee sustainable use of forest resources.

$511 \mathrm{C}$ : Health insurance, insurance coverage and safety measures

$503 \mathrm{~J}$ : Minimum social security provisions for the employees and their families are guaranteed. This includes especially the following aspects:

- sufficient medical assistance in the case of disease and accidents including appropriate continuation of payments to sick workers

- sufficient provisions for the surviving dependants in the event of death

- sufficient unemployment benefits provided for an appropriate period of unemployment on account of an accident nor brought about by the worker himself

- adequate old-age pension schemes

- sufficient provisions for workers unfit for work or incapable of earning a living at all due to an occupational disease or an accident at work, including provisions for the surviving dependants

- adeguate invalidity benefits.

These provisions/benefits are at least granted to the extent stated in the ILO agreement no. 102. In the absence of appropriate legal state or other public social security systems the forest manager/holder of a supra-regional concession applying for certification has ensured adequate insurance provisions within the enterprise.

504 I: There are safety measures and regulations for forest work (including protective clothing) and for the correnct use of machinery and equipment. These measures and regulations are adapted to the individual climatic and working conditions and they are observed. Corresponding instruction of the employees as well as the proper implementation of these rules and regulations are documented. In countries where there are no corresponding legal safety regulations and control mechanisms, relevant instruction is also documented with external contract crews.

506 I: Labour of children under 12 years is forbidden (does not occur). Children over 12 years are only called upon to do light labour corresponding to their age (e.g. collecting of non-timber products) and only for a limited period of time. Exempt from this prohibition of child labour is sporadical and temporary help in the enterprise of parents, step parents or foster parents (up to the third degree), provided that their legal representative/guardian gives his consent.

\subsubsection{Education and further training}

$\mathrm{P}$ : The sensitization to sustainable management as well as education and further training of forest managers and their employees has to be guaranteed. In this connection the ecological, economic and socio-economic sustainability of forest management has to be taken into consideration.

\section{$512 \mathrm{C}$ : Education and further training}

507 I: Those persons who are in charge of planning and control of forest management have received an adequate professional training:

*In enterprises of more than 500 ha which constitute an economic unit, even if not spatially coherent, the person in charge of planning and control has at least 3 years of a professional training in forestry. One single forestry authority may be in charge of a number of enterprises, provided that the total area of these enterprises does not exceed 2000 ha and that the location and accessibility of the total forested area allows sound combined management. In enterprises of more than 2000 ha, the person charged with planning and control has a professional training in forestry of at least 4 years.

* In enterprises of 200-500 ha at least a professional training in agriculture and/or forestry is required.

* In small forests (enterprises smaller than $200 \mathrm{ha}$ ) proof of several years of practical exerience in agriculture and forestry is regarded as being equivalent to a corresponding professional training. If these requirements are not met, at least proofs furnished of regular consulting of an advisory service. 508 I: Adequate professional training of the persons supervising and managing the silvicultural activites including the correct use of safety equipment, machinery and tools is pratical experience (e.g. of farmers working on contract, logging companies) are regarded as being equivalent to a corresponding professional training.

509 I: Further training of forest managers and /or the persons responsible for forest management of at least 3 days within 5 years (in the case of extension of the certification) is documented by participation in training events (courses, lectures, excursions, individual consultations, group discussions). 
Test Austria

513 I: There are sufficient education and training opportunities to obtain the necessary qualification. If there are no general education and training opportunities available, the forest manager/holder of the license provides the necessary training facilities (Only for large-scale enterprises of more than 5,000 ha).

\subsubsection{Freedom of organisation of the employees}

$\mathrm{P}$ : The right of the forest workers/the employers to organize themselves into unions and to negotiate with the employers upon request is to be respected.

271/5 C: Statement of employment policy and labour relations

510 I: Employees are adequately protected against any infringement of their right to unionize in the professional context. Labour relations are legally stipulated or - in case this is not sufficient - laid down in written agreements.

\subsubsection{Non-timber socio-economic forest services (multi-functional forest functions)}

These aspects are to a large extent treated in chapter 3.4. In the present chapter on socio-economic aspects they are only cited for completeness'sake: e.g. hunting; protection (against eroding forces) of human habitats and cultural areas; groundwater and spring protection; amenity and recreational functions; protection against noise and ambient air pollution; carbon dioxide absorption and reduction of the greenhouse effect, landscape and nature protection, conservation of forests as settlement and living areas - especially of indigenous peoples. 
This is a report on the first phase of CIFOR's research project on testing criteria and indicators (C\&I) for the sustainable management of forests, which was initiated in August 1994. The project has sought to identify reliable, relevant and cost-effective C\&I based on field evaluation of existing sets under forest management unit (FMU) conditions in Germany, Indonesia, Côte d'Ivoire, and Brazil. These evaluations were carried out using an inter-disciplinary and iterative approach developed by the project. This method is based on balancing the use of an inter-disciplinary team of experts and consultations with relevant stakeholders to evaluate C\&I within the frame-of-reference of a particular FMU. It has also been used successfully in an independent test carried out in Austria.

Results from the field tests in Indonesia, Côte d'Ivoire and Brazil suggest that more than half of the C\&I related to policy and legal frameworks, ecological impacts, and production aspects were common to all three sites. There was however a marked and sharp decrease in this level of commonality when it came to C\&I related to the social aspects of forest management. Comparison of these results with those obtained from the test in Austria reveal that most of the $\mathrm{C} \& \mathrm{I}$ identified as being common to the three tropical sites were also listed in the Austrian set. This suggests that at least in closed forest formations the development of a common 'core' set of C\&I seems possible, however site specific elements will continue to remain important particularly for social aspects and lower levels of hierarchy, such as verifiers.

In the second phase of the project, of two years duration, the aim is to develop a 'toolbox' approach to sustainability assessment at the FMU level. This will include giving special attention to criteria and indicators identified as being weak during the first phase. Examples of such areas of weak C\&I are impacts on biodiversity and social sustainability. The research will continue to focus on improving $\mathrm{C} \& \mathrm{I}$ especially with regard to their cost-effectiveness and reliability. In addition the project will test $C \& I$ in forests managed by local communities, thereby adding variation to both the question of spatial scales and management objectives.

The Center for International Forestry Research (CIFOR) was established in 1993 under the Consultative Group on International Agricultural Research (CGIAR) system in response to global concerns about the social, environmental and economic consequences of loss and degradation of forests. CIFOR's Mission is to contribute to the sustained wellbeing of people in developing countries, particularly in the tropics, through collaborative strategic and applied research and related activities in forest systems and forestry, and by promoting the transfer of appropriate new technologies and adoption of new methods of social organization, for national development. 